\title{
Delayed access to care for childhood malaria
}

\author{
Citation for published version (APA):
}

Castellani, J. S. (2020). Delayed access to care for childhood malaria: Financial determinants and economic consequences . [Doctoral Thesis, Maastricht University]. Maastricht University. https://doi.org/10.26481/dis.20201208jc

Document status and date:

Published: 01/01/2020

DOI:

10.26481/dis.20201208jc

Document Version:

Publisher's PDF, also known as Version of record

\section{Please check the document version of this publication:}

- A submitted manuscript is the version of the article upon submission and before peer-review. There can be important differences between the submitted version and the official published version of record.

People interested in the research are advised to contact the author for the final version of the publication, or visit the DOI to the publisher's website.

- The final author version and the galley proof are versions of the publication after peer review.

- The final published version features the final layout of the paper including the volume, issue and page numbers.

Link to publication

\footnotetext{
General rights rights.

- You may freely distribute the URL identifying the publication in the public portal. please follow below link for the End User Agreement:

www.umlib.nl/taverne-license

Take down policy

If you believe that this document breaches copyright please contact us at:

repository@maastrichtuniversity.nl

providing details and we will investigate your claim.
}

Copyright and moral rights for the publications made accessible in the public portal are retained by the authors and/or other copyright owners and it is a condition of accessing publications that users recognise and abide by the legal requirements associated with these

- Users may download and print one copy of any publication from the public portal for the purpose of private study or research.

- You may not further distribute the material or use it for any profit-making activity or commercial gain

If the publication is distributed under the terms of Article $25 \mathrm{fa}$ of the Dutch Copyright Act, indicated by the "Taverne" license above, 


\section{Delayed access to care for childhood malaria:}

Financial determinants and economic consequences

Joëlle Stéphanie Castellani 
The research presented in this thesis was conducted at CAPHRI Care and Public Health Research Institute, Department of Health Services Research (HSR) of Maastricht University. CAPHRI participates in the Netherlands School of Public Health and Care Research CaRe.

The different studies of this dissertation were made possible by funds from:

- The UNICEF/UNDP/World Bank/WHO Special Programme for Research \& Training in Tropical Diseases through funds made available by the European Commission (FP7) for research to improve community access to health interventions in Africa

- Grand Challenges Canada - Saving Brains Programme through the Mahidol Oxford Tropical Medicine Research Unit (MORU)

- The Sall Family Foundation via the Pan American Health and Education Foundation (renamed PAHO Foundation) and EUROHEALTH

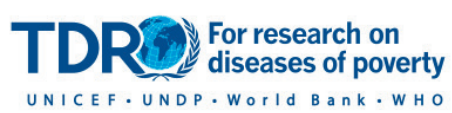

Grand Challenges Canada Grands Défis Canada

Copyright (C Joëlle Stéphanie Castellani, Maastricht 2020

Cover: $\quad$ Rachel van Esschoten || divingduckdesign.nl

Layout: $\quad$ Lara Leijtens || persoonlijkproefschrift.nl

Printing: $\quad$ Gildeprint Enschede || gildeprint.nl

ISBN: $\quad 978-94-6419-075-5$

All rights reserved. No part of this dissertation may be reproduced, stored in a retrieval system or transmitted in any form or by any means, electronic, mechanical, photocopying, recording or otherwise, without prior written permission from the holder of the copyright. 


\section{Delayed access to care for childhood malaria: Financial determinants and economic consequences}

\section{Dissertation}

to obtain the degree of Doctor at Maastricht University, on the authority of the Rector Magnificus,

Prof. dr. Rianne M. Letschert

in accordance with the decision of the Board of Deans, to be defended in public

on Tuesday 8 December 2020, at 13.00 hours

by

Joëlle Stéphanie Castellani 


\section{Supervisor}

Prof. dr. mr. S.M.A.A. Evers

\section{Co-supervisors}

Prof. dr. A.T.G. Paulus

Dr. M. Gomes (UNICEF/UNDP/World Bank/WHO Special Programme for Research \& Training in Tropical Diseases (TDR), Switzerland)

Prof. dr. B. Mihaylova (University of Oxford; Queen Mary University of London, United Kingdom)

\section{Assessment Committee}

Prof. dr. J.S.M. Krumeich (Chair)

Prof. dr. C.J.P.A. Hoebe

Dr. Y. Lubell (Mahidol Oxford Tropical Medicine Research Unit, Thailand; University of Oxford, United Kingdom)

Dr. I.M. van der Putten

Prof. dr. V. Wiseman (London School of Hygiene \& Tropical Medicine, United Kingdom; University of New South Wales, Australia) 


\section{CONTENTS}

Chapter 1 General introduction

Chapter 2 Out-of-pocket costs and other determinants of access to healthcare for children with febrile illnesses: a case-control study in rural Tanzania

Published in PLoS One (2015)

Chapter 3 Long-term consequences of cerebral infection: daily life and challenges faced by households with permanent childhood disability in rural Tanzania - a qualitative study Submitted for publication

Chapter 4 Impact of improving community-based access to malaria diagnosis and treatment on household costs Published in Clinical Infectious Diseases (2016)

Chapter 5 Household costs and time to treatment for children with 101 severe febrile illness in rural Burkina Faso: the role of rectal artesunate

Published in Malaria Journal (2018)

Chapter 6 Quantifying and valuing community health worker time in 129 improving access to malaria diagnosis and treatment Published in Clinical Infectious Diseases (2016)

Chapter 7 General discussion

Summary

Valorisation 


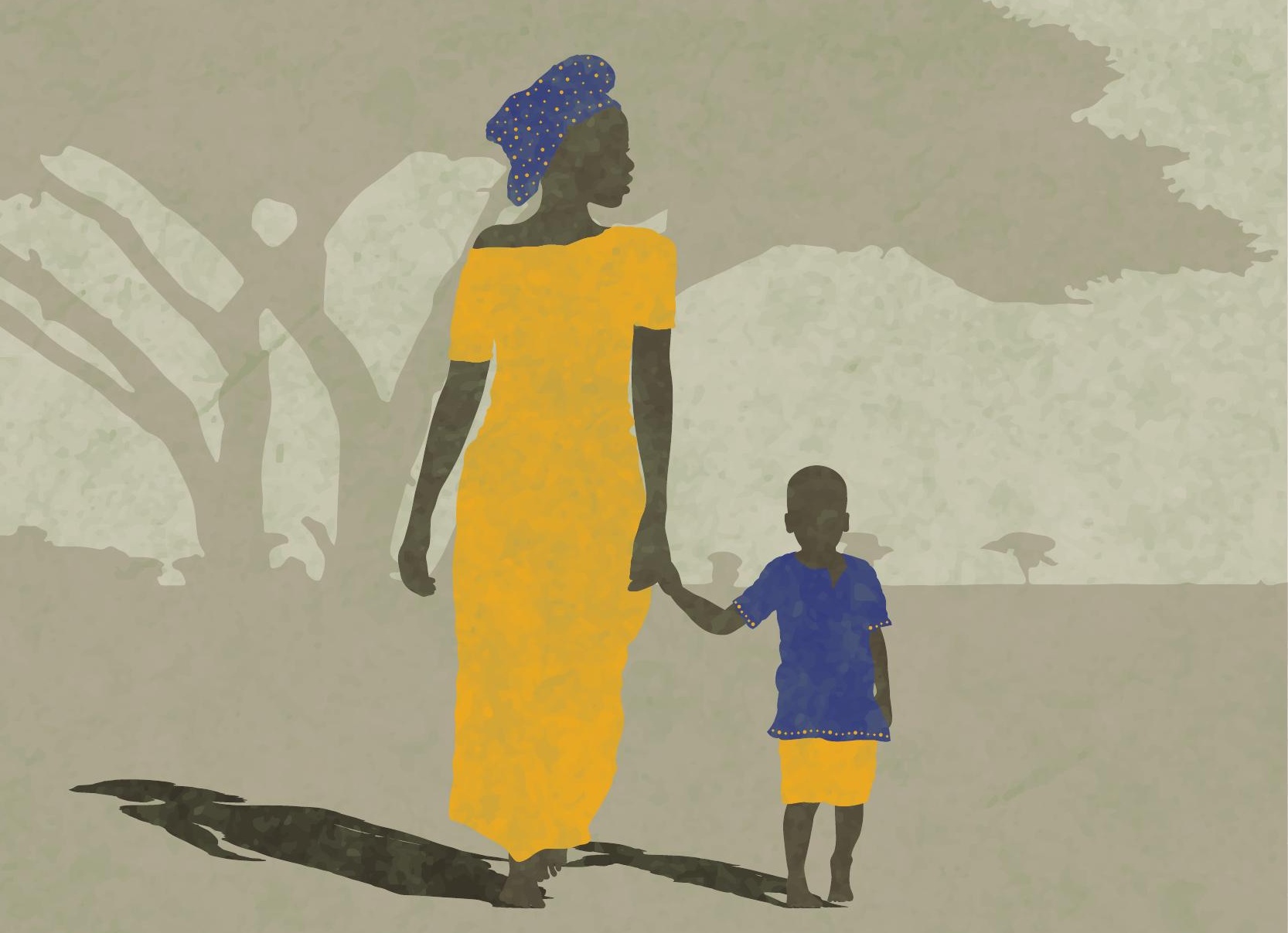




\section{CHAPTER 1}

\section{GENERAL INTRODUCTION}


This thesis explores the economic and financial factors that influence access to healthcare in rural Africa, describes the consequences of delayed access to diagnosis and treatment of childhood malaria, and tests strategies to decrease delays in healthcare.

In the first chapter of this thesis, a general background to malaria including the clinical features and evolution of the disease is summarized. This is followed by an overview of the adverse short and long-term consequences of the disease and a discussion on malaria control and treatment interventions. The first chapter ends with the objectives and outline of this thesis.

\subsection{MALARIA: GENERAL BACKGROUND, CLINICAL FEATURES AND EVOLUTION OF THE DISEASE}

Malaria is an illness caused by Plasmodium parasites transmitted to humans when infected female mosquitoes bite and suck blood [1-3]. Of several Plasmodium parasites, the most life-threatening is Plasmodium falciparum (P falciparum) [1]. In 2018 there were around 228 million cases of malaria worldwide causing 405,000 deaths [4], mainly among children under five who are most at risk until they acquire immunity [5]. Around $90 \%$ of these cases and deaths are found in SubSaharan Africa [4].

Malaria is mosquito-borne and therefore usually affects rural communities because mosquitoes breed in rainfall that collects in small patches of water thus increasing the risk of malaria for persons living in close proximity [6-8]. Transmission intensity is influenced by the density of human settlement and behaviour. The higher the number of persons, the greater the number of parasites in circulation for transmission. However, the more quickly infected people are treated, the fewer parasites there are for transmission $[3,9]$.

$P$ falciparum malaria in children usually starts with non-specific symptoms and signs, including fever. Other symptoms characterizing uncomplicated disease include a general malaise, accompanied by headaches, mild vomiting, dizziness, or less commonly mild diarrhoea, cough, nausea and non-specific abdominal pain $[2,10]$. Fever can be erratic. When the disease is parasitologically diagnosed (either through a rapid diagnostic test (RDT) or microscopy) and when there are only mild, uncomplicated symptoms that are treated quickly with an oral artemisinin-based combination therapy (ACT), full recovery is rapid [2, 3]. However, if malaria is not 
treated rapidly or if ineffective drugs are used, the parasites continue to multiply, invade and destroy red blood cells [11] and are available for transmission to others. In $P$ falciparum malaria, if the infection is not treated rapidly, the more mature pathogenic stages of the parasite lodge or sequester in the microvasculature of vital organs, including the brain, while the younger stages of the parasite circulate in the blood stream. Sequestration means that parasites occupy vital organs which cease functioning well so that the disease progresses within hours from uncomplicated to severe malaria. Severe malaria is initially visible through the child's inability to eat, drink or suck, repeated vomiting, lethargy (unable to sit, stand and walk unaided), repeated convulsions and altered consciousness [2]. If treatment is delayed, the child develops cerebral malaria and can die [2].

Patients with $P$ falciparum parasites who are unable to reliably take oral medications are at increased risk of death $[2,12,13]$. The exact risk depends upon transmission intensity, the number of organ systems affected, age (and therefore background immunity), and speed of access to appropriate treatment $[2,13]$. In severe malaria, the patient needs immediate diagnosis and treatment and, in cases where diagnosis is not available, treatment should be given on the assumption that the patient has malaria because severe malaria quickly evolves into potentially fatal cerebral malaria $[3,13]$.

Cerebral malaria refers to impaired consciousness or unrousable coma which persists for more than 1 hour with definite evidence of malaria infection. In cerebral malaria, small blood vessels in the brain are clogged by blood cells infected with malaria parasites $[14,15]$. There may be generalised convulsions followed by persisting unconsciousness, although sometimes the level of consciousness may decline gradually [2]. Many children survive severe or cerebral malaria but might be left with long-term sequelae including epilepsy, physical and cognitive impairments, limited mental capacity, and behavioural changes [2, 16-23].

\subsection{ADVERSE SHORT-TERM EFFECTS OF UNCOMPLICATED AND SEVERE/CEREBRAL MALARIA}

In many malaria-endemic African countries, where the burden of malaria is primarily in childhood, patients can seek medical advice and treatment from formal healthcare providers (e.g. community health workers (CHWs), dispensaries, laboratories, health centres, private clinics, private or public hospitals) as well as from informal providers (e.g. traditional healers, faith healers, itinerant 
drug sellers). Drugs such as quinine, antibiotics and antimalarials can often be purchased in pharmacies, shops and through itinerant drug sellers.

In several African countries, healthcare is provided free of charge to children under five in public facilities (e.g. Nigeria, Tanzania and Uganda) but patients may need to pay for a registration card, injections, a notebook (to record patient history) and essential commodities if these are out-of-stock at the time of the consultation/admission. In other countries, healthcare at public facilities is feebased (e.g. consultation fees and bed costs in Burkina Faso at the time this thesis was conducted).

Although a policy of free care for children under five encourages the use of public healthcare facilities, access remains difficult and expensive for poor families because of long distances and a lack of transport [24-26]. During emergencies, referral hospitals are difficult to reach quickly [24]. Therefore, despite a policy of free care for young children, parents incur private costs when seeking care and this influences their health-seeking behaviour [24, 26]. Jowett et al. [27] estimated that almost $75 \%$ of healthcare expenditure is borne by the household even in areas where there is apparently "free" care. Patients need to pay for transport to reach the facility, they need to buy food when they spend several hours or days at the facility and they often need to purchase drugs and other health commodities [24, 28-31]. In Uganda, the mean total out-of-pocket costs for seeking care for children under five irrespective of illness (i.e. malaria, diarrhoea and pneumonia) was USD $\$ 2.90$ at a public facility providing only primary care and USD $\$ 5.70$ at a public facility providing inpatient care in 2011 [32]. Food, transport and drugs have been shown to be the major cost-categories $[28,32]$.

Whereas uncomplicated malaria can be managed on an outpatient basis, severe or cerebral malaria requires hospital admission. For severe/cerebral malaria, studies have analysed the admission costs or the costs of an episode resulting in hospitalization, and reported costs ranging from USD \$0.70 to USD \$11.50 per admission in Africa [28-30, 33-35]. Another study estimated the direct household costs for an episode of malaria by disease severity showing that severe/cerebral malaria illness is generally more costly than uncomplicated malaria, with costs ranging from USD \$0.42 in Tanzania, USD \$0.73 in Kenya and USD \$4.44 in Ghana for uncomplicated malaria to USD \$7.86 in Tanzania, USD \$20.00 in Kenya and USD $\$ 36.75$ in Ghana for cerebral malaria with neurological sequelae [36]. 
High anticipated hospitalisation costs mean that children in wealthier households are more likely to be brought to a healthcare facility than those in poorer households [37-39] suggesting inequalities in the use of healthcare services. Although wealthier households spend more money to treat malaria and more money on transport so that they arrive faster at a healthcare facility [40], poorer households may bear a greater economic burden because they spend a larger proportion of their total income on malaria [41]. Anticipated costs thus prevent or delay care for poorer households [24, 26, 42] leading to children being admitted only when they have very severe symptoms, rather than when they have less severe symptoms [39]. In an emergency, when parents perceive that their child is at a risk of death, they might borrow money or sell assets to pay for care $[24,26,28]$.

As the economic and financial consequences of malaria may prevent access to a healthcare facility, better understanding of the private costs of care and treatment at a healthcare facility (i.e. financial factors) as well as other factors (i.e. economic factors) that influence rapid access to a facility is necessary to improve access and reduce inequalities. Although a few studies have analyzed the private costs of hospital admission [28, 33] or of an episode of illness [29-32, 34, 35, 40] and have investigated the relationship between access to healthcare and poverty [37-39], little is known about the changes that can be made either in provision of services or service costs to improve healthcare seeking and health outcomes, particularly for poorer households.

\subsection{ADVERSE LONG-TERM EFFECTS OF SEVERE/CEREBRAL MALARIA}

As mentioned above, when prompt diagnosis and treatment does not occur, uncomplicated malaria can evolve to severe or cerebral malaria. There is an association between cerebral malaria and the risk of disability, particularly epilepsy $[19,20]$ but cerebral malaria also affects motor skills, visual reception, and receptive and expressive language [23], and is associated with long-term cognitive sequelae for survivors [17]. Physical and/or mental disability affects not only the life of the child but also the lives of other members of the household by increasing their physical, emotional and financial burden and reducing time for incomegenerating activities. Disabled children might be dependent [43-45] and need assistance with daily tasks and activities [46,47]. Epilepsy can be one consequence of cerebral malaria $[19,20]$. Consequently, cerebral malaria is associated with later disability, and physical and mental burden on the family [44, 48-52]. Behaviour 
problems in children are associated with increased levels of stress and fatigue in caregivers $[46,53]$, particularly in poorer households with older disabled children [53]. In Zimbabwe, almost $80 \%$ of caregivers of children with physical impairments (i.e. cerebral palsy) report some problems with anxiety or depression [54]. Distress and frustration are mentioned by parents when children cannot hear or speak, because of the difficulties with communicating with the disabled child or understanding the child's needs [46]. In addition to emotional problems, caregivers of disabled children are also more likely to experience chronic illnesses (back problems, migraine) [48]. Physical pain has been documented among caregivers when their child cannot walk $[46,48,51,54]$ and needs to be carried $[46,54]$. When the child gets older and without adapted transport or wheelchairs, carrying the adolescent child becomes impossible [46] and mobility becomes restricted for both the mother and the child $[46,54]$.

Caring for a disabled child also has financial costs. Constant child-care means that parents reduce their working hours resulting in reduced financial resources for the household [55]. There is a positive correlation between households with disability and poverty [56]. Several studies have found that households with a disabled child have difficulties in meeting their basic needs such as food, clothes or drugs $[46,47]$. When children get older, they are expected to support their parents; but with a disabled child, the financial future and living conditions of the household become uncertain and the expectations are reversed. Disability tips households into poverty and exiting from this poverty trap remains difficult as families may never have the necessary resources to do so [57].

Childhood disability has an economic cost. Past and current research on disability quantifies the economic consequences for different types of disability at individual and household levels [56-71] as well as the consequences for the caregiver [44, 48-50, 52-55]. Lower school attendance rate is observed among disabled children $[56,58,64,65,67-71]$. However, lack of schooling may be due not only to disability but also to a combination of other factors such as a lack of money, the distance to the school and the attitude of the school towards disabled children [46]. Lower educational achievement among disabled children is reflected in lower educational attainment in adulthood for both physical and mental disabilities [56, 59, 63, 65, $66,71]$ and lower education translates into fewer employment opportunities [59, $61,62,64,66]$ and lower income $[56,57]$. Lower income in the current generation tends to transfer poverty to the next generation [57]. 
Although most studies on disability are quantitative, the consequences of disability for the household/caregiver and coping strategies have also been investigated through exploratory descriptive studies and focus group discussions in developed countries (e.g. Australia; United States) $[43,51]$ and through qualitative approaches in Africa [46, 47, 72]. However, research in Africa on disability challenges for the child and carers as the child develops is limited. Understanding changes is essential to understand the long-term consequences of cerebral malaria, the burden borne by children and their families and educational disparities that occur. Understanding disability consequential to malaria underlines the importance of preventing malaria, promoting rapid access to healthcare in remote areas, and helps to understand where social support could be focused and improved.

\subsection{EFFECTS OF MALARIA CONTROL INTERVENTIONS}

To reduce malaria transmission, both insecticide-treated mosquito nets (ITNs) and insecticide spraying are recommended in areas of high malaria transmission. Seasonal malaria chemoprevention (SMC) - intermittent administration of an antimalarial medicine - is used as mass drug administration for children under five only in areas which are subject to a very short intense rainy period, as occurs in West Africa. Although all these interventions are effective in reducing malaria transmission risk [73-76], many households/children are not covered by these interventions. The proportion of households with ITNs has increased to $75 \%$ in areas where a mass ITN campaign has been conducted but the percentage of households with enough nets for each family member remains inadequate [77]. Misuse of nets has been observed: a study showed that more than $87 \%$ of households living along Lake Tanganyika, Tanzania used their ITNs for fishing [78]. Regarding SMC, almost $50 \%$ of children in 12 Africa's Sahel sub-region countries who currently implement this method did not benefit from the intervention mainly because of a lack of funding from governments [79]. As a result, there is still a large burden borne by young children because access to some interventions remains difficult.

Considerable emphasis is put on early diagnosis and treatment of uncomplicated malaria to prevent evolution to severe or cerebral malaria and death. Prompt community-based diagnosis and treatment achieves this [3]. Diagnosis and treatments recommended by the World Health Organization (WHO) are rapid diagnostic tests (RDTs) for malaria, artemisinin-based combination therapies (ACTs) for uncomplicated malaria, and rectal artesunate (RA) plus referral to the closest healthcare facility for children presenting danger signs (unable to eat, drink or suck, 
lethargy, repeated vomiting, convulsions or altered consciousness/coma) [3, 80]. In villages, RDTs can be performed by (voluntary) community health workers (CHWs) who are community members, often chosen by the community, but trained by the Ministry of Health to perform basic health tasks in their communities, ranging from assessment of sick children to treatment and referral of severe patients. They are often the first point of formal healthcare within remote and marginalized communities and are usually unpaid, voluntary workers in many African settings. However, when trained and provided with adequate supervision and supported by the health system under integrated community case management (iCCM), CHWs can diagnose, test and treat children with uncomplicated disease [81-83]. Their training and proximity to patients also increases their use as first healthcare provider [84, 85]. However, very little is known about the time they spend on their activities as CHWs, and the true cost of their "voluntary" status and commitment remains uncertain. Two studies based on interviews and self-reports found that about 40 minutes per day were spent on children's healthcare in Uganda while about 4.8 hours per day were spent in Ghana [86,87]. The monthly time was valued at a median of USD \$4.10 in Uganda [87] and between USD \$21.10 and USD \$94.95 in Ghana [86]. The CHWs' time spent on providing voluntary healthcare reduces their time for other activities that may contribute to their household's income.

ACTs are effective in treating uncomplicated malaria [3] and can decrease mortality in children [88]. Although both RDTs and ACTs are expensive they are supported by the Global Fund to Fight AIDS, Tuberculosis and Malaria (GFATM), the main funding organization for malaria treatment and prevention. A review of malaria interventions from a provider's perspective shows that RDTs are more cost effective than microscopy when comparing only the costs of $P$ falciparum diagnosis [89] but when the cost of treatment is included, RDTs can be less costly in some areas [90-93] and microscopy can be more cost-effective in other areas [94-96]. In general, microscopy which requires electricity and skilled personnel is less expensive in a formal healthcare facility than in the community while RDTs are valuable in the community as they provide immediate diagnosis at the point of care [89]. From a provider's perspective - the cost per case correctly diagnosed with an RDT and treated with ACTs can be as high as USD \$4.22 in the community and USD \$6.12 in a facility [97]. Private family costs per case diagnosed and treated using RDTs and ACTs are not well studied. A study in Tanzania showed that the use of RDTs at healthcare facilities decreases the cost of drugs for patients although it did not decrease their total costs [96]. Another study found that there was no difference in costs for children under five diagnosed via RDTs and those who had a 
symptom-based clinical diagnosis [98]. Regarding ACTs, some studies report that ACTs are more expensive [99-101] but also more cost-effective than other drugs $[89,100-102]$. A study on the community response to ACTs in Tanzania notes that most caregivers report that using ACTs was less costly for a malaria episode than using sulphadoxine-pyrimethamine (SP) which took a much longer time to work and several trips to a healthcare facility [103].

For severe and cerebral malaria, RA has been shown to be an effective pre-referral treatment in controlling the evolution of severe disease and preventing death [104-107] especially when children are likely to have several hours in transit before arriving at a hospital [106]. However, not all parents follow referral advice. Parents often adhere with referral advice when the child does not improve [108]. Distance and costs of reaching a facility [108] and healthcare facility costs [109] are perceived as barriers to following referral advice.

RA can thus be seen not only as an attempt to decrease the risks of death and future disability but also as an approach to decrease the private costs for households as faster treatment and fewer visits to different providers might be expected. One study showed RA to be cost-effective as a treatment [110]. Another study assessed the societal costs for children who completed referral in an area where RA and ACTs were used via CHWs [111]. In this study, the societal costs which include the out-of-pocket costs for caregivers, the opportunity costs of time for both CHWs and caregivers, and the costs borne by health facilities showed a mean total cost of USD \$4.89 per case referred and USD \$7.35 for those who completed referral with $34 \%$ of the total costs per case referred allocated to the out-of-pocket costs [111].

Until recently, the effects of a combined community intervention of RDTs and treatment for both uncomplicated and severe malaria (ACTs and RA) on family and health system costs to control malaria were unknown. Understanding the impact of such an intervention is important as the approach has the potential for preventing the evolution of uncomplicated to severe/cerebral malaria and death by bringing diagnosis and treatment closer to patients, as well as for decreasing the household out-of-pocket costs for malaria.

\subsection{OBJECTIVES OF THE THESIS}

This thesis has two main objectives: first to provide information on the economic and financial factors that influence access to healthcare and on the consequences 
of delayed access to diagnosis and treatment of malaria, and second to test and evaluate a strategy for reducing delays by bringing access closer to sick children in the community. The main objectives can be further divided into the three following sub-objectives:

1. To understand the economic and financial factors that influence access to healthcare facilities and whether those factors prevented or delayed healthcare access (chapter 2)

2. To provide insight into the adverse long-term effects of severe/cerebral malaria on children, caregivers and households (chapter 3)

3. To understand the effects of community-based malaria control and management interventions on private costs and health system costs, on time to treatment and on time allocated by CHWs to child healthcare (chapters 4-6)

\subsection{OUTLINE OF THE THESIS}

This thesis is divided into two parts. The first part (chapters 2 and 3) discusses the out-of-pocket costs for households when community-based malaria control strategies are not available and the long-term consequences of a severe febrile illness, particularly malaria.

When a child has a severe illness, rapid access to an admitting facility is essential. However, the anticipated costs of healthcare can act as a barrier to prompt treatment when poor families find facility costs unaffordable. To understand the costs of an episode of malaria and other febrile illnesses, chapter 2 , assesses the out-of-pocket costs of care for children who went to a public healthcare facility versus a private facility versus the out-of-pocket costs of being treated in the community in Tanzania. In this study, other economic and socio-demographic factors that determine access to healthcare facilities are also discussed.

Some children have severe/cerebral malaria and are left with permanent disability. Chapter 3 reported the findings of a qualitative study on the daily challenges of children with severe physical and/or mental disability resulting from a cerebral infection and the long-term effects on their families. The study aimed at understanding how households cope with disability, how the physical and mental condition of the child affects family circumstances and how the burden of caring for a disabled child changes as the child grows older. 
The second part of this thesis describes a large-scale intervention bringing diagnosis and treatment for uncomplicated and severe malaria closer to patients and examines the consequences of this strategy for patients and the CHWs who deliver such an intervention in 3 African countries with a high childhood malaria burden. In chapters 4 to 6 , costs and opportunity costs of time are explored when community-based provision of diagnosis and treatment for uncomplicated and severe malaria becomes available. The intervention brought CHW care, diagnosis and treatment closer to patients. It was anticipated that the intervention would enable malaria to be treated with minimum delay, thus preventing the evolution of uncomplicated to severe malaria and reducing the burden of cerebral malaria, and the risks for later disability. The intervention provided community-based access to care in remote, rural malaria-endemic areas of Burkina Faso, Nigeria and Uganda. In this intervention, CHWs were identified, trained, and provided with support and commodities (RDTs and antimalarial treatment (ACTs and RA)) that would enable them to diagnose and treat children quickly, when sick. The CHWs were constantly supervised throughout the intervention and supplied with commodities at regular intervals. Within this extended research project, chapter 4 examines whether the intervention was effective in reducing the outof-pocket costs of care, and chapter 5 focuses on Burkina Faso and compares the out-of-pocket costs incurred for severe episodes and the time taken to seek care for households who took advantage of the intervention (RDTs and RA for severe disease) and those who did not.

When well trained and supervised, CHWs can manage simple healthcare tasks, reach the poorest in the most inaccessible areas, improve care and become a link with the formal health system. However, when CHWs volunteer their time towards the provision of healthcare services, their time allocated to other activities (i.e. income-generating work or leisure) correspondingly decreases. Chapter 6 examines the health system costs of bringing this intervention to the community - as measured by the time-allocation of CHWs to healthcare - and calculates the opportunity cost of their time.

Finally, chapter 7 summarizes the main findings, strengths and limitations of this thesis. Suggestions for further work and implications for policy and practice are discussed. 


\section{REFERENCES}

1. White NJ, Pukrittayakamee S, Hien TT, Faiz MA, Mokuolu OA, Dondorp AM. Malaria. Lancet. 2014;383:723-35.

2. World Health Organization. Severe malaria. Trop Med Int Health. 2014;19 Suppl 1:7-131.

3. World Health Organization. Guidelines for the treatment of malaria. $3^{\text {rd }}$ ed. Geneva: WHO; 2015.

4. World Health Organization. World malaria report 2019. Geneva: WHO; 2019.

5. Doolan DL, Dobaño C, Baird JK. Acquired immunity to malaria. Clin Microbiol Rev. 2009;22:13-36.

6. Bayoh MN, Lindsay SW. Effect of temperature on the development of the aquatic stages of Anopheles gambiae sensu stricto (Diptera: Culicidae). Bull Entomol Res. 2003;93:375-81.

7. Van Der Hoek W, Konradsen F, Amerasinghe PH, Perera D, Piyaratne MK, Amerasinghe FP. Towards a risk map of malaria for Sri Lanka: the importance of house location relative to vector breeding sites. Int J Epidemiol. 2003;32:280-5.

8. Nkuo-Akenji T, Ntonifor NN, Ndukum MB, Kimbi HK, Abongwa EL, Nkwescheu A, et al. Environmental factors affecting malaria parasite prevalence in rural Bolifamba, South West Cameroon. Afr J Health Sci. 2006;13:40-6.

9. Toure OA, Landry TN, Assi SB, Kone AA, Gbessi EA, Ako BA, et al. Malaria parasite clearance from patients following artemisinin-based combination therapy in Côte d'Ivoire. Infect Drug Resist. 2018;11:2031-8.

10. World Health Organization. Management of severe malaria - a practical handbook. $3^{\text {rd }}$ ed. Geneva: WHO; 2012.

11. White NJ. The parasite clearance curve. Malar J. 2011;10:278.

12. Molyneux ME, Taylor TE, Wirima JJ, Borgstein A. Clinical features and prognostic indicators in paediatric cerebral malaria: a study of 131 comatose Malawian children. Q J Med. 1989;71:441-59.

13. Newton CR, Krishna S. Severe falciparum malaria in children: current understanding of pathophysiology and supportive treatment. Pharmacol Ther. 1998;79:1-53.

14. Pongponratn E, Turner GD, Day NP, Phu NH, Simpson JA, Stepniewska K, et al. An ultrastructural study of the brain in fatal Plasmodium falciparum malaria. Am J Trop Med Hyg. 2003;69:345-59.

15. Dondorp AM, Pongponratn E, White NJ. Reduced microcirculatory flow in severe falciparum malaria: pathophysiology and electron-microscopic pathology. Acta Trop. 2004;89:309-17.

16. Newton CR, Hien TT, White N. Cerebral malaria. J Neurol Neurosurg Psychiatry. 2000;69:433-41.

17. John CC, Bangirana P, Byarugaba J, Opoka RO, Idro R, Jurek AM, et al. Cerebral malaria in children is associated with long-term cognitive impairment. Pediatrics. 2008;122:e92-9.

18. Idro R, Kakooza-Mwesige A, Balyejjussa S, Mirembe G, Mugasha C, Tugumisirize J, et al. Severe neurological sequelae and behaviour problems after cerebral malaria in Ugandan children. BMC Res Notes. 2010;3:104. 
19. Carter JA, Neville BG, White S, Ross AJ, Otieno G, Mturi N, et al. Increased prevalence of epilepsy associated with severe falciparum malaria in children. Epilepsia. 2004;45:978-81.

20. Ngoungou EB, Dulac O, Poudiougou B, Druet-Cabanac M, Dicko A, Mamadou Traore A, et al. Epilepsy as a consequence of cerebral malaria in area in which malaria is endemic in Mali, West Africa. Epilepsia. 2006;47:873-9.

21. Murphy SC, Breman JG. Gaps in the childhood malaria burden in Africa: cerebral malaria, neurological sequelae, anemia, respiratory distress, hypoglycemia, and complications of pregnancy. Am J Trop Med Hyg. 2001;64(1 Suppl):57-67.

22. Brewster DR, Kwiatkowski D, White NJ. Neurological sequelae of cerebral malaria in children. Lancet. 1990;336:1039-43.

23. Bangirana P, Opoka RO, Boivin MJ, Idro R, Hodges JS, John CC. Neurocognitive domains affected by cerebral malaria and severe malarial anemia in children. Learn Individ Differ. 2016;46:38-44.

24. Bedford KJ, Sharkey AB. Local barriers and solutions to improve care-seeking for childhood pneumonia, diarrhoea and malaria in Kenya, Nigeria and Niger: a qualitative study. PLoS One. 2014;9:e100038.

25. Buor D. Analysing the primacy of distance in the utilization of health services in the Ahafo-Ano South district, Ghana. Int J Health Plann Manage. 2003;18:293-311.

26. Hill Z, Kendall C, Arthur P, Kirkwood B, Adjei E. Recognizing childhood illnesses and their traditional explanations: exploring options for care-seeking interventions in the context of the IMCI strategy in rural Ghana. Trop Med Int Health. 2003;8:668-76.

27. Jowett M, Miller N, Mnzava N. Malaria expenditure analysis: Tanzania case study. Report prepared for DFID-EA (Tanzania) and the Roll Back Malaria Initiative. York: University of York; 2000.

28. Saksena P, Reyburn H, Njau B, Chonya S, Mbakilwa H, Mills A. Patient costs for paediatric hospital admissions in Tanzania: a neglected burden? Health Policy Plan. 2010;25:328-33.

29. Menon MP, Njau JD, McFarland DA, Uganda Malaria Indicator Survey Technical Working Group. Cost and predictors of care-seeking behaviors among caregivers of febrile children-Uganda, 2009. Am J Trop Med Hyg. 2016;94:932-7.

30. Hennessee I, Chinkhumba J, Briggs-Hagen M, Bauleni A, Shah MP, Chalira A, et al. Household costs among patients hospitalized with malaria: evidence from a national survey in Malawi, 2012. Malar J. 2017;16:395.

31. Asenso-Okyere WK, Dzator JA. Household cost of seeking malaria care. A retrospective study of two districts in Ghana. Soc Sci Med. 1997;45:659-67.

32. Soremekun S, Kasteng F, Lingam R, Vassall A, Kertho E, Settumba S, et al. Variation in the quality and out-of-pocket cost of treatment for childhood malaria, diarrhoea, and pneumonia: Community and facility based care in rural Uganda. PLoS One. 2018;13:e0200543.

33. Nabyonga Orem J, Mugisha F, Okui AP, Musango L, Kirigia JM. Health care seeking patterns and determinants of out-of-pocket expenditure for malaria for the children under-five in Uganda. Malar J. 2013;12:175.

34. Onwujekwe O, Uguru N, Etiaba E, Chikezie I, Uzochukwu B, Adjagba A. The economic burden of malaria on households and the health system in Enugu State southeast Nigeria. PLoS One. 2013;8:e78362. 
35. Castillo-Riquelme M, McIntyre D, Barnes K. Household burden of malaria in South Africa and Mozambique: is there a catastrophic impact? Trop Med Int Health. 2008;13:108-22.

36. Sicuri E, Vieta A, Lindner L, Constenla D, Sauboin C. The economic costs of malaria in children in three sub-Saharan countries: Ghana, Tanzania and Kenya. Malar J. 2013;12:307.

37. Schellenberg JA, Victora CG, Mushi A, de Savigny D, Schellenberg D, Mshinda H, et al. Inequities among the very poor: health care for children in rural southern Tanzania. Lancet. 2003;361:561-6.

38. Filmer D. Fever and its treatment among the more and less poor in sub-Saharan Africa. Health Policy Plan. 2005;20:337-46.

39. Burton DC, Flannery B, Onyango B, Larson C, Alaii J, Zhang X, et al. Healthcareseeking behaviour for common infectious disease-related illnesses in rural Kenya: a community-based house-to-house survey. J Health Popul Nutr. 2011;29:61-70.

40. Onwujekwe O, Hanson K, Uzochukwu B, Ichoku H, Ike E, Onwughalu B. Are malaria treatment expenditures catastrophic to different socio-economic and geographic groups and how do they cope with payment? A study in southeast Nigeria. Trop Med Int Health. 2010;15:18-25.

41. Somi MF, Butler JR, Vahid F, Njau JD, Kachur SP, Abdulla S. Economic burden of malaria in rural Tanzania: variations by socioeconomic status and season. Trop Med Int Health. 2007;12:1139-47.

42. Walter ND, Lyimo T, Skarbinski J, Metta E, Kahigwa E, Flannery B, et al. Why firstlevel health workers fail to follow guidelines for managing severe disease in children in the Coast Region, the United Republic of Tanzania. Bull World Health Organ. 2009;87:99-107.

43. Murphy NA, Christian B, Caplin DA, Young PC. The health of caregivers for children with disabilities: caregiver perspectives. Child Care Health Dev. 2007;33:180-7.

44. Sawyer MG, Bittman M, La Greca AM, Crettenden AD, Borojevic N, Raghavendra P, et al. Time demands of caring for children with cerebral palsy: what are the implications for maternal mental health? Dev Med Child Neurol. 2011;53:338-43.

45. Tadema AC, Vlaskamp C. The time and effort in taking care for children with profound intellectual and multiple disabilities: a study on care load and support. Br J Learn Disabil. 2010;38:41-8.

46. Hartley S, Ojwang P, Baguwemu A, Ddamulira M, Chavuta A. How do carers of disabled children cope? The Ugandan perspective. Child Care Health Dev. 2005;31:167-80.

47. Gona JK, Mung'ala-Odera V, Newton CR, Hartley S. Caring for children with disabilities in Kilifi, Kenya: what is the carer's experience? Child Care Health Dev. 2011;37:175-83.

48. Brehaut JC, Kohen DE, Raina P, Walter SD, Russell DJ, Swinton M, et al. The health of primary caregivers of children with cerebral palsy: how does it compare with that of other Canadian caregivers? Pediatrics. 2004;114:e182-91.

49. Brehaut JC, Kohen DE, Garner RE, Miller AR, Lach LM, Klassen AF, et al. Health among caregivers of children with health problems: findings from a Canadian populationbased study. Am J Public Health. 2009;99:1254-62.

50. Cheshire A, Barlow JH, Powell LA. The psychosocial well-being of parents of children with cerebral palsy: a comparison study. Disabil Rehabil. 2010;32:1673-7. 
51. Davis E, Shelly A, Waters E, Boyd R, Cook K, Davern M, et al. The impact of caring for a child with cerebral palsy: quality of life for mothers and fathers. Child Care Health Dev. 2010;36:63-73.

52. Navaie-Waliser M, Feldman PH, Gould DA, Levine C, Kuerbis AN, Donelan K. When the caregiver needs care: the plight of vulnerable caregivers. Am J Public Health. 2002;92:409-13.

53. Mobarak R, Khan NZ, Munir S, Zaman SS, McConachie H. Predictors of stress in mothers of children with cerebral palsy in Bangladesh. J Pediatr Psychol. 2000;25:427-33.

54. Dambi JM, Jelsma J, Mlambo T. Caring for a child with Cerebral Palsy: The experience of Zimbabwean mothers. Afr J Disabil. 2015;4:168.

55. Busch SH, Barry CL. Mental health disorders in childhood: assessing the burden on families. Health Aff (Millwood). 2007;26:1088-95.

56. Filmer D. Disability, poverty, and schooling in developing countries: results from 14 household surveys. World Bank Econ Rev. 2008;22:141-63.

57. Yeo R, Moore K. Including disabled people in poverty reduction work: "Nothing about us, without us". World Dev. 2003;31:571-90.

58. Contreras DG, Ruiz-Tagle JV, Garcés P, Azócar I. Socio-economic impact of disability in Latin America: Chile and Uruguay. Santiago de Chile: Universidad de Chile, Departamento de Economía; 2006.

59. Hoogeveen JG. Measuring welfare for small but vulnerable groups: Poverty and disability in Uganda. J Afr Econ. 2005;14:603-31.

60. Lamichhane K, Kawakatsu Y. Disability and determinants of schooling: A case from Bangladesh. Int J Educ Dev. 2015;40:98-105.

61. Mitra S. The recent decline in the employment of persons with disabilities in South Africa, 1998-2006. S Afr J Econ. 2008;76:480-92.

62. Mitra S, Sambamoorthi U. Disability and the rural labor market in India: Evidence for males in Tamil Nadu. World Dev. 2008;36:934-52.

63. Mont D, Cuong NV. Disability and poverty in Vietnam. World Bank Econ Rev. 2011;25:323-59.

64. O'Keefe P. People with disabilities in India: from commitments to outcomes. Washington, DC: World Bank, Human Development Unit - South Asia Region; 2009.

65. Rischewski D, Kuper H, Atijosan O, Simms V, Jofret-Bonet M, Foster A, et al. Poverty and musculoskeletal impairment in Rwanda. Trans R Soc Trop Med Hyg. 2008;102:608-17.

66. Trani J-F, Loeb M. Poverty and disability: A vicious circle? Evidence from Afghanistan and Zambia. J Int Dev. 2012;24 Suppl 1:S19-52.

67. Trani J-F, VanLeit B. Increasing inclusion of persons with disabilities: Reflections from disability research using the ICF in Afghanistan and Cambodia. London: Leonard Cheshire International; 2010.

68. Eide AH, Kamaleri Y. Living conditions among people with disabilities in Mozambique: A national representative study. Oslo: SINTEF; 2009.

69. Eide $\mathrm{AH}$, Loeb ME. Living conditions among people with activity limitations in Zambia: A national representative study. Oslo: SINTEF; 2006.

70. Loeb M, Eide AH. Living conditions among people with activity limitations in Malawi: A national representative study. Oslo: SINTEF; 2004. 
71. Loeb M, Eide AH, Jelsma J, Toni M, Maart S. Poverty and disability in Eastern and Western Cape Provinces, South Africa. Disabil Soc. 2008;23:311-21.

72. McNally A, Mannan H. Perceptions of caring for children with disabilities: Experiences from Moshi, Tanzania. Afr J Disabil. 2013;2:21.

73. Aponte JJ, Schellenberg D, Egan A, Breckenridge A, Carneiro I, Critchley J, et al. Efficacy and safety of intermittent preventive treatment with sulfadoxinepyrimethamine for malaria in African infants: a pooled analysis of six randomised, placebo-controlled trials. Lancet. 2009;374:1533-42.

74. Greenwood B. Review: Intermittent preventive treatment--a new approach to the prevention of malaria in children in areas with seasonal malaria transmission. Trop Med Int Health. 2006;11:983-91.

75. Lengeler C. Insecticide-treated bed nets and curtains for preventing malaria. Cochrane Database Syst Rev. 2004(2):CD000363.

76. Pluess B, Tanser FC, Lengeler C, Sharp BL. Indoor residual spraying for preventing malaria. Cochrane Database Syst Rev. 2010(4):CD006657.

77. Kilian A, Koenker H, Baba E, Onyefunafoa EO, Selby RA, Lokko K, et al. Universal coverage with insecticide-treated nets - applying the revised indicators for ownership and use to the Nigeria 2010 malaria indicator survey data. Malar J. 2013;12:314.

78. McLean KA, Byanaku A, Kubikonse A, Tshowe V, Katensi S, Lehman AG. Fishing with bed nets on Lake Tanganyika: a randomized survey. Malar J. 2014;13:395.

79. World Health Organization. World malaria report 2017. Geneva: WHO; 2017.

80. World Health Organization. T3: Test. Treat. Track. Scaling up diagnostic testing, treatment and surveillance for malaria. Geneva: WHO; 2012.

81. Gilroy K, Winch P. Management of sick children by community health workers: intervention models and programme examples. Geneva: WHO/UNICEF; 2006.

82. Hamer DH, Brooks ET, Semrau K, Pilingana P, MacLeod WB, Siazeele K, et al. Quality and safety of integrated community case management of malaria using rapid diagnostic tests and pneumonia by community health workers. Pathog Glob Health. 2012;106:32-9.

83. Ruizendaal E, Dierickx S, Peeters Grietens K, Schallig HD, Pagnoni F, Mens PF. Success or failure of critical steps in community case management of malaria with rapid diagnostic tests: a systematic review. Malar J. 2014;13:229.

84. Phiri TB, Kaunda-Khangamwa BN, Bauleni A, Chimuna T, Melody D, Kalengamaliro $\mathrm{H}$, et al. Feasibility, acceptability and impact of integrating malaria rapid diagnostic tests and pre-referral rectal artesunate into the integrated community case management programme. A pilot study in Mchinji district, Malawi. Malar J. 2016;15:177.

85. Seidenberg PD, Hamer DH, Iyer H, Pilingana P, Siazeele K, Hamainza B, et al. Impact of integrated community case management on health-seeking behavior in rural Zambia. Am J Trop Med Hyg. 2012;87(5 Suppl):105-10.

86. Agyei-Baffour P, Hansen KS, Browne EN, Magnussen P. The amount and value of work time of community medicine distributors in community case management of malaria among children under five years in the Ejisu-Juaben District of Ghana. Malar J. 2012;11:277. 
87. Kasteng F, Settumba S, Källander K, Vassall A, inSCALE Study Group. Valuing the work of unpaid community health workers and exploring the incentives to volunteering in rural Africa. Health Policy Plan. 2016;31:205-16.

88. Thwing J, Eisele TP, Steketee RW. Protective efficacy of malaria case management and intermittent preventive treatment for preventing malaria mortality in children: a systematic review for the Lives Saved Tool. BMC Public Health. 2011;11 Suppl 3:S14.

89. White MT, Conteh L, Cibulskis R, Ghani AC. Costs and cost-effectiveness of malaria control interventions--a systematic review. Malar J. 2011;10:337.

90. Batwala V, Magnussen P, Hansen KS, Nuwaha F. Cost-effectiveness of malaria microscopy and rapid diagnostic tests versus presumptive diagnosis: implications for malaria control in Uganda. Malar J. 2011;10:372.

91. Chanda P, Castillo-Riquelme M, Masiye F. Cost-effectiveness analysis of the available strategies for diagnosing malaria in outpatient clinics in Zambia. Cost Eff Resour Alloc. 2009;7:5.

92. Uzochukwu BS, Obikeze EN, Onwujekwe OE, Onoka CA, Griffiths UK. Costeffectiveness analysis of rapid diagnostic test, microscopy and syndromic approach in the diagnosis of malaria in Nigeria: implications for scaling-up deployment of ACT. Malar J. 2009;8:265.

93. Shillcutt S, Morel C, Goodman C, Coleman P, Bell D, Whitty CJ, et al. Cost-effectiveness of malaria diagnostic methods in sub-Saharan Africa in an era of combination therapy. Bull World Health Organ. 2008;86:101-10.

94. Ansah EK, Epokor M, Whitty CJM, Yeung S, Hansen KS. Cost-effectiveness analysis of introducing RDTs for malaria diagnosis as compared to microscopy and presumptive diagnosis in central and peripheral public health facilities in Ghana. Am J Trop Med Hyg. 2013;89:724-36.

95. Lubell Y, Reyburn H, Mbakilwa H, Mwangi R, Chonya K, Whitty CJ, et al. The costeffectiveness of parasitologic diagnosis for malaria-suspected patients in an era of combination therapy. Am J Trop Med Hyg. 2007;77(6 Suppl):128-32.

96. Yukich J, D’Acremont V, Kahama J, Swai N, Lengeler C. Cost savings with rapid diagnostic tests for malaria in low-transmission areas: evidence from Dar es Salaam, Tanzania. Am J Trop Med Hyg. 2010;83:61-8.

97. Chanda P, Hamainza B, Moonga HB, Chalwe V, Banda P, Pagnoni F. Relative costs and effectiveness of treating uncomplicated malaria in two rural districts in Zambia: implications for nationwide scale-up of home-based management. Malar J. 2011;10:159.

98. Msellem MI, Martensson A, Rotllant G, Bhattarai A, Strömberg J, Kahigwa E, et al. Influence of rapid malaria diagnostic tests on treatment and health outcome in fever patients, Zanzibar: a crossover validation study. PLoS Med. 2009;6:e1000070.

99. Kindermans J-M, Pécoul B, Perez-Casas C, Den Boer M, Berman D, Cox I. Changing national malaria treatment protocols in Africa: what is the cost and who will pay? - Case studies: Burundi, Kenya, Rwanda, Tanzania and Uganda. Geneva: Médecins sans frontières; 2002.

100. Muheki C, McIntyre D, Barnes KI. Artemisinin-based combination therapy reduces expenditure on malaria treatment in KwaZulu Natal, South Africa. Trop Med Int Health. 2004;9:959-66. 
101. Wiseman V, Kim M, Mutabingwa TK, Whitty CJ. Cost-effectiveness study of three antimalarial drug combinations in Tanzania. PLoS Med. 2006;3:e373.

102. Chanda P, Masiye F, Chitah BM, Sipilanyambe N, Hawela M, Banda P, et al. A costeffectiveness analysis of artemether lumefantrine for treatment of uncomplicated malaria in Zambia. Malar J. 2007;6:21.

103. Kamat VR, Nyato DJ. Community response to artemisinin-based combination therapy for child hood malaria: a case study from Dar es Salaam, Tanzania. Malar J. 2010;9:61.

104. Awad MI, Alkadru AM, Behrens RH, Baraka OZ, Eltayeb IB. Descriptive study on the efficacy and safety of artesunate suppository in combination with other antimalarials in the treatment of severe malaria in Sudan. Am J Trop Med Hyg. 2003;68:153-8.

105. Barnes KI, Mwenechanya J, Tembo M, Mcllleron H, Folb PI, Ribeiro I, et al. Efficacy of rectal artesunate compared with parenteral quinine in initial treatment of moderately severe malaria in African children and adults: a randomised study. Lancet. 2004;363:1598-605.

106. Gomes MF, Faiz MA, Gyapong JO, Warsame M, Agbenyega T, Babiker A, et al. Prereferral rectal artesunate to prevent death and disability in severe malaria: a placebo-controlled trial. Lancet. 2009;373:557-66.

107. Sam-Wobo SO, Agbeyangi OA, Ekpo UF, Akinloye OA, Mafiana CF, Adeleke MA. Rectal artesunates, their utilization, and parental perception in the management of malaria in children from Abeokuta, southwestern Nigeria. Vector Borne Zoonotic Dis. 2012;12:151-5.

108. Simba DO, Kakoko DC, Warsame M, Premji Z, Gomes MF, Tomson G, et al. Understanding caretakers' dilemma in deciding whether or not to adhere with referral advice after pre-referral treatment with rectal artesunate. Malar J. 2010;9:123.

109. Siribie M, Ajayi IO, Nsungwa-Sabiiti J, Sanou AK, Jegede AS, Afonne C, et al. Compliance with referral advice after treatment with prereferral rectal artesunate: a study in 3 Sub-Saharan African countries. Clin Infect Dis. 2016;63 Suppl 5:S283-S9.

110. Tozan Y, Klein EY, Darley S, Panicker R, Laxminarayan R, Breman JG. Prereferral rectal artesunate for treatment of severe childhood malaria: a cost-effectiveness analysis. Lancet. 2010;376:1910-5.

111. Nanyonjo A, Bagorogoza B, Kasteng F, Ayebale G, Makumbi F, Tomson G, et al. Estimating the cost of referral and willingness to pay for referral to higherlevel health facilities: a case series study from an integrated community case management programme in Uganda. BMC Health Serv Res. 2015;15:347. 


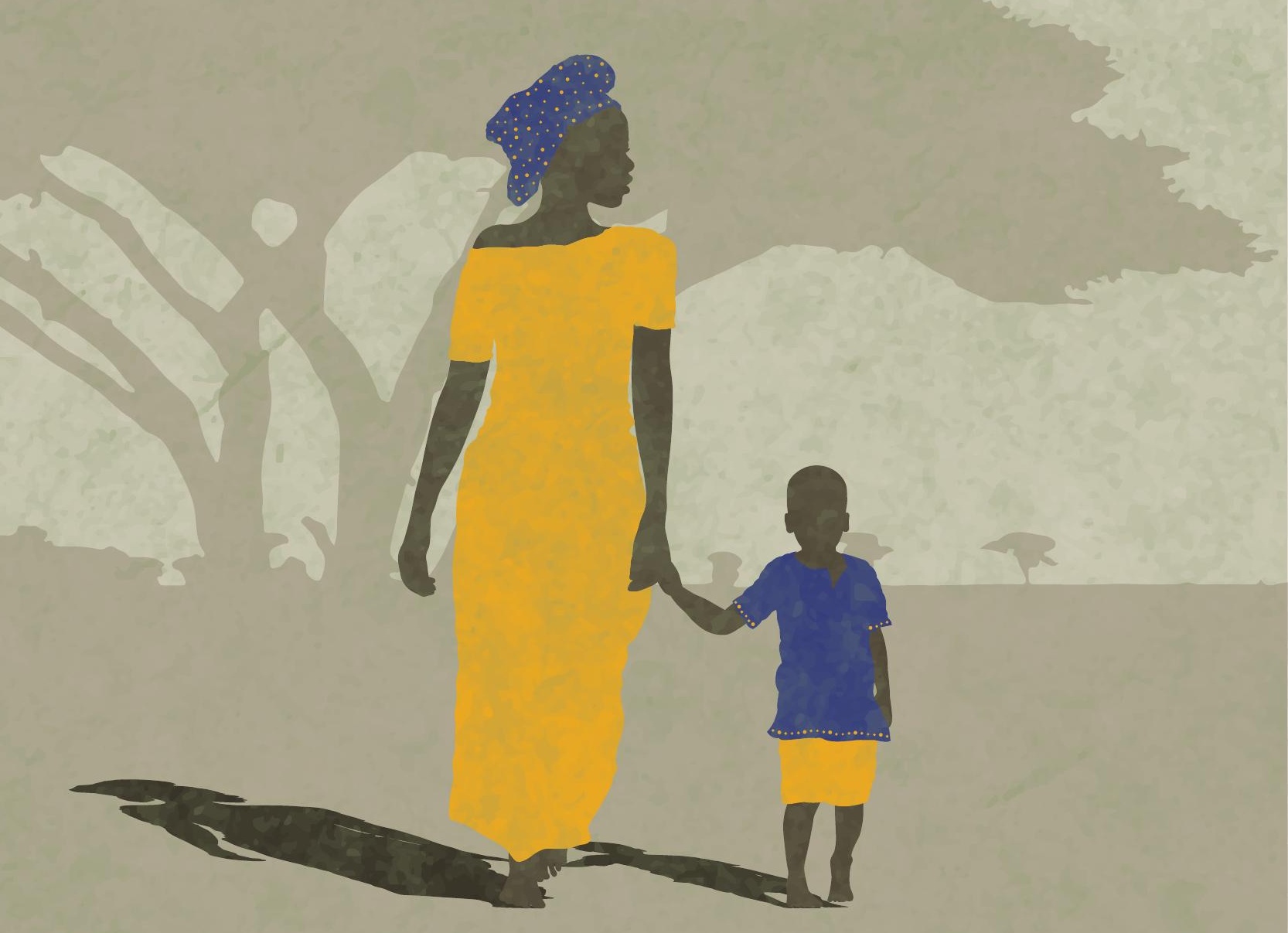




\section{CHAPTER 2}

\section{OUT-OF-POCKET COSTS AND OTHER DETERMIMANTS OF ACCESS TO HEALTHCARE FOR CHILDREN WITH FEBRILE ILLNESSES: A CASE-CONTROL STUDY IN RURAL TAMZAMA}

\section{Published as:}

Castellani J, Mihaylova B, Evers SMAA, Paulus ATG, Mrango ZE, Kimbute O, Shishira JP, Mulokozi F, Petzold M, Singlovic J, Gomes M. Out-of-pocket costs and other determinants of access to healthcare for children with febrile illnesses: a casecontrol study in rural Tanzania. PLoS One. 2015;10:e0122386. 


\section{ABSTRACT}

\section{Objectives}

To study private costs and other determinants of access to healthcare for childhood fevers in rural Tanzania.

\section{Methods}

A case-control study was conducted in Tanzania to establish factors that determine access to a health facility in acute febrile illnesses in children less than 5 years of age. Carers of eligible children were interviewed in the community; cases were represented by patients who went to a facility and controls by those who did not. A Household Wealth Index was estimated using principal components analysis. A multivariable logistic regression analysis was performed to understand the factors which influenced attendance of healthcare facility including severity of the illness and household wealth/socio-demographic indicators. To complement the data on costs from community interviews, a hospital-based study obtained details of private expenditures for hospitalised children under the age of 5 .

\section{Results}

Severe febrile illness is strongly associated with health facility attendance (OR: 35.76, 95\%CI: 3.68-347.43, p=0.002 compared with less severe febrile illness). Overall, the private costs of an illness for patients who went to a hospital were six times larger than private costs of controls ( $\$ 5.68$ vs. $\$ 0.90, \mathrm{p}<0.0001$ ). Household wealth was not significantly correlated with total costs incurred. The separate hospital based cost study indicated that private costs were three times greater for admissions at the mission versus public hospital: \$13.68 mission vs. \$4.47 public hospital (difference $\$ 9.21$ (95\% CI: 7.89-10.52), p<0.0001). In both locations, approximately $50 \%$ of the cost was determined by the duration of admission, with each day in hospital increasing private costs by about $12 \%$ (95\% CI: 5\% - 21\%).

\section{Conclusion}

The more severely ill a child, the higher the probability of attending hospital. We did not find association between household wealth and attending a health facility; nor was there an association between household wealth and private cost. 


\subsection{INTRODUCTION}

While malaria as a cause of severe childhood febrile illnesses declines, recent research emphasises the prevalence of other causes of infection as primary causes of fever and the importance of these infections in hospital admissions, especially in Africa [1-4]. Fevers appear to have been consistently over-diagnosed and treated as malaria [2, 3] sometimes with adverse outcomes [5].

In most severe febrile illness, speed of therapeutic intervention determines outcome. By definition, severely ill children have declared themselves as being unable to control the infection and have a lower probability for spontaneous cure. While uncomplicated illness may be managed at home, the evolution of an infection to a severe state or death suggests failure to diagnose and promptly treat the infection. Whereas a negative relationship has been reported between poverty and use of health services for uncomplicated febrile illness [6], the relationship between wealth and healthcare seeking behaviour in severe disease remains almost unexplored, except for one study which showed no association [7].

In rural areas, it has been reported that irrespective of illness, 41\% Tanzanian patients consult a healthcare provider when sick, and among those with "danger" signs of fast or difficult breathing, convulsions, inability to eat, drink or suck, repeated vomiting, altered consciousness or coma, $60 \%$ go to a public hospital/ health centre [6]. In order to decrease private costs and encourage greater and more equitable use of health services among children under 5 years old who bear the brunt of mortality, this group are exempt from healthcare charges, including inpatient fees [8]. Despite this policy, approximately $75 \%$ of health care expenditure appears to be borne by households [9] and high costs for hospital paediatric admissions are reported [10].

Reasons why households fail to reach a health facility are still not very clear. Anticipated total private costs, inability to pay in kind or pay over a longer period of time may be some of the reasons [11].

Understanding failed opportunities to access timely care is key to reducing the infectious disease burden. Some part of the failed opportunity may be due to delays in taking a decision to reach care. Another part may be the delay or failure of the family to reach appropriate care. The third delay may occur at the facility when 
clinicians do not have a high index of suspicion for the true cause in their diagnostic and treatment plan.

This study looks at determinants of access to health care for children with febrile illness. We carried out a case-control study in rural Tanzania, where malaria, acute respiratory infections and other causes of serious febrile illness are common, in order to understand whether economic and socio-demographic factors determine access to healthcare facilities.

\subsection{METHODS}

\subsubsection{Study sites}

Our study was implemented in two rural, malaria-endemic areas of Tanzania: Kilosa and Mvomero Districts, between September 2010 and March 2011. In Kilosa District, there is access to free care at a public hospital, and most families farm on their own land. In contrast, family income in Mvomero District is dependent upon large-scale, estate-owned, irrigated sugarcane and rice to which families contribute labour. The extensive irrigation makes malaria transmission intense and non-seasonal compared with surrounding areas [12]. Access to immediate care is through a mission hospital located close to the irrigated areas that charges fees.

\subsubsection{Health services provision in study areas}

At Kilosa District Hospital, facility registration/consultation, bed costs, inpatient cost of drugs and laboratory examinations are provided free of charge for young children. However, for older children and adults, a fixed fee of US\$1.4 is charged for registration/consultation/medication plus $\$ 0.3$ per night per bed and per test for each laboratory investigation. In public hospitals such as Kilosa District Hospital, drugs or other supplies used for patient care are provided at no cost when they are in stock. However if essential commodities happen to be out-of-stock at the time of the consultation/admission, the responsibility for purchase rests with the patient's carer.

Turiani Missionary Hospital in Mvomero District was set up in 1961 to provide medical services labourers of the local irrigation schemes [13]. Young children are charged $\$ 2.4$ for the first visit for registration/consultation plus $\$ 0.7$ per bed per night, $\$ 1.2$ for the second visit plus $\$ 0.7$ per night per bed. The cost for older children and adults is double that of Kilosa: $\$ 2.8$ for registration/consultation plus 
\$0.7 per night per bed. The cost of drugs and laboratory examinations are charged separately, per test and per drug.

Although costs charged to the patient are different between public and private facilities, both hospitals follow national treatment guidelines and provide the same standard of care. The number and quality of staff attending patients were not noticeably different between the two hospitals, but greater attention seemed to be paid to patient notes, hospital files, documentation of patient care and follow up in Turiani Missionary Hospital.

These hospitals serving both Districts represent the highest level of care; they are supported by several other public and private facilities (called health centres and dispensaries) which provide inpatient and outpatient health care respectively. The dispensary managed by nurses is usually the first point of consultation for patients and they are closer to the patients' residences and are more numerous than hospitals. The health centre admits patients, and is staffed by doctors and nurses and often located at an intermediate distance between the dispensary and hospital. In addition, there are a variety of private laboratories, governmental maternal-care clinics, traditional healers and voluntary health workers to whom patients can go for advice and care, in addition to the shops which sell medicines (antipyretics, antibiotics, and antimalarials including quinine) without prescription.

\subsubsection{Study population and data collection}

The case-control study was carried out in Kilosa and Mvomero Districts. The purpose was to establish why some parents or carers went to hospital/health centre with their child and others did not, especially for children who had a severe febrile illness. A list was developed identifying the villages where the majority of hospital/health-centre-admitted patients resided (excluding villages next to those facilities) and community interviews occurred in the twelve top communities listed, so that geographical distance was similar for patients admitted or not admitted to these facilities.

In each community, the study was explained to chiefs of villages and community health workers (CHWs) who are the front-line workers for community health care. These CHWs are required to keep a ledger of sick children in the community with their symptoms, consultations and outcome. We outlined our desire to interview parents of sick children focusing on those who had symptoms of a febrile illness in 
the past month. CHWs were approached to identify patients who met the inclusion criteria of age (between 3-59 months), symptoms (a febrile illness which prevented oral drug intake at some point during the illness), and illness resolution within the past month.

Children who did not meet these eligibility criteria, whose guardian was not present during the illness, who had been already interviewed regarding a previous episode of illness in the household or who refused to sign the informed consent form were excluded from interview. Once eligible children were identified by village health workers or village chiefs, the parents or guardians of the children were approached, the study was explained, informed consent obtained, and interviews were conducted.

Allocation of the participants to the cases or controls and determination of whether the episode met eligibility criteria could only occur post-interview. Cases were defined as children who had attended a health facility (i.e. hospital or health centre) and controls were those who did not.

Thirteen trained interviewers, with extensive research experience in Kilosa, carried out structured interviews in Swahili and filled out a Case Record Form (available on request). There was no purposeful selection of families for interviews: in each village, all families identified with a sick child who met the inclusion criteria were interviewed. Only one interview per household occurred even if many children in the household had been sick, or a child had more than one episode of illness during the study period.

To better understand the factors driving hospital costs, a complementary study was carried out in hospitals with a focus on all out-of-pocket costs of patients admitted, as well as the clinical history of children prior to admission. These interviews were carried out with parents of children about to be discharged from Kilosa District Hospital and Turiani Mission Hospital. Interviews occurred on the day of discharge so that most costs already incurred by parents could be captured. When many children were discharged on the same day, a selection of parents for interview was undertaken (first discharged, first interviewed); when only a few eligible children were to be discharged, every guardian (i.e. an adult carer accompanying the child) was interviewed. 


\subsubsection{Sampling strategy}

Our aim was to interview all patients meeting the eligibility criteria from the main 12 malaria endemic communities in the catchment areas of two major hospitals and one public health centre using CHWs records of childhood illnesses in the community. All families of a child meeting the eligibility criteria were interviewed. At intervals, after a visit to a village had already taken place, the $\mathrm{CHW}$ would inform the team that new patients had been identified, and the team would return to the village to complete additional interviews. The objective was to fully represent all eligible patients in these communities during the malaria season of September 2010 to March 2011. There was no attempt to have an equal number of patients from each of the 12 communities.

\subsubsection{Questionnaire design}

All questionnaires were in Swahili and pilot tested before use. The hospital questionnaire was similar to the community questionnaire but captured additional information on the date and time of arrival of the patient at the hospital, the clinical diagnoses and the treatments received/prescribed at the hospital, extracted from the patient's hospital file. Each interview lasted about fifty minutes. Participants were asked about the general social-demographic context of the family, and detailed information of the clinical course of the illness (timing, symptoms, actions taken, healthcare providers visited and costs incurred such as transportation, medicines, registration/consultation fees, laboratory/diagnostic tests, accommodation and food for each consultation).

\subsubsection{Data analysis}

\section{Patient and household characteristics}

Demographic information on the patient (sex, age) and patient's family (education, number of working members) was obtained. Household socioeconomic data focussed on living standards - durable family possessions (radio, lantern, bicycle, table, iron), ability to meet family food needs, and main occupation/means of the household. Baseline characteristics were compared between cases and controls.

\section{Severity of illness}

Classification of severity was by clinical symptoms as reported by the caretaker. Febrile children with reports of only some very short period of time when the child could not take oral drugs and where the child was largely able to take oral medications, were classified as Per Os (PO). This category included children who had fever only, diarrhoea, rash, cough, a cold/runny nose, headache, no appetite 
or abdominal pain. If the fever was accompanied by one of the following: repeated vomiting or lethargy (unable to sit/stand/walk unaided, too weak to eat, drink or suck) the illness was classified as Non-Per-Os (NPO). Children with repeated convulsions, altered consciousness or coma, difficulties in breathing or rapid breathing, a stiff neck, bulging fontanel or chest indrawing were classified as severely ill. There was no overlap in patients; children with symptoms in more than one category were categorised in the highest severity category.

\section{Private out-of-pocket costs}

Out-of-pocket costs reported by the parent or guardian of the child were categorised into "hotel" costs (defined as accommodation costs, registration costs, food, drinks and other costs for carer or patient), diagnostic/laboratory investigations, drugs and patient management, and transport. Transport cost included costs of the parent or guardian but excluded costs paid by a third party (i.e. a person not related to the household) accompanying the parent/guardian and child. Total private costs were compared by case-control status for each location. Total hospital costs were compared by location also for the patients interviewed at the hospital. Costs are presented in US dollars (\$) using the average exchange rate between September 2010 and March 2011: 1 US Dollar = 1,474.06 Tanzanian Shillings (www.oanda.com).

\section{Statistical methods}

All data were double entered (Epidata, 3.1) and analyzed using STATA v.9.2 (StataCorp, College Station, TX, USA). Information on household possessions (table, radio, lantern, bicycle and iron) and food problems (had or never had food problems) was used to calculate a Household Wealth Index (HWI) based upon principal components analysis to characterize the wealth variance between households within the community group $[14,15]$. Households were grouped into pre-determined 'wealth' categories - the lowest 40\%, middle $40 \%$ and highest $20 \%$ - reflecting different socioeconomic levels. Calculation of the HWI did not adjust for household size since the benefits of possessions would be available at the household level.

Since one of our objectives was to study factors influencing hospital care, we undertook a multivariable logistic regression analysis using community-based data in which attendance at a hospital or health centre was the dependent variable and independent variables were demographic, social or economic in nature location, age of the child, gender, highest education (in years) achieved within the 
family, number of working people in the household, severity of the illness and the household wealth index. Since the total private costs of illness were not known at the time of decision to go to a hospital/health centre, we excluded total private costs incurred for healthcare of the child during the episode of illness. A further linear regression analysis was used to determine which factors affected hospital costs.

When the study population was stratified with respect to the characteristic of interest, we used either the chi-squared test of homogeneity or a linear trend of odds if there were more than two ordered groups. We also used the student's t-test to determine equality of means. The level of significance of $p=0.05$ and a confidence level of $95 \%$ were used throughout.

\subsubsection{Ethics}

The research protocol was approved by the National Institute for Medical Research Ethics Committee (NIMR) and the Commission for Science and Technology (COSTECH) in Tanzania. Additional local permission was granted by the Regional Medical Officer in Morogoro, the District Medical Officers in Kilosa and Mvomero and village leaders. Individual written informed consent was obtained from all participants prior to interview.

\subsection{RESULTS}

\subsubsection{Patient characteristics}

Fig 1 shows the number of interviews conducted both in the community (Fig 1A) and at the hospital (Fig 1B), and the inclusion and exclusion of the data into the analysis. For our case-control study (Fig 1A), a total of 183 guardians, mostly mothers $(>90 \%)$, were interviewed in the community, but 12 interviews were excluded from analysis because the child was sick at the time of the interview $(\mathrm{N}=1)$, did not have a febrile illness $(\mathrm{N}=3)$ or the illness had not resolved within the month's eligibility period $(\mathrm{N}=5)$. Also excluded were 3 episodes in children whose guardians were interviewed twice for different illness episodes; only the first interview was retained $(\mathrm{N}=3)$. This left a total of 171 participants included in the case-control analysis (51 cases and 120 controls).

Fig 1B shows that out of 260 hospital interviews conducted to obtain detailed private costs for childhood admissions, 252 observations were included in the analysis. Eight patients were excluded: because the child was age-ineligible $(\mathrm{N}=2)$; 
guardians were interviewed for 2 different illness episodes from which only the first was retained $(\mathrm{N}=2)$; the guardian gave insufficient or inconsistent information $(\mathrm{N}=3)$ or guardian gave oral but not written consent $(\mathrm{N}=1)$.

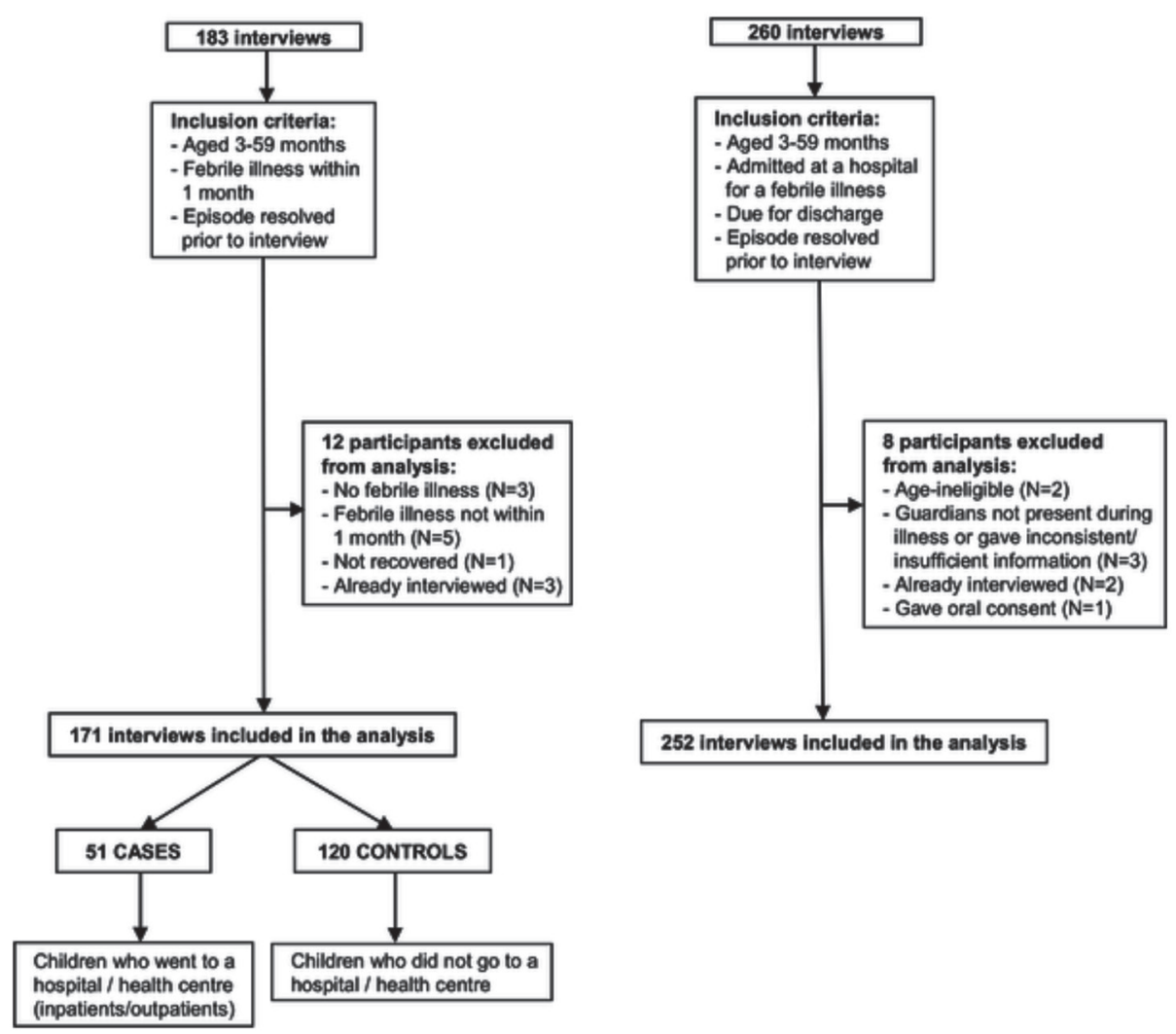

Figure 1. Community interviews - Cases and Controls (A); Hospital interviews (B).

\subsubsection{Baseline characteristics}

Most children were below 37 months of age (84.4\% Cases Kilosa, 73.7\% Cases Turiani, 71.2\% Controls Kilosa and 75.0\% Controls Turiani) (Table 1). The highest level of education completed by a household member was generally primary school (7 years or less) and for most households income was based on farming (mainly crops but sometimes pastoral farming). There was no difference in baseline characteristics between cases and controls in Kilosa. In Turiani, a significantly greater proportion of working people were in households of the cases compared with controls $(16 / 19$ vs. $8 / 16 ; p=0.0323)$. None of the controls were referred to a hospital and only 5 cases (2.9\%) were referred to a hospital/health centre. 
Table 1. Baseline characteristics: cases versus controls by location.

\begin{tabular}{|c|c|c|c|c|c|c|c|c|c|c|c|}
\hline \multirow[t]{3}{*}{ Category } & \multirow[t]{3}{*}{ Subcategory } & \multicolumn{4}{|c|}{ Cases } & \multicolumn{4}{|c|}{ Controls } & \multicolumn{2}{|c|}{ Total } \\
\hline & & \multicolumn{2}{|c|}{ Kilosa } & \multicolumn{2}{|c|}{ Turiani } & \multicolumn{2}{|c|}{ Kilosa } & \multicolumn{2}{|c|}{ Turiani } & \multirow[b]{2}{*}{$\%$} & \multirow[b]{2}{*}{$\mathbf{N}$} \\
\hline & & $\%$ & $\mathbf{N}$ & $\%$ & $\mathbf{N}$ & $\%$ & $\mathbf{N}$ & $\%$ & $\mathbf{N}$ & & \\
\hline & & 18.7 & 32 & 11.1 & 19 & 60.8 & 104 & 9.4 & 16 & 100.0 & 171 \\
\hline $\begin{array}{l}\text { Caregiver's } \\
\text { gender }\end{array}$ & Female & 93.8 & 30 & 100.0 & 19 & 93.3 & 97 & 93.8 & 15 & 94.2 & 161 \\
\hline $\begin{array}{l}\text { Child's } \\
\text { gender }\end{array}$ & Male & 43.8 & 14 & 52.6 & 10 & 51.9 & 54 & 37.5 & 6 & 49.1 & 84 \\
\hline \multirow{3}{*}{$\begin{array}{l}\text { Child's age, } \\
\text { months }{ }^{a}\end{array}$} & $\leq 18$ & 40.6 & 13 & 52.6 & 10 & 42.4 & 44 & 37.5 & 6 & 42.7 & 73 \\
\hline & $19-36$ & 43.8 & 14 & 21.1 & 4 & 28.8 & 30 & 37.5 & 6 & 31.6 & 54 \\
\hline & $37-59$ & 12.5 & 4 & 26.3 & 5 & 28.8 & 30 & 25.0 & 4 & 25.1 & 43 \\
\hline \multirow{3}{*}{$\begin{array}{l}\text { Highest } \\
\text { education in } \\
\text { family, years }^{\mathrm{b}}\end{array}$} & No education & - & - & 5.3 & 1 & 4.8 & 5 & - & - & 3.5 & 6 \\
\hline & $\leq 7$ & 93.8 & 30 & 68.4 & 13 & 82.7 & 86 & 87.5 & 14 & 83.6 & 143 \\
\hline & $>7$ & 6.2 & 2 & 26.3 & 5 & 12.5 & 13 & 6.3 & 1 & 12.3 & 21 \\
\hline \multirow{2}{*}{$\begin{array}{l}\text { Number of } \\
\text { working } \\
\text { people }^{c}\end{array}$} & $\leq 2$ & 50.0 & 16 & 15.8 & 3 & 61.5 & 64 & 50.0 & 8 & 53.2 & 91 \\
\hline & $>2$ & 50.0 & 16 & 84.2 & 16 & 38.5 & 40 & 50.0 & 8 & 46.8 & 80 \\
\hline \multirow{3}{*}{$\begin{array}{l}\text { Main } \\
\text { occupation/ } \\
\text { source of } \\
\text { income }\end{array}$} & Only farming & 96.9 & 31 & 68.4 & 13 & 92.3 & 96 & 81.2 & 13 & 89.5 & 153 \\
\hline & $\begin{array}{l}\text { Self-employment } \\
\text { mainly }\end{array}$ & - & - & 10.5 & 2 & 5.8 & 6 & 12.5 & 2 & 5.8 & 10 \\
\hline & $\begin{array}{l}\text { Paid employment } \\
\text { mainly }\end{array}$ & 3.1 & 1 & 21.1 & 4 & 1.9 & 2 & 6.3 & 1 & 4.7 & 8 \\
\hline \multirow{12}{*}{$\begin{array}{l}\text { Symptoms \& } \\
\text { severity }\end{array}$} & Per Os - Total & 59.4 & 19 & 10.5 & 2 & 55.8 & 58 & 56.2 & 9 & 51.5 & 88 \\
\hline & Fever only & 21.0 & 4 & 50.0 & 1 & 50.0 & 29 & 44.5 & 4 & 43.2 & 38 \\
\hline & Diarrhoea & 15.8 & 3 & 50.0 & 1 & 10.3 & 6 & 22.2 & 2 & 13.6 & 12 \\
\hline & Cough/cold & 63.2 & 12 & - & - & 34.5 & 20 & 33.3 & 3 & 39.8 & 35 \\
\hline & Rash & - & - & - & - & 5.2 & 3 & - & - & 3.4 & 3 \\
\hline & Non Per Os - Total & 25.0 & 8 & 84.2 & 16 & 43.2 & 45 & 43.8 & 7 & 44.4 & 76 \\
\hline & Repeating vomiting ${ }^{\mathrm{d}}$ & 75.0 & 6 & 87.5 & 14 & 77.8 & $35^{\mathrm{e}}$ & 71.4 & 5 & 78.9 & 60 \\
\hline & $\begin{array}{l}\text { Lethargy (too weak } \\
\text { to swallow, to sit)d }\end{array}$ & 25.0 & 2 & 12.5 & 2 & 22.2 & 10 & 28.6 & 2 & 21.1 & 16 \\
\hline & Severe - Total & 15.6 & 5 & 5.3 & 1 & 1.0 & 1 & - & - & 4.1 & 7 \\
\hline & $\begin{array}{l}\text { Altered } \\
\text { consciousness/coma }\end{array}$ & - & - & - & - & 100.0 & 1 & - & - & 14.2 & 1 \\
\hline & Convulsions & 40.0 & 2 & 100.0 & 1 & - & - & - & - & 42.9 & 3 \\
\hline & $\begin{array}{l}\text { Difficulties in } \\
\text { breathing }\end{array}$ & 60.0 & 3 & - & - & - & - & - & - & 42.9 & 3 \\
\hline
\end{tabular}


Table 1. Baseline characteristics: cases versus controls by location. (Continued)

\begin{tabular}{|c|c|c|c|c|c|c|c|c|c|c|c|}
\hline \multirow[t]{3}{*}{ Category } & \multirow[t]{3}{*}{ Subcategory } & \multicolumn{4}{|c|}{ Cases } & \multicolumn{4}{|c|}{ Controls } & \multicolumn{2}{|c|}{ Total } \\
\hline & & \multicolumn{2}{|c|}{ Kilosa } & \multicolumn{2}{|c|}{ Turiani } & \multicolumn{2}{|c|}{ Kilosa } & \multicolumn{2}{|c|}{ Turiani } & \multirow[b]{2}{*}{$\%$} & \multirow[b]{2}{*}{$\mathbf{N}$} \\
\hline & & $\%$ & $\mathbf{N}$ & $\%$ & $\mathbf{N}$ & $\%$ & $\mathbf{N}$ & $\%$ & $\mathbf{N}$ & & \\
\hline Cases & PerOs & - & - & - & - & - & - & - & - & - & - \\
\hline referred by a & Non Per Os & 6.2 & 2 & 15.8 & 3 & - & - & - & - & 2.9 & 5 \\
\hline $\begin{array}{l}\text { village health } \\
\text { worker or a } \\
\text { dispensary } \\
\text { to hospital/ } \\
\text { health centre }\end{array}$ & Severe & - & - & - & - & - & - & - & - & - & - \\
\hline
\end{tabular}

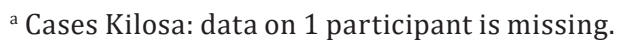

${ }^{\mathrm{b}}$ Controls Turiani: data on 1 participant is missing.

${ }^{\mathrm{c}}$ Cases Turiani vs. Controls Turiani (test of homogeneity): $\chi^{2}=4.58, p=0.0323$.

${ }^{\mathrm{d}}$ Plus other symptoms preventing oral treatment.

e Repeated vomiting only: 1 participant.

\subsubsection{Household Wealth Index}

Table 2 presents the Household Wealth Index (HWI). Households in the lowest wealth category were least likely to have all the possessions and had a greater frequency of food problems and vice versa. Wealth comparisons between cases and controls using the derived HWI show that there was a non-significant trend towards more cases than controls being in the higher wealth category in both Kilosa (25.0\% Cases vs. 18.3\% Controls) and Turiani (21.1\% Cases vs. 12.5\% Controls) (Table 2).

Table 2. Household Wealth Index for the community participants.

\begin{tabular}{|c|c|c|c|c|c|c|}
\hline \multirow{3}{*}{$\begin{array}{l}\text { Study } \\
\text { participants (\%) } \\
\text { by wealth category }\end{array}$} & \multicolumn{6}{|c|}{ Wealth category derived from Household Wealth Index ${ }^{a}$} \\
\hline & \multicolumn{2}{|c|}{$\begin{array}{l}\text { Lowest (Lowest } 40 \%) \\
\qquad(\mathrm{N}=69)\end{array}$} & \multicolumn{2}{|c|}{$\begin{array}{l}\text { Middle (Middle 40\%) } \\
\qquad(\mathrm{N}=69)\end{array}$} & \multicolumn{2}{|c|}{$\begin{array}{c}\text { Highest (Upper 20\%) } \\
(\mathrm{N}=33)\end{array}$} \\
\hline & $\%$ & $\mathbf{N}$ & $\%$ & $\mathbf{N}$ & $\%$ & $\mathbf{N}$ \\
\hline Cases Kilosa & 43.7 & 14 & 31.3 & 10 & 25.0 & 8 \\
\hline Cases Turiani & 42.1 & 8 & 36.8 & 7 & 21.1 & 4 \\
\hline Total Cases & 43.2 & 22 & 33.3 & 17 & 23.5 & 12 \\
\hline Controls Kilosa & 39.4 & 41 & 42.3 & 44 & 18.3 & 19 \\
\hline Controls Turiani & 37.5 & 6 & 50.0 & 8 & 12.5 & 2 \\
\hline Total Controls & 39.2 & 47 & 43.3 & 52 & 17.5 & 21 \\
\hline
\end{tabular}

${ }^{a}$ Estimated using information on household possessions (table, radio, lantern, bicycle and iron) and food problems. 


\subsubsection{Determinants of attending hospital or a health centre for febrile illness}

Using a multivariable logistic regression (Table 3) we studied factors that might determine healthcare facility attendance. The results of this regression model indicate that only 3 independent variables significantly influenced facility attendance: location, the number of working people in the household and severity of illness. Children in Turiani (OR: 3.55, 95\% CI: 1.48-8.51, p=0.005) and children living in households with more than two working people (OR: 2.25, 95\% CI: 1.03$4.95, \mathrm{p}=0.043$ ) were more likely to attend a health facility than children in Kilosa or children from households with fewer working people. Using our classification of severity, the more severe the episode, the greater was the likelihood that the child would be taken to a health facility (OR: 35.76, 95\% CI: 3.68-347.43, p=0.002), although the confidence interval is very wide. The index of household wealth was neither significant as an independent covariate, nor positively correlated with total costs (S1 Table).

Table 3. Determinants of attending healthcare facility for acute febrile illness based on a multivariable logistic regression model (169 participants).

\begin{tabular}{llrrr}
\hline Variable $^{\mathbf{a}}$ & Covariates & Odds ratio & $\mathbf{9 5 \%} \mathbf{C I}$ & p-value \\
\hline Community & Kilosa & reference & & \\
& Turiani & 3.55 & $1.48-8.51$ & 0.005 \\
\hline Age of the child (months) & - & 0.98 & $0.95-1.00$ & 0.080 \\
\hline Gender & Male & reference & & \\
& Female & 1.21 & $0.57-2.58$ & 0.617 \\
\hline Highest education in family (years) & - & 1.08 & $0.90-1.29$ & 0.405 \\
\hline Number of working people & $\leq 2$ & reference & \\
& $>2$ & 2.25 & $1.03-4.95$ & 0.043 \\
\hline Severity of febrile episode & Per Os & reference & & \\
& Non Per Os & 1.55 & $0.69-3.48$ & 0.287 \\
& Severe & 35.76 & $3.68-347.43$ & 0.002 \\
\hline Wealth Index & - & 0.99 & $0.76-1.28$ & 0.942 \\
\hline
\end{tabular}

${ }^{a}$ Total private costs of illness were excluded from the regression analysis since these were not known at the time of parental decision to go to a hospital/health centre. Its inclusion did not affect observed relationships.

${ }^{\mathrm{b}}$ The higher the score, the better the wealth.

\subsubsection{Household private out-of-pocket costs for healthcare}

Table 4 presents reported private costs for a whole episode of illness by cost category, for cases and controls, by location. Patients who attended a hospital/ health centre always had higher private costs: $\$ 1.37$ vs. $\$ 0.79$ (difference $\$ 0.58$ 
(95\% CI: -0.09-1.25), p=0.0874) for Kilosa; \$12.93 vs. \$1.62 for Turiani (difference $\$ 11.31$ (95\% CI: 8.22-14.41), $\mathrm{p}<0.0001$ ) with the difference in cost between cases and controls significant only in Turiani. Hence the private costs of patients who went to a hospital were six times larger than private costs of controls ( $\$ 5.68 \mathrm{vs}$. $\$ 0.90$, p < 0.0001). Patients who went to Turiani Missionary Hospital spent about 9.4 times more than patients who attended Kilosa facilities $\$ 12.93$ vs. \$1.37, (difference $\$ 11.56$ (95\% CI: 9.22-13.90), p<0.0001) and had a longer duration of hospital admission (3.17 days for Turiani vs. 1.91 days for Kilosa). A separate analysis of private costs for each wealth category for cases in Kilosa and Turiani (S1 Table) confirm significant cost differences by location, and found a significant trend in the total private costs paid by wealth category only in Kilosa $(p=0.042)$.

Table 5 uses data from the hospital interviews to classify the symptoms reported by the caretaker for children admitted and shows similar proportions of children with mild infections admitted, but a greater proportion of admissions for severe illnesses in Turiani than in Kilosa $28.9 \%$ vs. $19.1 \%$.

Table 6 explores in detail the components of hospital costs stratified by severity of illness for these patients. In both hospitals, the "hotel" costs of admission drove private costs, being approximately $50 \%$ of total costs incurred. Furthermore, the drugs and treatment costs in Turiani hospital represent more than $30 \%$ of the total hospital costs $(\$ 4.50 / 13.68)$ while in Kilosa hospital, these constituted a more modest 9\% (\$0.41/4.47). Transport costs were similar in both locations but constituted a relatively higher proportion of private costs for Kilosa admissions. Finally, for those who were admitted, there was no trend of increasing duration of admission or total private hospital costs with illness severity. In a generalized linear model assessing the independent factors contributing to hospital costs for admitted patients (S2 Table), the number of days of admission was a significant determinant of private cost, with each day in hospital increasing private costs by about 12\% (95\% CI: 5\%-21\%). The data confirm that patients admitted at Turiani hospital spent more than patients at Kilosa hospital: \$13.68 Turiani vs. \$4.47 Kilosa (difference $\$ 9.21$ (95\% CI: 7.89-10.52), p<0.0001) (Table 6) with the private costs of those admitted in Turiani about 3 times higher than those admitted in Kilosa (multiplicative effect 3.1 (95\% CI: 2.5-3.9; S2 Table). 


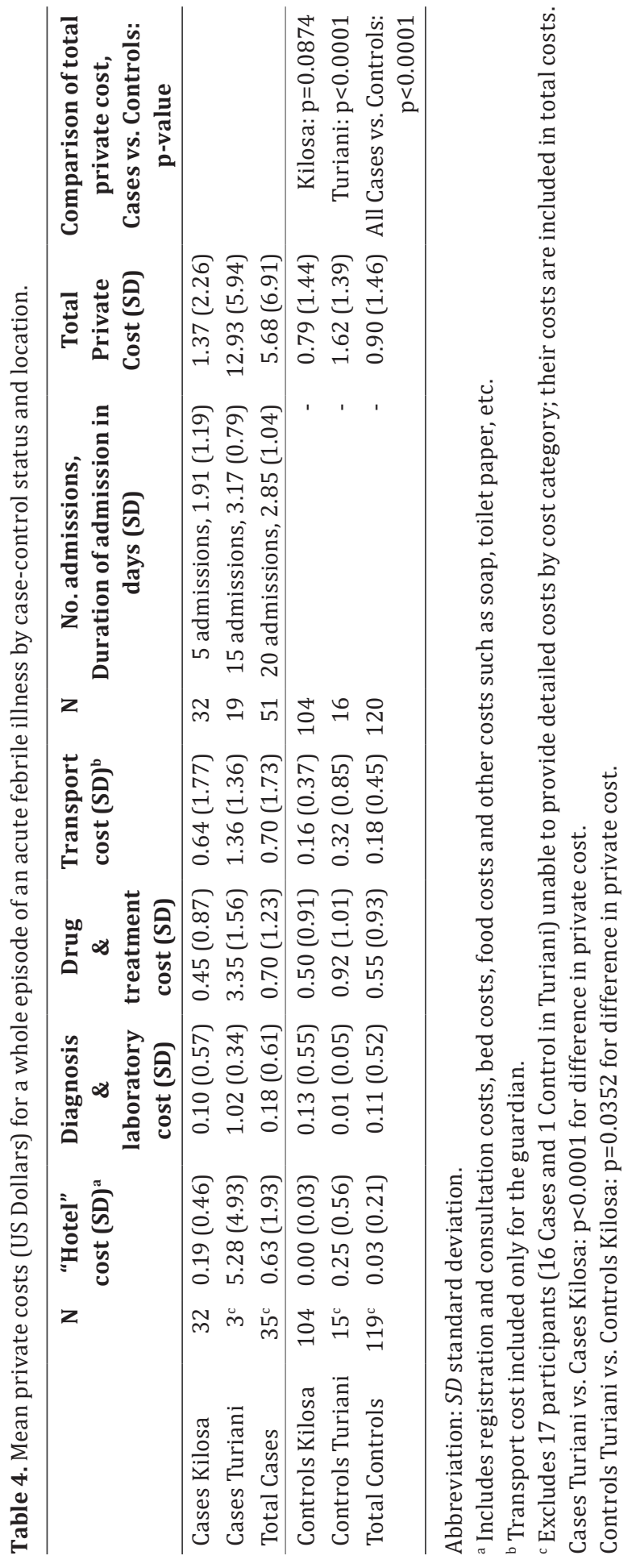


Table 5. Symptoms and severity of acute febrile illness for the participants interviewed at the hospital.

\begin{tabular}{|c|c|c|c|c|c|}
\hline \multirow[t]{3}{*}{ Category } & \multirow[t]{3}{*}{ Subcategory } & \multicolumn{4}{|c|}{ Hospital } \\
\hline & & \multicolumn{2}{|c|}{$\begin{array}{c}\text { Kilosa } \\
(\mathrm{N}=162)\end{array}$} & \multicolumn{2}{|c|}{$\begin{array}{l}\text { Turiani } \\
(\mathrm{N}=90)\end{array}$} \\
\hline & & $\%$ & $\mathbf{N}$ & $\%$ & $\mathbf{N}$ \\
\hline Symptoms & Per Os (PO) - Total & 19.8 & 32 & 20.0 & 18 \\
\hline \multirow[t]{12}{*}{ \& severity } & Fever only & 37.5 & 12 & 27.8 & 5 \\
\hline & Diarrhoea & 28.1 & 9 & 33.3 & 6 \\
\hline & Cough & 28.1 & 9 & 33.3 & 6 \\
\hline & Other febrile (headache, no appetite, abdominal pain) & 6.3 & 2 & 5.6 & 1 \\
\hline & Non Per Os (NPO) - Total & 61.1 & 99 & 51.1 & 46 \\
\hline & Repeated vomiting ${ }^{a}$ & 86.9 & $86^{\mathrm{b}}$ & 89.1 & 41 \\
\hline & Lethargy (too weak to swallow, to sit) ${ }^{\mathrm{a}}$ & 13.1 & 13 & 10.9 & 5 \\
\hline & Severe - Total & 19.1 & 31 & 28.9 & 26 \\
\hline & Altered consciousness/coma & - & - & 15.4 & 4 \\
\hline & Convulsions & 61.3 & 19 & 23.1 & 6 \\
\hline & Difficulties in breathing & 32.3 & 10 & 57.7 & 15 \\
\hline & $\begin{array}{l}\text { Other danger signs (stiff neck, bulging fontanel, chest } \\
\text { indrawing) }\end{array}$ & 6.4 & 2 & 3.8 & 1 \\
\hline
\end{tabular}

${ }^{\text {a }}$ Plus other symptoms preventing oral treatment.

${ }^{\mathrm{b}}$ Repeated vomiting only: 1 participant.

\subsection{DISCUSSION AND CONCLUSION}

In this study of determinants of access to health care for acutely ill children, severity of symptoms was the most important predictor of attending a hospital facility. Household wealth did not appear to influence this decision, although, as expected, total costs increased with admission and the number of days admitted at a facility.

These findings contrast with reports of surveys implemented almost 20 years ago, when $40 \%$ of young children with an acute febrile illness were reported to have died without contact with health services [16], and intermediate studies which indicated that $40 \%$ of children with danger signs were not taken to appropriate care and this tended to be worse in poorer families [6]. Thus our finding that symptoms, not wealth, was decisive in the decision to proceed to a hospital is both reassuring and indicative of behavioural changes in the management of serious paediatric infections that may have taken place more recently [7]. 


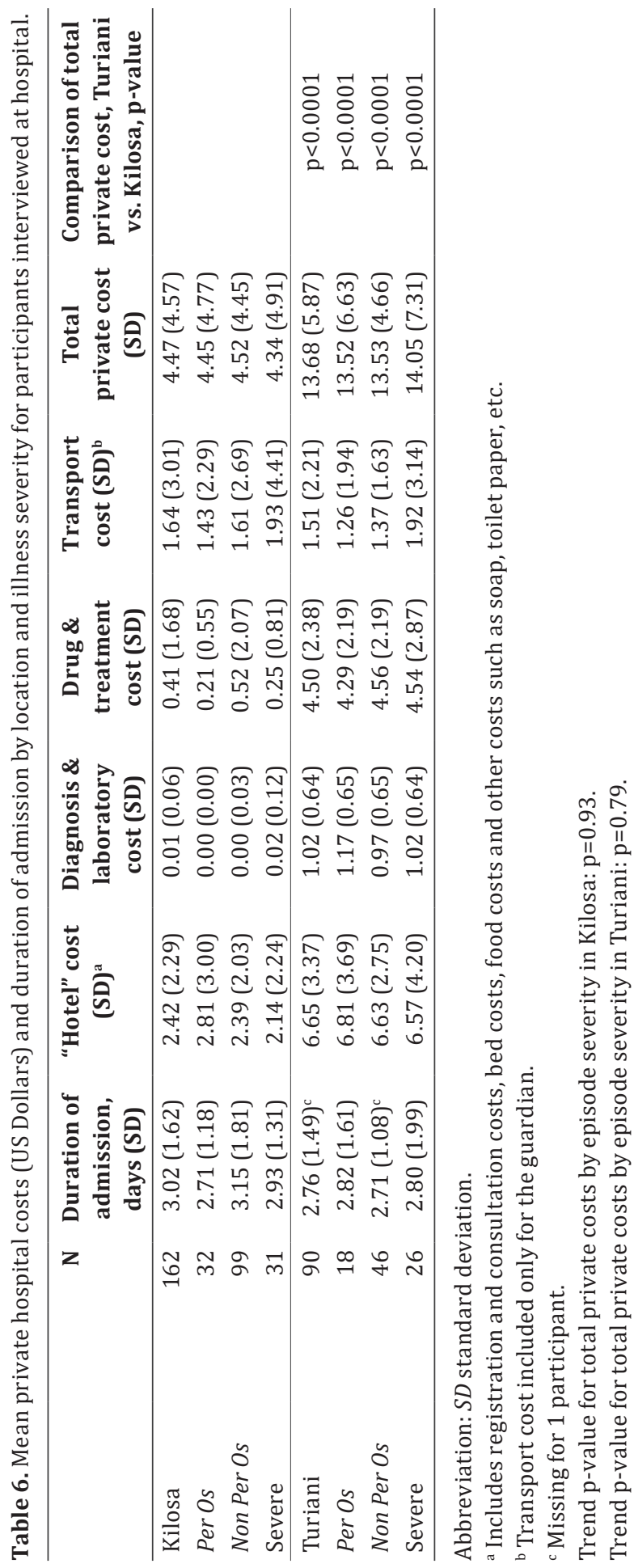


Most of our participants - cases (72.5\%) and controls (59.2\%) - indicated that they had incurred some out-of-pocket expenses and for those who went to hospital, our complementary study indicated that total costs incurred were linked to hospital type with approximately half of private costs for hospitalised patients being related to the food and accommodation costs of the child and guardian. The average expenditure at the public hospital was comparable with the average of $\$ 5.5$ reported in a review of private costs of paediatric hospital admissions carried out in Tanzania the year before our study [10]. However, unlike the review's findings on church-based hospitals, we found substantially greater private costs incurred at the mission hospital we studied. We note that Turiani Mission Hospital had not yet acquired a "designated district hospital" status, which would normally enable such a hospital to be jointly subsidized by the Government as well as private churchbased sources. Designated status also requires the hospital to follow the same policy of free provision of care for children (including drugs, laboratory expenses and food) as public hospitals, except for a patient-file fee at the time of admission. Hence the absence of the designated status meant that a substantial proportion of the costs of mission hospitalization were passed onto patients. The three-fold higher out-of-pocket average costs for the mission hospital lasted until 2012 when the hospital acquired the designated district hospital status.

Although mean hospitalization payments were lower in the government hospital compared with the mission hospital, poorer patients attending either hospital did not spend more on the episode compared with their wealthier counterparts. Costs for a child who had a severe febrile illness and was admitted at the public hospital were approximately $16.5 \%$ of the average monthly income of $\$ 27.14$ [17] while admission at the mission hospital meant a loss of about $50 \%$ of average monthly income. Assuming an incidence of 3.5 episodes of malaria for a child under 5 years old per year [18], health costs would have been about $5 \%$ of family income per child in the Kilosa area and about 15\% in the Turiani area. This supports the finding of Saksena et al. [10] which suggests that around 71\% of households lose income due to a child's admission at a health care facility. We did not obtain data on how families paid for their out-of-pocket costs, but reviews have shown that the immediate response is to use available cash and mobilise savings (which is only feasible for a small proportion of households) whereas other households reduce consumption (often food) or sometimes sell assets - that form an important source of the family's livelihood, such as land or livestock, or borrow from social networks, which can place them in debt for some period of time [19]. 
Our study has several limitations. First, we had assumed that the cases in Turiani and Kilosa could be pooled for the cost analysis; we did not anticipate the degree of cost heterogeneity that we found which required sub-group analyses. Secondly, because of the prior literature we anticipated a far larger number of patients with severe episodes who did not proceed to the hospital and thus a larger number of controls. In the event, from our patient sample with acute symptoms, less than $10 \%$ had severe symptoms (altered consciousness or convulsions) and all of them except for one participant went to hospital. Thirdly, we used a pragmatic symptomatic classification of patients into different categories of disease severity. This classification met WHO integrated management of childhood illness (IMCI) guidelines [20,21]. Children with danger signs (convulsions, repeated vomiting, failure to feed, lethargy/unconsciousness, chest in-drawing, noisy breathing, severe dehydration, and pallor) are referred to nearby health facilities. For our analysis, we classified the children with danger signs into two groups. Those who had repeated convulsions, altered consciousness or coma, difficulties in breathing or rapid breathing, a stiff neck, bulging fontanel or chest in-drawing were classified as severely ill, those who had repeated vomiting or lethargy (unable to sit/stand/ walk unaided, too weak to eat, drink or suck) were classified as Non-Per-Os. There is an obvious overlap between these two groups and misclassification between these categories might have occurred.

There is a high probability that we have underestimated total private costs. Return journeys to the hospital were not taken into account in the costs of participants interviewed at the hospital and although other studies have doubled the transport costs, we judged that transport costs to the hospital in an emergency would be higher than the costs of the return journey being undertaken in more favourable circumstances. Once the child had recovered and was on the point of discharge, participants indicated that they were not sure about the mode of transport they would use to go back home, or the costs associated with this journey but did not anticipate the costs to be as high as the journey to hospital. In addition, drugs used in home management of the episode, and perhaps bought during a previous occurrence of illness were not included in our tally of total costs because neither the amount of drug used nor the cost could be determined. We also excluded the opportunity costs of time since our study concentrated on direct out-of-pocket costs. Finally the cost data from the cases or controls would have been based upon recall of expenditures made since the episode and there are likely to be errors in recall of expenditures made, although we anticipate that the magnitude of the errors might be similar between the cases and controls. 
Our focus was on whether economic and socio-demographic variables played a role in accessing a hospital or health centre. Therefore, other factors that would influence behaviour, such as perception of illness and parental understanding of health needs in an emergency, qualitative data on perceptions about quality of care and services, staff attitude and competencies at the health facility were not sought. Such qualitative data might have been informative on choice and timing of care. Finally, although we would have wanted to investigate characteristics of missed opportunities - referred participants who did not comply with referral advice - none of our controls said that they had been referred to the hospital. Thus, supplementary work on failed referral may complement our findings.

\subsection{ACKNOWLEDGMENTS}

We thank all the participants and their children who agreed to take part in this study. We also thank Dr M. Shemsanga (Kilosa District Hospital Medical Officer in Charge), Sr E. Nga'nga' (Turiani Missionary Hospital Administrator) and Dr V. Mhando (Turiani Missionary Hospital Medical Officer in Charge) for their permission to conduct the research in their respective hospital and $\mathrm{Dr}$ Kitego (Kilosa Hospital) and the staff of both hospitals for their assistance in the recruitment of the children. We are grateful to village leaders and village health workers for their permission and help to carry the research in their communities. We would like to acknowledge the contribution of the research team: M. Goodluck, J. Kitua, F. Clement, A. Kapinga, Dr D. Mutayabalwa, S. Emanuel, N. Kunyamale, R. Mkongoza, B. Makau, T. Kipande, M. Ruhaga, I. Kisongele, and P. Lipingu. A special thanks to P. Affaticati for his help to set up the research in Kilosa. 


\section{REFERENCES}

1. Crump JA, Morrissey AB, Nicholson WL, Massung RF, Stoddard RA, Galloway RL, et al. Etiology of severe non-malaria febrile illness in Northern Tanzania: a prospective cohort study. PLoS Negl Trop Dis. 2013;7:e2324.

2. D’Acremont V, Kilowoko M, Kyungu E, Philipina S, Sangu W, Kahama-Maro J, et al. Beyond malaria - causes of fever in outpatient Tanzanian children. N Engl J Med. 2014;370:809-17.

3. Maltha J, Guiraud I, Kabore B, Lompo P, Ley B, Bottieau E, et al. Frequency of severe malaria and invasive bacterial infections among children admitted to a rural hospital in Burkina Faso. PLoS One. 2014;9:e89103.

4. Church J, Maitland K. Invasive bacterial co-infection in African children with Plasmodium falciparum malaria: a systematic review. BMC Med. 2014;12:31.

5. Reyburn H, Mbatia R, Drakeley C, Carneiro I, Mwakasungula E, Mwerinde O, et al. Overdiagnosis of malaria in patients with severe febrile illness in Tanzania: a prospective study. BMJ. 2004;329:1212.

6. Schellenberg JA, Victora CG, Mushi A, de Savigny D, Schellenberg D, Mshinda H, et al. Inequities among the very poor: health care for children in rural southern Tanzania. Lancet. 2003;361:561-66.

7. de Savigny D, Mayombana C, Mwageni E, Masanja H, Minhaj A, Mkilindi Y, et al. Care-seeking patterns for fatal malaria in Tanzania. Malar J. 2004;3:27.

8. Mubyazi GM. The Tanzanian policy on health-care fee waivers and exemptions in practice as compared with other developing countries: Evidence from recent local studies and international literature. East Afr J Public Health. 2004;1:11-7.

9. Jowett M, Miller N, Mnzava N. Malaria Expenditure Analysis: Tanzania Case Study. Report prepared for DFID-EA (Tanzania) and the Roll Back Malaria Initiative. York: University of York; 2000.

10. Saksena P, Reyburn H, Njau B, Chonya S, Mbakilwa H, Mills A. Patient costs for paediatric hospital admissions in Tanzania: a neglected burden? Health Policy Plan. 2010;15:328-33.

11. Muela SH, Mushi AK, Ribera JM. The paradox of the cost and affordability of traditional and government health services in Tanzania. Health Policy Plan. 2000;15:296-302.

12. Mboera LEG, Senkoro KP, Mayala BK, Rumisha SF, Rwegoshora RT, Mlozi MRS, et al. Spatio-temporal variation in malaria transmission intensity in five agro-ecosystems in Mvomero district, Tanzania. Geospat Health. 2010;4:167-78.

13. Tanzania Turiani-Hospital Foundation. Turiani Hospital, health for all in the Mvomero district, Masterplan May 2007.

14. Filmer D, Pritchett LH. Estimating wealth effects without expenditure data-or tears: an application to education enrollments in states of India. Demography. 2001;38:115-32.

15. Vyas S, Kumaranayake L. Constructing socio-economic status indices: how to use principal components analysis. Health Policy Plan. 2006;21:459-68.

16. Ministry of Health, AMMP team. Policy implications of adult morbidity and mortality: end of phase one report. Dar es Salaam: AMMP/Ministry of Health; 1997. 
17. Aikaeli J. Determinants of Rural Income in Tanzania: An Empirical Approach. Research Report 10/4. Dar es Salaam: Research on Poverty Alleviation; 2010.

18. Alilio MS, Kitua A, Njunwa K, Medina M, Rønn AM, Mhina J, et al. Malaria control at the district level in Africa: the case of the Muheza District in northeastern Tanzania. Am J Trop Med Hyg. 2004;71(2 Suppl):205-13.

19. McIntyre D, Thiede M, Dahlgren G, Whitehead M. What are the economic consequences for households of illness and of paying for health care in low- and middle-income country contexts? Soc Sci Med. 2006;62:858-65.

20. World Health Organization, United Nations Children's Fund. Integrated Management of Childhood Illness chart booklet. Geneva: WHO; 2008.

21. Kalyango JN, Rutebemberwa E, Karamagi C, Mworozi E, Ssali S, Alfven T, et al. High adherence to antimalarials and antibiotics under integrated community case management of illness in children less than five years in eastern Uganda. PLoS One. 2013;8:e60481. 


\section{SUPPLEMENTARY INFORMATION}

S1 Table. Mean private costs (US Dollars) for a whole episode of febrile illness for the cases by location, stratified by household wealth category.

\begin{tabular}{llrcc}
\hline & \multicolumn{4}{c}{ Mean private costs } \\
\hline Cases-Kilosa & Most poor & 14 & $0.56(0.72)$ & \\
& Poor & 10 & $1.67(2.37)$ & Total cost (SD) Cases Turiani vs. Cases Kilosa: p-value \\
& Least poor & 8 & $2.43(3.42)$ & $\mathrm{p}<0.0001$ \\
Cases-Turiani & Most poor & 8 & $16.05(4.95)$ & $\mathrm{p}=0.0009$ \\
& Poor & 7 & $10.43(6.18)$ & $\mathrm{p}=0.0076$ \\
& Least poor & 4 & $11.08(5.73)$ & \\
\hline \multirow{2}{*}{ Total Cases } & Most poor & 22 & $6.20(8.16)$ & \\
& Poor & 17 & $5.28(6.10)$ & \\
& Least poor & 12 & $5.31(5.88)$ & \\
\hline
\end{tabular}

Abbreviation: $S D$ standard deviation.

Test for trend across wealth category: Kilosa $p=0.042$, Turiani: $p=0.066$, Overall $p=0.719$.

S2 Table. Determinants of private hospital costs for an episode of febrile illness based on a generalized linear model for 249 participants interviewed at the hospital.

\begin{tabular}{|c|c|c|c|c|}
\hline Variable & Covariates & Multiplicative effect $^{a}$ & $95 \% \mathrm{CI}$ & p-value \\
\hline \multirow[t]{2}{*}{ Community } & Kilosa & reference & - & - \\
\hline & Turiani & 3.124 & $2.485-3.927$ & $\mathrm{p}<0.0001$ \\
\hline \multirow[t]{3}{*}{ Severity of febrile episode } & $\mathrm{PerOs}$ & reference & - & - \\
\hline & Non Per Os & 0.977 & $0.732-1.305$ & 0.876 \\
\hline & Severe & 0.984 & $0.704-1.377$ & 0.927 \\
\hline Age of child (months) & - & 1.001 & $0.992-1.010$ & 0.865 \\
\hline \multirow[t]{2}{*}{ Gender } & Male & reference & - & \\
\hline & Female & 0.863 & $0.693-1.075$ & 0.189 \\
\hline Wealth index ${ }^{\mathrm{b}}$ & - & 0.994 & $0.918-1.076$ & 0.881 \\
\hline $\begin{array}{l}\text { Number of days spent at the } \\
\text { hospital }\end{array}$ & - & 1.124 & $1.045-1.209$ & 0.002 \\
\hline
\end{tabular}

a These are the exponentiated coefficients of the GLM model with log-link function between the linear predictor and mean private cost. The reference private cost of a 20 -month-old male child from a family with an average household wealth admitted in Kilosa hospital for 2.9 days and of Per Os severity of illness throughout the episode is a median US $\$ 4.76$.

${ }^{\mathrm{b}}$ The higher the score, the better the wealth. 


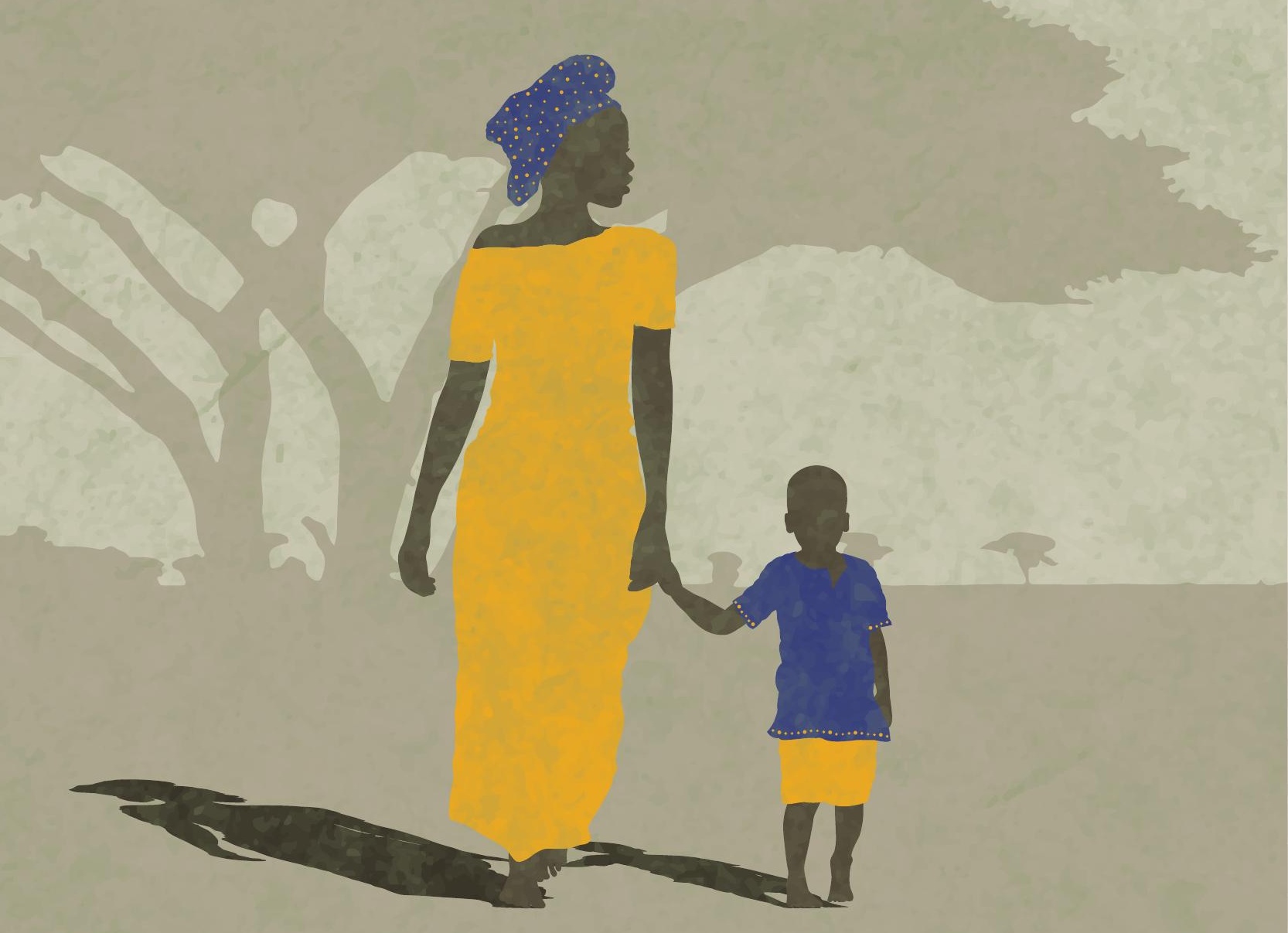




\title{
CHAPTER 3
}

\author{
LONO-TERM CONSEQUENCES OF \\ CEREBRAL INFECTION: \\ DAILY LIFE AMD CHALLENGES FACED \\ BY HOUSEHOLDS WITH PERMANENT \\ CHILDHOOD DISABILITY IM RURAL \\ TAMZAMIA - A QUALITATIVE STUDY
}

Submitted as:

Castellani J, Kimbute O, Makasi C, Mrango ZE, Paulus ATG, Evers SMAA, Hardy P, Sumner T, Keiya A, Mihaylova B, Faiz MA, Gomes M. Long-term consequences of cerebral infection: daily life and challenges faced by households with permanent childhood disability in rural Tanzania - a qualitative study. 


\section{ABSTRACT}

\section{Background}

Cerebral infections, such as malaria, can be fatal, but survivors can also be left with permanent mental or physical disability, which burdens the whole family. Qualitative research on how such disability affects the life of the child, caregivers and the household in rural Africa is very limited. We aimed to fill this research gap through a qualitative study of the experiences of families with children with severe disabilities resulting from a cerebral infection.

\section{Methods}

Ten years after a severe malaria trial, we traced all surviving children with serious permanent sequelae in Handeni, Tanzania and invited the parents/guardians and the child to a workshop to recount their experience living with serious disabilities. Six parents/guardians consented and participated with their children. During the workshop, data were collected through recording of personal stories and through an individual semi-structured interview. Common topics between the digital stories and the qualitative interviews were used to develop qualitative stories, separately for the child and parent/guardian.

\section{Results}

Most children (5 out of 6 [5/6]) had disabilities that severely reduced their autonomy and required constant care. Schooling had not been attempted for $4 / 6$ children and was halted for 2/6 either because of learning problems or the inability to meet specialized school costs. Parents were under constant physical, emotional and financial stress. Half the parents were divorced or separated, and one family was shunned by relatives. Time and other resources allocated to childcare increased family poverty by reducing occupational earnings.

\section{Conclusions}

Cerebral infections cause physical and mental disabilities that change the life of the child and their family. 


\subsection{BACKGROUND}

Cerebral infection, including cerebral malaria, is an important cause of disability and death. Children under 5 years old are at the highest risk and survivors are sometimes left with long term sequelae $[1,2]$. Studies quantify the consequences of cerebral infections for childhood survivors, citing epilepsy, motor and other physical impairments as well as cognitive and behavioural disability [3-15].

When there is unresolved physical or cognitive impairment from a cerebral infection, a child may need continuous care [16] with social and economic repercussions [17]. Disabled children are more likely to have lower school attendance [18-27], lower educational attainment [21, 23, 25, 28-30] and fewer employment opportunities as an adult [24, 28, 30-32]. Families with disabled members are generally poorer [25], have fewer possessions [20, 22, 24, 27, 33, $34]$ and live in worse conditions than families without disabilities [20, 22]. The consequences of disability are reported to tip households into poverty and transfer poverty to the next generation [35].

Research on disability associated with cerebral infection has usually been quantitative, classifying the short and long term clinical, neurological and cognitive impairments resulting from the infection [3-15]. The economic consequences for different types of disabilities have also been quantified for patients, households [18-32, 35, 36] and caregivers [37-44]. Challenges faced by caregivers (e.g. existing practices, experiences, and needs of children with disabilities and their families, attitude of others, impact of disability, access to education), and coping strategies to overcome these barriers have been described [45-47] but there are quite limited data on the burden of caring for disabled children, and how the burden changes as the child grows into adolescence, and the effects on caregivers and households in rural Africa. Our aim was to fill this gap by implementig a qualitative research that identified children with a cerebral infection in early childhood that caused serious permanent disability, with sequelae ranging from major cognitive disabilities to severe physical restrictions, or both, in early adolescence. We reviewed the difficulties and challenges for both the children and their families in managing daily tasks over the 10 years since the index episode. 


\subsection{METHODS}

\subsubsection{Study participants}

Tanzanian children with permanent or unresolved sequelae from one location of a clinical trial were selected for interview [48]. All children were enrolled in the trial because they could not take oral medication because of prostration, repeated seizures, altered consciousness or coma. Children who had suspected neurological sequelae within 30 days of the episode were assessed by a study clinician, and those with confirmed neurological sequelae were revisited periodically (for an average of 5.5 years) until the symptoms resolved, the child died, or the study ended. There were 15 children in Handeni, Tanzania whose sequelae had not resolved at the time the study ended. A decade later, six of the children were alive, six had died and three could not be located. The families of the six surviving children with persistent sequelae were contacted for consent to meet, recount stories and be interviewed about their lives in a 2-day workshop. Consenting parents/guardians were reimbursed for accommodation, meals and transport costs.

\subsubsection{Data collection, questionnaire design and data analysis}

The workshop had two components. The first part focused on the stories of the families, which were digitally recorded [49]. Patient stories air and give verbal expression to sometimes profound challenges faced by families experiencing an illness (or its aftermath), and promote reflection and debate [50]. Each parent/ guardian was free to choose specific moments of life regarding the illness/ disability of their child. They specified what they wanted to say in their own words and could focus on their feelings, the impact of the illness/disability and the challenges they faced associated with caring for a disabled child [51]. The digital stories were recorded in Swahili by the parents/guardians and then translated and recorded in English by a local researcher fluent in both languages (stories available at https://www.patientvoices.org.uk/savingbrains.htm).

The second qualitative component, conducted after the digital stories, was a semi-structured interview with parent-child pairs on the challenges of caring for a disabled child and living with disability. For this purpose, a questionnaire was developed to understand the general difficulties experienced by children and carers. The questionnaire contained open questions on seven topics on how disability affects daily life: the parent/guardian's views and worries; the physical consequences of the disability for the carer; the effects of disability on carer's time; the child's needs and medical health; social relationships; discipline/mood 
effects, and financial costs (S1 Table). Those seven topics were based on previous literature $[45 ; 46 ; 52 ; 53]$ and on the Behaviour Questionnaire for Parents - a questionnaire developed in East Africa adapted from the Kaufmann Assessment Battery for Children [54] which assesses behaviour difficulties in the home. Open questions (developed in English, translated into Swahili) on the seven topics, asked in the same sequence, guided the interview. All interviews were conducted in Swahili by an experienced bilingual researcher and each interview lasted about 30 minutes. Answers were immediately translated into English and transcribed, with clarifications on meaning sought, as necessary, during the workshop.

Based on both the digital stories and the semi-structured interview, different themes were developed, separately for the child and parent/guardian, summarizing and highlighting challenges and problems. The themes explored common topics allowing for the possibility of regrouping and putting information from one category to another.

\subsubsection{Ethics approval and consent to participate}

Ethics approval for the full study, of which this was part, was obtained from the Oxford Tropical Research Ethics Committee and the National Institute of Medical Research in Tanzania. Written consent was obtained from each guardian. Ethical clearance was received for recording digital stories.

\subsection{RESULTS}

\subsubsection{Baseline characteristics}

Table 1 summarizes the characteristics of the children and their (mostly female) parents/guardians. Only one child was accompanied by his father. Two guardians were married, three were separated or divorced and one was widowed at the time of the interview.

Among the six children (four females and two males), aged between 9 and 13 years during the interview, five had either convulsions or coma or both in the index episode causing sequelae [48]. Only one child had neither convulsions nor coma documented at enrolment, although these might have occurred during the episode, after enrolment. Except for one child who had been hospitalized (child 4), none of the other children reported any hospital admissions since the index episode, although they experienced episodes that did not require hospital admission (child 1: 1 episode; child 3: 5 episodes; child 5: 4 episodes). 


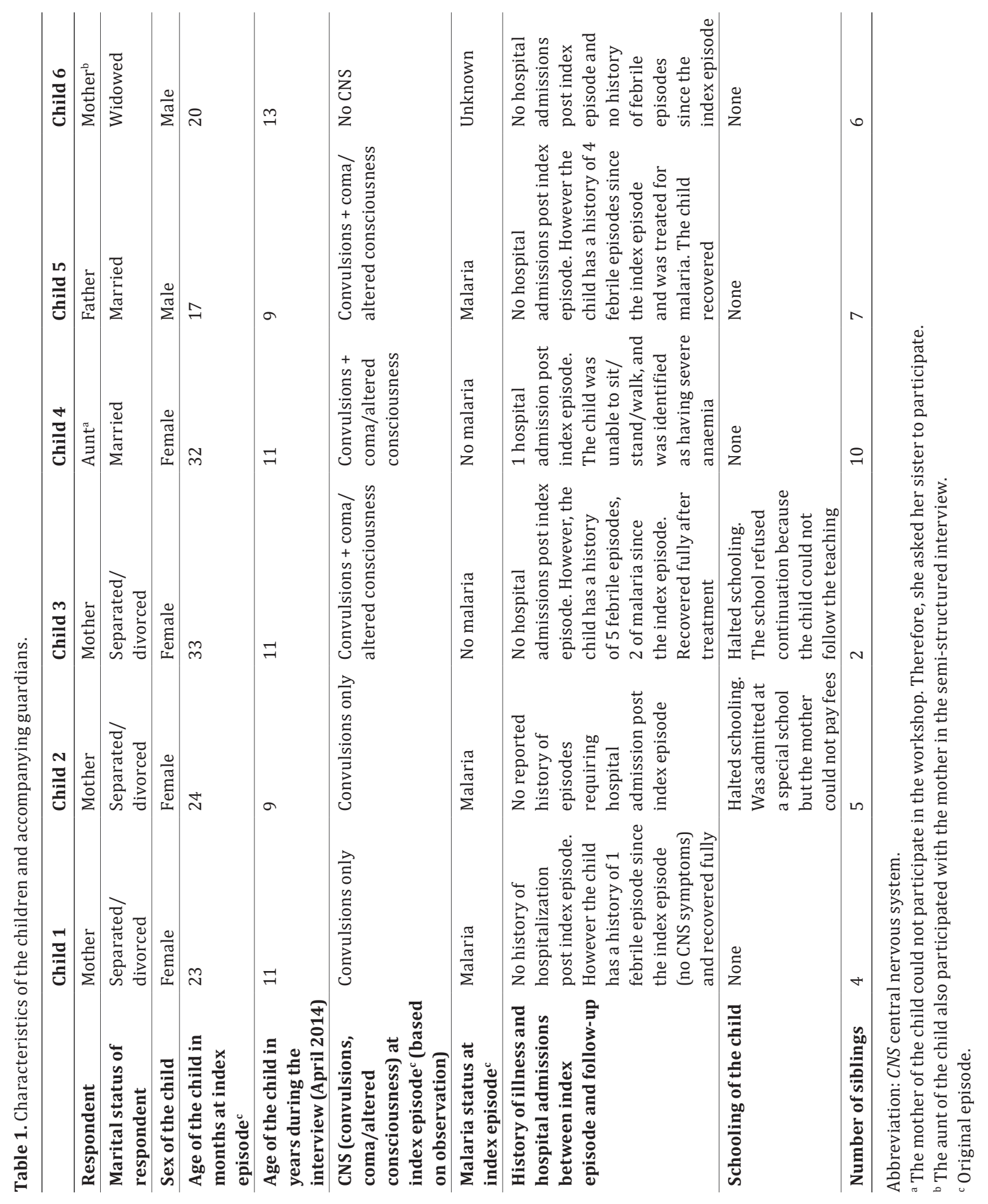




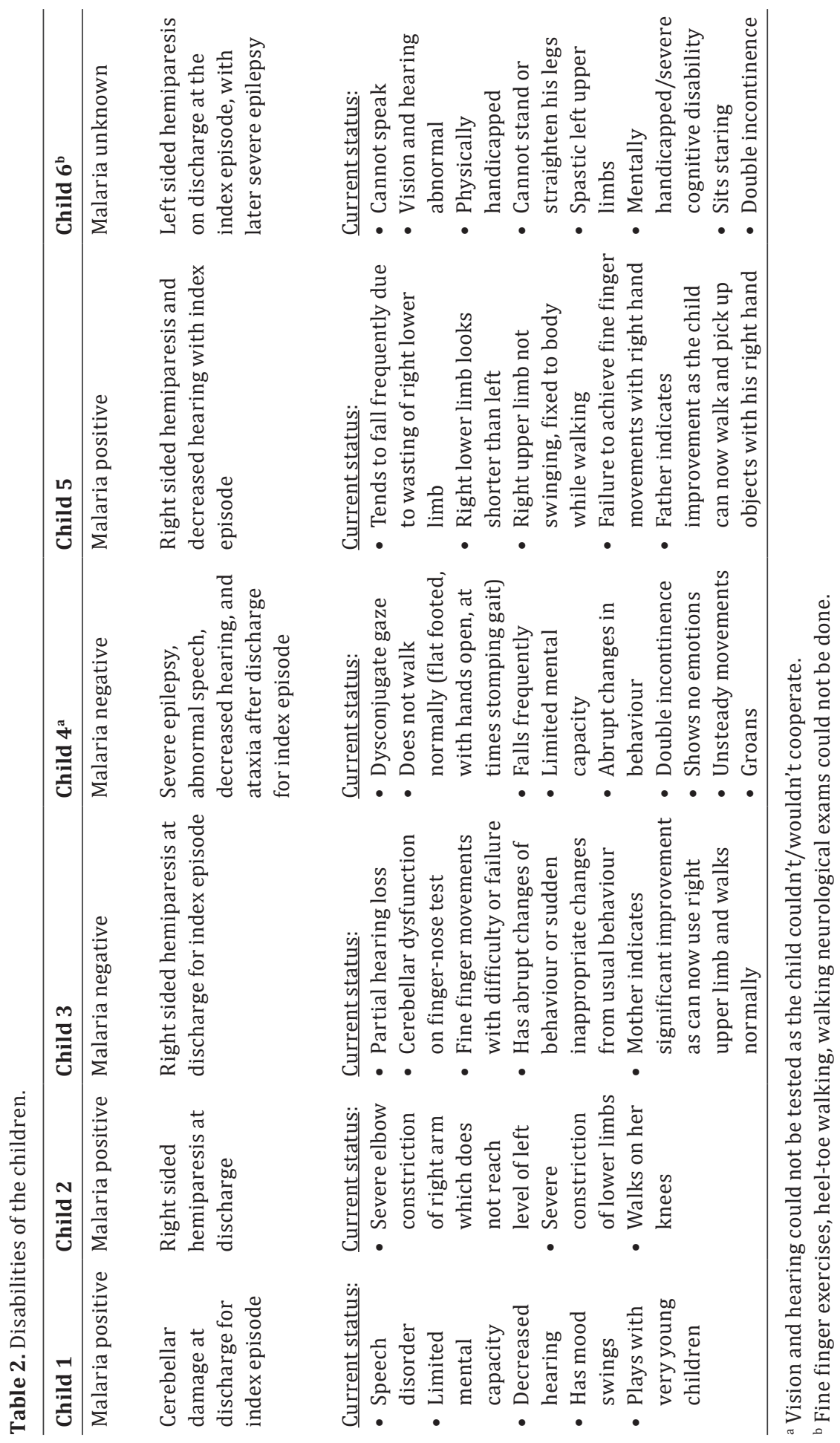




\subsubsection{Disabilities}

All children had one or more profound physical and/or cognitive disabilities (Table 2), all originating with the index episode. During the 5.5 years of follow up during the trial, child 1 was described as having limited cognition, as unable to speak and follow instructions and was reported to play only with much younger children. Child 2 could only walk on her knees and had elbow constrictions in her left arm. Child 3 had motor problems, abrupt changes of behaviour and partial hearing loss. Child 4 had epilepsy, dysconjugate gaze, impaired gait, made unsteady movements and frequently fell, could not articulate words, was doubly incontinent and was described as having limited cognition. Child 5 had problems with his right upper and lower limbs. Child 6 could not straighten his legs and therefore could not stand, had limited vision and hearing and was unable to speak; he was diagnosed with epilepsy and was described as having restricted cognition.

\subsubsection{Schooling}

Only two children (children 2 and 3) had begun school; neither could continue (Table 1). Child 2, who was severely physically disabled and was not able to walk, started to attend a boarding school which was free the first year but was not allowed to stay beyond a year as her mother could not pay the tuition fees for the second year. Child 3, who had partial hearing loss, motor problems and mental disability, went to two different mainstream (normal) schools but as she was not able to cope, the schools did not agree to her continuation. For the other four children - one with severe cognitive disability (child 1), two with epilepsy, limited cognition, physical disability and speech impairments (children 4 and 6) and one with severe lower limb weakness and restricted upper limb abilities (child 5) - school was never initiated. For child 5, the walking distance to the school contributed to a decision not to enrol the child in school.

\subsubsection{Qualitative stories: consequences of disability for children and parents/guardians}

The consequences of disability, separately for children and parents/guardians, were summarized into seven topics.

\subsubsection{Consequences of disability for children}

Autonomy and impact on health

Disability affected the child's autonomy and the quality of life for both the child and the rest of the household members. Most disabled children were dependent on their parents/guardians who fed, dressed and bathed them. Some children were 
unable to communicate when they were hungry, when they needed to go to the toilet or when they were not feeling well.

“...She [the child] cannot talk. She cannot walk properly. She is doubly incontinent. She cannot ask for food. She moans a lot. She is completely dependent." (Aunt of child 4)

For children with epilepsy, there was often considerable concern about what to do when an epileptic fit occurs:

"When my child has convulsions, I do nothing. I don't give anything. I just watch and wait." (Mother of child 6)

"The mother then puts water on her [the child] and fans her." (Aunt of child 4 - once convulsions are over)

None of the children received rehabilitative care for their physical and/or mental disability, but for the two children who had epilepsy, one received regular treatment (child 4). Drugs for epilepsy are free and available from healthcare facilities. However some healthcare facilities, especially those that can manage epileptic cases, are located far away from communities, and therefore, access to treatment is difficult. Parents must walk long distances and may not have funds for transport, and if they pay for transport, their financial burden is increased.

Traditional healers were considered as an alternative to modern medicine. In Tanzania and other African countries, convulsions are often associated with evil (bad) spirits [55-57]. One mother whose child had convulsions during the enrolment episode was told by a traditional healer that the convulsions were caused because evil spirits were looking for her child, and therefore it was important to deal with them before healing could occur:

“...We [the parents] took the child to hospital and she received treatment... We went back home. The convulsions continued after we returned home. We sought assistance from the traditional healer who advised that we change the child's name. Before she was known by one name, and now she is known by a different name. I am thankful that she has slightly better understanding now that she is growing up, but her intelligence is not yet normal." (Mother of child 1) 
Social-interaction, behaviour and self-expression

The guardians described how disability affected social relationships for both the child and the rest of the family. Serious social problems were mentioned in relation to children with mental disabilities and epilepsy. Children with epilepsy or mental disabilities were socially disengaged. They exhibited unsociable behaviour and did not respond in ways which were normally expected; their responses and changes in facial expressions suggested that they did not know which behaviours were appropriate and which were not. This apparently led to problems in interactions with both adults and children. An aunt described how her epileptic niece reacted to others:

"She [the child] likes to be alone. She is never playing with other children or with her siblings, and she does not like to be touched by people she does not know... She does not laugh and does not smile. Most of the time, she stands or sits and makes some noise. If her siblings are coming to play with her, she will hit them because she does not want to be with them. If some children want to play with her, she will go somewhere else. If they follow her, she will hit them as well." (Aunt of child 4)

For a child with epilepsy, mood changes were sudden and could greatly impact on the quality of life of the child and the household. Unpredictable outbursts of the child were often difficult to control. The same aunt added:

"Discipline is a real problem... She [the child] might have some explosive, angry outburst. She screams and kicks, mainly 3 times per day. When she is hungry, she can bite and hit." (Aunt of child 4)

Two mothers described the behaviour and mood swings of their children:

"When she [the child] is angry, she cries, goes behind the house and undresses herself. It is her way to express herself since she cannot talk." (Mother of child 1)

"When in a bad mood, she [the child] does not allow any guests to come in the house... She is in a bad mood on average once a day." (Mother of child 3) 
The mother of a child with frequent convulsions and emotional outbursts explained:

"His mood can change frequently... When he [the child] is angry, he needs about 2 hours to calm down. He stays for 2 hours in the same position and then he starts laughing. I am really tired of my child." (Mother of child 6)

In addition, social interactions with other people could be problematic and inappropriate:

"...Sometimes she [the child] is playing with children and then she bites one of them and runs to the house. Then the parents [of the bitten child] will come to complain." (Mother of child 1)

Even for parents of children who are not mentally disabled, the attitude of their child might be unpredictable, extreme and uncontrollable which made it difficult to manage:

"Since my son was 4 years old, he has sometimes an explosive, angry outburst... For instance, he will throw and break cups." (Father of child 5)

When physically disabled children are aware of their disability, they can become sad, depressed and angry. One mother described the frustration, despair and melancholy of her daughter who was constantly dependent on somebody else for toileting and unable to contribute to the household when she said:

"My child complains that she cannot walk and fetch water like other children... She is also very depressed because she cannot go to the toilet by herself. She needs my help and that makes her angry." (Mother of child 2)

Schooling (child's intelligence and cost of schooling)

Children under the age of 14 are normally required to go to school in Tanzania. However, parents said schools typically did not accept disabled children or did not make efforts to integrate them into classes. In addition, schools might not have the required infrastructure, teachers might not be trained to teach children with problems and learning materials might not be adapted. The mother of a child with motor problems, abrupt changes of behaviour and partial hearing loss, attempted 
registration at two different (normal) schools but her child was not allowed to stay because she could not understand what was being taught:

“...She [the child] cannot cope. Her comprehension is poor. She cannot read or write. She does not understand anything. If she could go to a special school, she might be able to learn more but at the normal school where everyone is included, she cannot cope." (Mother of child 3)

Parents stated that they would like to enrol their child in a specialized school. However, education in such schools is fee based and unaffordable for families living in rural areas. The mother of a child who could not talk and whose "intelligence was not yet normal" said:

"I have not taken her [the child] to a primary school because children like her [must] go to a specialized school. I cannot afford that kind of school." (Mother of child 1)

Another mother explained how expensive schooling is for a divorced parent and sole provider of the household who has barely enough money for food. Her child, unable to walk, had started in a specialized school, which did not require fees for the first year but was withdrawn thereafter:

"You see, I cannot make the requirements of the school. I am the only one at home. I am divorced and everyone in the household depends on me. I was expected to provide 30,000 TSH ( 12 USD), 3 measures of cereals, 20 kilos of beans and a uniform." (Mother of child 2)

For other families, the problem of schooling was similarly complex, involving limited access to a distant school, treatment costs (which reduced income for other purposes), and not knowing whether education would improve the condition of the child:

"We have tried a number of different approaches - the hospital, the traditional healer. I have lost a lot of money in the process, around 16,000 TSH ( 6.4 USD). Up to now there is no solution to the problem. I don't know what else I should be doing and so I don't know who can help me... He [the child] does not go to school. I am still watching him for any change in his condition and in his intelligence... I am looking into possible ways of taking 
him to school. I would like to see him attending school, but the school where he should go is very far away. I have had a lot of trouble during this time trying to find some way of helping the child to have some opportunities in his life!" (Father of child 5)

Unschooled, disabled children spent all their time at home and were often trained to help with housework:

"Her sister shows her [the disabled child] how to fetch water, how to wash the dishes, and teaches her how to count." (Mother of child 3)

\subsubsection{Consequences of disability for the parents/guardians}

Feelings and emotions

All parents/guardians expressed being stressed, depressed, sad and/or worried about the future. The normal stresses and worries of bringing up a disabled child were magnified when a child did not respond well to social situations and was prone to seizures or public outbursts. The parents/guardians found communication with their child difficult:

"If you ask her [the child] to bring a cooking pot, she brings back a broom.

She is now 12 years old." (Mother of child 1)

The parents/guardians were concerned that the child could not understand practical issues and required constant supervision. The aunt of one child said that if her niece is left unattended for a few minutes, "she might leave home and then it will be difficult to find her because she does not know how to come back home." (Aunt of child 4)

With age and the hormonal and physical changes of adolescence, more difficulties were anticipated, especially when the child was not able to understand the changes or consequences. Bringing up a female child increased parental tension. They were concerned that the child would never be independent, was not aware of social implications of any actions, was unable to understand what is socially right and what is wrong, or protect herself from her lack of understanding on sexual matters:

"I am worried... because when she [the child] will get her periods, she will not understand... and not know what to do. She even cannot wash her 
clothes by herself. I am also scared that someone could abuse her and get her pregnant." (Mother of child 1)

Consequently, disabilities that were bearable (physically and emotionally) when the child was younger, created worries and fears for parents when the child became older and was sexually vulnerable.

For children with epilepsy, convulsions might occur at any time, requiring constant vigilance. Fear of not being available or not knowing what to do was often expressed by carers. Convulsions caused the family to panic or be extremely sad, and parents/guardians said that they feared the worst when the epileptic seizures stopped and the child fell into a deep sleep of unconsciousness:

"Very often my niece collapses and has convulsions. Then nothing happens. It is silent and we [the family] think that she is going to die." (Aunt of child 4)

\section{Physical health}

Parents/guardians described physical fatigue and pain caused by children who were unable to walk because this meant that they had to carry their child, usually on their back (children 2, 4 and 6). This was easier when the child was young, but as the child got older and heavier, this was more difficult or impossible. One mother (child 2) moved her household and her disabled child to her farm, even though it meant a significant decline in the quality of her life, and increased isolation from the village and other social interactions:

\footnotetext{
"In the past, I was walking every day to the farm, carrying my child on my back (1 hour for one way) but I decided to move there because it was too exhausting to carry her every day... In the future I hope I can build my own house and move out from the farm because life here is not good." (Mother of child 2)
}

Disability meant that households had reduced financial resources. A mother mentioned the consequences of not having funds for necessities, and the need to renounce medical care because the child became too heavy to be carried:

"There is no bed. We [the mother and the child] just sleep on the floor... That it is why we both get ill frequently. I am just using medicine because I cannot take my son and myself to hospital... They ask for money. The child often 
suffers from vomiting and diarrhoea and I am shivering with fever. People ask why we are sleeping on the floor without any mosquito nets, when the child is vomiting and I am shivering. It is only God who can rescue me..." (Mother of child 6)

"There were some "clinic" days where my child could have received some vaccinations but I did not manage to go there because I cannot carry my child. I could have taken a motorcycle [taxi] but I have no money for that." (Mother of child 6)

Carrying the child was physically exhausting - described by three mothers/ guardians (children 2, 4 and 6). They were always fatigued and had back and/or chest pain but had not been to a doctor or sought medication. They said that in their culture, complaining is not well accepted or is a taboo:

"We [the family] are tired but we cannot say it. We don't want to show that we are tired." (Aunt of child 4)

Family relationships and support

Although all participants said that they were socially integrated and not excluded by their communities, when asked they said that caring for a disabled child negatively affected family relationships, modified decisions about resources, selfesteem, and changed relationships between family members, living arrangements, and family structure. One family was rejected and had become isolated from their relatives (child 4). The fathers of three children (children 1, 2 and 3) had left their households, at least in part due to disabled child's needs, leaving the mother as the sole economic provider for the household.

"I don't have a husband now, he has left me. I am the only person raising the children. The father does not give me any assistance. I am raising the children [on] my own." (Mother of child 3)

Insufficient time for the guardians to work or to complete household tasks was also mentioned. For a (divorced/separated) mother with many children to support, the burden fell on all members of the household. Siblings living in the household had often a role in caretaking as they were required to take care of the disabled child after school or during the weekends, but sometimes this was not possible. When siblings grow up and leave the household, family support was lacking: 
"I don't receive any help. I have older children who are married but they don't come to help me. I also have two sons who are still living with me but for cultural reasons, they are not allowed to take care of their sister." (Mother of child 2)

\section{Working and financial issues}

The child's lack of autonomy influenced household's life and limited activities of the family: the child could not stay alone and needed permanent vigilance, assistance (e.g. going to the toilet, eating, washing) or instructions. The time required to take care of the child meant reduced time to work to earn an income. The difficulties increased when the father left the house and the mother became the only sole economic provider for the household. A solution mentioned by a widow mother (child 6) was to lock her epileptic child (who was moody and jumped around the house) while she was working at the farm. This strategy worked for some time when the child had fewer fits and was younger, but when the child started to convulse more often, he became a danger to himself when left alone. The mother decided that she needed to stop working so that she could allocate all her time to her child. As a result of a reduction in occupational work, financial resources decreased, and the family was pushed into extreme poverty. The same mother showed her despair and loss of hope for a better life for her, her family and child:

"I have no food and no money. I cannot go to the farm anymore and I cannot start a business. Before I was farming. Now my older sister helps me and I depend on her. My [5] daughters can even not help me because they are also very poor." (Mother of child 6)

"So we [the family] remain silent. There is nothing we can do. I just have to endure." (Mother of child 6)

Another mother mentioned:

"Before [disability] I was farming and selling food in a small business. When my child became disabled, I had to stop selling food. I am now only farming and my finances decreased... I have some food problems... I even cannot afford to buy pens or exercise books [for school] for my two sons." (Mother of child 2) 
Selling personal assets became one solution to survive:

"I was selling food at a gold mine but I had to stop because I wanted to be close to my child. After I stopped my work at the gold mine, my finances went down. I had to sell everything in my house." (Mother of child 3)

\subsection{DISCUSSION}

Three major consequences of disability emerged from the data: no or reduced school attendance for the child, significant physical and emotional burden of caring for disabled children, and unrelenting financial pressure on family income, assets and savings. In some cases, the challenges of struggling with a disabled child had led to divorce or separation.

Most children in our study never went to school. Children with epilepsy had difficulties in attending normal schools especially when the epileptic seizures were frequent, unexpected, or were followed by coma, drowsiness, confusion, irritability, aggression, dizziness, loss of concentration, memory problems and mood swings. Seizures caused memory loss and confusion, and children appeared to have significant problems with learning, language or behaviour throughout their childhood, in addition to social stigma (bullying, anxiety, depression, selfconsciousness). For both children with physical and/or cognitive disability, the distance to the school, and the lack of infrastructure, adequate learning materials and trained teachers, made access to normal schools even more difficult [58]. In Uganda, the negative attitude of normal schools was also seen as a contribution for not being enrolled [46]. Specialized schools are usually fee-based and often inaccessible both physically and financially. Similar results were found in other studies in Tanzania and Uganda $[46,47]$. Lack of education led to parental concerns about the future of their child [46]. Lower school participation led to lower educational attainment which translated into lower employment opportunities and lower income in adulthood [25, 35].

Long-term care needs clearly placed an emotional burden on each family. Children were not autonomous and had little prospect of improvement and children with epilepsy had unpredictable seizures. Parents felt the pressure of being constantly present for their dependent, disabled child. Consequently, as confirmed by other studies, all parents were exhausted, stressed, depressed and worried [38-40, $42-44,52]$. Some expressed desperation. Difficulties in communicating and 
understanding the needs of children with mental disability increased parental stress, anxiety, and depression both about the current circumstances [46] as well as about the future. As mentioned elsewhere, physical disability increased the physical burden of carers looking after a physically disabled child [38, 40, 46, 52]. Stress and distress were voiced by mothers whose spouse had abandoned the household, leaving them to support the whole family. Long-term disability appeared to damage carers' health, destroy family structures, decrease household income and reduce the quality of family life [37].

Parents either resigned their job or worked less because their disabled child required full-time care. As a result of a reduction in work, household income decreased leading to financial problems in purchasing necessities such as food or clothes [45-47]. To cope with extra expenses, the families reported selling their assets suggesting that disability often push households who were already poor into extreme poverty $[32,35]$.

To decrease stress and reduce the risk of depression, worries, and isolation, social support has been shown to be effective [59-62]. However, none of the households received more than family support. Social support can be found at specialized centres, such as community-based rehabilitation centres $[63,64]$, even in Tanzania. Free home-based therapies for children with physical and/or mental disabilities as well as regular home and school follow-up visits are offered $[63,64]$. Children are taught how to increase their independence (e.g. washing, moving from their bed to a chair) and how to help the household (e.g. washing the dishes) [63]. However, community-based centres are rare and most centres are located in major (urban) cities which are not accessible or expensive for households living in rural areas. Another option to support disabled children and their families could be the implementation of community rehabilitation facilitators to provide home visits, exercises and training in activities of daily living (ADL - i.e. eating; bathing; getting dressed; toileting; transferring and continence) [65]. This kind of intervention can provide ADL independence and increase social integration, self-esteem, selfconfidence, mobility and acceptance of disability [65].

Our study is rare in examining the practical difficulties and challenges for disabled children and their families in managing serious long-term disability occurring early in infancy and continuing into adolescence without resolution. The ability to probe deeply through qualitative research on how disability affects the family is a strength. Thematic saturation was achieved with the small number of children. 
However, the small number of children and parents interviewed does not provide a complete picture of the challenges in living with disability. More topics might have emerged if a larger number of parent-child pairs had been interviewed. A further limitation is that only one male guardian participated in the study and male views on the consequences of disability, especially on stress, work and financial burdens, may differ from the views of female guardians. The qualitative interviews were not tape-recorded because ethical clearance was received only for recording digital stories [51]. Finally, only severely disabled children took part in our research and, therefore, this study does not represent the challenges of caring for children with milder disabilities.

\subsection{CONCLUSIONS}

Cerebral episodes can cause physical and/or mental impairment. If such impairment is serious, it affects not only the life of the child but that of the whole household. Serious disability increases physical, emotional and financial burdens of the child and carers. Children have very limited educational support - either from normal or specialized schools - and access to rehabilitative home-based support is inaccessible or unaffordable. Family structures break down. Parental income is reduced because time for caring is increased and consequently households that are poor get pushed further into poverty.

\subsection{ACKNOWLEDGEMENTS}

We would like to thank all children and their parents who agreed to be interviewed. 


\section{REFERENCES}

1. World Health Organization. Severe Malaria. Trop Med Int Heal. 2014;19 Suppl 1:7131.

2. Gitau EN, Newton CR. Review Article: blood-brain barrier in falciparum malaria. Trop Med Int Health. 2005;10:285-92.

3. Idro R, Karamagi C, Tumwine J. Immediate outcome and prognostic factors for cerebral malaria among children admitted to Mulago Hospital, Uganda. Ann Trop Paediatr. 2004;24:17-24.

4. Boivin MJ, Bangirana P, Byarugaba J, Opoka RO, Idro R, Jurek AM, et al. Cognitive impairment after cerebral malaria in children: a prospective study. Pediatrics. 2007;119:e360-6.

5. Idro R, Kakooza-Mwesige A, Asea B, Ssebyala K, Bangirana P, Opoka RA, et al. Cerebral malaria is associated with long-term mental health disorders: a cross sectional survey of a long-term cohort. Malar J. 2016;15:184.

6. Birbeck GL. Epilepsy in Africa: caution and optimism. Lancet Neurol. 2013;12:220-2.

7. Carter JA, Neville BG, White S, Ross AJ, Otieno G, Mturi N, et al. Increased prevalence of epilepsy associated with severe falciparum malaria in children. Epilepsia. 2004;45:978-81.

8. Ngoungou EB, Dulac O, Poudiougou B, Druet-Cabanac M, Dicko A, Mamadou Traore A, et al. Epilepsy as a consequence of cerebral malaria in area in which malaria is endemic in Mali, West Africa. Epilepsia. 2006;47:873-9.

9. Bangirana P, Opoka RO, Boivin MJ, Idro R, Hodges JS, John CC. Neurocognitive domains affected by cerebral malaria and severe malarial anemia in children. Learn Individ Differ. 2016;46:38-44.

10. John CC, Bangirana P, Byarugaba J, Opoka RO, Idro R, Jurek AM, et al. Cerebral malaria in children is associated with long-term cognitive impairment. Pediatrics. 2008;122:e92-9.

11. Bhutto E, Naim M, Ehtesham M, Rehman M, Siddique MA, Jehan I. Prognostic indicators of childhood acute viral encephalitis. J Pak Med Assoc. 1999;49:311-6.

12. Michaeli O, Kassis I, Shachor-Meyouhas Y, Shahar E, Ravid S. Long-term motor and cognitive outcome of acute encephalitis. Pediatrics. 2014;133:e546-52.

13. Edmond K, Clark A, Korczak VS, Sanderson C, Griffiths UK, Rudan I. Global and regional risk of disabling sequelae from bacterial meningitis: a systematic review and meta-analysis. Lancet Infect Dis. 2010;10:317-28.

14. Ramakrishnan M, Ulland AJ, Steinhardt LC, Moïsi JC, Were F, Levine OS. Sequelae due to bacterial meningitis among African children: a systematic literature review. BMC Med. 2009;7:47.

15. Khandaker G, Muhit M, Rashid H, Khan A, Islam J, Jones C, et al. Infectious causes of childhood disability: results from a pilot study in rural Bangladesh. J Trop Pediatr. 2014;60:363-9.

16. Heywood J. Childhood disability: ordinary lives for extraordinary families. Community Pract. 2010;83:19-22.

17. Stabile M, Allin S. The economic costs of childhood disability. Futur Child. 2012;22:65-96. 
18. Eide AH, Loeb ME. Living conditions among people with activity limitations in Zambia: A national representative study. Oslo: SINTEF; 2006.

19. Contreras DG, Ruiz-Tagle JV, Garcés P, Azócar I. Socio-economic impact of disability in Latin America: Chile and Uruguay. Santiago de Chile: Universidad de Chile, Departamento de Economía; 2006.

20. Eide AH, Kamaleri Y. Living conditions among people with disabilities in Mozambique: A national representative study. Oslo: SINTEF; 2009.

21. Loeb M, Eide AH, Jelsma J, Toni M, Maart S. Poverty and disability in Eastern and Western Cape Provinces, South Africa. Disabil Soc. 2008;23:311-21.

22. Loeb M, Eide AH. Living conditions among people with activity limitations in Malawi: A national representative study. Oslo: SINTEF; 2004.

23. Rischewski D, Kuper H, Atijosan O, Simms V, Jofret-Bonet M, Foster A, et al. Poverty and musculoskeletal impairment in Rwanda. Trans R Soc Trop Med Hyg. 2008;102:608-17.

24. O'Keefe P. People with disabilities in India: from commitments to outcomes. Washington, DC: World Bank, Human Development Unit - South Asia Region; 2009.

25. Filmer D. Disability, poverty, and schooling in developing countries: results from 14 household surveys. World Bank Econ Rev. 2008;22:141-63.

26. Trani J-F, VanLeit B. Increasing inclusion of persons with disabilities: Reflections from disability research using the ICF in Afghanistan and Cambodia. London: Leonard Cheshire International; 2010.

27. Eide AH, Van Rooy G, Loeb ME. Living conditions among people with disabilities in Namibia: A national, representative study. Oslo: SINTEF; 2003.

28. Hoogeveen JG. Measuring welfare for small but vulnerable groups: Poverty and disability in Uganda. J Afr Econ. 2005;14:603-31.

29. Mont D, Cuong NV. Disability and poverty in Vietnam. World Bank Econ Rev. 2011;25:323-59.

30. Trani J-F, Loeb M. Poverty and disability: A vicious circle? Evidence from Afghanistan and Zambia. J Int Dev. 2012;24 Suppl 1:S19-52.

31. Mitra S. The recent decline in the employment of persons with disabilities in South Africa, 1998-2006. S Afr J Econ. 2008;76:480-92.

32. Mitra S, Sambamoorthi U. Disability and the rural labor market in India: Evidence for males in Tamil Nadu. World Dev. 2008;36:934-52.

33. Mitra S, Posarac A, Vick BC. Disability and poverty in developing countries: a snapshot from the world health survey. Washington, DC: World Bank; 2011.

34. Palmer MG, Thuy NTM, Quyen QTN, Duy DS, Huynh HV, Berry HL. Disability measures as an indicator of poverty: a case study from Viet Nam. J Int Dev. 2012; 24 Suppl 1:S53-68.

35. Yeo R, Moore K. Including disabled people in poverty reduction work: "Nothing about us, without us". World Dev. 2003;31:571-90.

36. Lamichhane K, Kawakatsu Y. Disability and determinants of schooling: A case from Bangladesh. Int J Educ Dev. 2015;40:98-105.

37. Mobarak R, Khan NZ, Munir S, Zaman SS, McConachie H. Predictors of stress in mothers of children with cerebral palsy in Bangladesh. J Pediatr Psychol. 2000;25:427-33. 
38. Brehaut JC, Kohen DE, Raina P, Walter SD, Russell DJ, Swinton M, et al. The health of primary caregivers of children with cerebral palsy: how does it compare with that of other Canadian caregivers? Pediatrics. 2004;114:e182-91.

39. Brehaut JC, Kohen DE, Garner RE, Miller AR, Lach LM, Klassen AF, et al. Health among caregivers of children with health problems: findings from a Canadian populationbased study. Am J Public Health. 2009;99:1254-62.

40. Dambi JM, Jelsma J, Mlambo T. Caring for a child with Cerebral Palsy: The experience of Zimbabwean mothers. Afr J Disabil. 2015;4:168.

41. Busch SH, Barry CL. Mental health disorders in childhood: assessing the burden on families. Health Aff (Millwood). 2007;26:1088-95.

42. Sawyer MG, Bittman M, La Greca AM, Crettenden AD, Borojevic N, Raghavendra $\mathrm{P}$, et al. Time demands of caring for children with cerebral palsy: what are the implications for maternal mental health? Dev Med Child Neurol. 2011;53:338-43.

43. Navaie-Waliser M, Feldman PH, Gould DA, Levine C, Kuerbis AN, Donelan K. When the caregiver needs care: the plight of vulnerable caregivers. Am J Public Health. 2002;92:409-13.

44. Cheshire A, Barlow JH, Powell LA. The psychosocial well-being of parents of children with cerebral palsy: a comparison study. Disabil Rehabil. 2010;32:1673-7.

45. Gona JK, Mung'ala-Odera V, Newton CR, Hartley S. Caring for children with disabilities in Kilifi, Kenya: what is the carer's experience? Child Care Health Dev. 2011;37:175-83.

46. Hartley S, Ojwang P, Baguwemu A, Ddamulira M, Chavuta A. How do carers of disabled children cope? The Ugandan perspective. Child Care Health Dev. 2005;31:167-80.

47. McNally A, Mannan H. Perceptions of caring for children with disabilities: Experiences from Moshi, Tanzania. Afr J Disabil. 2013;2:21.

48. Gomes MF, Faiz MA, Gyapong JO, Warsame M, Agbenyega T, Babiker A, et al. Prereferral rectal artesunate to prevent death and disability in severe malaria: a placebo-controlled trial. Lancet. 2009;373:557-66.

49. Patient Voices. https://www.patientvoices.org.uk/

50. Stacey G, Hardy P. Challenging the shock of reality through digital storytelling. Nurse Educ Pract. 2011;11:159-64.

51. Patient Voices. Patient Voices: Saving Brains [Internet]. 2014. [cited 2017 Jan 11]. Available from: https://www.patientvoices.org.uk/savingbrains.htm.

52. Davis E, Shelly A, Waters E, Boyd R, Cook K, Davern M, et al. The impact of caring for a child with cerebral palsy: quality of life for mothers and fathers. Child Care Health Dev. 2010;36:63-73.

53. Murphy NA, Christian B, Caplin DA, Young PC. The health of caregivers for children with disabilities: caregiver perspectives. Child Care Health Dev. 2007;33:180-7.

54. Kaufman AS, Kaufman NL. Kaufman Assessment Battery for Children. $2^{\text {nd }}$ edition. Circle Pines, MN: American Guidance Service; 2004.

55. Ofovwe GE, Ibadin OM, Ofovwe EC, Okolo AA. Home management of febrile convulsion in an African population: a comparison of urban and rural mothers' knowledge attitude and practice. J Neurol Sci. 2002;200:49-52.

56. Makundi EA, Malebo HM, Mhame P, Kitua AY, Warsame M. Role of traditional healers in the management of severe malaria among children below five years of age: the case of Kilosa and Handeni Districts, Tanzania. Malar J. 2006;5:58. 
57. Nuwaha F. People's perception of malaria in Mbarara, Uganda. Trop Med Int Health. 2002;7:462-70.

58. The African Child Policy Forum (ACPF). Access denied: Voices of persons with disabilities from Africa. Addis Ababa: ACPF; 2014.

59. Ainbinder JG, Blanchard LW, Singer GH, Sullivan ME, Powers LK, Marquis JG, et al. A qualitative study of Parent to Parent support for parents of children with special needs. Consortium to evaluate Parent to Parent. J Pediatr Psychol. 1998;23:99-109.

60. Bray L, Carter B, Sanders C, Blake L, Keegan K. Parent-to-parent peer support for parents of children with a disability: a mixed method study. Patient Educ Couns. 2017;100:1537-43.

61. Kerr SM, Mcintosh JB. Coping when a child has a disability: exploring the impact of parent-to-parent support. Child Care Health Dev. 2000;26:309-22.

62. Telleen S, Herzog A, Kilbane TL. Impact of a family support program on mothers' social support and parenting stress. Am J Orthopsychiatry. 1989;59:410-9.

63. Cameron DL, Nixon S, Parnes P, Pidsadny M. Children with disabilities in low-income countries. Paediatr Child Health. 2005;10:269-72.

64. Comprehensive Community Based Rehabilitation in Tanzania (CCBRT). Bringing Services Home [Internet]. [cited 2019 May 22]. Available from: http://www.ccbrt. or.tz/programmes/disability/community-based-rehab/

65. Chappell P, Johannsmeier C. The impact of community based rehabilitation as implemented by community rehabilitation facilitators on people with disabilities, their families and communities within South Africa. Disabil Rehabil. 2009;31:7-13. 


\section{SUPPLEMENTARY INFORMATION}

S1 Table. Examples of questions of the case report form.

\begin{tabular}{|c|c|}
\hline Categories & Questions \\
\hline Worries & $\begin{array}{l}\text { Could you please tell me more about how the disability of your child } \\
\text { affects you? } \\
\text { Examples of elements to be included: } \\
\text { - More stress, sadness and worries? } \\
\text { - How do you see the future for you, your child and your family? }\end{array}$ \\
\hline $\begin{array}{l}\text { Physical } \\
\text { efforts of the } \\
\text { guardian }\end{array}$ & $\begin{array}{l}\text { Could you please tell me how you are physically affected? (For } \\
\text { instance, how do you deal if your child cannot walk?) } \\
\text { Examples of elements to be included: } \\
\text { - More physical efforts? } \\
\text { - If yes, do you have any health problems due to these additional physical } \\
\text { efforts? } \\
\text { - Are you feeling exhausted by these additional efforts? }\end{array}$ \\
\hline $\begin{array}{l}\text { Effects on } \\
\text { guardian's } \\
\text { time }\end{array}$ & $\begin{array}{l}\text { Could you please tell me more about how your time is affected by } \\
\text { the disability of your child when comparing to a child who has no } \\
\text { disability? } \\
\text { Examples of elements to be included: } \\
\text { - When you are at home, are you always together with him/her the whole } \\
\text { day? } \\
\text { - How do you manage your time at home? Is some of your time allocated } \\
\text { to basic stuff such as dressing, feeding, toileting, sleeping etc.? In which } \\
\text { areas? } \\
\text { - Do you have some extra help? If yes, what kind of "other" help do you } \\
\text { have? }\end{array}$ \\
\hline $\begin{array}{l}\text { Child's } \\
\text { needs and } \\
\text { medication } \\
\text { health }\end{array}$ & $\begin{array}{l}\text { Could you please tell me how you deal with your child's needs, } \\
\text { medication and special treatment? } \\
\text { Examples of elements to be included: } \\
\text { - How do you understand your child's needs (because cannot speak)? } \\
\text { - Need of special treatment? } \\
\text { - What about the toilet? What help does your child need? } \\
\text { - Need to take drugs regularly? }\end{array}$ \\
\hline $\begin{array}{l}\text { Social } \\
\text { relationships }\end{array}$ & $\begin{array}{l}\text { Could you please let me know how your relations with your family } \\
\text { and other people have been affected and how your child is socially } \\
\text { affected? } \\
\text { Examples of elements to be included: } \\
\text { - How has your child been with his/her siblings over the past month? Do } \\
\text { they argue much? } \\
\text { - Are there other children around here who your child can play with? If yes, } \\
\text { is (s)he willing to play with them? Are they playing together? } \\
\text { - Have you or your child already been socially excluded? } \\
\text { - Have you already encountered some difficult situations within the family } \\
\text { (e.g. father left)? }\end{array}$ \\
\hline
\end{tabular}


S1 Table. Examples of questions of the case report form. (Continued)

\begin{tabular}{ll}
\hline Categories & Questions \\
\hline Discipline & Could you please tell me how you deal with discipline? Do you think \\
& your child is more difficult than a child with no disability? Is (s)he \\
& often angry, does (s)he scream a lot? \\
& Examples of elements to be included: \\
& - Mood changes frequently? \\
& - Has explosive, angry outbursts? \\
& - What does your child do when angry? \\
& - Does (s)he scream and kick? How many times in the past month? \\
\hline Financial & What are the financial consequences for your household? \\
issues & Examples of elements to be included: \\
& - Did you need to give up or change your job? Or did you need to work less? \\
& - If you have any other children, how are they affected? Do they also need \\
& to allocate their time to take care of the child? Maybe cannot go to school \\
& or do their homework? Did some of your children need to give up school \\
& in order to work?
\end{tabular}




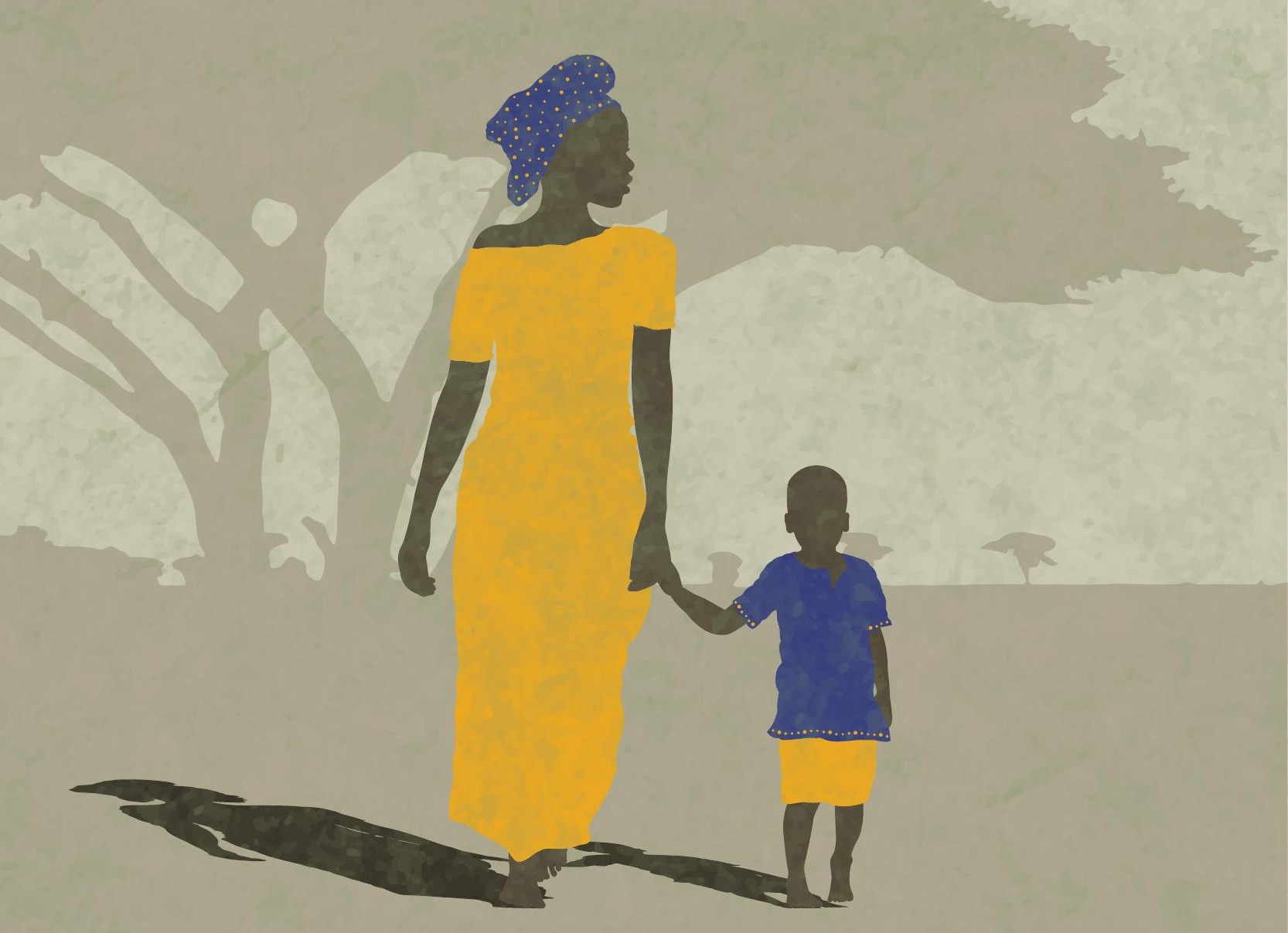




\section{CHAPTER 4}

\section{IMPACT OF IMPROVING COMMUNITY. BASED ACCESS TO MALARIA DIAGNOSIS AND TREATMENT ON HOUSEHOLD COSTS}

\section{Published as:}

Castellani J, Nsungwa-Sabiiti J, Mihaylova B, Ajayi IO, Siribié M, Afonne C, Balyeku A, Sermé L, Sanou AK, Sombié BS, Tiono AB, Sirima SB, Kabarungi V, Falade CO, Kyaligonza J, Evers SMAA, Paulus ATG, Petzold M, Singlovic J, Gomes M. Impact of improving community-based access to malaria diagnosis and treatment on household costs. Clin Infect Dis. 2016;63 Suppl 5:S256-63. 


\section{ABSTRACT}

\section{Background}

Community health workers (CHWs) were trained in Burkina Faso, Nigeria, and Uganda to diagnose febrile children using malaria rapid diagnostic tests, and treat positive malaria cases with artemisinin-based combination therapy (ACT) and those who could not take oral medicines with rectal artesunate. We quantified the impact of this intervention on private household costs for childhood febrile illness.

\section{Methods}

Households with recent febrile illness in a young child in previous 2 weeks were selected randomly before and during the intervention and data obtained on household costs for the illness episode. Household costs included consultation fees, registration costs, user fees, diagnosis, bed, drugs, food, and transport costs. Private household costs per episode before and during the intervention were compared. The intervention's impact on household costs per episode was calculated and projected to districtwide impacts on household costs.

\section{Results}

Use of CHWs increased from 35\% of illness episodes before the intervention to $50 \%$ during the intervention $(\mathrm{p}<0.0001)$, and total household costs per episode decreased significantly in each country: from US Dollars (USD) \$4.36 to USD \$1.54 in Burkina Faso, from USD \$3.90 to USD \$2.04 in Nigeria, and from USD \$4.46 to USD \$1.42 in Uganda (all p<0.0001). There was no difference in the time used by the child's caregiver to care for a sick child (59\% before intervention vs. 51\% during intervention spent $\leq 2$ days). Using the most recent population figures for each study district, we estimate that the intervention could save households a total of USD $\$ 29,965$, USD $\$ 254,268$, and USD $\$ 303,467$, respectively, in the study districts in Burkina Faso, Nigeria, and Uganda.

\section{Conclusions}

Improving access to malaria diagnostics and treatments in malaria-endemic areas substantially reduces private household costs. The key challenge is to develop and strengthen community human resources to deliver the intervention, and ensure adequate supplies of commodities and supervision. We demonstrate feasibility and benefit to populations living in difficult circumstances. 


\subsection{BACKGROUND}

It is estimated that approximately 214 million cases of malaria occurred in 2015, almost $90 \%$ in sub-Saharan Africa [1]. Children aged $<5$ years are at greatest risk of illness and death $[1,2]$. Rapid diagnostic tests (RDTs) reliably diagnose malaria at the point of care and identify children to be treated with artemisininbased combination therapy (ACT); rectal artesunate is recommended for patients who can no longer take oral drugs before transfer to a facility for continued management [3]. Data on the feasibility of providing an integrated package are essential, particularly in remote rural areas where malaria has not yet declined [3-5]. Evidence is needed about the potential health benefits as well as costs and savings of introducing such interventions in underserved areas.

Malaria can be successfully treated with existing medicines, but access to them is limited in affected populations. In rural Africa, households frequently rely on private, for-profit providers where they make direct payments for healthcare, due to long distances to public facilities, or because such facilities do not function adequately or do not have appropriate medicine and consumable stocks [6-8]. The burden of paying privately for healthcare is a major financial cost to the household, and is exacerbated by income lost from not being able to carry out normal activities because malaria often occurs in the rainy season, simultaneous with an increased need for labor on the farm. Ill health and the associated costs tip families into catastrophic economic conditions, recovery from which may take considerable time $[9,10]$. At the same time, there is an increasing literature on interventions using community health workers (CHWs) to successfully provide basic care [1113]. A number of interventions have demonstrated the extent to which CHWs can substantially improve health when trained adequately and when provided with commodities and supervision $[14,15]$. CHWs have been shown to be able to assess and diagnose children and improve access to healthcare by reaching the poorest in the most inaccessible areas. Several studies have shown a reduction in child mortality associated with CHWs' provision of care [13-16].

As part of an implementation study that trained CHWs to assess sick children, diagnose malaria using RDTs, and treat with ACTs or rectal artesunate in 3 African countries (Burkina Faso, Nigeria, and Uganda) chosen because they are among the top 10 countries contributing $80 \%$ of global malaria cases [17], we studied the private household costs for a febrile episode in a child before the intervention was launched, and after the CHWs' training was completed and the intervention was 
in force. Our objective was to quantify the impact of this intervention improving access to malaria diagnosis and treatment on private household costs of illness, and to provide policy makers with reliable estimates of these costs if they were to consider scaling up the intervention at the district or national level.

\subsection{METHODS}

\subsubsection{Study sites}

The main intervention study was carried out in 3 rural areas of Burkina Faso (health area of Sidéradougou, Health District of Mangodara), Nigeria (Ona-Ara local government area), and Uganda (Sheema district) in 2014, and consequently the pre-intervention household questionnaire was implemented between May and July 2013 (Nigeria and Uganda) and in July 2014 (Burkina Faso) to understand how people normally managed febrile illness (mostly malaria) before the intervention, and to quantify the costs they incurred.

In total, 45, 33, and 32 study communities were included in Burkina Faso, Nigeria, and Uganda, respectively, during the pre-intervention phase and 45, 33, and 84 communities during the intervention; in Uganda, Kayunga district was added to the intervention study. ACTs and rectal artesunate were provided to all CHWs, except in Burkina Faso, where rectal artesunate was provided to 31 out of 50 CHWs.

In all study areas, households are mainly agricultural, and therefore, dependent upon the rains for irrigating crops. The malaria season is also associated with rainfall, because the rains increase the number of mosquitoes that can transmit Plasmodium falciparum parasites to humans, mainly nonimmune children. In Mangodara, Burkina Faso, malaria transmission peaks between June to August and sometimes tails off in November/December, and in the Ona-Ara area, Nigeria, malaria peaks between May and October. However, in Uganda, malaria is seasonal in Sheema district (between March and June/July and September/October) but stable through the whole year in Kayunga district.

\subsubsection{Health provision in the study area}

In all 3 countries, people typically go for advice and care for suspected malaria to traditional healers, faith homes (churches), CHWs, traditional birth attendants (Nigeria), drug shops/patent medicine sellers, drug hawkers, maternities, dispensaries (not in Nigeria), health centers, or private clinics (Nigeria and Uganda). The closest hospital is situated $25 \mathrm{~km}$ away from the study area in 
Burkina Faso, approximately $8 \mathrm{~km}$ (private hospital) or between 20 and $22 \mathrm{~km}$ (public hospital) away in Nigeria, and $36 \mathrm{~km}$ away for Sheema district (Uganda); in Kayunga district (Uganda), it takes about 2-3 hours walking from Kayunga's Grade IV health center to the hospital.

In Burkina Faso, healthcare at any public facility is fee-based. Consultation costs about 200 West African CFA francs (XOF; US Dollars [USD] \$0.33) and when admitted, patients pay for their bed. In Nigeria and Uganda, consultations, drugs, and bed costs at public facilities are theoretically provided free of charge for children $<5$ years old, but caregivers still have to pay for a registration card and injections (Nigeria) or an exercise book and drugs bought outside the hospital (Uganda). In all 3 countries, shops and pharmacies sell quinine, antibiotics, and antimalarials without prescription.

Before the intervention, no RDTs, ACTs, or rectal artesunate were available to the communities in the public sector. CHWs were available but relatively dormant as a means of providing healthcare. During the intervention, RDTs and drugs were provided free of charge in the study areas of Nigeria and Uganda. However, in Burkina Faso, RDTs and rectal artesunate were free of charge, but ACT was sold (as per public policy) to CHWs at a cost of 70 XOF (USD $\$ 0.12$; 6 tablets per blister pack) for children aged $<37$ months and 150 XOF (USD $\$ 0.25 ; 12$ tablets per blister pack) for children aged 37-59 months. Each CHW was authorized to make a nominal profit by charging parents these costs plus a nominal profit of 30 XOF (USD \$0.05) for each young child treated with 6 ACTs and 50 XOF (USD \$0.08) for each older child treated with 12 ACTs.

\subsubsection{Household questionnaires on costs}

The purpose of the study questionnaire was to determine treatment-seeking behavior and expenditure for a recent childhood illness by households randomly selected from the villages before and during the intervention. In all 3 countries, a visit was made to households, and if they had a child who was between 6 and 59 months of age and had a fever in the preceding 2 weeks, questions were asked regarding the illness, healthcare received, and their healthcare expenses. Households that did not have children who were ill, or whose caregiver was not present during the illness or who refused to give consent, were excluded from interview.

\subsubsection{Questionnaire content, selection of the interviewers, and data collection}

Two questionnaires (one for each phase) were developed: in French for Burkina Faso and in English for Nigeria and Uganda. In Nigeria and Uganda, these 
questionnaires (hereinafter called case report forms [CRFs]) were translated into local languages (Yoruba in Nigeria, and Luganda in Kayunga district and Lunyankole in Sheema district, Uganda) and pilot tested for comprehension before use. For the pre-intervention phase, there were 10 interviewers in Burkina Faso and Nigeria and 8 in Uganda; for the intervention phase, there were 10 in Burkina Faso, 13 in Nigeria, and 20 in Uganda. Interviewers were fluent in local languages and had good education and prior experience in research/data collection. Most interviewers were used for both pre-intervention and the intervention phase. In all 3 countries, interviewers were trained for at least 1 day. Training sessions were interactive with question-and-answer sessions and role plays. Each interviewer was tested through completing CRFs before certification.

Each interview lasted between 20 minutes and 1 hour. Although the preintervention and intervention CRFs were adapted to the country, they contained the same main questions on general sociodemographic context of the household, clinical course of the episode (timing, symptoms, actions taken, healthcare providers visited), costs incurred (for transportation, medicines, registration/ consultation fees, laboratory/diagnostic tests, accommodation, and food for each consultation) and what happened during a consultation visit to a health provider (RDTs, treatments). The CRF during intervention was identical to the pre-intervention CRF but attempted to capture additional information on reasons for not going to a CHW where relevant.

\subsubsection{Sampling strategy}

In calculating our sample size for household surveys, we assumed that the average number of children $<5$ years of age per household was 2 , except in Uganda, where the average was assumed as 1.4 . Requiring a precision of $\pm 5 \%$ points for the point estimates of proportions, a minimum sample size would be 384 for the worst-case scenario of $50 \%$. Accounting for a design effect of 2 for clustering on household level would give us a total sample size of 768 interviews before and during the intervention in each country. We achieved interviews with 1,856 caretakers in Burkina Faso (514 before, 1,342 during), 1,560 in Nigeria (775 before, 785 during), and 1,529 in Uganda (457 before and 1,072 during), with a total of 4,945 households interviewed.

\subsubsection{Data analysis and statistical methods Baseline characteristics}

Demographic information on the child and household (gender, age, education, occupation, food problems, number of working people in the household) and 
information on the illness episode (danger signs, number of children who went to a $\mathrm{CHW} /$ trained health worker, main reasons for not going to a $\mathrm{CHW}$, number of days lost) was obtained. Baseline characteristics for sampled illness cases were compared before and during intervention.

\section{Private costs}

Household costs reported by the parent or guardian of the child were categorized into registration, consultation, user fee, diagnosis, drugs, bed, food, informal, transport, and other costs for caretaker or patient. Transport cost included costs of the parent or guardian but excluded costs paid by a third party (i.e. a person not related to the household) accompanying the parent/guardian and child. In addition, the costs reported by caregivers of children who were still sick at the time of interview were excluded from the analysis as it would underestimate the total cost for a whole episode of illness. Total private costs per illness episode before and during intervention were compared separately for each country. Costs during the intervention were also compared between those who went to a CHW and those who did not. In the latter comparison, total costs were further stratified by severity of the episode (uncomplicated vs. severe). Costs are presented in USD using the average exchange rate in the period May 2013 to August 2014: 1 USD $=487.80 \mathrm{XOF}$ (Burkina Faso); 1 USD = 161.76 Nigerian naira (NGN); 1 USD = 2,631.58 Ugandan shilling (UGX) for the pre-intervention phase; and the average exchange rate between April and October 2015: 1 USD = 598.09 XOF; 1 USD = 200.36 NGN; 1 $\mathrm{USD}=3,472.22$ UGX for the intervention phase (www.oanda.com).

\section{Projecting impact of intervention on household costs at the whole district level}

To project the impact of intervention on household costs at district level, external data were used for the number of children $<5$ years old in each district and the number of malaria episodes per year and per child $<5$ years old. Estimates of the impact per child and per episode are presented and mean cost savings were then calculated for malaria episodes per year. Overall cost impacts were converted into USD.

\section{Statistical methods}

For each phase and each country separately, all data were double entered in EpiData 3.1 and analyzed using Stata software, version 13.0 (StataCorp, College Station, Texas). A Student $t$ test was performed on the equality of means with a level of significance of $\mathrm{p}=0.05$ and a confidence level of $95 \%$, and a test for heterogeneity was used to compare baseline characteristics of participating households before and during the intervention by country and overall. 


\subsubsection{Ethical considerations}

The research protocol of the main study was approved by the National Health Research Committee, the University of Ibadan/University College Hospital Institutional Review Committee, and Oyo State Ministry of Health in Nigeria; the National Ethics Committee for the Research on Health and the National Regulatory Authority in Burkina Faso; the National Council for Science and Technology in Uganda; and the World Health Organization Research Ethics Review Committee. In addition, Nigeria obtained permission from the local government secretariat as well as from the head of the communities. In Burkina Faso, additional approvals were obtained from the community via their leader by signing a written consent, and in Uganda, from the district heath officer and the local council I (village level). Finally, in Burkina Faso as well as in Uganda, oral consent was obtained from caregivers while written consent was obtained in Nigeria.

\subsection{RESULTS}

\subsubsection{Baseline characteristics}

The majority of children in the study were $<36$ months of age $60 \%$ before and $63 \%$ during intervention) (Table 1). Respondents were mainly female (80\% before and $96 \%$ during intervention), most being <36 years old (69\% before and $77 \%$ during intervention). In Burkina Faso, most of the caregivers had never been to school (80\% before and 89\% during intervention) while in Nigeria and Uganda, the caretakers were better educated and many had completed primary school (Nigeria: 40\% before and 35\% during intervention; Uganda: 62\% before and 61\% during intervention). Income was mainly based on agriculture in Burkina Faso and Uganda, and most of the households declared they did not have food problems (Burkina Faso: 70\% before and 74\% during intervention; Uganda: 54\% before and 44\% during intervention), while in Nigeria, households sometimes had food problems (30\% before and $43 \%$ during intervention). In Nigeria, a large proportion of caregivers were self-employed (57\% before and $71 \%$ during intervention). Most episodes were without danger signs (75\% before vs. $82 \%$ during intervention). Before the intervention, 35\% of caretakers went to a CHW while $50 \%$ went during the intervention $(\mathrm{p}<0.0001)$. For those who did not go to a CHW during the intervention, the main reasons were that parents believed that their child was not very sick (18\%), were not aware of the presence of the CHW in their community (13\%), believed that CHWs cannot treat well (8\%), or because the CHW was often not at home (7\%) (S1 Table). 


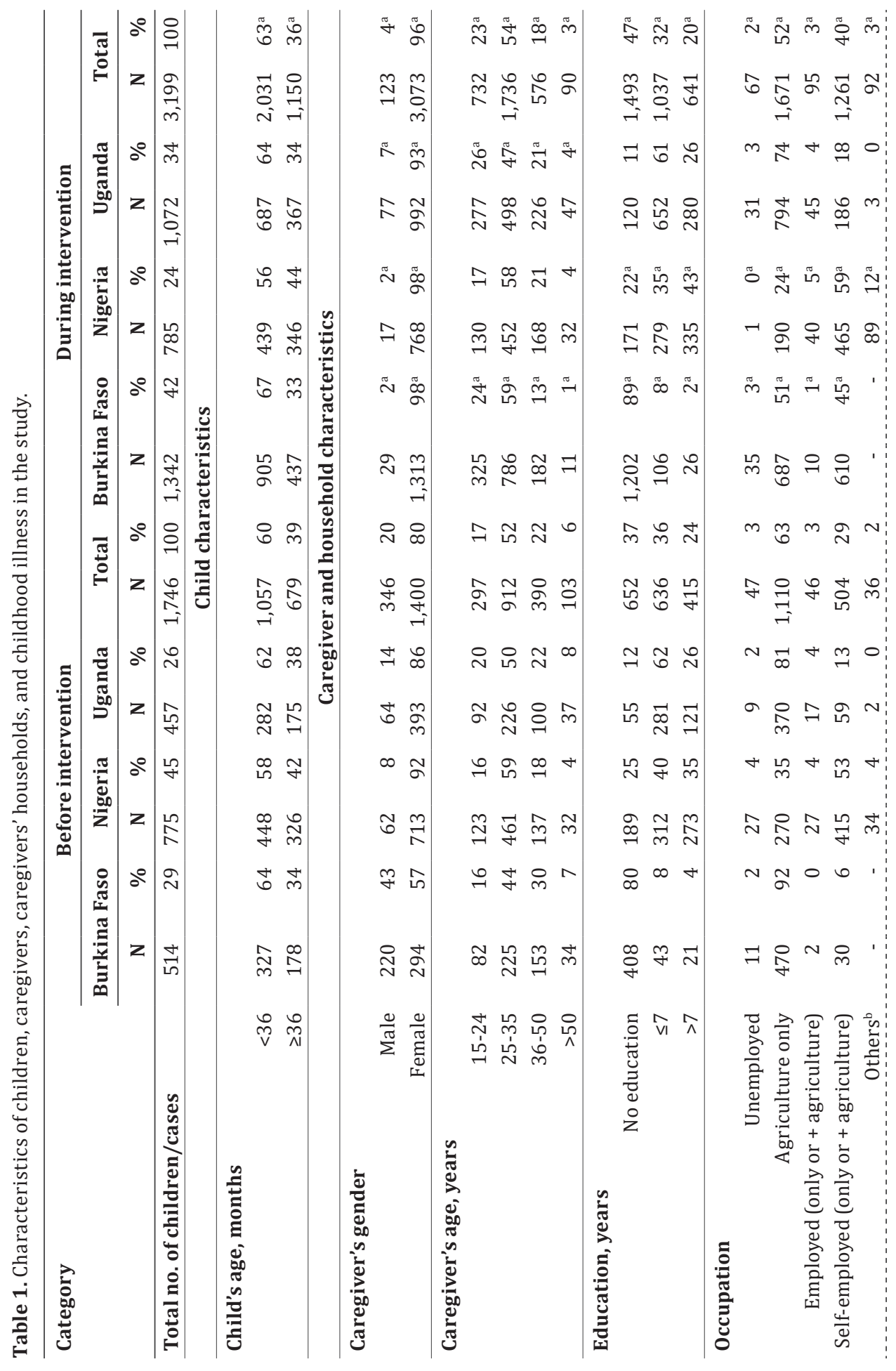




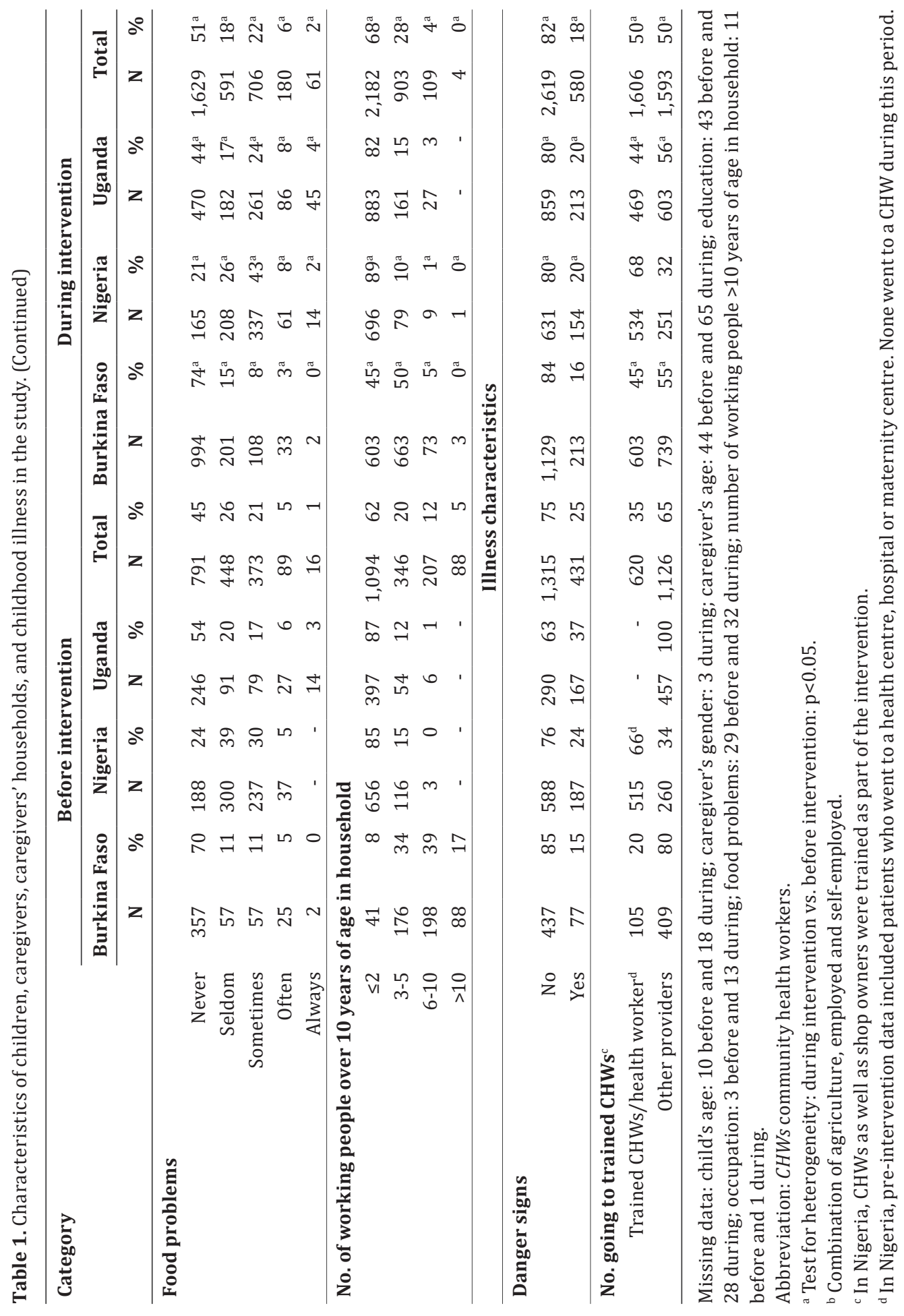




\subsubsection{Household out-of-pocket costs for illness episode}

Table 2 presents the out-of-pocket costs incurred by caregivers of sick children before and during the intervention split into different cost categories. During the intervention, total household costs per episode were lower in all 3 countries, about 3 times lower in Burkina Faso: USD \$1.54 vs. USD \$4.36 (difference, USD $\$ 2.82$ [95\% confidence interval $\{\mathrm{CI}\}$, USD \$2.09 - USD \$3.55]; $\mathrm{p}<0.0001$ ), twice lower in Nigeria: USD \$2.04 vs. USD \$3.90 (difference, USD \$1.86 [95\% CI, USD $\$ 1.01$ - USD \$2.70]; $\mathrm{p}<0.0001$ ), and 3 times lower in Uganda: USD \$1.42 vs. USD $\$ 4.46$ (difference, USD \$3.04 [95\% CI, USD \$2.29 - USD \$3.79]; $\mathrm{p}<0.0001$ ). Similar decreases were observed for total costs for those who incurred some costs, with the largest reductions observed in drug and transport costs (drugs: USD \$1.74 during vs. USD \$4.15 before intervention; transport: USD \$1.42 vs. USD \$2.49, respectively). The percentage of households that paid something during the episode decreased for both Nigeria (12\% less) and Uganda (15\% less) but slightly increased for Burkina Faso (+2\%). Comparing those who went to a CHW during the intervention with those who did not, those who went had lower costs: USD \$1.32 vs. USD \$2.03 (difference, USD \$0.71 [95\% CI, USD \$0.34 - USD \$1.09]; p<0.0001) (S2 Table), and more than half of them had a RDT ( $94 \%$ in Burkina Faso, 55\% in Nigeria, and 66\% in Uganda; unpublished data). There was no difference in time spent by the guardian in caring for the sick child (59\% before vs. $51 \%$ during intervention spent $\leq 2$ days; Table 2 ).

\subsubsection{Cost savings due to the intervention at household and district levels}

Table 3 presents estimates of the total household costs saved per year due to the intervention. With 1.18 (Burkina Faso [18]), 3.5 (Nigeria [19]), and 0.98 (Uganda [20]) malaria episodes per year per child and a private household cost savings per episode of USD \$2.82 (Burkina Faso), USD \$1.86 (Nigeria), and USD \$3.04 (Uganda), the projected total mean household cost savings at district level per year were USD $\$ 29,965$ for Mangodara (Burkina Faso), USD \$254,268 for Ona-Ara (Nigeria), and USD \$303,467 for Sheema and Kayunga (Uganda). 


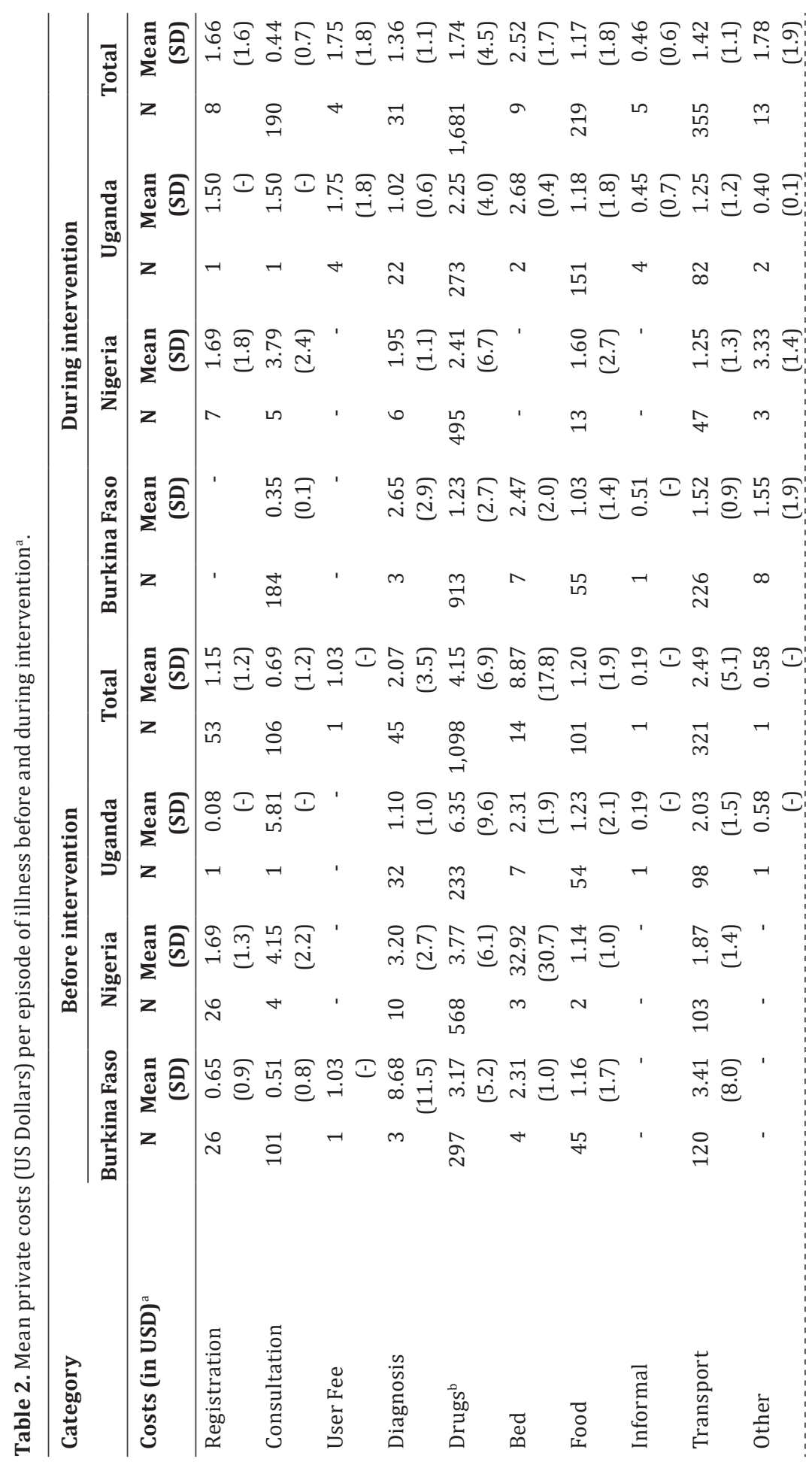




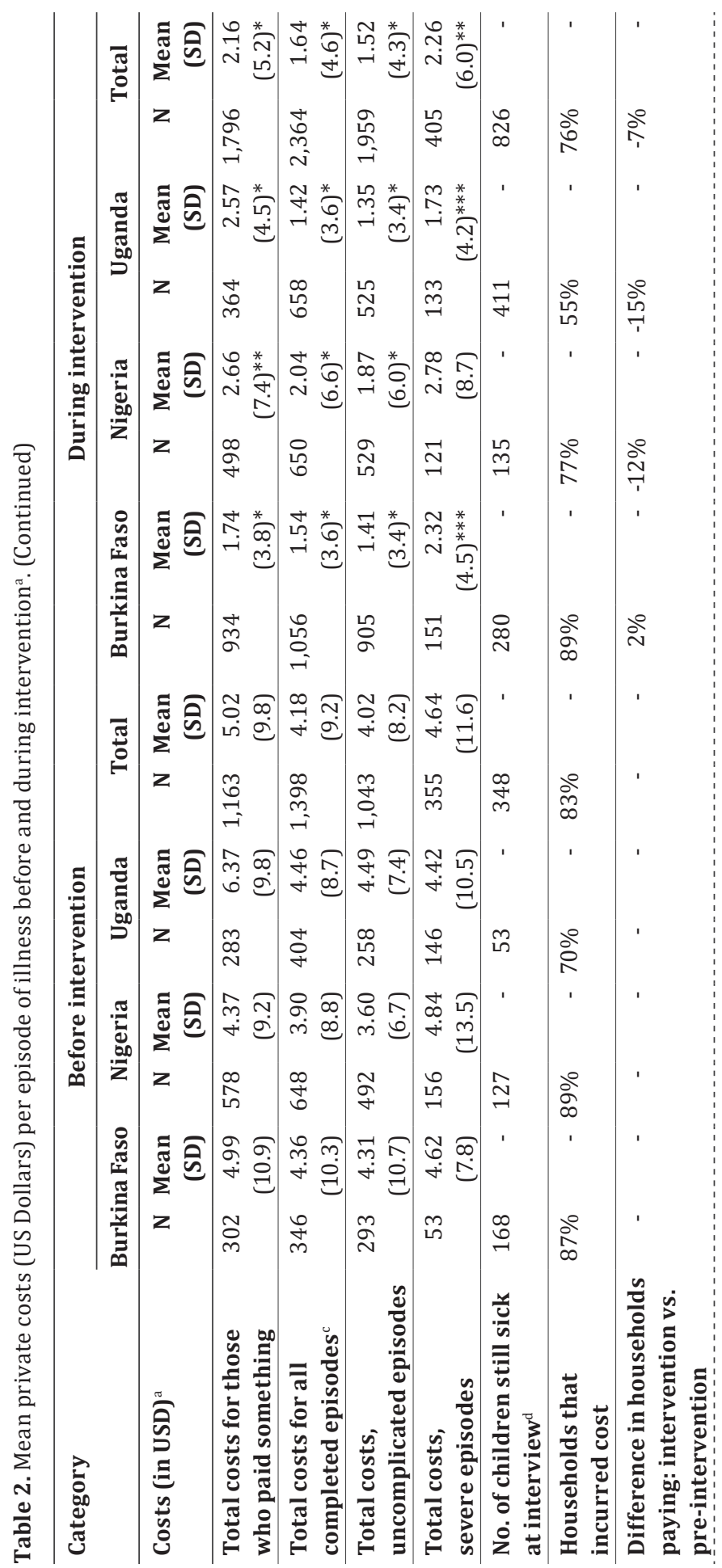




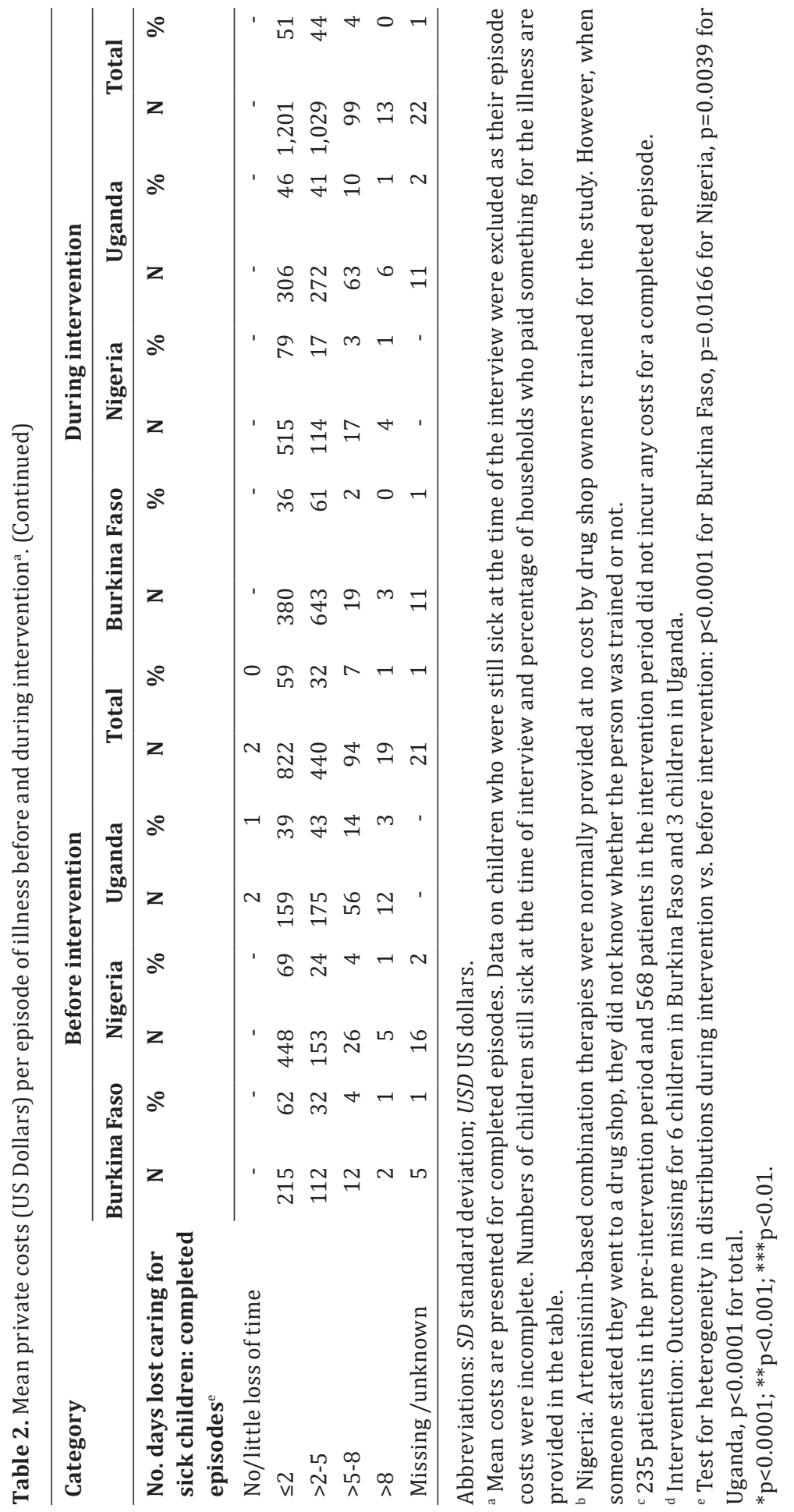


Table 3. Estimated household savings (US Dollars) for malaria due to the intervention for the whole district of the study areas.

\begin{tabular}{|c|c|c|c|}
\hline Category & $\begin{array}{r}\text { Mangodara, } \\
\text { Burkina Faso }\end{array}$ & $\begin{array}{r}\text { Ona-Ara, } \\
\text { Nigeria }\end{array}$ & $\begin{array}{r}\text { Sheema and } \\
\text { Kayunga, Uganda }\end{array}$ \\
\hline $\begin{array}{l}\text { No. of malaria episodes per year, per child } \\
<5 \text { years old }\end{array}$ & 1.18 & 3.50 & 0.98 \\
\hline No. of children $<5$ years old ${ }^{b, c}$ & 9,005 & 39,058 & 101,862 \\
\hline $\begin{array}{l}\text { Mean household costs (USD) per episode } \\
\text { (SD) }{ }^{\mathrm{d}} \text { before intervention }\end{array}$ & $4.36(10.3)$ & $3.90(8.8)$ & $4.46(8.7)$ \\
\hline $\begin{array}{l}\text { Mean household costs (USD) per episode } \\
\text { (SD) }{ }^{\mathrm{d}} \text { during intervention }\end{array}$ & $1.54(3.6)$ & $2.04(6.6)$ & $1.42(3.6)$ \\
\hline Savings per child (USD) per episode (SE) & $2.82(0.6)$ & $1.86(0.4)$ & $3.04(0.5)$ \\
\hline $\begin{array}{l}\text { Total mean savings (USD) per child and } \\
\text { per year (SE) }\end{array}$ & $3.33(0.7)$ & $6.51(1.5)$ & $2.98(0.5)$ \\
\hline $\begin{array}{l}\text { Before intervention: total mean costs (USD) } \\
\text { per year for malaria for the whole district }\end{array}$ & 46,329 & 533,142 & 445,218 \\
\hline $\begin{array}{l}\text { During intervention: total mean costs (USD) } \\
\text { per year for malaria for the whole district }\end{array}$ & 16,364 & 278,874 & 141,751 \\
\hline $\begin{array}{l}\text { Total mean savings (USD) per year for } \\
\text { malaria for the whole district }\end{array}$ & 29,965 & 254,268 & 303,467 \\
\hline
\end{tabular}

Abbreviations: $S D$ standard deviation; $S E$ standard error; USD US dollars.

a References [18-20].

${ }^{\mathrm{b}}$ References [21-23].

${ }^{\mathrm{c}}$ For Mangodara, Sheema and Kayunga: To calculate the number of children $<5$ years of age in the district, we used the total population in the district and the percentage of children $<5$ years in the country (based on the total number of children $<5$ years and the total population in the country).

${ }^{\mathrm{d}}$ Mean costs (SD) per completed episode.

e The number of malaria episodes/child was assumed to be fixed (i.e. without uncertainty).

\subsection{DISCUSSION}

In this study in 3 malaria-endemic African countries, we quantified household costs incurred in managing an episode of febrile illness before and after integrated provision of RDTs, ACTs, and rectal artesunate by CHWs. There was a $>2$-fold reduction in household private costs per illness episode as a consequence of the intervention - from USD $\$ 4.18$ before to USD \$1.64 during the intervention. The findings were separately significant for each country, although the magnitude was larger in Burkina Faso and Uganda (two-thirds reduction) than in Nigeria (reduction of approximately 40\%). Cost categories with largest reductions were drug costs (reducing from USD \$4.15 to USD \$1.74 for those reporting such costs) and transport (from USD \$2.49 to USD \$1.42, respectively). 
CHWs were located closer to patients; consequently, caregivers were more likely to seek care faster, and we expected this to halt the progression of the disease and decrease the length of the illness episode. We found evidence of this through a significant reduction in the proportion of children with danger signs requiring referral to hospital during the intervention: $24.7 \%$ vs. $18.1 \%$ [17]. The illness recovery was shorter during the intervention, reducing from 3.69 to 3.47 days [17]. Those who went to a CHW during the intervention incurred significantly lower out-of-pocket costs compared with those who did not do so. Household private costs per episode during the intervention for those who went to a CHW was approximately 63\% lower in Burkina Faso and approximately 44\% lower in Uganda, but remained similar in Nigeria, where drug costs were substantial even during the intervention.

Mean household savings per child per year due to the intervention constitutes an important component of household budgets as the money saved through more rapid access to diagnosis and treatment can be used for other household needs. On a district basis, the cost savings would be expected to be considerable, depending on the number of children who become ill (illness frequency was less but the child population was greater in the study areas of Uganda compared with the study areas of Burkina Faso and Nigeria), making the cost reduction substantial in all 4 study districts.

CHWs were located closer to patients and were provided either with free (or lowcost) drugs and diagnostics; both of these features of the intervention may have changed caregivers' behavior. A parallel qualitative study on the acceptability of the intervention indicated that during the intervention caregivers stated that they were more likely to choose the CHW because they were aware that CHWs had diagnostics and free drugs and they were more likely to go where there were commodities instead of seeking other alternatives [24]. Second, there is evidence that early treatment of uncomplicated malaria reduces the risk of severe malaria and hence hospital referral and associated transport costs [8]. Nevertheless, some caretakers did not go to a CHW during the intervention (55\% in Burkina Faso, 32\% in Nigeria, and 56\% in Uganda). The main reasons were a belief that their child was not sufficiently sick, not being aware of the CHW presence in their community, or the CHW not being at home because of farm duties. Many participants in Uganda also mentioned stockout of drugs at the CHW during the intervention [24]. To ensure better use of CHWs and access to care at the community level, future implementations should aim to better sensitize communities, provide advance 
information of the presence of the CHWs and symptoms of malaria, and improve stock management. Compensation for CHWs' time might be explored as motivation for CHWs to be more available when needed.

The Global Fund from which most malaria-endemic countries apply for commodities has, during the past 5 years, indicated that essential items for malaria control can be secured through successful applications; these include training and salary costs for community health workers, RDTs for malaria diagnosis, ACTs for malaria treatment, supportive supervision, supply chain system strengthening, and health information system strengthening (http://www.rollbackmalaria.org/files/files/ resources/HWG-2014-country-briefing-note.pdf). The Global Fund still continues to encourage applicants to include community system strengthening initiatives in proposals wherever relevant to improve health outcomes (www.theglobalfund. org/documents/core/infonotes/Core_CSS_InfoNote_en/). Consequently, our results provide governments with an understanding of how the system can work in their countries in support of the role advocated by the Global Fund and provide a strong economic rationale for scaling up the intervention in underserved areas to improve the speed of malaria diagnosis and treatment. The main barriers that can be anticipated, as identified in this study, are underuse of CHWs because of a lack of awareness, financial constraints (mainly transport to a CHW), beliefs about the etiology of disease, and limited autonomy of caregivers.

Our study has several limitations. Perhaps the most important is that data on costs are for all febrile illnesses in children both before and during the intervention. Few RDTs were used before the intervention, and therefore, costs before the intervention would necessarily include any febrile illness. Consequently, the cost reduction could not exclude costs of managing nonmalaria illnesses. However, during the study, the vast majority of cases seen by CHWs were malaria-positive (81.2\%), and there were no differences in household costs per episode between malaria-positive and malaria-negative cases overall and separately in the 3 participating countries. Second, we kept cost calculations to documented costs provided by the caretaker for the episode of the child. We did not calculate the lost income due to time taken to look after the sick child. Third, in Burkina Faso, in the period before intervention, for cultural reasons, fathers of sick children answered the questionnaire as would be culturally normal in the district; during the intervention period, the study team explained that the primary caretaker, usually the mother, should answer questions. In the localities in which the study was conducted, it was probable that both parties might be present during the 
interview, but it is not possible to rule out bias in the answers provided on costs. Finally, all costs were based on interviews and were therefore dependent upon participants' recollection of costs incurred within the 2 weeks prior to interview.

\subsection{ACKNOWLEDGMENTS}

We thank the participants in this study and all interviewers for their collaboration in the collection of the data. We are also grateful to village leaders for their permission to carry the research in their communities, and appreciate the efforts of J. Bwoye, L. Ojanduru, G. Ouattara, B. Orimolade, A. Suberu, and J. Wandera who led fieldwork and provided intellectual and administrative support. L. Ojanduru was responsible for data management onsite. A. Adewale, M. Ainemukama, I. Akorede, H. Barigye, O. Kayode, M. Namanya, R. Ngabirano, O. Ojo, E. Oyeniran, P. Tou, and J. J. Wembabazi supported data entry. 


\section{REFERENCES}

1. World Health Organization. World malaria report 2015. Geneva: WHO; 2015.

2. World Health Organization. Severe malaria. Trop Med Int Health. 2014;19 Suppl 1:7-131.

3. World Health Organization. Guidelines for the treatment of malaria. $3^{\text {rd }}$ ed. Geneva: WHO; 2015.

4. Lubell Y, Reyburn H, Mbakilwa H, Mwangi R, Chonya K, Whitty CJ, et al. The costeffectiveness of parasitologic diagnosis for malaria-suspected patients in an era of combination therapy. Am J Trop Med Hyg. 2007;77(6 Suppl):128-32.

5. McIntyre D, Thiede M, Dahlgren G, Whitehead M. What are the economic consequences for households of illness and of paying for health care in low- and middle-income country contexts? Soc Sci Med. 2006;62:858-65.

6. D'Acremont V, Kahama-Maro J, Swai N, Mtasiwa D, Genton B, Lengeler C. Reduction of anti-malarial consumption after rapid diagnostic tests implementation in Dar es Salaam: a before-after and cluster randomized controlled study. Malar J. 2011;10:107.

7. de Savigny D, Mayombana C, Mwageni E, Masanja H, Minhaj A, Mkilindi Y, et al. Care-seeking patterns for fatal malaria in Tanzania. Malar J. 2004;3:27.

8. Tawfik Y, Nsungwa-Sabitii J, Greer G, Owor J, Kesande R, Prysor-Jones S. Negotiating improved case management of childhood illness with formal and informal private practitioners in Uganda. Trop Med Int Health. 2006;11:967-73.

9. Xu K, Evans DB, Kawabata K, Zeramdini R, Klavus J, Murray CJ. Household catastrophic health expenditure: a multicountry analysis. Lancet. 2003;362:111-7.

10. Mills A, Ataguba JE, Akazili J, Borghi J, Garshong B, Makawia S, et al. Equity in financing and use of health care in Ghana, South Africa, and Tanzania: implications for paths to universal coverage. Lancet. 2012;380:126-33.

11. Bhutta ZA, Lassi ZS, Pariyo G, Huicho L. Global experience of community health workers for delivery of health related Millennium Development Goals: a systematic review, country case studies and recommendations for integration into National Health Systems. Geneva: WHO/Global Health Workforce Alliance; 2010.

12. Haines A, Sanders D, Lehmann U, Rowe AK, Lawn JE, Jan S, et al. Achieving child survival goals: potential contribution of community health workers. Lancet. 2007;369:2121-31.

13. Sazawal S, Black RE, Pneumonia Case Management Trials Group. Effect of pneumonia case management on mortality in neonates, infants, and preschool children: a metaanalysis of community-based trials. Lancet Infect Dis. 2003;3:547-56.

14. Kidane G, Morrow RH. Teaching mothers to provide home treatment of malaria in Tigray, Ethiopia: a randomised trial. Lancet. 2000;356:550-5.

15. Gilroy K, Winch P. Management of sick children by community health workers: intervention models and programme examples. Geneva: UNICEF, WHO; 2006.

16. Sirima SB, Konaté A, Tiono AB, Convelbo N, Cousens S, Pagnoni F. Early treatment of childhood fevers with pre-packaged antimalarial drugs in the home reduces severe malaria morbidity in Burkina Faso. Trop Med Int Health. 2003;8:133-9. 
17. Ajayi IO, Nsungwa-Sabiiti J, Siribié M, Falade CO, Sermé L, Balyeku A, et al. Feasibility of malaria diagnosis and management in Burkina Faso, Nigeria, and Uganda: a community-based observational study. Clin Infect Dis. 2016;63 Suppl 5:S245-55.

18. Tiono AB, Kangoye DT, Rehman AM, Kargougou DG, Kaboré Y, Diarra A, et al. Malaria incidence in children in South-West Burkina Faso: comparison of active and passive case detection methods. PLoS One. 2014;9:e86936.

19. United Nations Children's Fund. UNICEF says malaria still number-one killer of children under five in Nigeria. [cited 2016 Jul 6]. Available from: http://www.unicef. org/nigeria/media_4221.html.

20. Orem JN, Kirigia JM, Azairwe R, Kasirye I, Walker O. Impact of malaria morbidity on gross domestic product in Uganda. Int Arch Med. 2012;5:12.

21. Ministère de l'Economie et des Finances, Comité National du Recensement, Bureau Central du Recensement. Recensement Général de la Population et de l'Habitation (RGPH) de 2006 du Burkina Faso-Résultats définitifs. Burkina Faso, 2008. [cited 2016 Jul 16]. Available from: http://www.insd.bf/documents/publications/insd/ publications/resultats_enquetes/autres\%20enq/Resultats_definitifs_RGPH_2006. pdf.

22. Federal Republic of Nigeria, National Population Commission. 2006 population and housing census, priority table volume IV, population distribution by age and sex (state and local government area). [cited 2016 Jul 12]. Available from: http:// www.population.gov.ng/index.php/publications/141-population-distribution-byage-and-sex2006-census-priority-tables-vol-4.

23. Uganda Bureau of Statistics. National population and housing census 2014 - main report. Kampala, 2016. [cited 2016 Jul 16]. Available from: http://www.ubos.org/ onlinefiles/uploads/ubos/NPHC/2014\%20National\%20Census\%20Main\%20 Report.pdf.

24. Jegede AS, Oshiname FO, Sanou AK, Nsungwa-Sabiiti J, Ajayi IO, Siribié M, et al. Assessing acceptability of a diagnostic and malaria treatment package delivered by community health workers in malaria-endemic settings of Burkina Faso, Nigeria, and Uganda. Clin Infect Dis. 2016;63 Suppl 5:S306-11. 


\section{SUPPLEMENTARY INFORMATION}

S1 Table. Reasons for not going to a CHW during the intervention.

\begin{tabular}{|c|c|c|c|c|c|c|c|c|}
\hline \multirow[t]{2}{*}{$\begin{array}{l}\text { Main reasons for not going to a } \\
\text { CHW }^{\mathrm{a}}\end{array}$} & \multicolumn{2}{|c|}{$\begin{array}{l}\text { Burkina } \\
\text { Faso }\end{array}$} & \multicolumn{2}{|c|}{ Nigeria } & \multicolumn{2}{|c|}{ Uganda } & \multicolumn{2}{|c|}{ Total } \\
\hline & $\mathbf{N}$ & $\%$ & $\mathbf{N}$ & $\%$ & $\mathbf{N}$ & $\%$ & $\mathbf{N}$ & $\%$ \\
\hline $\begin{array}{l}\text { No. of respondents who did not go } \\
\text { to a trained CHW/health worker }\end{array}$ & 739 & - & 251 & - & 603 & - & 1,593 & - \\
\hline Not aware of the presence of CHW & 78 & 11 & 6 & 2 & 120 & 20 & 204 & 13 \\
\hline CHW lives too far away & 48 & 6 & - & - & 39 & 6 & 87 & 5 \\
\hline CHW often not at home & 36 & 5 & 1 & 0 & 73 & 12 & 110 & 7 \\
\hline Afraid that cannot pay & 10 & 1 & 7 & 3 & 3 & 0 & 20 & 1 \\
\hline Child was not too sick & 232 & 31 & 21 & 8 & 30 & 5 & 283 & 18 \\
\hline CHW cannot treat well & 92 & 12 & 1 & 0 & 28 & 5 & 121 & 8 \\
\hline Not satisfied with previous treatment & 1 & 0 & - & - & 9 & 1 & 10 & 1 \\
\hline $\begin{array}{l}\text { Prefer traditional medicine for those } \\
\text { symptoms }\end{array}$ & 73 & 10 & 2 & 1 & 5 & 1 & 80 & 5 \\
\hline Don't like the drugs given by CHW & 2 & 0 & - & - & 7 & 1 & 9 & 1 \\
\hline I was too busy or sick & 10 & 1 & 9 & 4 & 6 & 1 & 25 & 2 \\
\hline Not allowed from husband/elders & 16 & 2 & - & - & 6 & 1 & 22 & 1 \\
\hline Others & 301 & 41 & 38 & 15 & 306 & 51 & 645 & 40 \\
\hline Missing & 9 & 1 & 178 & 71 & 35 & 6 & 222 & 13 \\
\hline
\end{tabular}

Abbreviation: $\mathrm{CHW}$ community health worker.

${ }^{a}$ A multiple choice question. Most of the participants in Nigeria did not answer this question as this question was added at a later stage.

${ }^{\mathrm{b}}$ In Nigeria, CHWs as well as shop owners were trained as part of the intervention. 


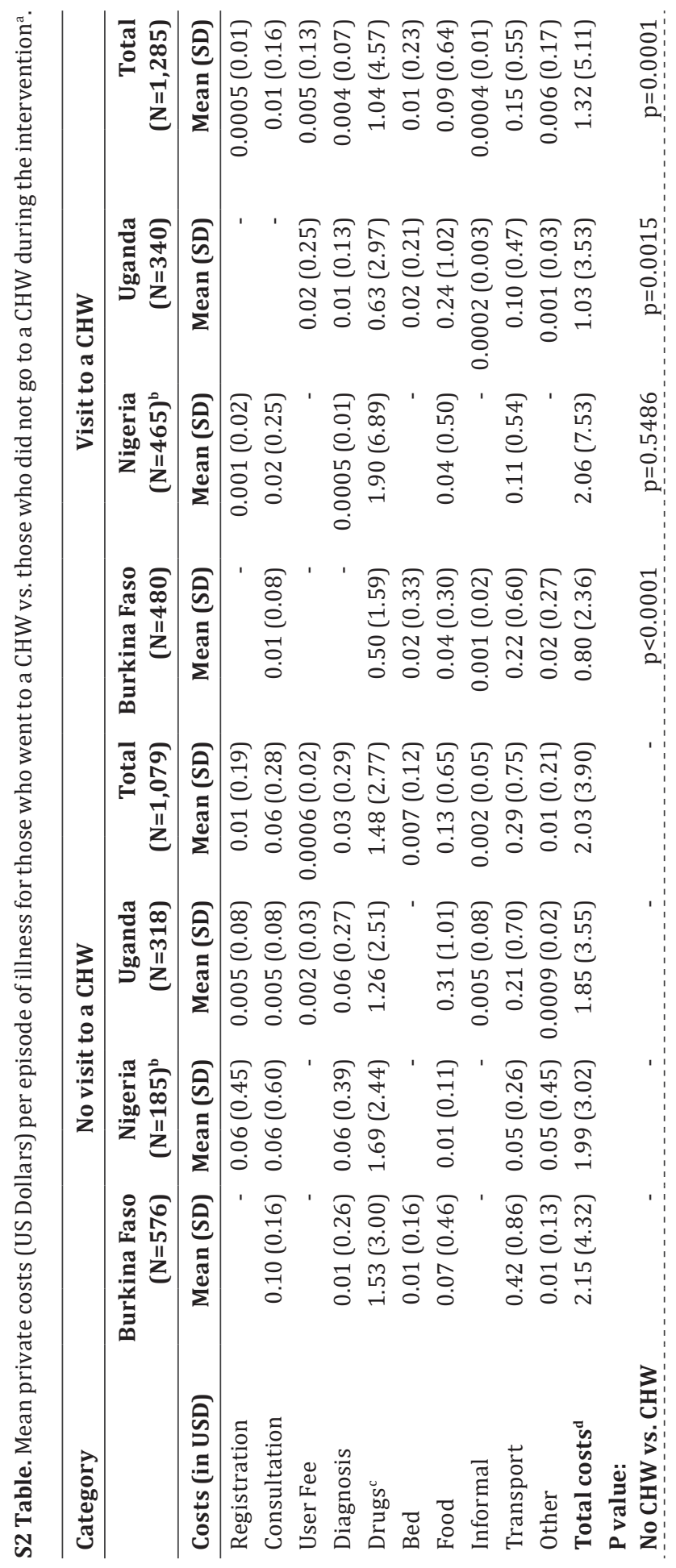




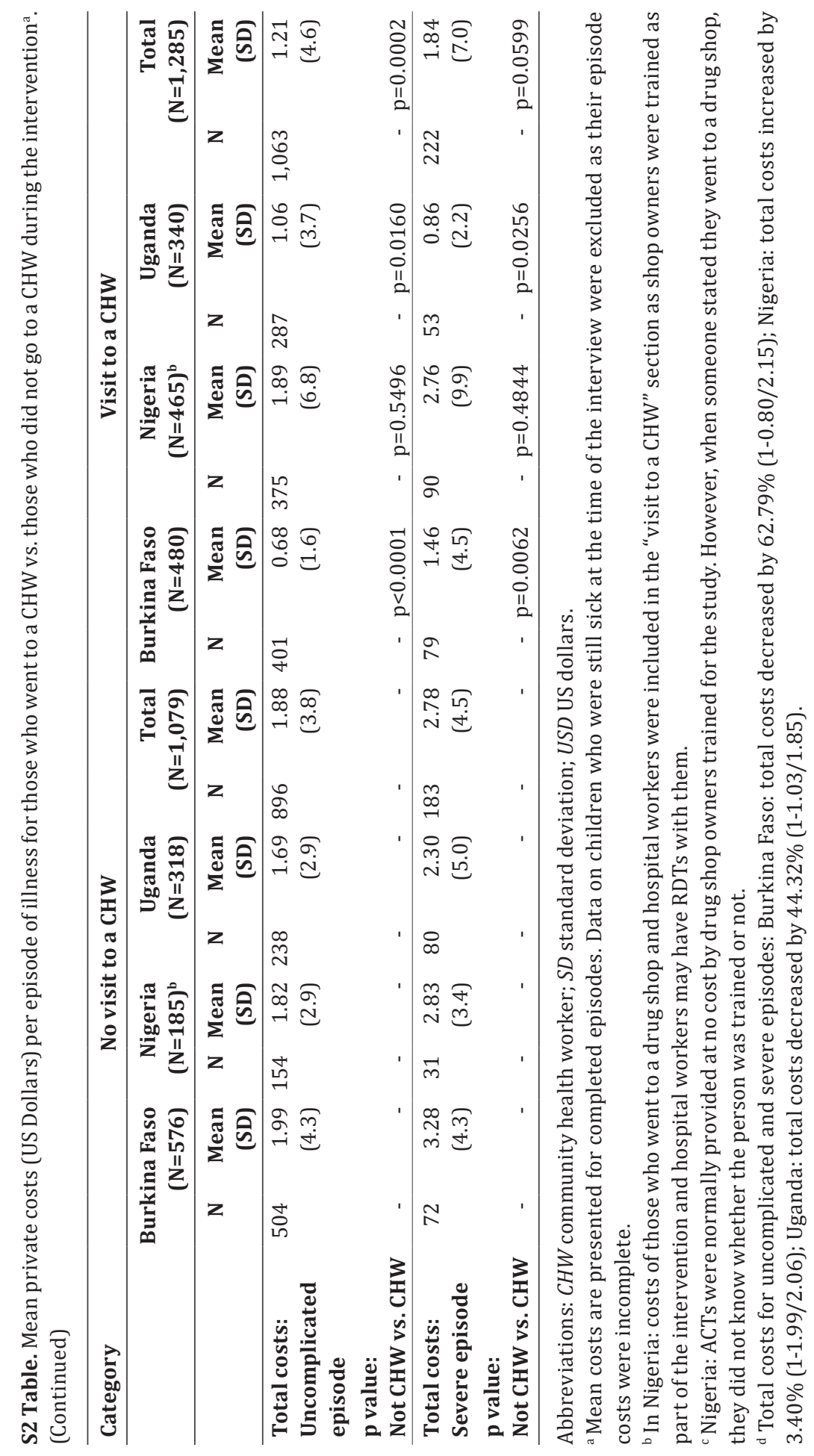




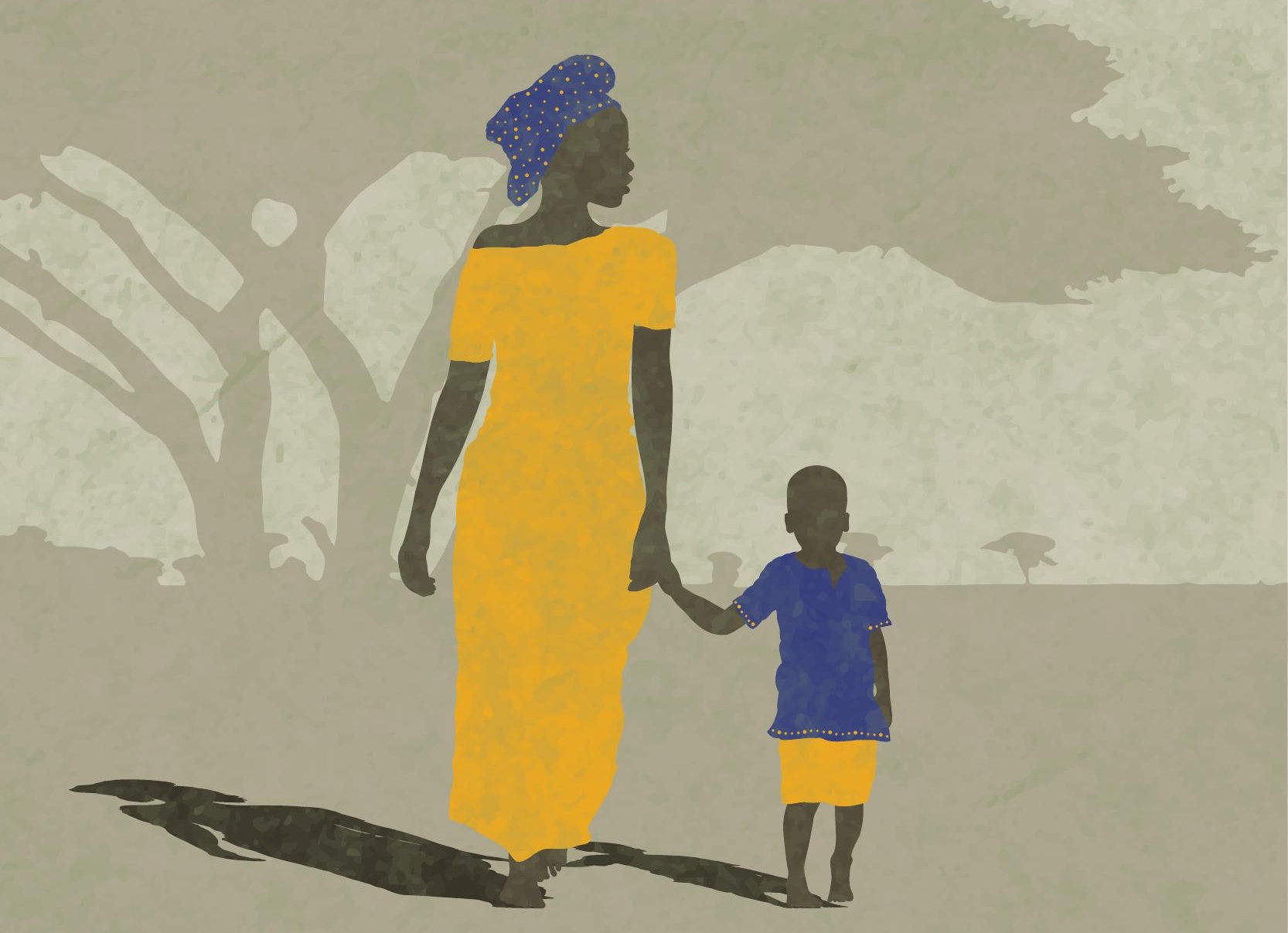




\section{CHAPTER 5}

\section{HOUSEHOLD COSTS AND TIME TO TREATMENT FOR CHILDREN WITH SEVERE FEBRILE ILLNESS IN RURAL BURKIMA FASO: THE ROLE OF RECTAL ARTESUMATE}

\section{Published as:}

Castellani J, Mihaylova B, Siribié M, Gansane Z, Ouedraogo AZ, Fouque F, Sirima SB, Evers SMAA, Paulus ATG, Gomes M. Household costs and time to treatment for children with severe febrile illness in rural Burkina Faso: the role of rectal artesunate. Malar J. 2018;17:380. 


\section{ABSTRACT}

\section{Background}

Community health workers (CHWs) were trained to identify children with malaria who could not take oral medication, treat them with rectal artesunate (RA) and refer them to the closest healthcare facility to complete management. However, many children with such symptoms did not seek CHWs' care. The hypothesis was that the cost of referral to a health facility was a deterrent. The goal of this study was to compare the out-of-pocket costs and time to seek treatment for children who sought CHW care (and received RA) versus those who did not.

\section{Methods}

Children with symptoms of severe malaria receiving RA at CHWs and children with comparable disease symptoms who did not go to a CHW were identified and their parents were interviewed. Household out-of-pocket costs per illness episode and speed of treatment were evaluated and compared between RA-treated children vs. non-RA treated children and by central nervous symptoms (CNS: repeated convulsions, altered consciousness or coma).

\section{Results}

Among children with CNS symptoms, costs of RA-treated children were similar to those of non-RA treated children ( $\$ 5.83$ vs. $\$ 4.65 ; \mathrm{p}=0.52$ ), despite higher transport costs ( $\$ 2.74$ vs. $\$ 0.91 ; p<0.0001)$. However, among children without CNS symptoms, costs of RA-treated children were higher than the costs of non-RA treated children with similar symptoms ( $\$ 5.62$ vs. $\$ 2.59 ; \mathrm{p}=0.0001$ ), and the main driver of the cost difference was transport. After illness onset, CNS children reached CHWs for RA an average of $9.0 \mathrm{~h}$ vs. $16.1 \mathrm{~h}$ for non-RA treated children reaching first treatment [difference $7.1 \mathrm{~h}$ (95\% CI -1.8 to 16.1), p=0.11]. For non-CNS patients the average time to CHW-delivered RA treatment was $12.2 \mathrm{~h}$ vs. $20.1 \mathrm{~h}$ for those reaching first treatment [difference $7.9 \mathrm{~h}$ (95\% CI 0.2-15.6), p=0.04]. More non-RA treated children developed CNS symptoms before arrival at the health centre but the difference was not statistically significant ( $6 \%$ vs. $4 \%$; $=0.58$ ).

\section{Conclusions}

Community health worker-delivered RA does not affect the total out-of-pocket costs when used in children with CNS symptoms, but is associated with higher total out-of-pocket costs when used in children with less severe symptoms. RAtreated children sought treatment more quickly. 


\section{1 BACKGROUND}

Children with severe disease deteriorate rapidly and die. Malaria deaths can be prevented by prompt treatment. Rectal artesunate (RA) is effective in preventing malaria deaths when given to children with danger signs (defined as inability to eat, drink or breastfeed, repeated vomiting, lethargy, convulsions, altered consciousness or coma) [1,2] together with a referral to the nearest hospital to complete management [3].

The World Health Organization's strategy for child survival, the Integrated Management of Childhood Illness (WHO-IMCI), focuses on the major childhood causes of mortality, including malaria $[2,4,5]$. In the community component of this strategy (often referred to as integrated community case management (iCCM) [6]), several interventions have been implemented to improve access to health care for children living in poor and remote areas [7]. In malaria endemic areas, under iCCM, community health workers (CHWs) are trained to recognize children with danger signs, to diagnose, and, if malaria positive, to treat with RA and refer the child to the closest healthcare facility for further management $[5,8]$.

Studies have investigated why children with uncomplicated fever, malaria or childhood illness in rural settings do not seek care at a CHW [9-14]. Often the symptoms were not perceived as severe and warranting CHW intervention [12, 14], drugs were out-of-stock [11-13], or parents had more confidence in the health centres and their drug supplies, personnel and training $[11,13,14]$. Research examined fatal episodes and utilization of CHWs/modern biomedical care during severe fatal illness in Ethiopia, Uganda and Tanzania [15-17]. In the Ethiopian study [15], delays in seeking care were attributed to the waxing and waning of children's symptoms which delayed seeking care, and inadequate knowledge about the need for early diagnosis and treatment whereas in the Tanzanian study the majority (78.7\%) sought modern biomedical care, often from more than one provider; CHWs were not mentioned [17]. In both Uganda and Tanzania caregivers sought facility care [16,17] with a minority using traditional care [17]. Other studies have reported that the majority of children who either die from severe illness or whose illness was recognized as being severe by the caregiver did not receive adequate treatment $[18,19]$, with one of the studies attributing this partially to the caregivers' inability to pay for the costs of transport and treatment at a facility [19]. Household and health system costs of malaria episodes (uncomplicated or severe) have been estimated and modelled for 3 African countries showing that 
malaria household costs increase with disease severity and hospitalization [20]. Unfortunately, as pointed out in a 2003 review of the economic costs of malaria [21], direct information on household costs of severe malaria is lacking, partly because the condition is rare, making it difficult to obtain data through representative household surveys in a community, and because its symptoms (e.g. convulsions, loss of consciousness) may not lead to the condition being reported as malaria.

For children with severe illness, understanding the speed of treatment and referral is essential as delays in seeking care for severe malaria are associated with higher risk of death. Such a study also provides an important indicator of the quality of malaria interventions where the goal is to achieve malaria treatment within $24 \mathrm{~h}$. However little is known about the speed of seeking treatment at CHWs or compliance with referral advice. One study reported that $1 / 3$ of children who were urgently referred by drug distributors experienced delays of more than $24 \mathrm{~h}$ [22].

Illness episodes impose costs on carers of sick children and these anticipated costs might influence their health-seeking behaviour. While several studies have assessed the out-of-pocket costs of an episode of severe illness [23-26], there is no information on the out-of-pocket costs of households when RA is used and whether these costs might act as a deterrent. One study evaluated the cost-effectiveness of RA [27] and another assessed the out-of-pocket and societal costs for children who completed referral in an area where CHW-delivered RA was used [28]. A further study reported that children who received RA had poor adherence to referral to fee-based facilities [29]. The goal of this study was thus to evaluate household out-of-pocket costs for an episode of severe illness in children who received CHWdelivered RA compared to similar illness episodes in children who did not seek CHW's care.

\subsection{METHODS}

\subsubsection{Study area and population}

The study was undertaken in Burkina Faso and was nested within an intervention implementing malaria rapid diagnosis tests (RDTs) and oral and RA malaria treatment in malaria endemic villages via CHWs in the rural area of Sidéradougou, Mangodara District in 2015 [30].

For this study, children who received CHW-delivered RA-treatment and children who did not were identified, and the out-of-pocket costs incurred by their families, 
clinical outcomes (i.e. deterioration to CNS symptoms by arrival at health centre) and the time from illness onset to treatment were compared. By definition, children who did not receive RA did not attend a CHW for diagnosis and treatment. Comparisons were made between children with similar illness severity (such as repeated vomiting, lethargy, convulsions or altered consciousness/coma), but there was no attempt to sample similar number of children in different categories.

Guardians of children 6-59 months of age in the intervention villages with a fever in the past 2 weeks were randomly selected for interview without knowledge of whether the children had uncomplicated or severe illness or sought CHW care [30]. Households without sick children, whose caregiver was not present during the illness or refused consent were excluded from interview.

Children with similar symptoms to RA-treated children, who did not seek CHW help, were identified from these random household sampling surveys and only illness episodes which had completed at the time when the parent or carer was questioned about out-of-pocket costs were included in the analysis. 1,342 household interviews were conducted [30], but only 72 severe episodes contributed to this analysis by meeting the eligibility criteria of a completed illness episode in a child with danger signs warranting RA treatment, but where RA treatment was not sought (Fig. 1). Households were asked questions regarding the illness symptoms, treatment-seeking behaviour (healthcare providers visited, date and clock time visited, treatments provided) and the associated out-of-pocket costs.

Identical data on illness, treatment-seeking behaviour and costs was obtained from RA-treated children 6-59 months, who were identified from the CHWs' treatment record forms. A total of 139 children received RA in Burkina Faso, 134 of whom were alive at the end of the episode (Fig. 1) [30]. At the time of study interviews (mid-2016), a further 11 children had died (and were excluded from the study as it was considered culturally insensitive to seek out-of-pocket cost data after a death); 23 children had moved residence and were lost to follow up; and one child was inappropriately treated with RA. Thus, study data on a total of 99 RA-treated children with danger signs during illness episode was available. 


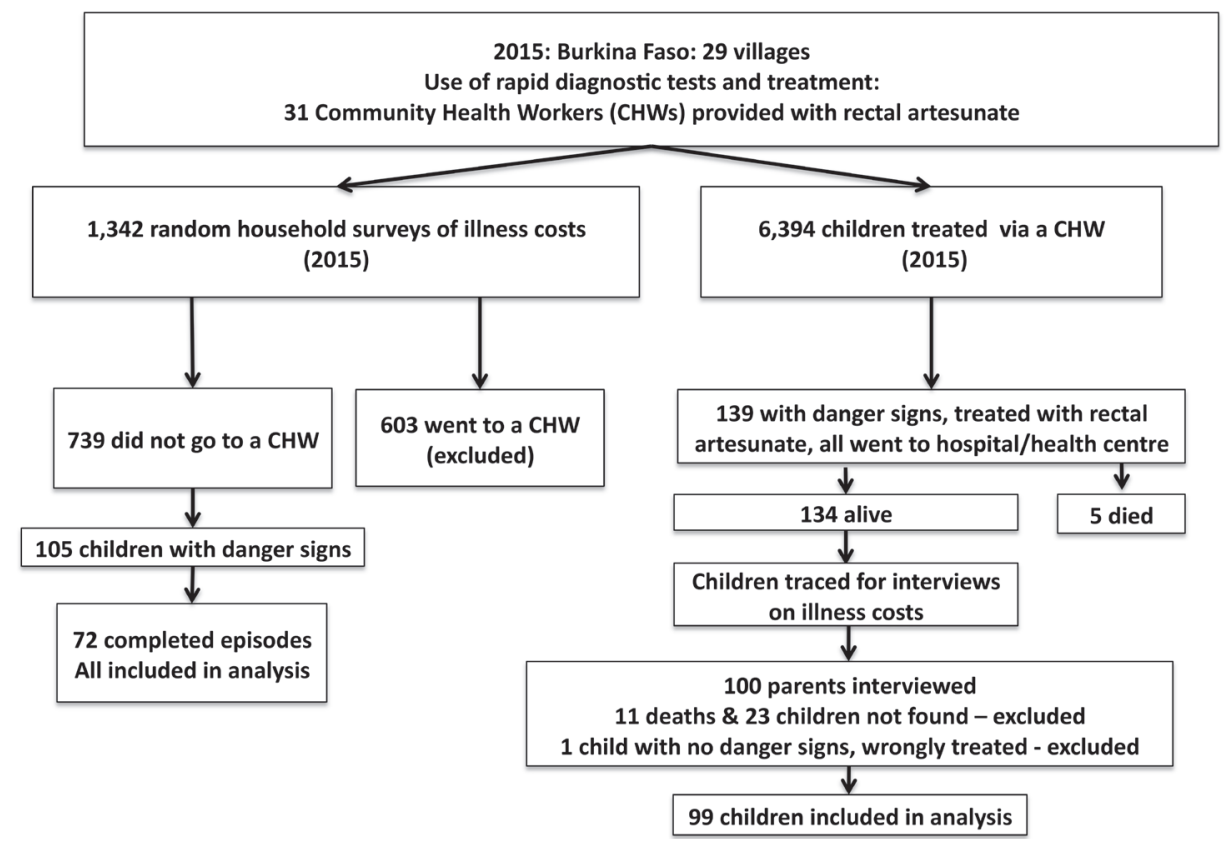

Figure 1. Identifying children with danger symptoms who received or not rectal artesunate.

\subsubsection{Healthcare provision in the study area}

In Burkina Faso, the "Centre de santé et de promotion sociale (CSPS)" is the first level of care for patients. CSPS are managed by nurses in outpatient facilities. Patients needing specialized care are referred to a "centre médical" (health centre) where admission and supervision by medical doctors is available; referral to the regional hospital occurs if required. There is only one health centre in the study area. However, there are many traditional healers, CHWs, dispensaries/CSPS, and drug hawkers in addition to shops and pharmacies which sell quinine, antibiotics and anti-malarials (excluding the artemisinin derivatives) without prescription.

At the time of the study, health care provided at public facilities was fee-based. The cost of consultation was about 200 West African CFA francs (XOF; US Dollars [USD] \$0.33) and when admitted, the patient had to pay for their bed; no other costs were charged to the patient.

\subsubsection{CHW training}

As part of the intervention, CHWs were trained to diagnose malaria using RDTs at no cost to the patient, recognize severe illness (where children were unable to take oral medication and had "danger signs" requiring immediate attention inability to eat, drink or suck; repeated vomiting; lethargy; convulsions or altered 
consciousness/coma) and treat malaria positive patients. For children with danger signs, free RA was provided, and all RA-treated patients were referred to the closest healthcare facility for further management, with an explanation of the importance of reaching the facility quickly, to complete patient management.

Community health worker training was in accordance with WHO Guidelines on IMCI which require that children with fever or a history of fever within the previous $24 \mathrm{~h}$ are assessed by a CHW. Training lasted 3 days and was evaluated through pre- and post-tests [31]. $31 \mathrm{CHWs}$ passed certification for delivery of RA in 29 rural villages [30].

\subsubsection{Questionnaires and data}

Case report forms (CRFs) were developed in French and pilot tested before use. In CRFs, information was sought about the characteristics of the child and households (sex, age, education, occupation, household food scarcity, the number of working people over 10 years old), the date and clock time from onset of each symptom, the date and clock time of visit (for each provider visited) and the out-of-pocket costs associated with each visit. Guardians provided detail about the costs incurred at each healthcare provider for registration, consultation, diagnosis, drugs, bed, food/drinks and transport [14, 24-26]. All data were reported by the guardians from memory and the same interviewers were used for all household interviews to minimize interviewers' bias. Identical information on illness, treatment-seeking behaviour and household costs was obtained for RA-treated and non-RA treated patients. However, interviews for RA-treated patients did not occur within 2 weeks of the episode, but at the end of the intervention period.

\subsubsection{Data analysis}

For both RA and non-RA treated children, their illness symptoms were classified into cerebral symptoms involving the central nervous system (CNS - convulsions, coma or altered consciousness) and non-CNS symptoms (lethargy and/or repeated vomiting). Baseline characteristics, the out-of-pocket costs and the duration of time from onset of symptoms to seeking treatment were compared between RA and non-RA treated children categorized by CNS status.

\section{Out-of-pocket costs}

Only direct out-of-pocket costs from onset of illness to recovery were collected and analysed. The opportunity cost of time taken by guardians to look after the child was beyond the scope of the study. In a sensitivity analysis, the costs of 
non-RA treated patients who attended a health centre were also analysed. All data on costs were collected in XOF and were converted and presented in USD using the average exchange rate between April and October 2015: 1 USD = 598.09 XOF (http://www.oanda.com).

\section{Time delays in seeking treatment}

Because children with severe malaria deteriorate fast and die, time delays were calculated from clock times and dates provided by carers on the clinical course of illness and actions taken. From the clock times and dates reported by the main caregiver of the child, the duration of delay (in hours) was calculated: from onset of illness to arrival at 1st modern healthcare provider outside the home (CHWs, drug shops, dispensaries, health centres) and from onset of illness (and onset of danger signs) to arrival at the health centre. The time from administration of RA to arrival at health centre was calculated.

\section{Deterioration}

For both groups, deterioration was defined as the onset of CNS symptoms [32] prior to arrival at the health centre after a visit to a healthcare provider. For children in the RA-treatment group, this provider was the CHW.

\subsubsection{Statistical methods}

Data were double entered in EpiData 3.1 and analysed using Stata software, version 13.0 (StataCorp, College Station, Texas). A Student t-test was performed on the equality of means and a test of proportion on the equality of proportion with a level of significance of $\mathrm{p}=0.05$ and a confidence level of $95 \%$, and either a test for heterogeneity or a linear trend of odds (if there were more than two ordered groups) was used to compare baseline characteristics of those who received RA vs. those who did not, by CNS status.

\subsubsection{Ethics approval and consent to participate}

The research protocol was approved by the National Ethics Committee for the Research on Health and the National Regulatory Authority in Burkina Faso, and the World Health Organization Research Ethics Review Committee. Individual written informed consent was obtained from each guardian prior to interview. 


\subsection{RESULTS}

\subsubsection{Baseline characteristics}

Table 1 presents the baseline characteristics of the children, caregivers and illness episodes for RA-treated children and non-RA treated children by CNS status. Most children in both RA and non-RA groups were less than 36 months of age $(86.9 \%$ RA; $59.7 \%$ non-RA). More than $75 \%$ of the guardians had no education and for the remaining, although not statistically significant, the guardians of RA-treated children were more educated than the guardians of non-RA treated children (e.g.: $2.0 \%$ RA vs. $0.0 \%$ non-RA treated guardians reported having $>7$ years of education).

Most households' income was derived from agriculture (99.0\% RA; 56.9\% nonRA) but in $38.9 \%$ of the households of non-RA treated children, income was based on self-employment. RA-treated children went to a larger number of "modern" providers ( $>1$ provider: $100.0 \%$ RA vs. $1.4 \%$ non-RA), lived in households with higher number of working people ( $>5$ working people: $17.1 \%$ RA vs. $2.8 \%$ nonRA), but lacked more food than non-RA families (household food scarcity: often or always: $24.2 \%$ RA vs. $0.0 \%$ non-RA). Finally, most of the guardians (in both groups) spent less than 5 days in caring for their sick child (85.9\% RA; $95.8 \%$ non-RA).

\subsubsection{Household out-of-pocket costs for illness episode}

All RA-treated patients incurred some costs during the illness episode (S1 Table). In the non-RA treated group, $83 \%$ of the patients with CNS and $77 \%$ without CNS incurred some costs, but in the case of non-RA treated children who went to a health centre, they all incurred costs mainly because they paid for transport to the facility (87\%), and the remaining $13 \%$ who did not incur transport costs paid for medications.

Table 2 presents the household costs by cost category, for those who sought CHW care and were treated with RA and those who did not, by CNS status. Among patients who were not treated with RA, costs are presented also separately for those who went to a health centre. All patients treated with RA delivered by a CHW were referred to the health centre and all of them completed subsequent referral. 


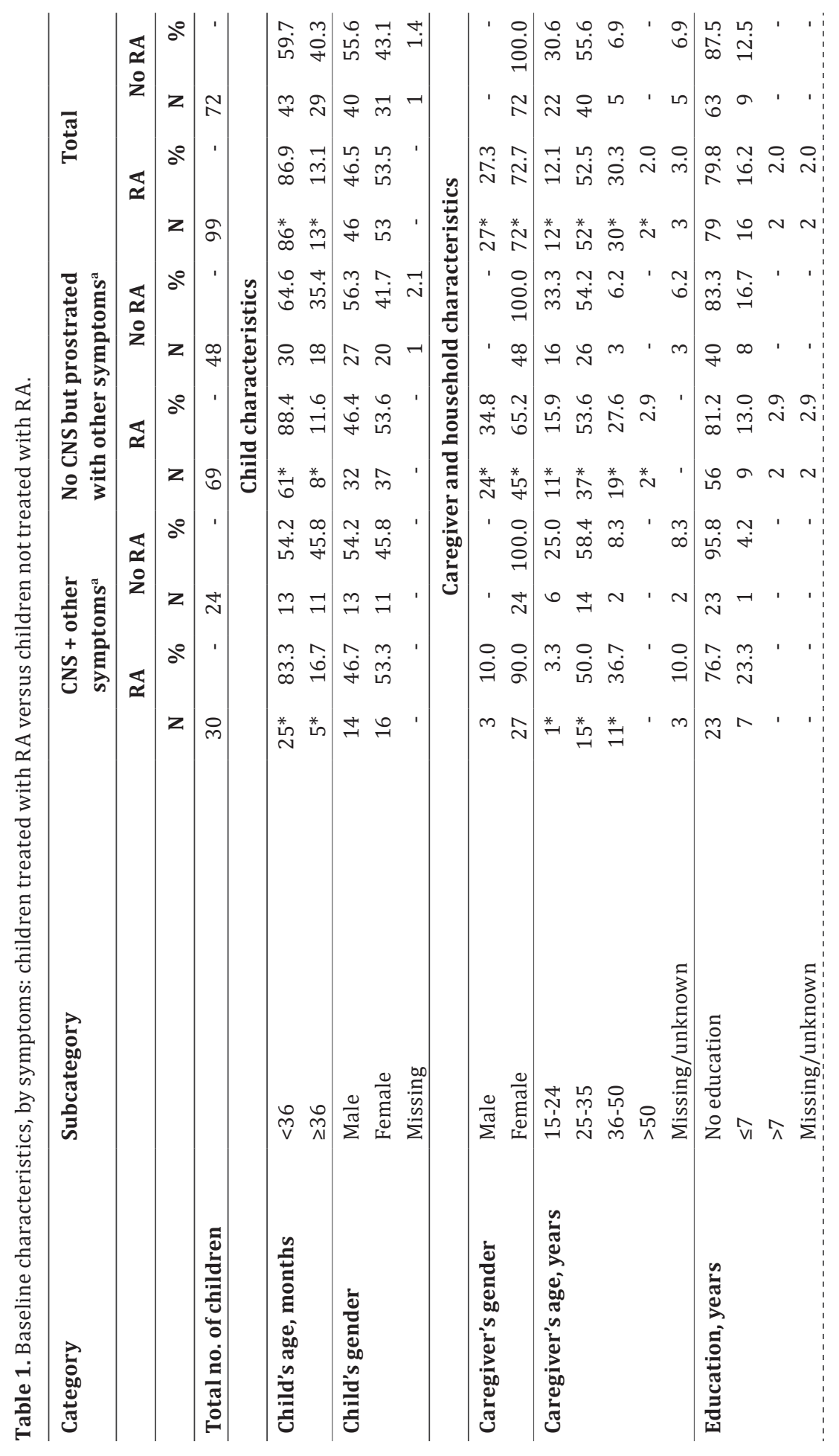




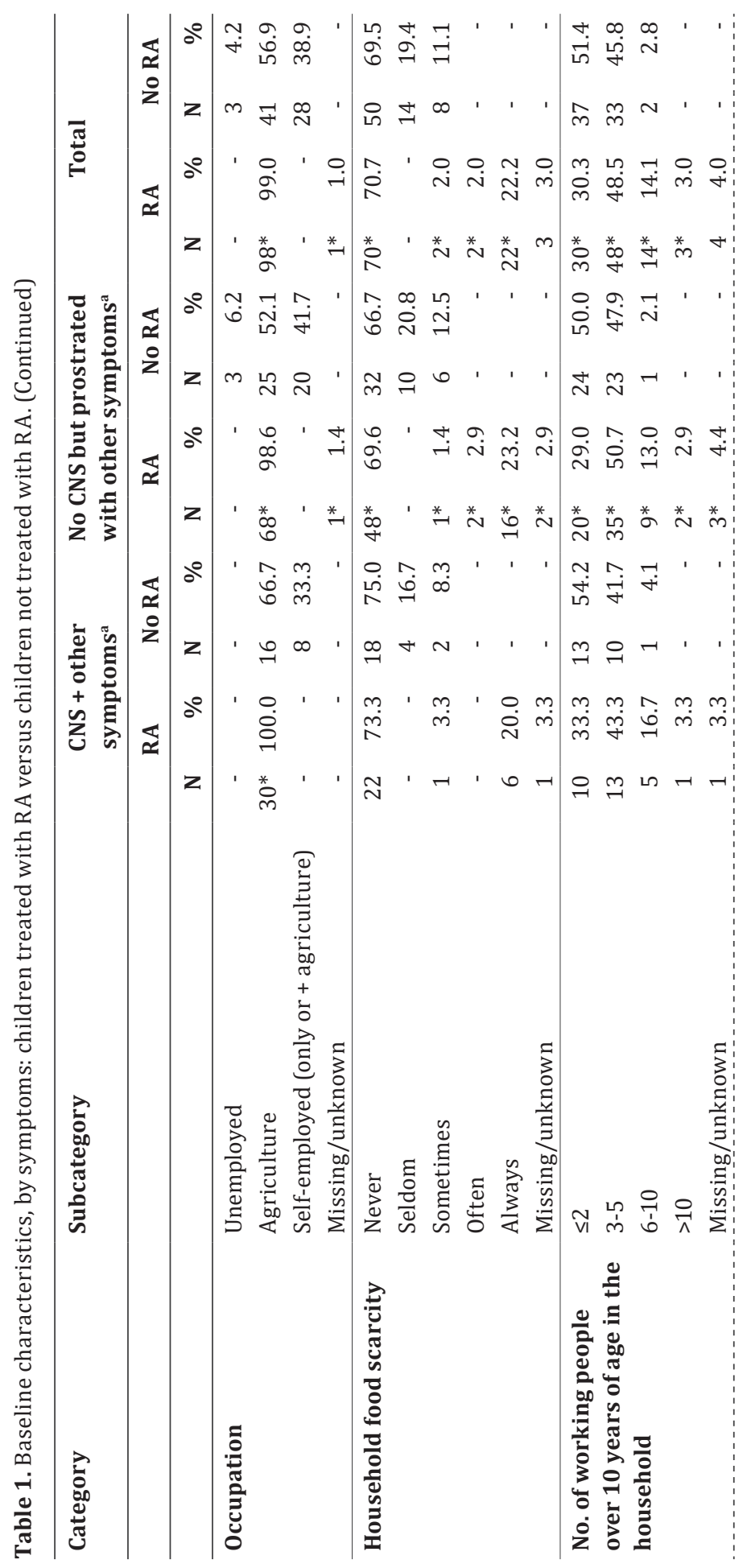




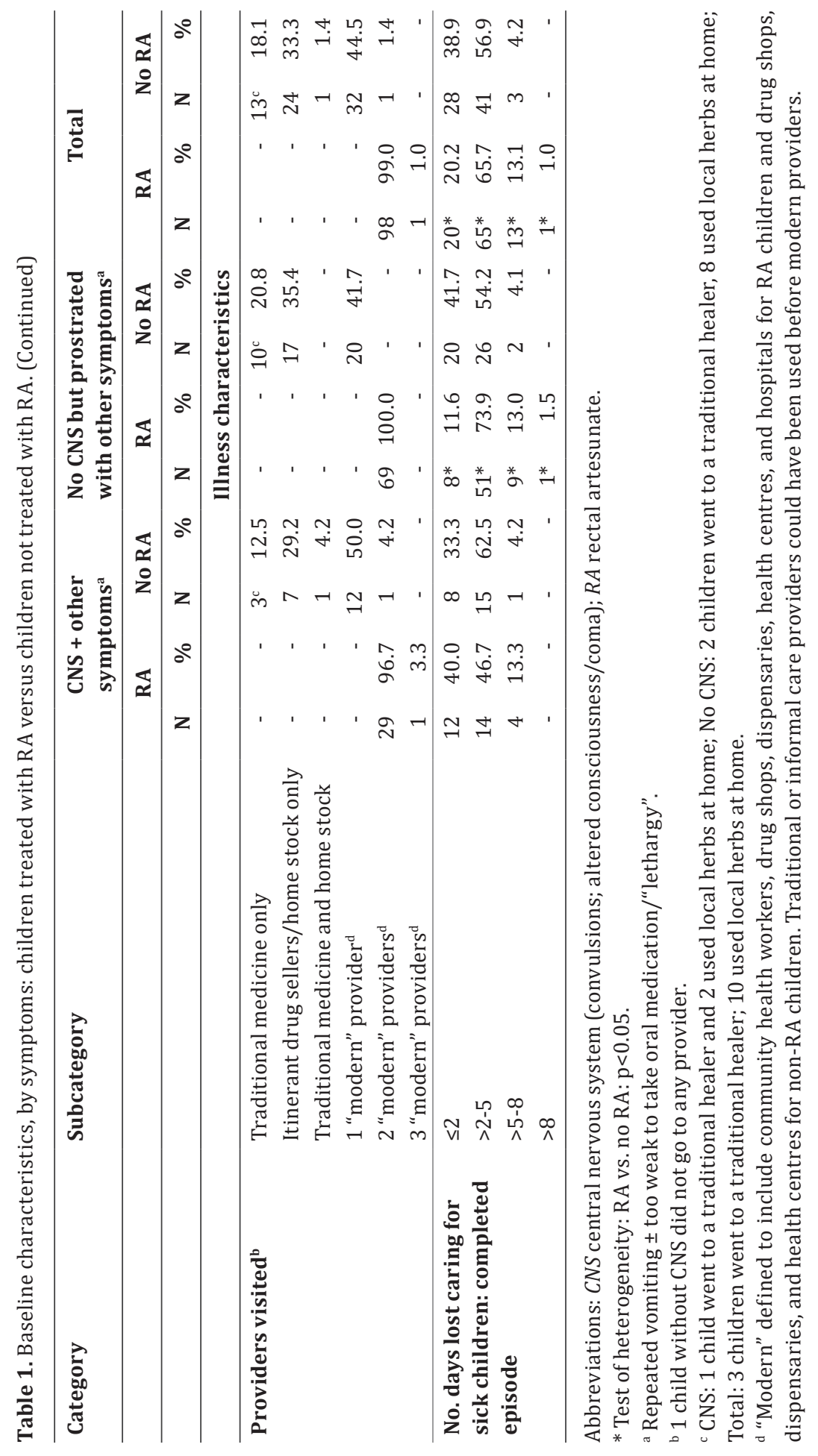




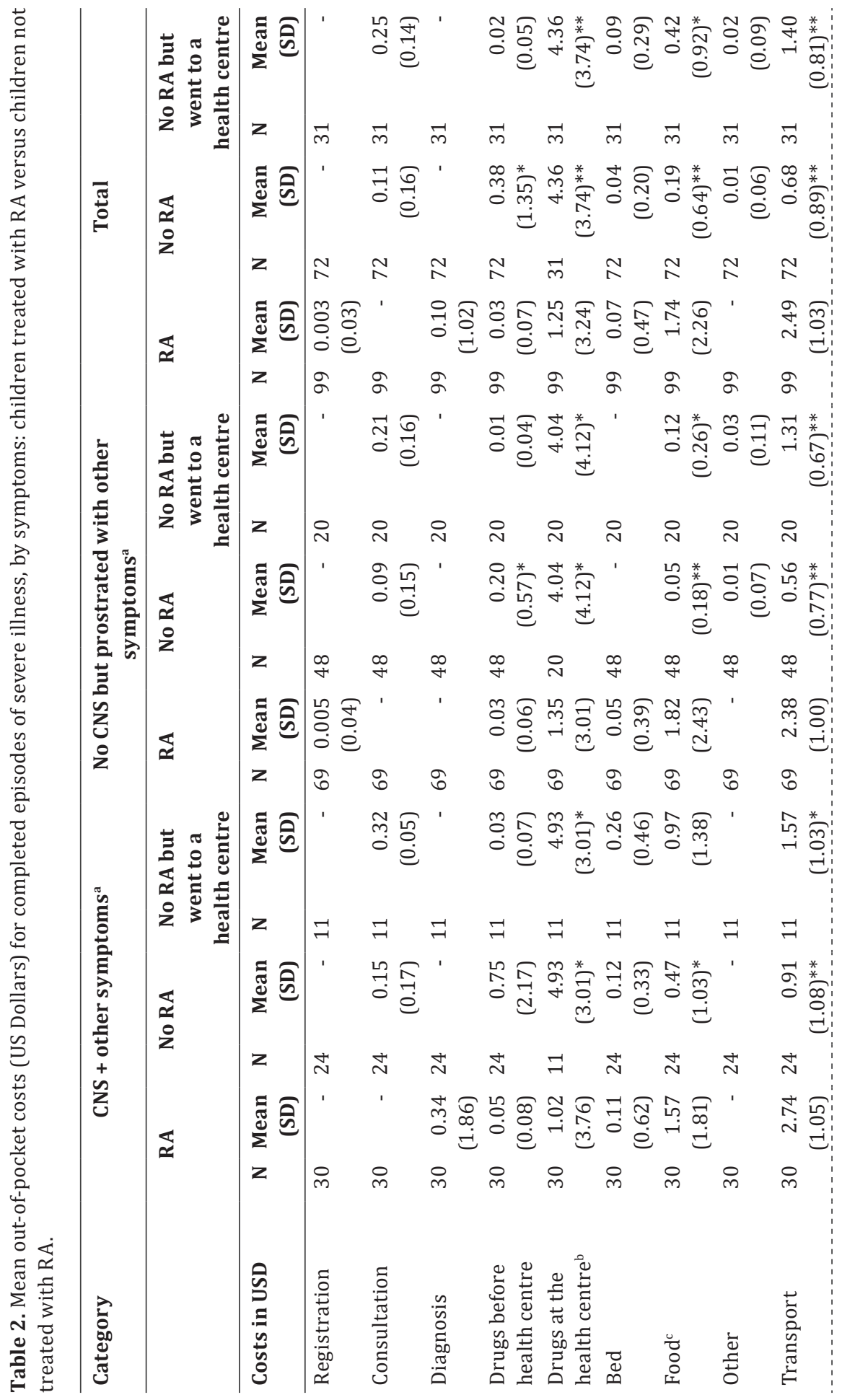




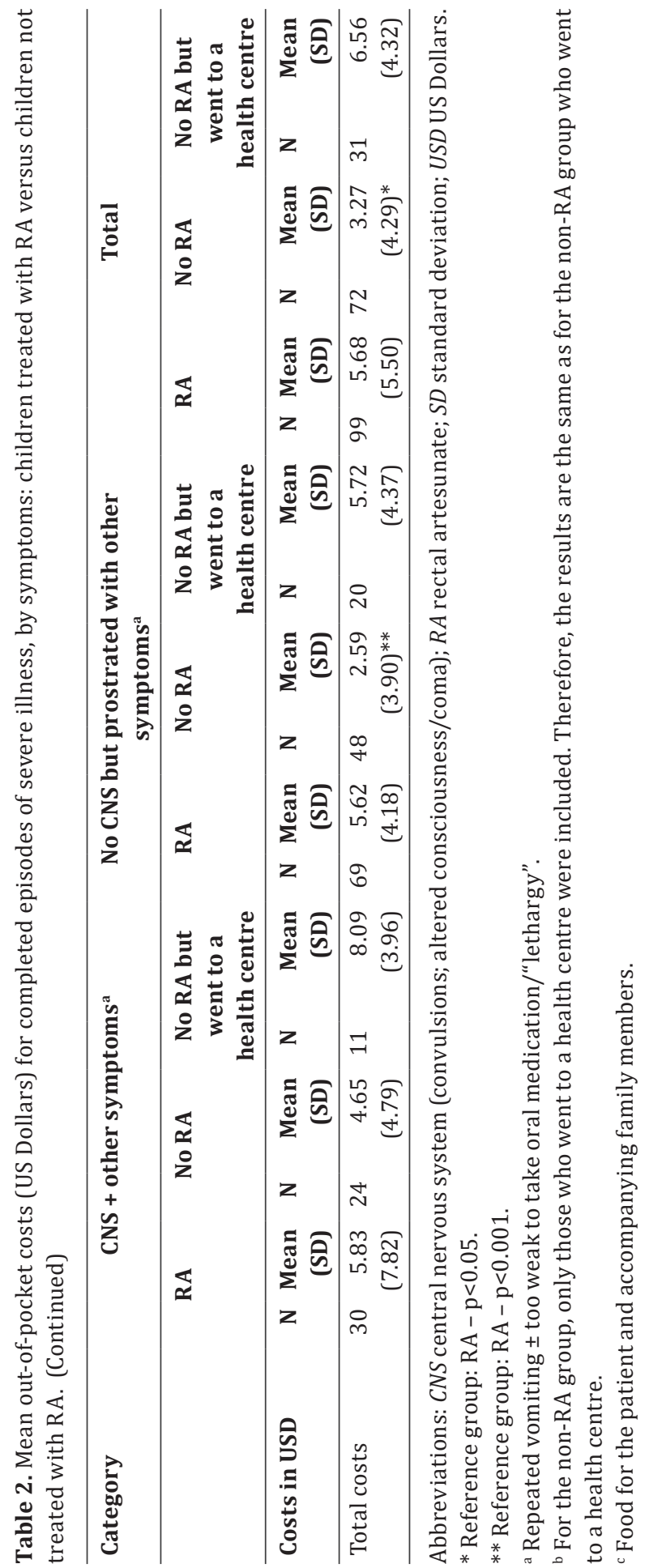




\section{Total costs}

For CNS patients, total costs were similar for RA-treated and non-RA treated patients, regardless of whether the latter went to a health centre ( $\$ 5.83$ vs. $\$ 4.65$ $\mathrm{p}=0.52$ ) (Table 2). For non-CNS patients, RA-treated children incurred significantly higher total costs than non-RA treated children and the main driver of the cost difference was transport to a health centre and/or to a CHW: Total costs for nonCNS children: $\$ 5.62$ for RA-treated vs. $\$ 2.59$ for non-RA treated [difference $\$ 3.03$ (95\% CI 1.51-4.54), $\mathrm{p}=0.0001]$. For patients who went to a facility, there was no significant difference in costs between RA-treated and non-RA treated patients.

\section{Transport costs}

Children treated with RA had significantly higher mean transport costs than children who were not because all RA-treated children completed referral at the health centre (Table 2). Transport was between 3 and 4.25 times higher for the RA group compared with all patients in the non-RA group, but only 1.7 times higher compared with the non-RA children who went to a facility. For CNS children the average transport cost was $\$ 2.74$ for RA-treated patients vs. $\$ 0.91$ for non-RA treated patients [difference $\$ 1.83$ (95\% CI 1.25-2.42); $\mathrm{p}<0.0001$ ] and for non-CNS children, the transport cost was $\$ 2.38$ for RA-treated patients vs. $\$ 0.56$ for non-RA treated patients [difference $\$ 1.82$ (95\% CI 1.48-2.16), $\mathrm{p}<0.0001$ ]. For CNS patients who went to a facility the transport cost difference was just over one US dollar between the 2 groups: $\$ 2.74$ for RA-treated patients vs. $\$ 1.57$ for non-RA treated patients [difference $\$ 1.17$ (95\% CI 0.42-1.91), $\mathrm{p}=0.0031$ ]. For non-CNS patients who went to a facility the difference was similar: $\$ 2.38$ vs. $\$ 1.31$ or $\$ 1.07$ difference [(95\% CI 0.59-1.54), $\mathrm{p}<0.0001]$.

\section{Drug costs}

It is important to note that non-RA treated patients who went to the single referral health centre in the District had higher mean drug costs at the facility than RA patients (Table 2). In general, drug costs at the facility constituted around $66 \%$ of the total episode costs for non-RA patients and 22\% for the RA group. For CNS patients who went to a health centre the drug cost difference was \$3.91: \$1.02 vs. $\$ 4.93$ [(95\% CI 1.36-6.47), p=0.0036]. For non-CNS patients the difference was lower, but still significant \$2.69: \$1.35 vs. \$4.04 [(95\% CI 1.04-4.36), p=0.0017].

\section{Other costs}

For the other categories (registration, consultation, diagnosis, bed), costs were minor for both the RA and non-RA groups while food costs were in general nine 
times higher for the RA group vs. the non-RA group: \$1.74 vs. \$0.19 [difference $\$ 1.55$ (95\% CI 1.01-2.09), p<0.0001] (Table 2).

\subsubsection{Speed of treatment}

Table 3 reports the time taken in hours to seek treatment for those who were treated with RA vs. those who were not, by CNS status. Almost half of the non-RA treated children went to a "modern" healthcare provider and were taken there within $24 \mathrm{~h}$. However, comparing the mean time to obtain treatment from illness onset it is clear that RA-treated patients sought treatment substantially faster, usually in less than half the time of those not treated with RA. For CNS RA-treated children, the average time to RA treatment was $9.0 \mathrm{~h}$ vs. $16.1 \mathrm{~h}$ for those treated with other medications [time difference $7.1 \mathrm{~h}$ (95\% CI -1.8 to 16.1), p=0.11] and for non-CNS patients, the average time was $12.2 \mathrm{~h}$ for RA-treated children vs. $20.1 \mathrm{~h}$ for non-RA treated children [time difference $7.9 \mathrm{~h}$ (95\% CI 0.2-15.6), p=0.04]. For RA-treated children, the average referral time to reach the health centre after RA was $3.2 \mathrm{~h}$.

In general, although not significant in this study, non-RA treated patients took more time to reach a health centre after onset of illness: $15.0 \mathrm{~h}$ vs. $19.1 \mathrm{~h}$ [time difference $4.1 \mathrm{~h}$ (95\% CI -2.0-10.2), p=0.18], and a higher through not statistically significant different percentage of them deteriorated to one or more CNS symptoms by arrival ( $6 \%$ vs. $4 \%$; $=0.58)$.

\subsection{DISCUSSION}

This study examines the out-of-pocket costs and time to seek treatment for children with severe febrile illness. Children treated with CHW-delivered RA were compared with children who were not treated with RA in categories by cerebral malaria (CNS) status. Parents of children with CNS symptoms of repeated convulsions, altered consciousness or coma, treated with RA did not pay more than non-RA treated children. There was a trend for RA-treated children with CNS to reach the only healthcare facility more quickly, and consequently higher transport was their main expenditure. Despite higher transport costs, they had equivalent total costs to the CNS non-RA group, primarily because the latter spent significantly more on drugs. The higher costs may have been attributable to clinical deterioration, but this could not be confirmed. 


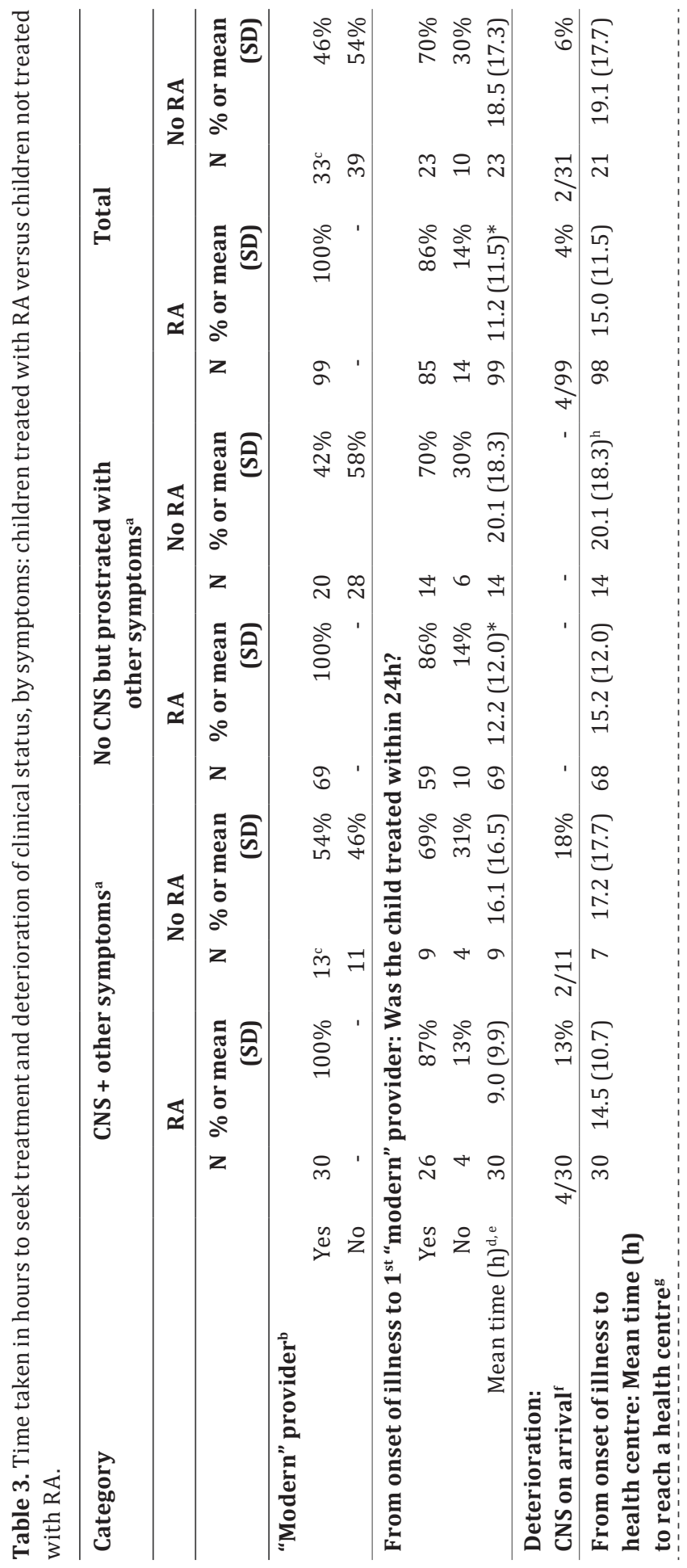




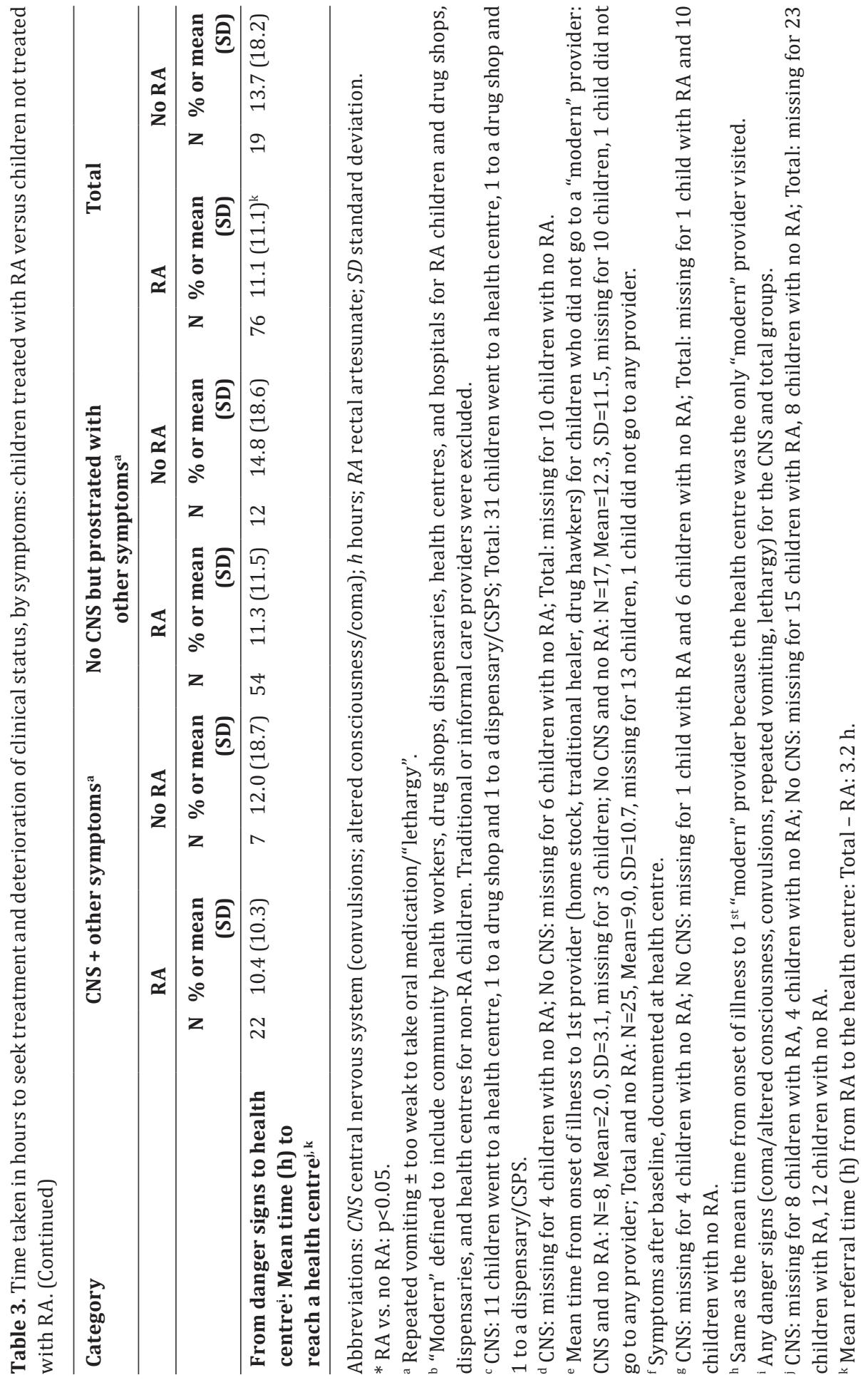


The lack of a difference in out-of-pocket costs for RA-treated and not treated children with CNS symptoms is an important finding. Firstly, children with CNS symptoms are at very high risk of death $[33,34]$. Secondly, the requirement to proceed to hospital/health centre after treatment is essential, but often perceived to be a major cost deterrent to compliance with referral advice, thus potentially delaying assessment and definitive treatment at the referral facility [35, 36]. In this study, trained CHWs explained the importance of referral and emphasized the need for rapid compliance with referral advice. Their consistent advice was heeded, even though parents probably spent more for transport in order to arrive rapidly at the referral facility [37] as emergency transfer usually costs more than nonemergency transport [38]. Among patients with CNS symptoms, the transport and food costs of RA-treated children were three times higher than those of non-RA treated patients. However, parents of non-RA treated children arrived around $3 \mathrm{~h}$ later at the health centre, and paid almost five times more on drugs at the health centre than parents of RA-treated patients.

In contrast, although not significant in this study, children with CNS symptoms who did not seek CHW-delivered RA but eventually went to a health centre not only took a longer time from the first symptom to consult a "modern" provider $(9.0 \mathrm{~h}$ vs. $16.1 \mathrm{~h}$ ) but also 1.19 times longer than RA-treated children with CNS symptoms to reach a health centre (14.5 h vs. $17.2 \mathrm{~h}$ ). A higher, not statistically significant, proportion of children (6\%) not treated with RA deteriorated to CNS symptoms by arrival at the health centre compared to RA-treated patients (4\%). Since children were seen at the same health centre, it is possible that the clinical deterioration of the non-RA treated patients contributed to their higher drug expenditures at the centre compared with RA-treated children with CNS symptoms (\$1.02 vs. \$4.93).

The cost pattern and time delays for children without CNS symptoms (e.g. children with repeated vomiting/lethargy but at lower risk of death [32, 33]) presented a different picture. Time delays from onset of illness to the first "modern" healthcare provider were significantly longer (12.2 h vs. $20.1 \mathrm{~h}$ ) and episode costs were significantly lower for non-RA treated children than for RA-treated children without CNS symptoms, probably because low-cost traditional treatments or home treatments were used [39]. RA-treated children incurred twice higher costs, mainly because of transport costs to a facility. However, it was noted that non-RA treated patients spent substantially more on drugs at the health centre, possibly because of the deteriorating condition of the child at arrival. 
The ideal is that all parents of children with danger signs recognize the gravity of the symptoms and proceed to a CHW or health centre as quickly as possible for diagnosis and treatment. However, these results are consistent with previous work suggesting that symptoms are dominant in decisions to proceed to hospital [23]. The results also confirm anthropological work [39], carried out in Burkina Faso which suggests that treatment for symptoms corresponding with the biomedical picture of cerebral malaria and characterized by convulsions and coma (kono, a "bird-illness") is the domain of guérisseurs (traditional health practitioners), used first, and often because traditional treatment is cheaper than the formal healthcare services; modern care occurs later. In contrast, the word sumaya linked to symptoms of fever, weakness, cold, loss of appetite, general body pain, diarrhoea, and vomiting is usually treated at home, by mothers, with herbs or paracetamol. It is, therefore, possible that parents considered that repeated vomiting and lethargy could be self-managed and delayed consultation with a modern provider; the delay was apparent even for those who eventually went to a health centre.

Household costs for children who sought care at health centre are higher than reported in other countries. In Uganda, the mean total out-of-pocket costs of patients who completed referral, some of whom received RA, were \$2.52 [28] vs. $\$ 5.68$ in Burkina Faso although only the costs after referral were calculated in Uganda. Since the full costs of the episode were calculated in this study, these data are unique in providing direct total household costs for an episode of severe illness, excluding the opportunity cost of time, for patients treated with RA in their community.

The non-RA children who went to a health centre paid on average $\$ 6.56$ (\$8.09 if they had CNS symptoms and \$5.72 if they had repeated vomiting/lethargy). Menon et al. [24] found similar results (\$6.84) in Uganda and other studies reported similar out-of-pocket costs (Ghana: $\$ 6.40$ for severe cases; Malawi: $\$ 5.30$ for children under 5) [25, 26].

The analysis has been limited to financial costs incurred by patients who survived the episode until the interview. The opportunity cost of labour, either forfeited to look after a sick child or withdrawn from agriculture because of the episode, was not calculated. It was not possible to obtain costs of RA-treated patients who survived the episode but died before the interview date because this would have been culturally insensitive. RDT results were not available for children in the non-RA group, and many of these children may not have had malaria, whereas all 
children in the RA-treated group had RDT-confirmed malaria. A further limitation is that, although all cost and time data relied upon memory, the data for the non-RA treated patients was obtained within 2 weeks of the episode, whereas data for the RA-treated patients were collected several months after the episode. It is difficult to determine whether costs in the RA-treated group were over or under-reported.

For several children in each group, the parents could not recall the exact date and/or time of symptoms/visits to a provider, and this resulted in incomplete information on time-intervals for several patients. Deterioration to CNS symptoms between visiting the last treatment provider and arrival at the health centre was used as an exploratory analysis of the higher drugs costs of the non-RA group. Although it is possible that higher drug costs could have been due to clinical deterioration, this hypothesis could not be confirmed. Furthermore, there was no attempt to ask qualitative questions about the reasons for not going to the health centre, and, for those who went, on the difficulties/barriers encountered in reaching the facility. With hindsight, such qualitative data would have been informative. Finally, it should be mentioned that RDTs and RA costs are not included in out-of-pocket costs as these were provided free of charge.

\subsection{CONCLUSIONS}

This study reports evidence that children with CNS symptoms treated with RA incur similar household costs as children not treated with RA, despite the higher transport costs incurred in following the referral advice. Children without CNS symptoms treated with RA incurred higher total costs because of the costs of following referral advice. RA-treated children sought treatment more quickly, whether with or without CNS symptoms.

\subsection{ACKNOWLEDGEMENTS}

We thank all the participants and their children for their collaboration in this study. We are also grateful to community health workers for their help in locating the residences of children and interviewers for data collection. We would like to acknowledge the contribution of G. Ky, P. Tou, K. Sagnon and V. Kielem for data entry support. 


\section{REFERENCES}

1. World Health Organization, United Nations Children's Fund. Improving child health: IMCI: the integrated approach. Geneva: WHO; 1999.

2. Tulloch J. Integrated approach to child health in developing countries. Lancet. 1999;354 Suppl 2:16-20.

3. Gomes MF, Faiz MA, Gyapong JO, Warsame M, Agbenyega T, Babiker A, et al. Prereferral rectal artesunate to prevent death and disability in severe malaria: a placebo-controlled trial. Lancet. 2009;373:557-66.

4. World Health Organization, United Nations Children's Fund. Handbook IMCI: Integrated Management of Childhood Illness. Geneva: WHO; 2005.

5. World Health Organization. Integrated management of childhood illness: caring for newborns and children in the community. Geneva: WHO; 2011.

6. World Health Organization, United Nations Children's Fund. WHO/UNICEF Joint Statement Integrated Community Case Management (iCCM): an equity-focused strategy to improve access to essential treatment services for children. New York: UNICEF; 2012.

7. Bhutta ZA, Darmstadt GL, Hasan BS, Haws RA. Community-based interventions for improving perinatal and neonatal health outcomes in developing countries: a review of the evidence. Pediatrics. 2005;115(2 Suppl):519-617.

8. World Health Organization. Guidelines for the treatment of malaria. $3^{\text {rd }}$ ed. Geneva: WHO; 2015.

9. Sauerborn R, Nougtara A, Diesfeld HJ. Low utilisation of community health workers: results from a household interview survey in Burkina Faso. Soc Sci Med. 1989;29:1163-74.

10. Akweongo P, Agyei-Baffour P, Sudhakar M, Simwaka BN, Konaté AT, Adongo PB, et al. Feasibility and acceptability of ACT for the community case management of malaria in urban settings in five African sites. Malar J. 2011;10:240.

11. Mukanga D, Tibenderana JK, Peterson S, Pariyo GW, Kiguli J, Waiswa P, et al. Access, acceptability and utilization of community health workers using diagnostics for case management of fever in Ugandan children: a cross-sectional study. Malar J. 2012;11:121.

12. Druetz T, Kadio K, Haddad S, Kouanda S, Ridde V. Do community health workers perceive mechanisms associated with the success of community case management of malaria? A qualitative study from Burkina Faso. Soc Sci Med. 2015;124:232-40.

13. Druetz T, Ridde V, Kouanda S, Ly A, Diabaté S, Haddad S. Utilization of community health workers for malaria treatment: results from a three-year panel study in the districts of Kaya and Zorgho, Burkina Faso. Malar J. 2015;14:71.

14. Castellani J, Nsungwa-Sabiiti J, Mihaylova B, Ajayi IO, Siribié M, Afonne C, et al. Impact of improving community-based access to malaria diagnosis and treatment on household costs. Clin Infect Dis. 2016;63 Suppl 5:S256-63.

15. Alemayehu T, Ghebreyesus TA, Witten KH, Bosman A, Teklehaimanot A. Communitybased malaria control programme in Tigray Region, Northern Ethiopia: results of a mortality survey of rural under-five children. Ethiop J Health Dev. 1998;12:203-11. 
16. Källander K, Hildenwall H, Waiswa P, Galiwango E, Peterson S, Pariyo G. Delayed care seeking for fatal pneumonia in children aged under five years in Uganda: a case-series study. Bull World Health Organ. 2008;86:332-8.

17. de Savigny D, Mayombana C, Mwageni E, Masanja H, Minhaj A, Mkilindi Y, et al. Care-seeking patterns for fatal malaria in Tanzania. Malar J. 2004;3:27.

18. Müller O, Traoré C, Becher H, Kouyaté B. Malaria morbidity, treatment-seeking behaviour, and mortality in a cohort of young children in rural Burkina Faso. Trop Med Int Health. 2003;8:290-6.

19. Hill Z, Kendall C, Arthur P, Kirkwood B, Adjei E. Recognizing childhood illnesses and their traditional explanations: exploring options for care-seeking interventions in the context of IMCI strategy in rural Ghana. Trop Med Int Health. 2003;8:668-76.

20. Sicuri E, Vieta A, Lindner L, Constenla D, Sauboin C. The economic costs of malaria in children in three sub-Saharan countries: Ghana, Tanzania and Kenya. Malar J. 2013;12:307.

21. Chima RI, Goodman CA, Mills A. The economic impact of malaria in Africa: a critical review of the evidence. Health Policy. 2003;63:17-36.

22. Källander K, Tomson G, Nsungwa-Sabiiti J, Senyonjo Y, Pariyo G, Peterson S. Community referral in home management of malaria in western Uganda: a case series study. BMC Int Health Hum Rights. 2006;6:2.

23. Castellani J, Mihaylova B, Evers SM, Paulus AT, Mrango ZE, Kimbute O, et al. Out-ofpocket costs and other determinants of access to healthcare for children with febrile illnesses: a case-control study in rural Tanzania. PLoS One. 2015;10:e0122386.

24. Menon MP, Njau JD, McFarland DA. Cost and predictors of care-seeking behaviors among caregivers of febrile children - Uganda 2009. Am J Trop Med Hyg. 2016;94:932-7.

25. Asenso-Okyere WK, Dzator JA. Household cost of seeking malaria care. A retrospective study of two districts in Ghana. Soc Sci Med. 1997;45:659-67.

26. Hennessee I, Chinkhumba J, Briggs-Hagen M, Bauleni A, Shah MP, Chalira A, et al. Household costs among patients hospitalized with malaria: evidence from a national survey in Malawi, 2012. Malar J. 2017;16:395.

27. Tozan Y, Klein EY, Darley S, Panicker R, Laxminarayan R, Breman JG. Prereferral rectal artesunate for treatment of severe childhood malaria: a cost-effective analysis. Lancet. 2010;376:1910-5.

28. Nanyonjo A, Bagorogoza B, Kasteng F, Ayebale G, Makumbi F, Tomson G, et al. Estimating the cost of referral and willingness to pay for referral to higherlevel health facilities: a case series study from an integrated community case management programme in Uganda. BMC Health Services Res. 2015;15:347.

29. Simba DO, Warsame M, Kimbute O, Kakoko D, Petzold M, Tomson G, et al. Factors influencing adherence to referral advice following pre-referral treatment with artesunate suppositories in children in rural Tanzania. Trop Med Int Health. 2009;14:775-83.

30. Ajayi IO, Nsungwa-Sabiiti J, Siribié M, Falade CO, Sermé L, Balyeku A, et al. Feasibility of diagnosis and management of malaria in Burkina Faso, Nigeria and Uganda: a community-based observational study. Clin Infect Dis. 2016;63 Suppl 5:S245-55. 
31. Siribié M, Ajayi IO, Nsungwa-Sabiiti J, Afonne C, Balyeku A, Falade CO, et al. Training community health workers to manage uncomplicated and severe malaria: experience from 3 rural malaria-endemic areas in Sub-Saharan Africa. Clin Infect Dis. 2016;63 Suppl 5:S264-9.

32. World Health Organization. Severe malaria. Trop Med Int Health. 2014;19 Suppl 1:7-131.

33. Molyneux ME. Malaria--clinical features in children. J R Soc Med. 1989;82 Suppl 17:35-8.

34. Von Seidlein L, Olaosebikan R, Hendriksen IC, Lee SJ, Adedoyin OT, Agbenyega T, et al. Predicting the clinical outcome of severe falciparum malaria in african children: findings from a large randomized trial. Clin Infect Dis. 2012;54:1080-90.

35. Phiri TB, Kaunda-Khangamwa BN, Bauleni A, Chimuna T, Melody D, Kalengamaliro $\mathrm{H}$, et al. Feasibility, acceptability and impact of integrating malaria rapid diagnostic tests and pre-referral rectal artesunate into the integrated community case management programme. A pilot study in Mchinji district, Malawi. Malar J. 2016;15:177.

36. Siribié M, Ajayi IO, Nsungwa-Sabiiti J, Sanou AK, Jegede AS, Afonne C, et al. Compliance with referral advice after treatment with prereferral rectal artesunate: a study in 3 Sub-Saharan African countries. Clin Infect Dis. 2016;63 Suppl 5:S283-9.

37. Singlovic J, Ajayi IO, Nsungwa-Sabiiti J, Siribié M, Sanou AK, Jegede AS, et al. Compliance with malaria rapid diagnosis testing by community health workers in 3 malaria-endemic countries of Sub-Saharan Africa: an observational study. Clin Infect Dis. 2016;63 Suppl 5:S276-82.

38. Hains IM, Marks A, Georgiou A, Westbrook JI. Non-emergency patient transport: what are the quality and safety issues? A systematic review. Int J Qual Health Care. 2011;23:68-75.

39. Beiersmann C, Sanou A, Wladarsch E, De Allegri M, Kouyaté B, Müller O. Malaria in rural Burkina Faso: local illness concepts, patterns of traditional treatment and influence on health-seeking behaviour. Malar J. 2007;6:106. 


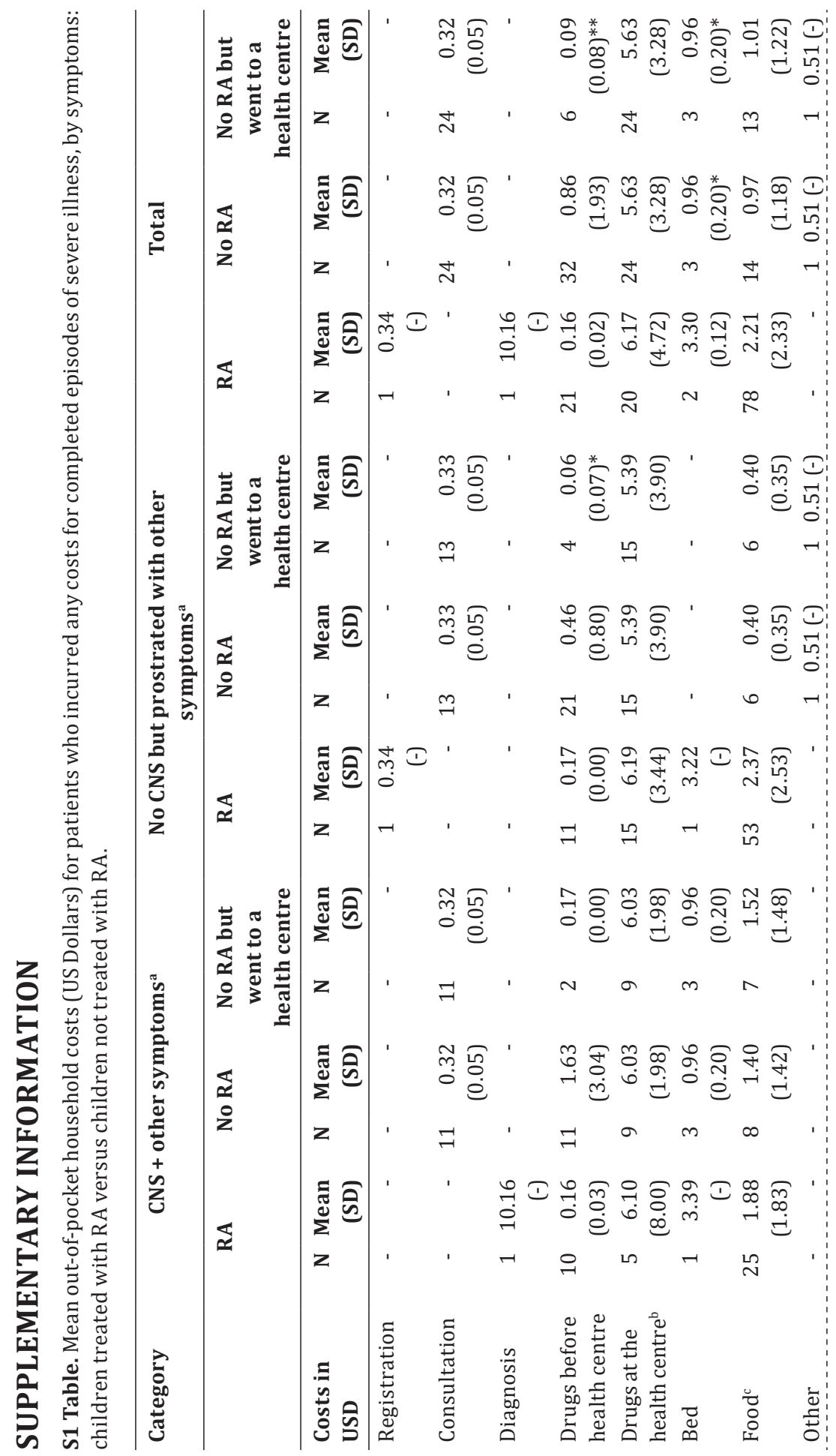




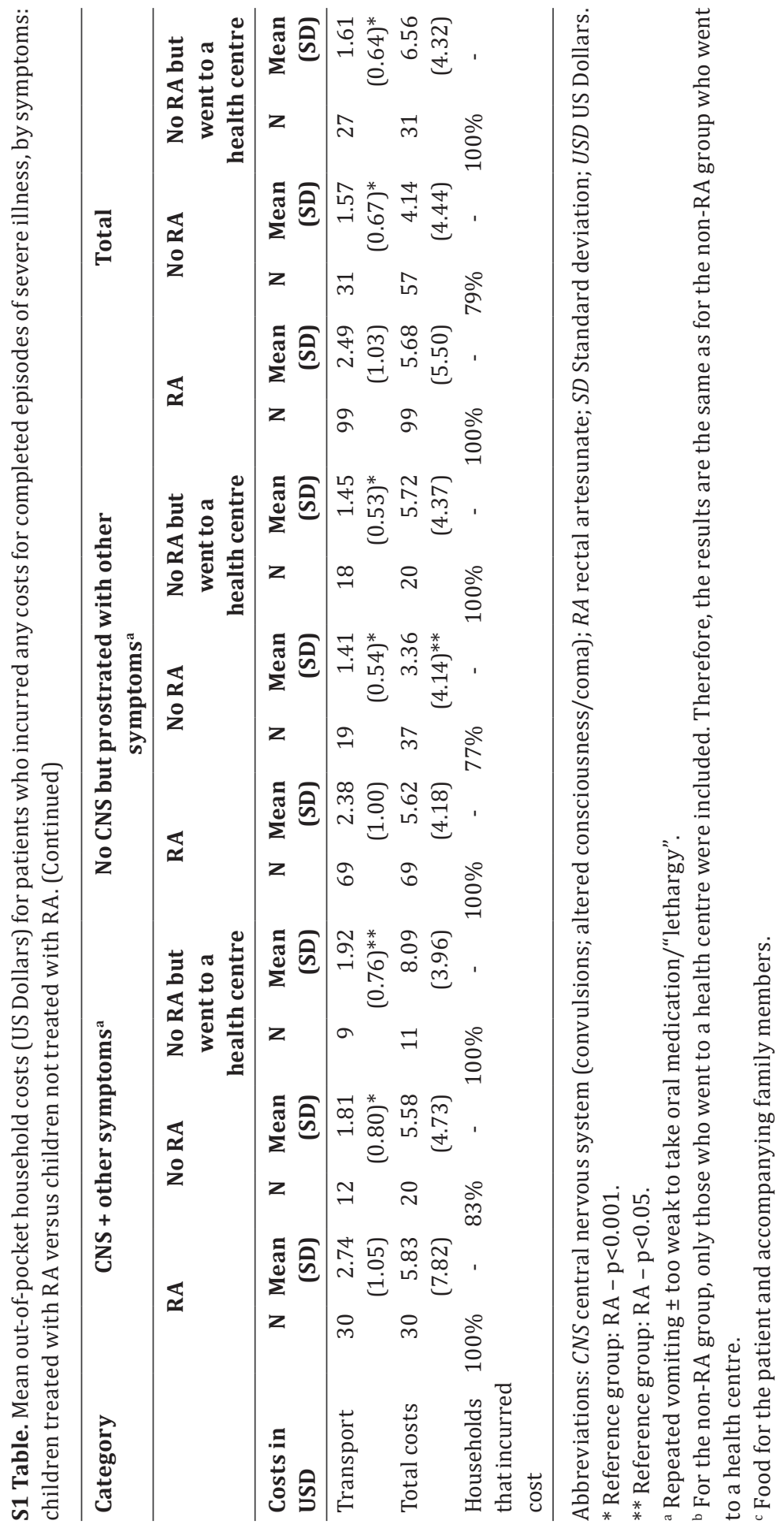




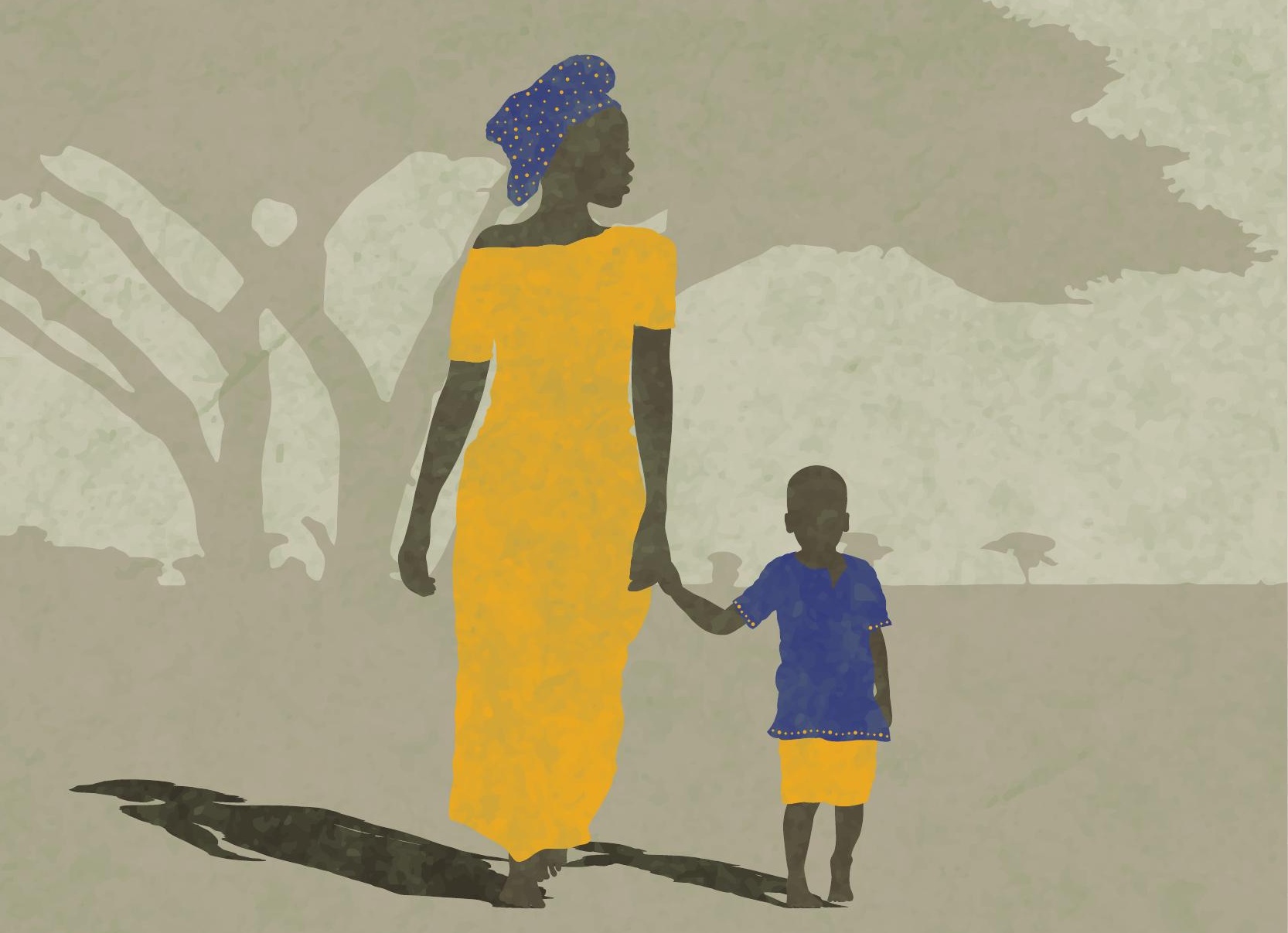




\section{CHAPTER 6}

\section{QUANTIFYIMG AND VALUINO COMMUNITY HEALTH WORKER TIME IN IMPROVING ACCESS TO MALARIA DIAGNOSIS AND TREATMENT}

\section{Published as:}

Castellani J, Mihaylova B, Ajayi IO, Siribié M, Nsungwa-Sabiiti J, Afonne C, Sermé L, Balyeku A, Kabarungi V, Kyaligonza J, Evers SMAA, Paulus ATG, Petzold M, Singlovic J, Gomes M. Quantifying and valuing community health worker time in improving access to malaria diagnosis and treatment. Clin Infect Dis. 2016;63 Suppl 5:S298S305. 


\section{ABSTRACT}

\section{Background}

Community health workers (CHWs) are members of a community who are chosen by their communities as first-line, volunteer health workers. The time they spend providing healthcare and the value of this time are often not evaluated. Our aim was to quantify the time CHWs spent on providing healthcare before and during the implementation of an integrated program of diagnosis and treatment of febrile illness in 3 African countries.

\section{Methods}

In Burkina Faso, Nigeria, and Uganda, CHWs were trained to assess and manage febrile patients in keeping with Integrated Management of Childhood Illness recommendations to use rapid diagnostic tests, artemisinin-based combination therapy, and rectal artesunate for malaria treatment. All CHWs provided healthcare only to young children usually $<5$ years of age, and hence daily time allocation of their time to child healthcare was documented for 1 day (in the high malaria season) before the intervention and at several time points following the implementation of the intervention. Time spent in providing child healthcare was valued in earnings of persons with similar experience.

\section{Results}

During the high malaria season of the intervention, CHWs spent nearly 50 minutes more in daily healthcare provision (average daily time, 30.2 minutes before the intervention vs. 79.5 minutes during the intervention; test for difference in means $\mathrm{p}$ <.01). On average, the daily time spent providing healthcare during the intervention was 55.8 minutes (Burkina Faso), 77.4 minutes (Nigeria), and 72.2 minutes (Uganda). Using the country minimum monthly salary, CHWs' time allocated to child healthcare for 1 year was valued at US Dollars (USD) \$52 in Burkina Faso, USD \$295 in Nigeria, and USD \$141 in Uganda.

\section{Conclusions}

CHWs spend up to an hour and a half daily on child healthcare in their communities. These data are informative in designing reward systems to motivate CHWs to continue providing good-quality services. 


\subsection{BACKGROUND}

The run-up to meet the Millennium Development Goals witnessed an upsurge in programs using community health workers (CHWs) to improve health, particularly child health [1]. CHWs offer a wide range of services to their communities in low-income countries and improve access to healthcare by reaching the poorest and most inaccessible areas [2]. Because health facilities often concentrate on curative care over prevention, and families in poorer areas are less likely to reach health facilities than those in wealthier areas [3], CHWs are seen as a means of bringing both preventive and curative care closer to the patient, improving health and reducing inequities. CHWs perform a wide range of tasks, from first aid and treatment of simple, common illnesses to interventions that promote healthy behavior; some of them also keep records and collect data on vital events [2]. In their case management roles, CHWs do not replace the need for skilled health workers, but when they are trained and assigned to manage simple tasks in their communities, including screening for illness condition and referring patients who need specialized management, and when properly supervised and supported, they become effective links to the formal healthcare system [4]. Several studies have shown a decrease of neonatal and child mortality when early signs of severe illness are identified and interventions delivered by CHWs in the communities [5-8].

In sub-Saharan Africa, CHWs' activities are largely voluntary and unpaid. However, the evidence on the extent to which CHWs can be effective in improving health has led to an increase in the number of tasks they are assigned without financial remuneration, while their performance is increasingly examined, which has raised stress and increased attrition [2, 9]. The time CHWs contribute to their community reduces the time they can allocate to other tasks, including care of their own children and, as their healthcare activities are voluntary, their income may also decrease. However, assessments of the volume of activities CHWs provide, the time allocated to these tasks, and whether and how this time load affects other tasks and income are extremely rare $[10,11]$.

Given the number of health programs that depend upon CHWs to implement health interventions in their communities without quantifying the impact upon their time, our goal was to redress the balance. We aimed to quantify changes in time allocation that were brought by an intervention using CHWs to increase access to diagnosis and treatment for malaria in remote communities in 3 African countries. The intervention involved the provision in malaria-endemic 
communities of malaria rapid diagnostic tests (RDTs), and for malaria-positive cases, oral artemisinin-based combination therapies (ACTs), or for patients who need immediate transit to health facilities, pre-referral rectal artesunate [12].

\subsection{METHODS}

\subsubsection{Study sites}

This time-allocation study was carried out in 42 villages before the intervention and in 124 villages during the intervention in 4 rural malaria-endemic areas of Burkina Faso (health area of Sidéradougou, Health District of Mangodara), Nigeria (Ona-Ara local government area), and Uganda (Kayunga and Sheema districts). The aim was to quantify the number of hours of time spent by CHWs on different activities during the course of a normal day before and following the implementation of an intervention delivered by CHWs to diagnose and treat malaria.

Data collection for the pre-intervention phase of the time-allocation study took place between May and September 2013 in Nigeria and during the month of August 2014 in Burkina Faso; for the intervention phase, time-allocation data were collected between January 2014 and October 2015 in Nigeria, between January and July 2015 in Uganda, and between May and September 2015 in Burkina Faso. There was no pre-intervention time-allocation study in Uganda because there were no CHWs operating before the intervention. In Nigeria, those functioning as CHWs previously (some participating in previous studies) and those selected for the intervention were interviewed. Nineteen study communities in Burkina Faso and 23 in Nigeria before the intervention and 32 study communities in Burkina Faso, 14 in Nigeria, and 78 in Uganda during the intervention participated in this time-allocation study.

\subsubsection{Role of the CHWs}

In all 3 countries, health centers are situated far away from people's homes, and travel to health centers is expensive. Therefore, CHWs, typically chosen by their communities, are often an initial point of healthcare treatment before referral to the next level of care. The intervention involved training CHWs to assess, diagnose, treat, and refer children in their communities according to standard treatment guidelines [13]. Once successfully identified and trained, the CHWs were provided with malaria RDTs, ACTs, and rectal artesunate, and supported in their diagnosis and treatment of RDT-positive patients, identification of danger signs (repeated 
vomiting, unable to eat/drink/suck, convulsions, altered consciousness, lethargy, and difficulties in breathing) and provision of rectal artesunate to patients with danger signs before referring them to the nearest health facility for further management [12].

In each country, CHWs voluntarily contribute to health services, and this practice did not change during the study. In Burkina Faso, as per government policy, ACTs are subsidized by the Ministry of Health and CHWs are permitted to retail subsidized ACTs at 100 West African CFA francs (XOF) (US Dollars [USD] \$0.17) and 200 XOF (USD \$0.33) for children younger and older than 37 months respectively. In Nigeria, CHWs were unpaid but received gifts during festivities and gifts if they performed well (number of cases, quality of record-keeping), and were reimbursed for transport to meetings. They were paid USD \$10 per month in Nigeria and USD \$3 per visit in Uganda for their transport to replenish commodities. Short message service (SMS)/phone calls regarding specific patients were reimbursed. A stipend was given for team meeting days. Conforming to policy in Nigeria and Uganda, RDTs and ACTs were provided at no cost to patients; in all countries, rectal artesunate was provided at no cost to the patient.

\subsubsection{Questionnaire design and data collection}

Basic characteristics of the CHWs such as gender, age, marital status, occupation, and number of years of experience as a CHW were recorded before and during the intervention.

During the intervention, any use of RDTs and medicines was recorded by the CHWs. The CHWs monitored their allocation of time during the day, but also measured for a random sample of treated children the time needed for the guardians to give an illness history; the time used to prepare, perform, and read a RDT; the time spent waiting for results and giving explanations of the RDT procedure; the time for providing medicine to a child; and the time needed to explain the referral and follow-up process. Information on test results, severity of the episode with or without any danger signs (difficult/fast breathing, repeated vomiting, unable to eat/drink/suck, pallor, convulsions/chills/ rigors, weakness/lethargy, anorexia, bulging fontanel, coma/altered consciousness), treatments given, and referral was recorded. The children for whom the $\mathrm{CHW}$ monitored time allocation in greater detail were randomly selected, and data were usually obtained on the same day as other data for daily time allocation were collected. 
Structured case report forms (CRFs) were in French for Burkina Faso and in English for Nigeria and Uganda. Each $\mathrm{CHW}$ was asked to list what they did on the day before, from 6 AM to 6 PM, in slots of 20 minutes. Activities listed by the CHWs consisted of healthcare provision, family/personal time and housework (e.g. cleaning the house, looking after the children, washing the clothes/dishes), agriculture, paid work (e.g. teaching), self-employment (e.g. tailor), and going to the market. Completing forms took approximately 30 minutes to 1 hour. Local translations (except for Burkina Faso) were made and tested before use. In Burkina Faso and in Nigeria, during the pre-intervention data collection, each CHW was visited once by an investigator who filled in the CRF for the CHW. During the intervention, CHWs were trained to fill in the questionnaires themselves, except in Uganda where a trained research assistant (11 research assistants in Sheema and 10 in Kayunga) helped CHWs to fill the forms.

\subsubsection{Data analysis}

The activities that contributed to the CHWs' healthcare provision were detailed (taking care of sick children, working as health workers, going to CHW meetings, etc). For each completed CRF, time in different activities was aggregated and mean time (in minutes) reported. Time for guardians to give the history of the illness, for preparation and performing a RDT, waiting for results, explaining RDT procedures, treating the child, and explaining the referral and follow-up process was quantified.

Only CHWs were included. Formal health sector staff ( $\mathrm{n}=2$ before intervention) and owners of drug shops ( $n=7$ before intervention; $n=5$ during intervention) were excluded. A maximum number of CRFs per CHW was 8 forms irrespective of the number completed (varied numbers were completed: 9-59 in Nigeria during the intervention phase and 9-58 for Burkina Faso and Nigeria for the CRF on the time needed to perform RDTs and give treatment). All forms were filled within 24 hours of respective activities to reduce risks of recall bias.

In Burkina Faso, CHWs charged patients for each treatment pack. We calculated income received from ACTs using treatment data from registers, numbers of children assessed, child's age, and treatment received. These data were used to calculate the average income from retailing ACTs per month during low and high malaria seasons, as well as the annual income. 
The CHWs' time for healthcare was valued using external data on minimal monthly salary in each country. In Burkina Faso, the hourly minimum wage was 176.83 XOF (about 28,292 XOF per month or USD \$52.10) [14]. In Nigeria, the monthly minimum wage was 18,000 Nigerian naira (NGN) (USD \$100) [14] and in Uganda, USD \$54 [11]. CHWs' time value is presented in US dollars (USD \$) using average exchange rates between 2014 and 2015: USD \$1=542.75 XOF (Burkina Faso) and USD \$1=180 NGN (www.oanda.com).

\subsubsection{Statistical methods}

Data were double entered, separately for each country, in EpiData 3.1 and analyzed using Stata software version 13.0 (StataCorp, College Station, Texas). We report average daily times as well as distribution of time in the following categories: none, $>0-2$ hours, $>2$ hours; or none, $>0-4$ hours, $>4-8$ hours, and $>8$ hours. Twotailed $t$ tests were used to compare means and $\chi^{2}$ tests for heterogeneity to compare distributions of times allocated to a particular activity before and during the intervention in each country and across countries. P values $<0.05$ indicated statistically significant differences.

\subsubsection{Ethics issues}

The research protocol of the main study was approved by the National Health Research Committee, the University of Ibadan/University College Hospital Institutional Review Committee, and the Oyo State Ministry of Health in Nigeria; the National Ethics Committee for the Research on Health and the National Regulatory Authority in Burkina Faso; the National Council for Science and Technology in Uganda; and the World Health Organization Research Ethics Review Committee. In each country, CHWs as well as guardians of sick children gave consent for the main study.

\subsection{RESULTS}

\subsubsection{Exclusion of CHWs for this sub-research}

During the pre-intervention phase, in Burkina Faso, 3 CHWs who filled the forms were excluded because 1 was a minor at the time of the study, and 2 did not take part in the intervention because 1 was not accepted by the community and the other was not able to calculate the age of the children. 


\subsubsection{Profile of the CHWs contributing to the time-allocation study}

In Burkina Faso and Nigeria, 20 and 42 CHWs, respectively, took part in the preintervention phase of the time-allocation study; there were no CHWs yet in the study area of Uganda (Table 1). During the intervention, 36 CHWs in Burkina Faso, 17 CHWs in Nigeria, and 147 CHWs in Uganda participated. In Nigeria, for cultural reasons, all CHWs were females while in Burkina Faso, a larger proportion of CHWs were males (75\%). In Uganda, about 75\% of CHWs were females.

Table 1. Characteristics of community health workers.

\begin{tabular}{|c|c|c|c|c|c|}
\hline \multirow[t]{2}{*}{ Category } & \multicolumn{2}{|c|}{ Before intervention } & \multicolumn{3}{|c|}{ During intervention } \\
\hline & Burkina Faso & Nigeria & Burkina Faso & Nigeria & Uganda \\
\hline $\begin{array}{l}\text { No. of community health } \\
\text { workers }\end{array}$ & 20 & 42 & 36 & 17 & 147 \\
\hline \multicolumn{6}{|l|}{ Gender } \\
\hline Male & $15(75)$ & - & $27(75)$ & - & $37(25)$ \\
\hline Female & $5(25)$ & $42(100)$ & $9(25)$ & $17(100)$ & $110(75)$ \\
\hline \multicolumn{6}{|l|}{ Age, years } \\
\hline$\leq 20$ & - & - & $1(3)$ & - & \\
\hline $21-30$ & $9(45)$ & $8(19)$ & $13(36)$ & $1(6)$ & $25(17)$ \\
\hline $31-40$ & $4(20)$ & $14(33)$ & $10(28)$ & $6(36)$ & $62(42)$ \\
\hline $41-50$ & $6(30)$ & $10(24)$ & $11(30)$ & $5(29)$ & $42(29)$ \\
\hline$>50$ & $1(5)$ & $10(24)$ & $1(3)$ & $5(29)$ & $16(11)$ \\
\hline Missing data & - & - & - & - & $2(1)$ \\
\hline \multicolumn{6}{|l|}{ Marital status } \\
\hline Single & $1(5)$ & - & $3(8)$ & - & $5(3)$ \\
\hline Married & $19(95)$ & $37(88)$ & $32(89)$ & $13(76)$ & $129(88)$ \\
\hline Separated & - & $2(5)$ & - & - & - \\
\hline Divorced & - & - & - & $2(12)$ & $5(3)$ \\
\hline Widowed & - & $3(7)$ & $1(3)$ & $2(12)$ & $8(6)$ \\
\hline \multicolumn{6}{|l|}{ Main occupation } \\
\hline Only farming & $14(70)$ & $4(10)$ & $32(89)$ & $1(6)$ & $111(76)$ \\
\hline Paid employment mainly & $2(10)$ & $6(14)$ & - & $3(18)$ & $11(7)$ \\
\hline Self-employment mainly & $4(20)$ & $32(76)$ & $3(8)$ & $13(76)$ & $22(15)$ \\
\hline Housewife/unemployed & - & - & $1(3)$ & - & $3(2)$ \\
\hline \multicolumn{6}{|c|}{ How long served as a community health worker? } \\
\hline$<1$ year & $4(20)$ & $22(52)$ & $10(28)$ & - & $9(6)$ \\
\hline 1 year to $<2$ years & $2(10)$ & $2(5)$ & - & $2(12)$ & $15(10)$ \\
\hline 2 years to $<3$ years & - & - & $4(11)$ & $2(12)$ & $34(23)$ \\
\hline$\geq 3$ years & $14(70)$ & $18(43)$ & $22(61)$ & $13(76)$ & $89(61)$ \\
\hline
\end{tabular}

Data are presented as No. (column \%). 
In all 3 countries, most CHWs were between 21 and 50 years old ( $>70 \%$ ) and mainly married ( $>75 \%)$. Their main occupation was farming in Burkina Faso $(>70 \%)$ and in Uganda (76\%) but mainly self-employed in Nigeria (76\%). The majority of CHWs had been working as CHWs for at least 2 years ( $>70 \%)$. During the pre-intervention phase, Nigerian CHWs were not officially in place but had participated in previous studies on community management of malaria; more than half (57\%) had $<2$ years of experience while the remaining CHWs (43\%) had at least 3 years of experience.

\subsubsection{Time allocation of the CHWs}

Data on time spent on categories of daily activities during the high malaria season (i.e. pre-intervention questionnaires were completed exclusively during the high malaria season) are summarized in Table 2. Before the intervention, the average daily time spent by CHWs on healthcare activities was 30.16 minutes. After the provision of training and commodities (RDTs and medicines), CHWs spent on average 79.47 minutes (test for difference in mean times before vs. during the intervention, $\mathrm{p}<0.01$, with effects similar separately among sites in Burkina Faso and Nigeria). However, although their average daily time spent on family activities appears increased (246.23 before vs. 325.79 during intervention; $\mathrm{p}<0.01$ ), their time spent on self-employment ( 166.56 vs. 30.79 minutes; $\mathrm{p}<0.0001)$ had decreased. The effect on time spent on self-employment was driven by a large effect observed exclusively in Nigeria ( 246.83 vs. 23.03 minutes; $p<0.0001$ ). There were no important differences in mean daily time spent on agricultural activities or paid work ( $\mathrm{p}$ values not significant).

When all data of CHWs' time allocation during the intervention (i.e. not just during high malaria season) are taken into account, the time spent on healthcare activities was on average 55.8 minutes in Burkina Faso, 77.4 minutes in Nigeria, and 72.2 minutes in Uganda (Table 3). Most of the daily time was allocated to agriculture in Burkina Faso (345.6 minutes) and to family/personal time in Nigeria and Uganda (395.1 minutes for Nigeria and 334.9 minutes in Uganda). When the time was stratified by low and high malaria seasons, more time on healthcare activities was spent during the high malaria season in Burkina Faso and in Uganda (S1 Table). As a consequence, family/personal time as well as the time spent on agriculture decreased. However, in Nigeria, CHWs spent on average 21.5 minutes less time providing healthcare during the high malaria season compared with the low malaria season. 


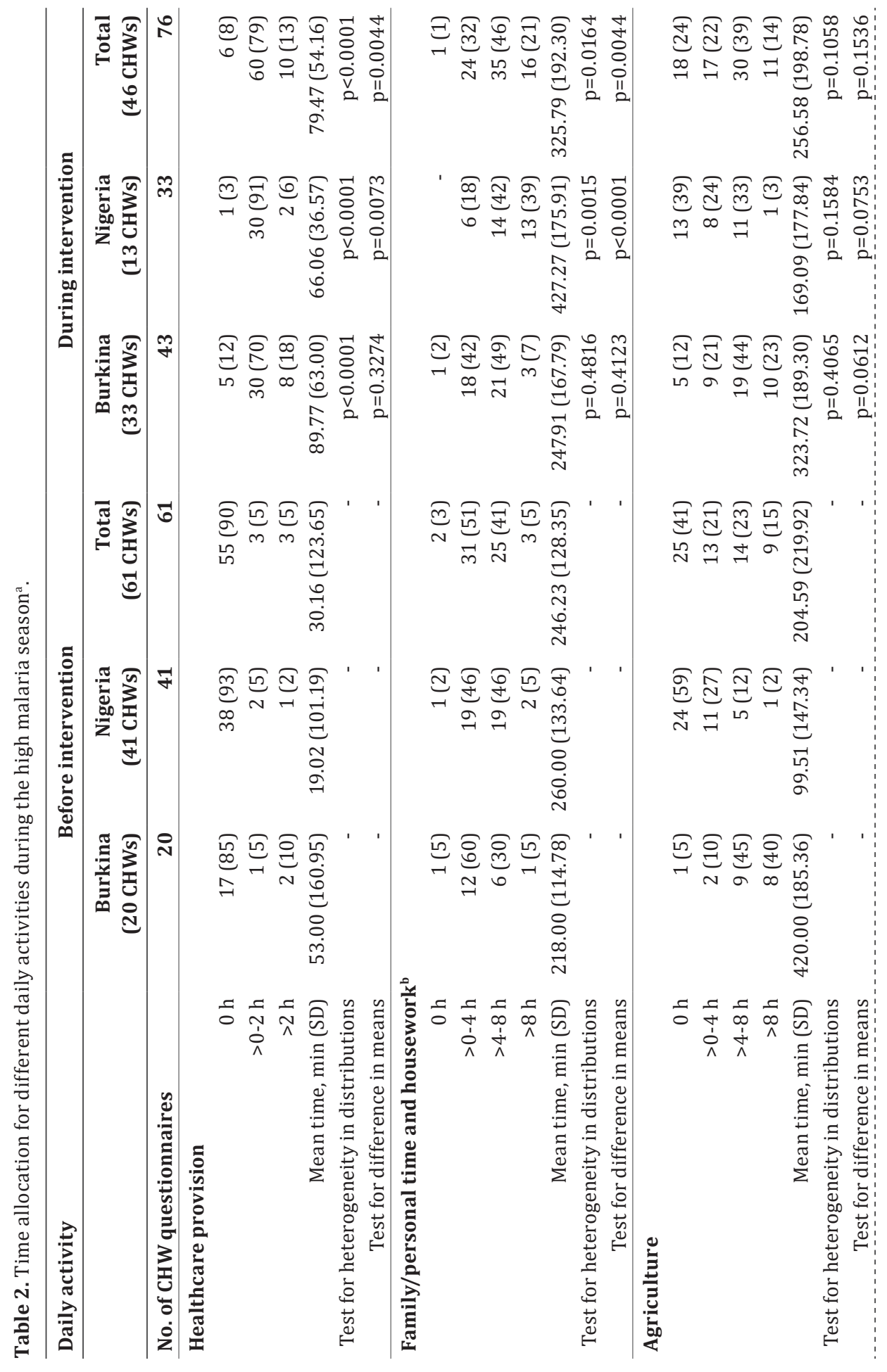




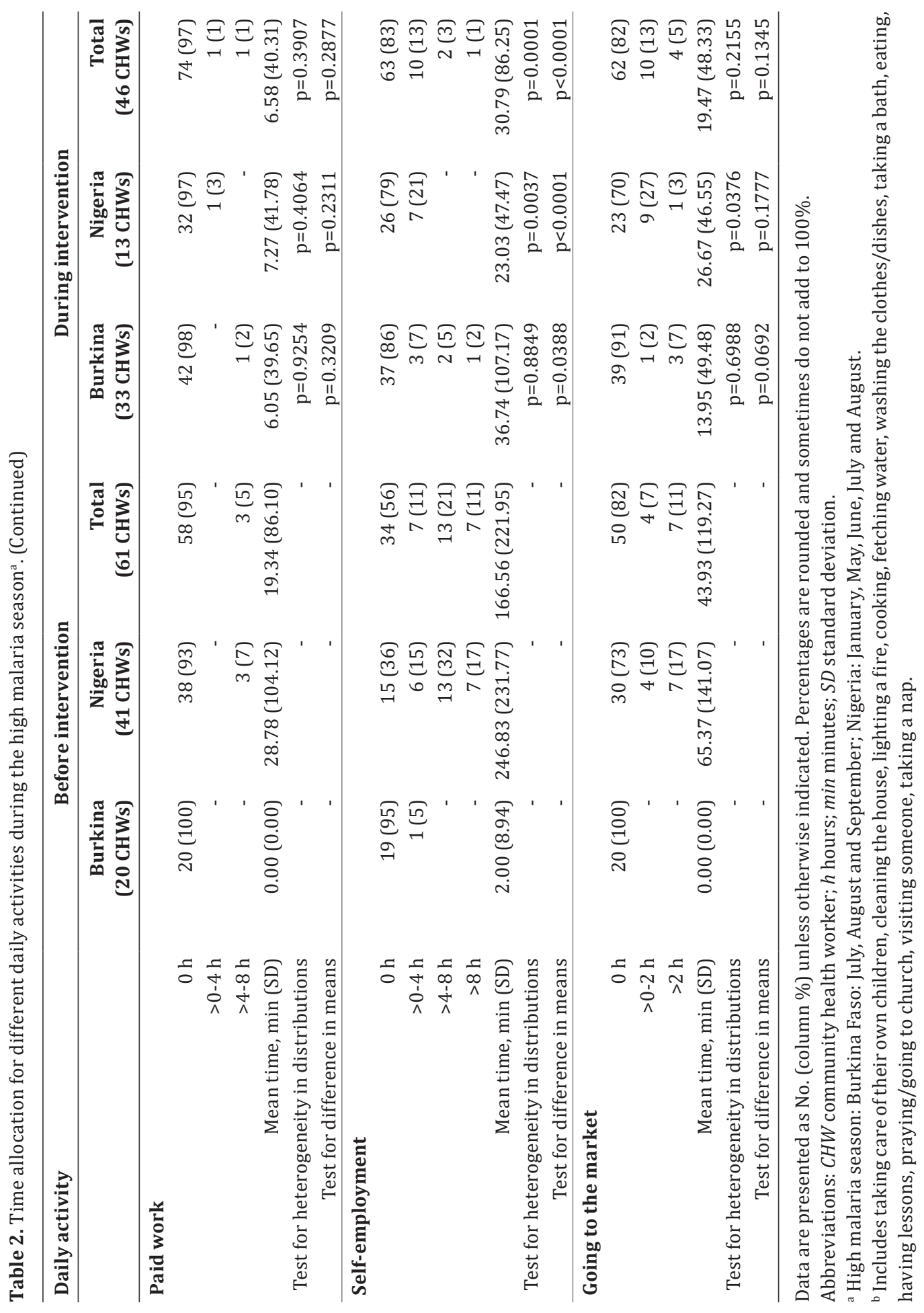


Table 3. Allocation of community health workers' time across categories of daily activities during the intervention period.

\begin{tabular}{|c|c|c|c|}
\hline \multirow[t]{2}{*}{ Daily activity } & \multicolumn{3}{|c|}{ During intervention } \\
\hline & $\begin{array}{r}\text { Burkina Faso } \\
(36 \text { CHWs })\end{array}$ & $\begin{array}{r}\text { Nigeria } \\
(17 \text { CHWs })\end{array}$ & $\begin{array}{r}\text { Uganda } \\
(147 \text { CHWs })\end{array}$ \\
\hline No. of CHW questionnaires & 72 & 70 & 467 \\
\hline \multicolumn{4}{|l|}{ Healthcare provision } \\
\hline $0 \mathrm{~h}$ & $31(43)$ & $3(4)$ & $26(6)$ \\
\hline$>0-2 \mathrm{~h}$ & $33(46)$ & $61(87)$ & $411(88)$ \\
\hline$>2 \mathrm{~h}$ & $8(11)$ & $6(9)$ & $30(6)$ \\
\hline Mean time, min (SD) & $55.8(64.9)$ & $77.4(65.0)$ & $72.2(55.9)$ \\
\hline \multicolumn{4}{|c|}{ Family/personal time and housework ${ }^{\mathrm{a}}$} \\
\hline $0 \mathrm{~h}$ & $1(1)$ & - & $17(4)$ \\
\hline$>0-4 \mathrm{~h}$ & $34(47)$ & $14(20)$ & $101(21)$ \\
\hline$>4-8 \mathrm{~h}$ & $31(43)$ & $36(51)$ & $299(64)$ \\
\hline$>8 \mathrm{~h}$ & $6(8)$ & $20(29)$ & $50(11)$ \\
\hline Mean time, min (SD) & $254.4(162.2)$ & $395.1(166.4)$ & 334.9 (141.7) \\
\hline \multicolumn{4}{|l|}{ Agriculture } \\
\hline $0 \mathrm{~h}$ & $7(10)$ & $28(40)$ & $35(7)$ \\
\hline$>0-4 \mathrm{~h}$ & $15(21)$ & $22(32)$ & $186(40)$ \\
\hline$>4-8 \mathrm{~h}$ & $29(40)$ & $17(24)$ & $231(50)$ \\
\hline$>8 \mathrm{~h}$ & $21(29)$ & $3(4)$ & $15(3)$ \\
\hline Mean time, min (SD) & $345.6(194.7)$ & $156.9(172.0)$ & $257.7(121.6)$ \\
\hline \multicolumn{4}{|l|}{ Paid work } \\
\hline $0 \mathrm{~h}$ & $71(99)$ & $66(94)$ & 464 (99) \\
\hline$>0-4 \mathrm{~h}$ & - & $2(3)$ & $1(0)$ \\
\hline$>4 \mathrm{~h}$ & $1(1)$ & $2(3)$ & $2(1)$ \\
\hline Mean time, min (SD) & $3.6(30.6)$ & $16.6(69.5)$ & $2.3(32.1)$ \\
\hline \multicolumn{4}{|l|}{ Self employment } \\
\hline $0 \mathrm{~h}$ & $61(85)$ & $45(64)$ & $411(88)$ \\
\hline$>0-4 \mathrm{~h}$ & $4(6)$ & $23(33)$ & $21(5)$ \\
\hline$>4-8 \mathrm{~h}$ & $5(7)$ & $2(3)$ & $25(5)$ \\
\hline$>8 \mathrm{~h}$ & $2(3)$ & $0(0)$ & $10(2)$ \\
\hline Mean time, min (SD) & $48.3(130.0)$ & $44.3(82.5)$ & $39.7(124.4)$ \\
\hline \multicolumn{4}{|l|}{ Going to the market } \\
\hline $0 \mathrm{~h}$ & $67(93)$ & $42(60)$ & $403(86)$ \\
\hline$>0-2 \mathrm{~h}$ & $1(1)$ & 27 (39) & $54(12)$ \\
\hline$>2 \mathrm{~h}$ & $4(6)$ & $1(1)$ & $10(2)$ \\
\hline Mean time, min (SD) & $10.6(42.6)$ & $29.1(41.8)$ & $13.2(38.9)$ \\
\hline
\end{tabular}

Data are presented as No. (column \%) unless otherwise indicated. Percentages are rounded and sometimes do not add to $100 \%$. Data of all participating CHWs are included.

Abbreviations: $C H W$ community health worker; $h$ hours; min minutes; SD standard deviation. ${ }^{a}$ Includestaking care of their own children, cleaningthe house, lighting a fire, cooking, fetching water, washing the clothes/dishes, taking abath, eating, havinglessons, praying/going to church, visitingsomeone, taking anap. 
We evaluated the average number of hours spent by CHWs per year in providing healthcare in the communities to 159.5 in Burkina Faso, 471.9 in Nigeria, and 417.0 in Uganda. With an average salary per month (US dollars) of USD \$52.1 (Burkina Faso), USD $\$ 100.0$ (Nigeria), and USD \$54.0 (Uganda), the value of the time that CHWs spent on treating sick children in the study areas was estimated at USD \$2,544 (Burkina Faso), USD \$15,040 (Nigeria), and USD \$23,081 (Uganda) per year (S2 Table).

\subsubsection{Use of rapid diagnostic tests and treatment package}

Table 4 presents the CHWs' time per child for administering a RDT and appropriate treatment as well as the RDT results, the illness severity, and the treatment given during the intervention. In Uganda, a CHW needed on average 45.7 minutes, while the time needed in Burkina Faso and Nigeria was shorter (39.9 minutes in Burkina Faso and 32.1 in Nigeria). Most of the time needed concerned the preparation and the use of a RDT (18.0 minutes for Burkina Faso, 17.9 for Nigeria, and 14.5 minutes for Uganda). Most of the children were tested malaria positive and uncomplicated $(>73 \%)$. Only a few of them had danger signs $(<2.5 \%)$. Among the children included in the detailed time-allocation sub-study, $>76 \%$ received ACT and only 2 received rectal artesunate (1 in Nigeria [0.9\%] and 1 in Uganda [0.2\%]), while about $23.6 \%$ of the children in Burkina Faso, 16.0\% in Nigeria, and 13.8\% in Uganda received no treatment or only paracetamol (acetaminophen). In Burkina Faso, because CHWs were allowed to retail ACTs to patients and could keep the profit margin for themselves, we estimated their income from ACTs to be USD \$3.41 for the 3 months of high malaria season and USD $\$ 3.60$ for the 9 months of low malaria season (S3 Table).

Table 4. Community health workers' time for rapid diagnostic tests (RDTs) and treatment, illness severity, RDT results and treatment given.

\begin{tabular}{|c|c|c|c|c|c|c|}
\hline \multirow[t]{3}{*}{ Characteristic } & \multicolumn{6}{|c|}{ During intervention } \\
\hline & \multicolumn{2}{|c|}{ Burkina Faso } & \multicolumn{2}{|c|}{ Nigeria } & \multicolumn{2}{|r|}{ Uganda } \\
\hline & $\mathbf{N}$ & $\begin{array}{r}\text { Mean (SD) } \\
\text { or \% }\end{array}$ & $\mathbf{N}$ & $\begin{array}{r}\text { Mean (SD) } \\
\text { or } \%\end{array}$ & $\mathbf{N}$ & $\begin{array}{r}\text { Mean (SD) } \\
\text { or } \%\end{array}$ \\
\hline $\begin{array}{l}\text { No. of febrile cases in children }<5 \\
\text { years of age }\end{array}$ & 195 & - & 106 & - & 465 & - \\
\hline No. of community health workers & 30 & - & 22 & - & 147 & - \\
\hline \multicolumn{7}{|c|}{ Time used for RDTs and treatment, min, mean (SD) } \\
\hline History of the illness & 195 & $7.0(4.4)$ & 106 & $5.5(3.1)$ & 465 & $8.8(7.3)$ \\
\hline Preparation and taking a RDT & 195 & $18.0(7.2)$ & 106 & $17.9(5.5)$ & 465 & $14.5(8.1)$ \\
\hline Giving results and explanations & 195 & $5.3(3.7)$ & 106 & $4.2(2.2)$ & 465 & $10.6(7.3)$ \\
\hline Treatment & 176 & $5.8(3.7)$ & 100 & $4.7(1.9)$ & 465 & $7.5(5.0)$ \\
\hline
\end{tabular}


Table 4. Community health workers' time for rapid diagnostic tests (RDTs) and treatment, illness severity, RDT results and treatment given. (Continued)

\begin{tabular}{|c|c|c|c|c|c|c|}
\hline \multirow[t]{3}{*}{ Characteristic } & \multicolumn{6}{|c|}{ During intervention } \\
\hline & \multicolumn{2}{|c|}{ Burkina Faso } & \multicolumn{2}{|c|}{ Nigeria } & \multicolumn{2}{|c|}{ Uganda } \\
\hline & $\mathbf{N}$ & $\begin{array}{r}\text { Mean (SD) } \\
\text { or \% }\end{array}$ & $\mathbf{N}$ & $\begin{array}{r}\text { Mean (SD) } \\
\text { or \% }\end{array}$ & $\mathbf{N}$ & $\begin{array}{r}\text { Mean (SD) } \\
\text { or \% }\end{array}$ \\
\hline Referral and follow-up advice & 181 & $4.9(3.2)$ & 2 & $5.0(0.0)$ & 373 & $5.4(3.8)$ \\
\hline Total time per RDT and treatment & 195 & $39.9(13.1)$ & 106 & $32.1(7.5)$ & 465 & $45.7(15.7)$ \\
\hline \multicolumn{7}{|c|}{ RDTs results, severity and treatments, No. (\%) } \\
\hline \multicolumn{7}{|l|}{ Uncomplicated febrile children ${ }^{\mathrm{a}}$} \\
\hline Malaria positive & 144 & 73.9 & 81 & 76.4 & 389 & 83.7 \\
\hline Malaria negative & 41 & 21.0 & 4 & 3.8 & 69 & 14.8 \\
\hline Not conclusive & - & - & 1 & 0.9 & - & - \\
\hline \multicolumn{7}{|l|}{ Unable to take oral medications } \\
\hline Malaria positive & 7 & 3.6 & 3 & 2.8 & 5 & 1.1 \\
\hline Malaria negative & 3 & 1.5 & - & - & 1 & 0.2 \\
\hline \multicolumn{7}{|l|}{ Missing severity } \\
\hline Malaria negative & - & - & 17 & 16.1 & 1 & 0.2 \\
\hline & $\mathbf{N}$ & $\%$ & $\mathbf{N}$ & $\%$ & $\mathbf{N}$ & $\%$ \\
\hline \multicolumn{7}{|l|}{ Treatment decisions } \\
\hline ACT treatment provided & 149 & 76.4 & 82 & 77.4 & 396 & 85.2 \\
\hline $\begin{array}{r}\text { Rectal artesunate treatment } \\
\text { provided }\end{array}$ & - & - & - & - & 1 & 0.2 \\
\hline Rectal artesunate and ACT & - & - & 1 & 0.9 & - & - \\
\hline $\begin{array}{r}\text { Paracetamol (acetaminophin) + } \\
\text { other drugs (recommended to be } \\
\text { purchased by patient) }\end{array}$ & 21 & 10.8 & 15 & 14.1 & - & - \\
\hline $\begin{array}{r}\text { No treatment given, but eventually } \\
\text { recommendation to purchase other } \\
\text { drugs }\end{array}$ & 25 & 12.8 & 2 & 1.9 & 64 & 13.8 \\
\hline $\begin{array}{r}\text { Given other treatment: paracetamol, } \\
\text { antibiotics, Septrin, folic acid, } \\
\text { ORS, amodiaquine, sulfadoxine/ } \\
\text { pyrimethamine }\end{array}$ & - & - & - & - & 4 & 0.8 \\
\hline Missing & - & - & 6 & 5.7 & - & - \\
\hline $\begin{array}{l}\text { No. of children with danger signs } \\
\text { seen/treated }\end{array}$ & 4 & 2.1 & 2 & 1.9 & 1 & 0.2 \\
\hline
\end{tabular}

Abbreviations: $A C T$ artemisinin-based combination therapy; min minutes; ORS oral rehydration solution; $R D T$ rapid diagnostic test; $S D$ standard deviation.

${ }^{a}$ Children with no danger signs (difficult/fast breathing, repeated vomiting, unable to eat/ drink/suck, pallor, convulsions/chills/rigors, weakness/child not playing/lethargy, anorexia, bulging fontanel, coma/altered consciousness).

${ }^{\mathrm{b}}$ Danger signs mentioned above. 


\subsection{DISCUSSION}

A total of 265 CHWs provided access to diagnosis and treatment to about 16,000 young children in 162 villages in 3 countries. The intervention increased access to diagnosis and treatment by $80 \%$, reduced the number of children with signs of severe illness from $24.7 \%$ to $18.1 \%$, and reduced illness duration from 3.7 to 3.5 days for uncomplicated episodes and from 4.2 to 3.7 days for severe episodes [12]. This study shows that because of the intervention, the total time on healthcare activities by the CHWs rose from about 30 minutes to about 80 minutes overall (from 53 to 90 minutes in Burkina Faso and from 19 to 66 minutes in Nigeria). The daily volume of time spent on childcare was modest both before and after the intervention, and the bulk of the time was spent on diagnosis of malaria, with a smaller fraction on treatment. Our findings are considerably less than the 4.8 hours per day found in Ghana, but comparable to findings in Uganda reporting about 40 minutes daily taken by CHWs to provide integrated care for common childhood illnesses $[10,11]$.

All of the CHWs were contributing voluntarily. They had on average $>3$ years of experience, and most went to primary school in Burkina Faso and Nigeria and to secondary school in Uganda. Using the average income in each country for people of equivalent education and experience, the estimated value of their time during 1 year ranged from USD \$51.9 in Burkina Faso to USD \$294.9 in Nigeria. Some CHWs, but not all, benefited from payments in kind; most stated gaining improved community status; and all were supervised [15]. Each of these incentives contributed to the success of the intervention and increased motivation. In Burkina Faso, permission to retail treatment to patients meant that each transaction contributed to CHWs' income. The cost was nominal for patients [16] but enabled CHWs to earn an average monthly income of USD \$1.14 (maximum USD \$3.61) during the peak 3-month malaria season and USD \$0.40 per month (maximum USD \$1.28) during the rest of the year. These earnings, however, still fall short of the estimated value of time they contributed to healthcare.

The case for using CHWs depends on the assumption that there is a health benefit and that any alternative means of providing that benefit would cost more than using CHWs. We did not compare alternatives to improving access to healthcare, but the substantial health benefit provided in improving access and reducing illness duration with a modest CHW time allocation suggests that a cost per month 
that varies from USD $\$ 4.30$ per person in Burkina Faso to USD $\$ 24.60$ in Nigeria might be economically attractive.

The results from this article, in combination with the health outcomes results reported elsewhere [12], provide a strong case for the intervention to be scaled up at the cost of a modest increase in CHWs' time. The key dilemma is how best to remunerate $\mathrm{CHWs}$ for their time and/or provide incentives that can sustain their contributions to healthcare. Financial remuneration may well be CHWs' preferred option, but policies intent upon reducing their attrition rates and maintaining their effectiveness will need to respond to what motivates them. Sanou et al [15] indicate that a substantial component of CHWs' motivation derives from their status in the community and technical supervision; these 2 components apparently reinforce their technical skills (and hopes of a career path) and link them to community members and the formal health system. If CHWs are highly motivated by community status, then policies can be designed to reinforce that status; if they are motivated more by income prospects, then compensation for their time needs to be structured in a way that improves income and efficient use of time (i.e. reduces incentives to "waste time"). The model in Burkina Faso has the disadvantage of giving them an incentive to treat more, but a mixed model combining variations of the Burkina Faso approach plus nonfinancial incentives may be possible. Most CHWs in the study were relatively young with small children of their own, living in an agricultural area. Providing free health coverage for their children plus some financial motivation might be a model to be tested.

Nonfinancial incentives, such as training, adequate supervision, community recognition, certification, identification badges, reduced stockouts, and bicycles that are appropriate for the CHWs' work were mentioned by CHWs as helping to increase their sense of self-worth, a source of pride, and relevant to future job prospects [15]. They indicate that CHWs' motivation, retention, and effectiveness is heavily influenced by who they are in the community context, how they are perceived by community members, and the extent to which they are supported to maintain a stable relationship with their clients. Appropriate training and supervision were stated to improve their confidence and competence, and regular replenishment of supplies ensured that their relationship with their clients was not undermined by stockouts. The most successful CHWs programs have recognized that it is important to use multiple nonfinancial incentives to build CHWs' continuing sense of self-worth and consolidate their relationship with their communities - some pairing CHWs so that they can work together and provide 
mutual support, and others where the community provides free labor on the CHW's farm [17].

This study has several limitations. First, it may underestimate time allocated to healthcare, as some parents may have visited a CHW at night (between $6 \mathrm{PM}$ and $6 \mathrm{AM}$ ), but information during night visits was not collected. In Burkina Faso and, to a large degree, in Nigeria, data before intervention were collected during the peak of malaria transmission, whereas data during the intervention were collected more evenly. A comparison of time use before and during the intervention is therefore limited to the high malaria transmission season. In Nigeria, some CHWs were reluctant to fill in the time forms because this was perceived to increase their workload, whereas others enthusiastically completed multiple forms. To reduce the documentation burden and increase representativeness of time use across most CHWs, the research team assisted in completing the forms and we limited data use to 8 forms per CHW.

\subsection{ACKNOWLEDGMENTS}

We are grateful to the community health workers and parents of children for whom data on RDTs and time were collected. We are also grateful to village leaders for their permission to carry out the research in their communities, and to the health staff of Sidéradougou hospital and Kyengeni and Busaana health centers for their contribution in the supervision of CHWs. We thank J. Bwoye, G. Egunyomi, L. Ojanduru, B. Orimolade, G. Ouattara, A. Suberu, and J. Wandera who led fieldwork and provided intellectual and administrative support; B. S. Sombié and L. Ojanduru who were responsible for data management onsite; and A. Adewale, I. Akorede, 0. Kayode, M. Namanya, R. Ngabirano, O. Ojo, E. Oyeniran, P. Tou, and J. J. Wembabazi who supported data entry. 


\section{REFERENCES}

1. Haines A, Sanders D, Lehmann U, Rowe AK, Lawn JE, Jan S, et al. Achieving child survival goals: potential contribution of community health workers. Lancet. 2007;369:2121-31.

2. Bhutta ZA, Lassi ZS, Pariyo GW, Huicho L. Global experience of community health workers for delivery of health related Millennium Development Goals: a systematic review, country case studies and recommendations for integration into National Health Systems. Geneva: WHO/Global Health Workforce Alliance; 2010.

3. Schellenberg JA, Victora CG, Mushi A, de Savigny D, Schellenberg D, Mshinda H, et al. Inequities among the very poor: health care for children in rural southern Tanzania. Lancet. 2003;361:561-6.

4. Lehmann U, Sanders D. Community health workers: what do we know about them? The state of the evidence on programmes, activities costs and impact on health outcomes of using community health workers. Geneva: WHO; 2007.

5. Bang AT, Bang RA, Baitule SB, Reddy MH, Deshmukh MD. Effect of home-based neonatal care and management of sepsis on neonatal mortality: field trial in rural India. Lancet. 1999;354:1955-61.

6. Kidane G, Morrow R. Teaching mothers to provide home treatment of malaria in Tigray, Ethiopia: a randomised trial. Lancet. 2000;356:550-5.

7. Kumar V, Mohanty S, Kumar A, Misra RP, Santosham M, Awasthi S, et al. Effect of community-based behaviour change management on neonatal mortality in Shivgarh, Uttar Pradesh, India: a cluster-randomised controlled trial. Lancet. 2008;372:1151-62.

8. Gomes MF, Faiz MA, Gyapong JO, Warsame M, Agbenyega T, Babiker A, et al. Prereferral rectal artesunate to prevent death and disability in severe malaria: a placebo-controlled trial. Lancet. 2009;373:557-66.

9. Haq Z, Iqbal Z, Rahman A. Job stress among community health workers: a multimethod study from Pakistan. Int J Ment Health Syst. 2008;2:15.

10. Agyei-Baffour P, Hansen KS, Browne EN, Magnussen P. The amount and value of work time of community medicine distributors in community case management of malaria among children under five years in the Ejisu-Juaben District of Ghana. Malar J. 2012;11:277.

11. Kasteng F, Settumba S, Källander K, Vassall A, inSCALE Study Group. Valuing the work of unpaid community health workers and exploring the incentives to volunteering in rural Africa. Health Policy Plan. 2016;31:205-16.

12. Ajayi IO, Nsungwa-Sabiiti J, Siribié M, Falade CO, Sermé L, Balyeku A, et al. Feasibility of malaria diagnosis and management in Burkina Faso, Nigeria, and Uganda: a community-based observational study. Clin Infect Dis. 2016;63 Suppl 5:S245-55.

13. World Health Organisation. Caring for newborns and children in the community. Geneva: WHO; 2015.

14. International Labour Organization. ILO working conditions laws database. Geneva: ILO; 2011. [cited 2016 Jul 5]. Available from: http://www.ilo.org/dyn/travail.

15. Sanou AK, Jegede AS, Nsungwa-Sabiiti J, Siribié M, Ajayi IO, Turinde A, et al. Motivation of community health workers in diagnosing, treating, and referring sick young children in a multicountry study. Clin Infect Dis. 2016;63 Suppl 5:S270-5. 
16. Jegede AS, Oshiname FO, Sanou AK, Nsungwa-Sabiiti J, Ajayi IO, Siribié M, et al. Assessing acceptability of a diagnostic and malaria treatment package delivered by community health workers in malaria-endemic settings of Burkina Faso, Nigeria, and Uganda. Clin Infect Dis. 2016;63 Suppl 5:S306-11.

17. Bhattacharyya K, Winch P, LeBan K, Tien M. Community health worker incentives and disincentives: how they affect motivation, retention, and sustainability. Arlington, VA: Basic Support for Institutionalizing Child Survival Project (BASICS II) for the United States Agency for International Development; 2001. 


\section{SUPPLEMENTARY INFORMATION}

S1 Table. Allocation of community health worker's time across categories of daily activities during the intervention period stratified by low/high malaria season ${ }^{a}$.

\begin{tabular}{|c|c|c|c|c|c|c|}
\hline \multirow[t]{3}{*}{ Daily activity } & \multicolumn{6}{|c|}{ During intervention } \\
\hline & \multicolumn{2}{|c|}{$\begin{array}{c}\text { Burkina Faso } \\
\text { (36 CHWs) }\end{array}$} & \multicolumn{2}{|c|}{$\begin{array}{c}\text { Nigeria } \\
\text { (17 CHWs) }\end{array}$} & \multicolumn{2}{|c|}{$\begin{array}{c}\text { Uganda } \\
\text { (147 CHWs) }\end{array}$} \\
\hline & $\begin{array}{r}\text { Low } \\
\text { season }\end{array}$ & $\begin{array}{r}\text { High } \\
\text { season }\end{array}$ & $\begin{array}{r}\text { Low } \\
\text { season }\end{array}$ & $\begin{array}{r}\text { High } \\
\text { season }\end{array}$ & $\begin{array}{r}\text { Low } \\
\text { season }\end{array}$ & $\begin{array}{r}\text { High } \\
\text { season }\end{array}$ \\
\hline $\begin{array}{l}\text { No. of CHW } \\
\text { questionnaires }\end{array}$ & 29 & 43 & 37 & 33 & 162 & 305 \\
\hline \multicolumn{7}{|l|}{ Healthcare provision } \\
\hline $0 \mathrm{~h}$ & $26(90)$ & $5(12)$ & $2(5)$ & $1(3)$ & $8(5)$ & $18(6)$ \\
\hline$>0-2 \mathrm{~h}$ & $3(10)$ & $30(70)$ & $3184)$ & $30(91)$ & $150(93)$ & $261(86)$ \\
\hline$>2 \mathrm{~h}$ & - & $8(19)$ & $4(11)$ & $2(6)$ & $4(2)$ & $26(8)$ \\
\hline Mean time, min (SD) & $\begin{array}{r}5.5 \\
(18.3)\end{array}$ & $\begin{array}{r}89.8 \\
(63.0)\end{array}$ & $\begin{array}{r}87.6 \\
(81.7) \\
\end{array}$ & $\begin{array}{r}66.1 \\
(36.6)\end{array}$ & $\begin{array}{r}60.7 \\
(28.8) \\
\end{array}$ & $\begin{array}{r}78.3 \\
(65.1) \\
\end{array}$ \\
\hline \multicolumn{7}{|c|}{ Family/personal time and housework ${ }^{\mathrm{b}}$} \\
\hline $0 \mathrm{~h}$ & - & $1(2)$ & - & - & $4(3)$ & $13(4)$ \\
\hline$>0-4 \mathrm{~h}$ & $16(55)$ & $18(42)$ & $8(22)$ & $6(18)$ & 29 (18) & $72(24)$ \\
\hline$>4-8 \mathrm{~h}$ & $10(35)$ & $21(49)$ & $22(59)$ & $14(42)$ & $114(70)$ & $185(61)$ \\
\hline$>8 \mathrm{~h}$ & $3(10)$ & $3(7)$ & 7 (19) & $13(40)$ & $15(9)$ & 35 (11) \\
\hline Mean time, min (SD) & $\begin{array}{r}264.1 \\
(155.9)\end{array}$ & $\begin{array}{r}247.9 \\
(167.8)\end{array}$ & $\begin{array}{r}366.5 \\
(154.1) \\
\end{array}$ & $\begin{array}{r}427.3 \\
(175.9)\end{array}$ & $\begin{array}{r}350.9 \\
(131.6)\end{array}$ & $\begin{array}{r}326.2 \\
(146.3)\end{array}$ \\
\hline \multicolumn{7}{|l|}{ Agriculture } \\
\hline $0 \mathrm{~h}$ & $2(7)$ & $5(12)$ & $15(41)$ & $13(40)$ & $6(4)$ & $29(10)$ \\
\hline$>0-4 \mathrm{~h}$ & $6(21)$ & $9(21)$ & $14(38)$ & $8(24)$ & $67(41)$ & 119 (39) \\
\hline$>4-8 \mathrm{~h}$ & $10(34)$ & $19(44)$ & $6(16)$ & $11(33)$ & $84(52)$ & $147(48)$ \\
\hline$>8 \mathrm{~h}$ & $11(38)$ & $10(23)$ & $2(5)$ & $1(3)$ & $5(3)$ & $10(3)$ \\
\hline Mean time, min (SD) & $\begin{array}{r}377.9 \\
(201.4)\end{array}$ & $\begin{array}{r}323.7 \\
(189.3) \\
\end{array}$ & $\begin{array}{r}145.9 \\
(168.3)\end{array}$ & $\begin{array}{r}169.1 \\
(177.8) \\
\end{array}$ & $\begin{array}{r}264.3 \\
(108.2) \\
\end{array}$ & $\begin{array}{r}254.2 \\
(128.2) \\
\end{array}$ \\
\hline \multicolumn{7}{|l|}{ Paid work } \\
\hline $0 \mathrm{~h}$ & $29(100)$ & $42(98)$ & $34(92)$ & $32(97)$ & $162(100)$ & 302 (99) \\
\hline$>0-4 \mathrm{~h}$ & - & - & $1(3)$ & $1(3)$ & - & $1(0)$ \\
\hline$>4 \mathrm{~h}$ & - & $1(2)$ & $2(5)$ & - & - & $2(1)$ \\
\hline Mean time, min (SD) & $0.0(0.0)$ & $6.0(39.6)$ & $24.9(87.0)$ & $7.3(41.8)$ & $0.0(0.0)$ & 3.5 (39.7) \\
\hline \multicolumn{7}{|l|}{ Self employment } \\
\hline $0 \mathrm{~h}$ & $24(82)$ & $37(86)$ & $19(51)$ & $26(79)$ & $151(93)$ & $260(85)$ \\
\hline$>0-4 \mathrm{~h}$ & $1(4)$ & $3(7)$ & $16(43)$ & 7 (21) & $1(1)$ & $20(7)$ \\
\hline$>4-8 \mathrm{~h}$ & $3(10)$ & $2(5)$ & $2(6)$ & - & $7(4)$ & $18(6)$ \\
\hline$>8 \mathrm{~h}$ & $1(4)$ & $1(2)$ & - & - & $3(2)$ & $7(2)$ \\
\hline Mean time, min (SD) & $\begin{array}{r}65.5 \\
(158.5)\end{array}$ & $\begin{array}{r}36.7 \\
(107.2)\end{array}$ & $\begin{array}{r}63.2 \\
(101.3)\end{array}$ & $\begin{array}{l}323.0 \\
(47.5)\end{array}$ & $\begin{array}{r}28.3 \\
(112.6)\end{array}$ & $\begin{array}{r}45.8 \\
(130.0)\end{array}$ \\
\hline
\end{tabular}


S1 Table. Allocation of community health worker's time across categories of daily activities during the intervention period stratified by low/high malaria season ${ }^{\mathrm{a}}$. (Continued)

\begin{tabular}{rrrrrrr}
\hline Daily activity & \multicolumn{7}{c}{ During intervention } \\
\hline & \multicolumn{2}{c}{$\begin{array}{c}\text { Burkina Faso } \\
\text { (36 CHWs) }\end{array}$} & \multicolumn{2}{c}{ Nigeria } \\
(17 CHWs $)$ & \multicolumn{2}{c}{$\begin{array}{c}\text { Uganda } \\
\text { (147 CHWs) }\end{array}$} \\
\hline & $\begin{array}{r}\text { Low } \\
\text { season }\end{array}$ & $\begin{array}{c}\text { High } \\
\text { season }\end{array}$ & $\begin{array}{r}\text { Low } \\
\text { season }\end{array}$ & $\begin{array}{r}\text { High } \\
\text { season }\end{array}$ & $\begin{array}{r}\text { Low } \\
\text { season }\end{array}$ & $\begin{array}{r}\text { High } \\
\text { season }\end{array}$ \\
\hline Going to the market & & & & & & \\
$0 \mathrm{~h}$ & $28(97)$ & $39(91)$ & $19(51)$ & $23(70)$ & $134(83)$ & $269(88)$ \\
$>0-2 \mathrm{~h}$ & - & $1(2)$ & $18(49)$ & $9(27)$ & $26(16)$ & $28(9)$ \\
$>2 \mathrm{~h}$ & $1(3)$ & $3(7)$ & $0(0)$ & $1(3)$ & $2(1)$ & $8(3)$ \\
Mean time, min (SD) & 5.5 & 14.0 & 31.4 & 26.7 & 15.8 & 11.8 \\
& $(29.7)$ & $(49.5)$ & $(37.6)$ & $(46.5)$ & $(38.9)$ & $(39.0)$ \\
\hline
\end{tabular}

Data are presented as No. (column \%) unless otherwise indicated. Percentages are rounded and sometimes do not add to $100 \%$.

Abbreviations: $C H W$ community health worker; $h$ hours; min minutes; $S D$ standard deviation.

${ }^{a}$ High malaria season: Burkina Faso: July, August and September; Nigeria: January, May, June, July and August; Uganda: January, June, July, August, September and October.

${ }^{\mathrm{b}}$ Includes taking care of their own children, cleaning the house, lighting a fire, cooking, fetching water, washing the clothes/dishes, taking a bath, eating, having lessons, praying/going to church, visiting someone, taking a nap. 


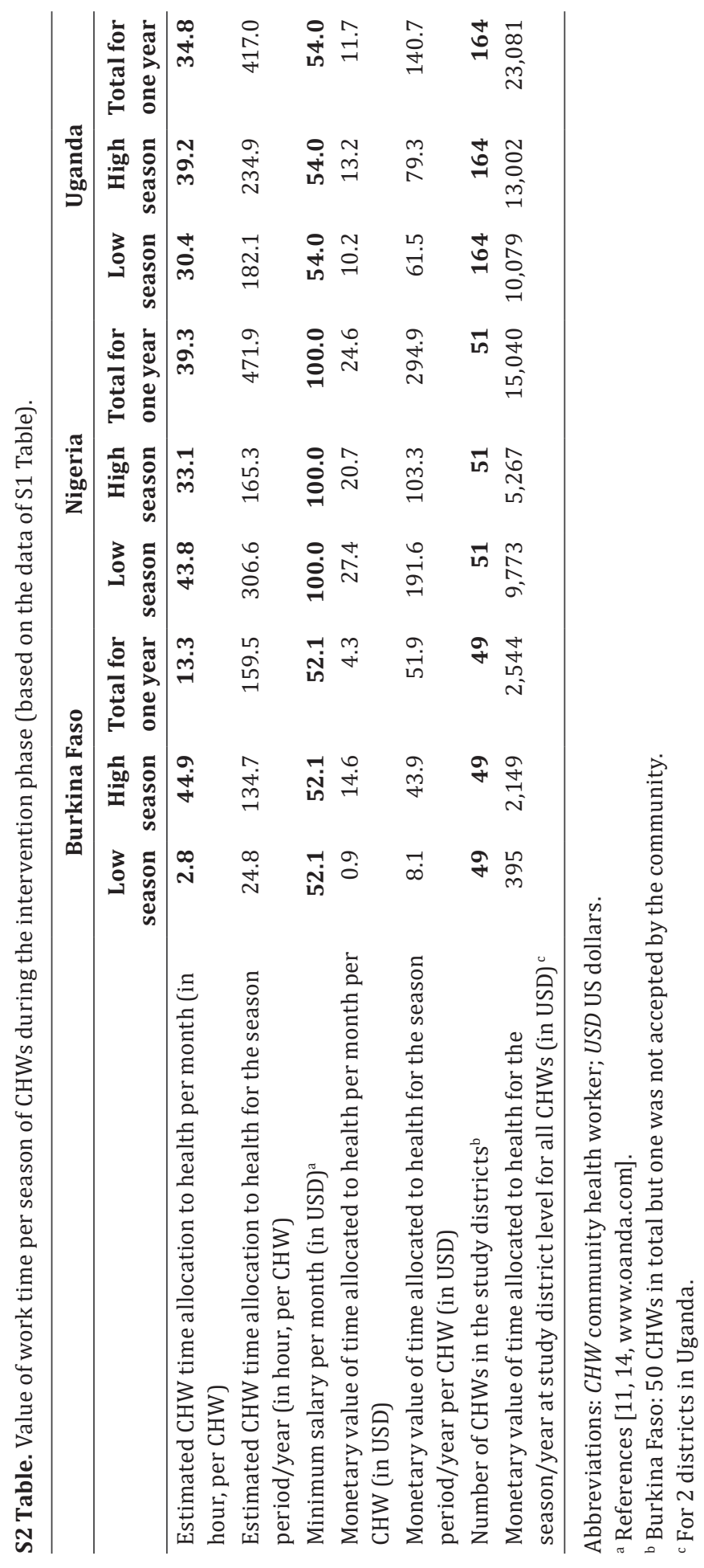


S3 Table. Mean CHW's income (US Dollars) from ACTs sold to sick children in Burkina Faso.

\begin{tabular}{|c|c|c|c|c|}
\hline & $\begin{array}{r}\text { During the } \\
\text { intervention: } \\
\text { Sept } 2014 \text { - } \\
\text { Oct } 2015\end{array}$ & $\begin{array}{r}\text { Estimate } \\
\text { for } 1 \\
\text { calendar } \\
\text { year }\end{array}$ & $\begin{array}{r}\text { High malaria } \\
\text { season }^{\text {a }} \\
\text { during the } \\
\text { intervention } \\
\text { (3 months) }\end{array}$ & $\begin{array}{r}\text { Low malaria } \\
\text { season during } \\
\text { the intervention } \\
(9 \text { months })\end{array}$ \\
\hline Number of CHWs ${ }^{b}$ & 49 & 49 & 49 & 49 \\
\hline $\begin{array}{l}\text { Number of children }<37 \\
\text { months who received ACT }\end{array}$ & 3,684 & 3,158 & 1,799 & 1,885 \\
\hline $\begin{array}{l}\text { Number of children } \geq 37 \\
\text { months who received ACT }\end{array}$ & 1,684 & 1,443 & 814 & 870 \\
\hline Total income in USD & 343.68 & 294.58 & 167.09 & 176.59 \\
\hline $\begin{array}{l}\text { Mean (SD) income per } \\
\text { CHW in USD }\end{array}$ & $7.01(4.14)$ & 6.01 & $3.41(2.33)$ & $3.60(2.03)$ \\
\hline $\begin{array}{l}\text { Mean monthly income per } \\
\text { CHW in USD }\end{array}$ & 0.50 & 0.50 & $1.14(\max : 3.61)^{\mathrm{c}}$ & $0.40(\max : 1.28)^{\mathrm{c}}$ \\
\hline
\end{tabular}

Abbreviations: $A C T$ artemisinin-based combination therapy; $C H W$ community health worker; $S D$ standard deviation; USD US dollars.

a July, August \& September.

b 50 CHWs in total but one was not accepted by the community.

c The maximum is calculated based on number of patients treated with ACTs in Burkina Faso by CHWs (see Ajayi et al. [12]). 


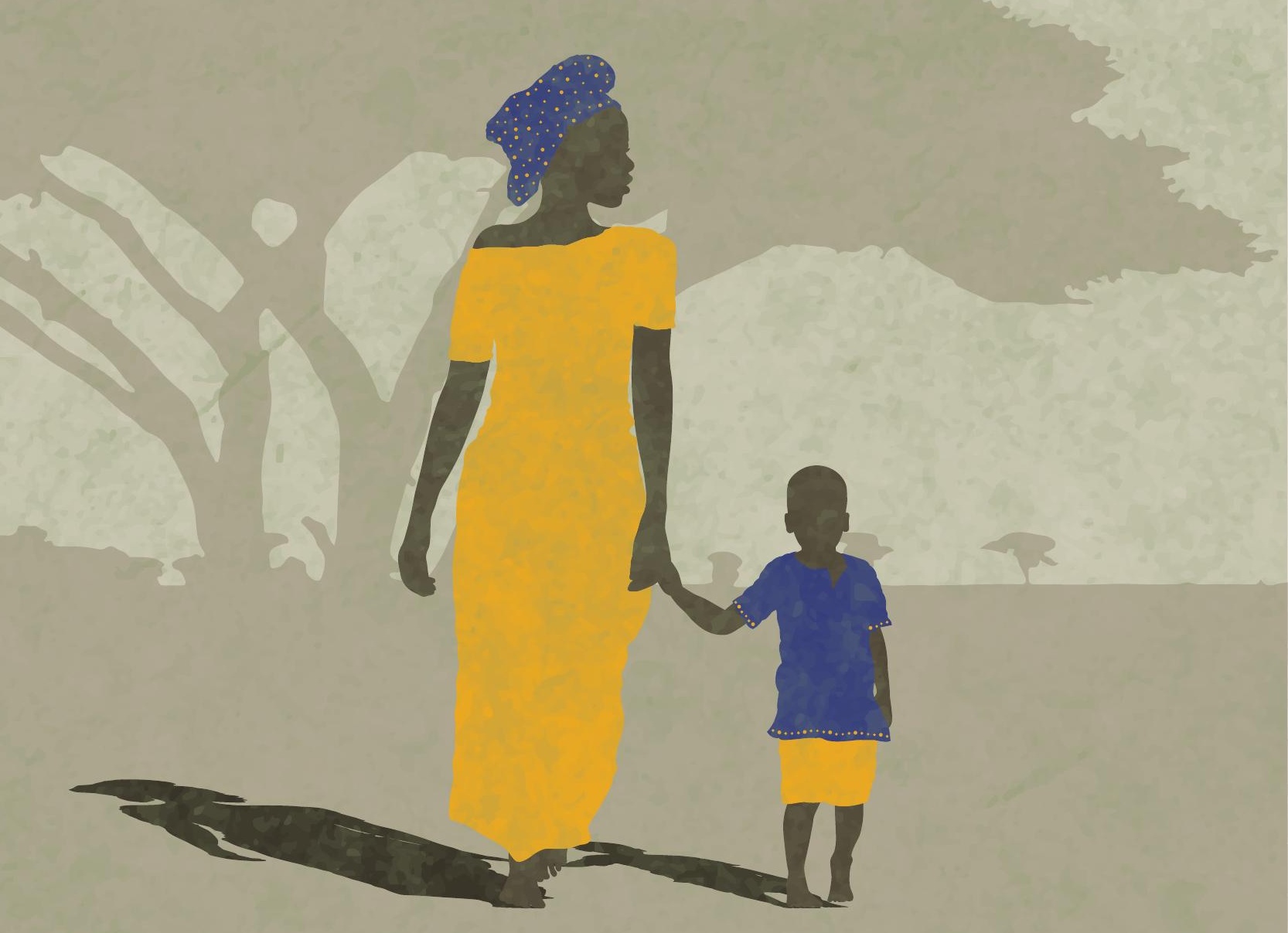




\section{CHAPTER 7}

geNERAL DISCUSSION 
The goals of this thesis were first to provide information on the economic and financial factors that influence access to healthcare and on the consequences of delayed access to diagnosis and treatment of malaria in rural Africa, and second to test and evaluate a strategy for reducing delays by bringing access closer to sick children in the community. The main goals were divided into three sub-objectives, as introduced in chapter 1:

1. To understand the economic and financial factors that influence access to healthcare facilities and whether those factors prevented or delayed healthcare access (chapter 2)

2. To provide insight into the adverse long-term effects of severe/cerebral malaria on children, caregivers and households (chapter 3 )

3. To understand the effects of community-based malaria control and management interventions on private costs and health system costs, on time to treatment and on time allocated by CHWs to child healthcare (chapters 4-6)

Chapters 2 and 3 discussed the causes and consequences of delayed access to diagnosis and treatment, and chapters 4 to 6 showed how financial hazard can be reduced or avoided in remote areas of Africa where the burden of malaria is greatest. In this final chapter, we summarise the main findings and discuss the strengths and limitations as well as the research, policy and practice implications of the work carried out.

\subsection{SUMMARY OF THE MAIN FINDINGS}

Information on the economic and financial causes of delayed access to diagnosis and treatment was obtained through a case-control study that compared the outof-pocket costs and characteristics of children with febrile illness who went to a hospital versus those who did not go to a hospital (chapter 2). The study aimed to understand whether illness costs were an important reason for delayed access to diagnosis and treatment. An important result was that parents often saved costs by initiating treatment of a sick child at home and waited to see if the child improved; if the child deteriorated, the parents would proceed to a healthcare facility.

Information on the consequences of delayed care in severe/cerebral malaria was obtained through tracing and interviewing parents of children with childhood 
disability resulting from a cerebral infection (mainly malaria) in early childhood (chapter 3). The results describe how cerebral infection can affect a child for life, causing major disabilities with long-term consequences for the child and family. Severe cerebral symptoms such as coma or convulsions increase the risk for later disability and death. A child's disability places physical, emotional and financial burden on households and the physical demands of care increase with the age of the child. As disabled children grow, parents can no longer carry them, or do so with considerable difficulty. The physical demands leave them exhausted and worried about the future, and the need to constantly monitor the disabled child reduces family occupational income. Female children were considered particularly vulnerable. None of the disabled children had completed much schooling. Reduced education decreases occupational prospects [1-5] and lowers income-earning potential $[6,7]$. Disability therefore reduced immediate household income when parents cared for their child instead of earning an income, and disability led to reduced potential for later income compared to an able-bodied child.

To test and evaluate a strategy for reducing treatment delays in highly endemic malaria communities, a consortium of researchers and Ministries of Health collaborated to test an approach recommended by the World Health Organization (WHO) for bringing treatment closer to patients in 3 African countries. In the largest study of its kind, the strategy introduced diagnosis and treatment into 162 communities via 265 trained and supervised community health workers (CHWs) in a total of 16,000 patients who were assessed in remote, malaria-endemic villages in the 3 countries. Children with uncomplicated and severe malaria symptoms were either diagnosed and treated or if they had severe malaria they were diagnosed, treated and referred to the closest healthcare facility for further management. The cost aspects of the intervention were part of this thesis (chapters 4-6). Access to malaria treatment increased and was faster than before the introduction of the intervention. Out-of-pocket costs and clinical episode duration in uncomplicated malaria were reduced. The time allocated by CHWs to healthcare during the intervention did not increase significantly despite an increased workload of diagnosis and treatment in the community. We concluded that bringing access closer to patients and increasing treatment of patients with uncomplicated malaria brought benefits to the population. The strategy appeared to decrease the risk of severe/cerebral disease and the potential risks for disability - because very few cases of severe malaria were observed during the intervention. Household expenditure for malaria significantly reduced and CHWs' increased workload in healthcare did not prevent them from allocating most of their time to their main 
income-earning occupation. However, the extra time CHWs spent on bringing treatment closer to patients would likely require financial support if the strategy were to become routinely available through Ministries of Health.

\subsection{DISCUSSION: CONSIDERATIONS}

In this section, some general strengths, limitations and results of this thesis are discussed.

\subsubsection{Strengths and limitations}

\subsubsection{Consistency of the results}

Diagnosis and treatment

To avoid the adverse consequences of severe malaria (i.e. lifelong disability or death), the WHO recommends immediate diagnosis and treatment of malaria through rapid diagnostic tests (RDTs), artemisinin-based combination therapies (ACTs) for uncomplicated and rectal artesunate (RA) for severe malaria. The WHO strategy was implemented in 162 malaria endemic villages in three countries contributing $80 \%$ of global malaria cases [8]. About 5,000 households were interviewed before and during the intervention to measure changes brought about by immediate access to care. The very large randomised controlled intervention trial confirmed a reduction in the out-of-pocket costs for households, a high use of CHWs, faster access to healthcare, shorter duration of clinical episodes, and documented a limited number of severe malaria cases. The consistent reductions in costs in 3 hyperendemic malaria countries of the trial suggested that these were not chance results, and this is a major strength of the study.

\section{Estimates of time and potential remuneration of CHWs}

CHWs are key to bring diagnosis and treatment closer and faster to sick children in the community. In principle, they attend the largest number of sick persons but their contribution to health is often not measured and in many African countries they are unpaid, "voluntary" health workers. A strength of the work carried out is the provision of estimates of the time CHWs spend on healthcare when they are fully active, together with estimates of potential remuneration that would be required to compensate their time.

\section{Financial involvement of the community}

In the intervention, the cost of diagnosis and treatment was not charged to patients in Nigeria and Uganda. However, in Burkina Faso, parents contributed 
to the cost of uncomplicated malaria treatment through partial payment of oral medication; this payment was retained by the CHWs as partial remuneration of their time. The approach of community support via partial payment of medication was a condition of the intervention set by the Government of Burkina Faso and the strength of imposing a partial, not a total subsidy, was that treatment costs were shared between the Government and the community. Thus the Government and communities had a vested interest in how the intervention was implemented. The communities' greater control over the intervention was more likely to influence the intervention (more effective CHWs would treat more children) and make the package sustainable over time. Although only Burkina Faso financially involved their communities, the cost results were similar for all 3 countries and this suggests that community contributions to $\mathrm{CHW}$ income were not a barrier to access. These results are a strength of the research and have future research implications for understanding the tipping-point between private and social financing of healthcare.

\subsubsection{Reliability and validity of the data}

Another strength of the work carried out in this thesis is that we used several strategies to increase the reliability and validity of the data. First in each study, the case report form (CRF) in English and the local language was reviewed and discussed with (local) experts to adapt questionnaires to the local context and culture. Thereafter, CRFs were translated into the local language (Yoruba in Nigeria; Swahili in Tanzania, and Luganda or Lunyankole in Uganda). Questions on costs from the different studies (chapters 2, 4 and 5) were similar in order to enable comparison and generalizability of the results. To decrease interviewer bias, all interviewers were trained and examined and received a written manual on the use of the CRFs and codes. During the training sessions, the written manual was explained, and questions-answers sessions, role-play exercises and a final test were organized. All CRFs were also pre-tested for comprehension and some questions/codes were adjusted or dropped out in case of misunderstanding. When a study contained 2 phases (chapters $\mathbf{2 , 4}$ and 5), we tried to use the same interviewers for both phases. All CRFs were doubled entered and data were cleaned and checked for consistency and missing values. Important missing data or inconsistencies were minimized by a second interview when necessary or by tracing, when possible, children/parents in case the interview was not community/ home-based (i.e. hospital interviews - chapter 2). Finally, the data and results of the intervention study (chapters $\mathbf{4}$ and $\mathbf{6}$ ) were discussed with all the researchers in meetings (2015) organized by the WHO. 


\subsubsection{Study implementation}

A limitation observed from the findings of the intervention (chapters 4-6) is that the intervention did not reach or was not used by almost half of the children who might have benefited [8]. The reasons given by the parents were that the child was not sick enough to warrant $\mathrm{CHW}$ consultation, or parents were not aware that there was a CHW in their community, or they believed that CHWs could not treat children well or that CHWs were not at home. As shown in chapters 2 and 3 , delayed treatment risks evolution of the illness from uncomplicated to severe disease, with fatal or disabling consequences. The intervention assumed that introducing diagnosis and drugs at a $\mathrm{CHW}$ would automatically result in universal community uptake, which did not occur.

\subsubsection{Selection and data collection biases}

Another limitation concerns the potential for bias in the selection of the children in some studies. In the case-control study in Tanzania (chapter 2), CHWs selected children based on their knowledge on who was ill and these families were interviewed to obtain information on costs of illness. CHWs might not have been aware of all the cases of sick children in the community and consequently some patients (of whom CHWs were not aware) would not have been selected for interview.

Second, children who did not receive RA (chapter 5) were not diagnosed and therefore although they may have had similar symptoms to severe malaria, malaria diagnosis cannot be confirmed. Malaria was presumed to be the main cause of severe illness, but it is possible that some children had another severe illness such as sepsis, typhoid fever or meningitis. Therefore, the costs for the children who were not treated with RA may have included non-malaria illnesses. The lack of a diagnosis in the comparison group is a limitation of this particular study.

Recall bias of costs and time to treatment for children with severe illness might also have occurred in chapter 5 where we compared costs and time to treatment for those who received RA in the intervention with those who did not. Information on costs and time for children who did not use RA was obtained through household interviews during the intervention, but information on children treated with RA during the intervention was obtained post-intervention, when data were available on treatment. Different recall periods for each comparison group could have biased cost estimates in either direction. This important limitation could have been avoided by using the same recall period for both groups. 
Another bias was response bias. In the study of the time allocated by CHWs to child healthcare (chapter 6), the time-use forms describing how much time CHWs spent on healthcare before the intervention were filled out by a researcher in Nigeria and Burkina Faso but CHWs themselves filled in the forms during the intervention. The change in the method of collecting the data, a decision taken by the principal investigators in the countries, may have biased the estimates of CHW time allocation to healthcare during the intervention.

\subsubsection{Costs analysis}

Financial cost analyses were used in most studies and financial costs are often below the full economic costs. In the case of illness costs, economic costs would have included the value of parental time, and in the case of valuing CHW time, they would have included the full cost of CHW time. The opportunity costs of time of parents looking after sick children (chapters 2, 4 and 5) and of CHWs working at night (chapter 6) were not measured and therefore did not contribute to cost calculations. Production losses (for parents of sick children and CHWs) were not estimated (chapters 2, 4, 5 and 6). In each chapter we made it clear that by not calculating the full economic costs, our calculations underestimated the full episode cost for parents of sick children and the total opportunity cost of time of CHWs.

Another limitation of the cost analysis is that the pre-intervention and intervention phases did not occur during the same period (chapter 4). It is thus possible that during the intervention (a year after the pre-intervention), prices and/or incomes might have changed. A change in the cost of living could have affected not only the costs comparison but also health-seeking behaviour.

\subsubsection{Discussion of the results}

\subsubsection{Delayed access to care: out-of-pocket costs and disability}

One of our first results was that in the absence of diagnosis and treatment in the community, parents tended to wait until the child was severely ill before going to a hospital (chapter 2). An important reason for not seeking immediate care was the anticipated out-of-pocket costs. On average, in our case-control study (chapter 2), patients who went to a hospital paid USD \$5.68 for an episode of illness. Similar results were found in Malawi for hospitalized patients (USD \$5.30) for their full episode [9]. However, these costs were almost twice in Nigeria (USD \$10.32) [10] and in Uganda, $\$ 11.58$ [11]. In comparison to the costs borne by patients who did not go to a hospital, those who went to a hospital paid around 6 times more 
(USD $\$ 5.68$ vs. USD $\$ 0.90$ ) (chapter 2 ). Several studies have obtained comparable results [12-14]. In Ghana the costs for those who went to a hospital were 1.7 and 3.6 times higher compared to those who used home treatment or went to a drug shop respectively [12] (among all age groups). In Nigeria, the costs of treatment were almost 7 times higher by using private hospital than patent medicine shops [13], and in Malawi, formal care (i.e. hospital, health centre, dispensary and private clinic) was more expensive than informal care (i.e. self-medication, pharmacy/ chemist, shop) [14]. Children living far away from a healthcare facility were also reported to have higher costs when seeking treatment [15].

As high out-of-pocket costs can delay access to care, uncomplicated malaria could evolve to severe or cerebral malaria. One of the consequences for survivors of severe/cerebral malaria is physical and/or mental disability. Our findings on the daily life and challenges of disabled children and their families showed that disability puts physical, emotional and financial burden on households (chapter 3). Other research found similar results showing that parents of disabled children are mentally burdened - stressed, depressed, worried [16-22], and bear physical burdens when the child is physically disabled [17, 19, 20,23]. Parents looking after disabled children have less time for earning occupational income and decreased income leads to impoverishment. Three studies in East Africa found comparable results [23-25]. We also found that none of the disabled children were attending a school. Two other studies report that distance, the lack of infrastructure, learning materials and trained teachers [26] as well as the attitude of the staff [23] account for non-enrolment of disabled children into normal schools and that even when specialized schools exist, they are rare and usually fee-based and non-affordable for poor households [23, 25].

\subsubsection{Improved access to diagnosis and treatment}

Chapters 4 and 5 show that introducing trained CHWs, RDTs and treatment increases access to care and reduces time to treatment. This finding confirms other research showing improvements in access to care with diagnosis and treatment in the community $[27,28]$. Several studies also show that RDTs are easy to use and can be implemented in areas where microscopy is not available [29-31]. Research confirms that when trained and supervised, CHWs (and private medicine retail outlets - PMRs) can use RDTs safely and correctly [32-34]. CHWs are usually well accepted, trusted, accessible [35] and allow households to save money on transport [33]. Because of the availability of community-based services, the use of CHWs increases while care sought at a health center $[36,37]$ or from an informal source 
[38] decreases. Reductions of malaria transmission, mortality and morbidity are also mentioned [37]. However, several barriers related to RDTs are observed non-adherence to negative test results, low referral completion, lack of transport for patient follow-up and problems obtaining supplies, stock-outs, and exclusion of adults from diagnosis [28, 33, 35, 39].

Regarding the impact of community-based ACTs on access, two studies have pointed out that ACTs provide increased and faster access $[28,40]$ but access is sensitive to stock outs and distance to treatment [41]. Despite community acceptance, some mothers delay care before accessing ACTs with 88\% of mothers waiting 48 hours or more before reaching care [42]. Other research shows that ACTs are perceived to be effective [42-44] with no serious side effects [40, 43-45]. Children are usually correctly treated in terms of dose and duration $[40,45,46]$ although some research mentions that non-adherence to the full dose remains a challenge [41,47,48], especially when the drugs are obtained from the retail sector [49]. The main reasons are that caregivers do not understand how to use the drugs, forget to give treatment, do not have food/drinks to give with the medication or see improvements rapidly and then halt treatment [47]. Other topics on ACTs relate to their acceptability and perception of caregivers and communities, the impact on hospital admission and mortality, parasitological, cost-effectiveness and the challenges in deploying ACTs [40, 43, 44, 50-56].

The research on RA [38, 57-62] has mainly studied its parasitological effect [57, 60], safety [57], reduction of mortality and disability when patients are treated several hours before referral to a healthcare facility [58] and acceptance by caregivers [38, 60]. After RA administration, children should be referred to a healthcare facility for comprehensive management. In our study, all parents of children who received RA followed referral advice (chapter 5). However, compliance with referral advice could be problematic if children improve [61]. Distance to a healthcare facility and the quality of care obtained are also elements contributing to the decision to comply with referral [61].

\subsubsection{Impact of the intervention on the out-of-pocket costs}

An important result of the intervention was that the introduction of the package of trained CHWs, RDTs and treatment decreased out-of-pocket costs for households. The largest reductions were noticed in transport (43\% reduction) and drug costs (58\% reduction) (chapter 4). Because of the proximity of CHWs, diagnosis and treatment, parents usually did not need to pay for transport, and rapid access 
to care (reducing severe disease) likely decreased drug consumption during the whole episode. Three other studies in Uganda and a systematic review also found that direct costs of households declined when care was sought from CHWs/ community medicine distributors (CMD), with much lower or no transport costs [33, 63-65]. A decrease in drug costs was also found in one study [65] while in another, only few caregivers had cost reductions [63]. With these exceptions, no other research could be found on the use of CHWs on private health costs in SubSaharan African communities.

Most research on the cost impact of diagnosis and treatment has been implemented at healthcare facilities, separately for diagnosis and treatment. One healthcare facility-based study showed that the costs for patients under five who had a RDT were similar to the costs of those who had a symptom-based clinical diagnosis, and cost savings were possible only for patients aged 15 and older [66]. A review that compared the actual median retail price of RDTs (at PMRs) to the recommended retail price mentioned that RDTs were sometimes free for patients (e.g. Uganda; Ghana) but could also be sold at a higher price (e.g. Nigeria) [34]. Other cost studies on RDTs examined the costs and cost-effectiveness from a provider's perspective [67-76] and the impact on drugs and diagnostic costs (reduction between 10-15\%) from the health system side when RDTs were used compared to clinical judgment [77].

Regarding ACTs, several studies have mentioned that ACTs are more expensive from a provider's perspective $[53,56,78]$ but also more cost-effective than other drugs $[51,53,56,76]$. However, two studies found that using ACTs were less costly for households, for a malaria episode, than using older drugs - sulphadoxinepyrimethamine (SP) $[42,56]$ or amodiaquine (AQ) [56].

Studies on the influence of RA on costs are extremely rare. There are no studies on the out-of-pocket costs of an episode of illness when RA is used. On a larger cost aspect, RA has been shown to be cost-effective [62], and another study examined the out-of-pocket and societal costs of referral when RA is provided at CHWs [79].

\subsubsection{CHWs time allocation to healthcare and potential remuneration}

Our estimates show that the time CHWs spent on healthcare activities was less than 2 hours per day (chapter 6). Although CHWs spent more time in Ghana, with an average of 4.8 hours per day on all community case management of malaria activities [80], other studies found similar results to ours [81-83]. In Uganda, a 
median of 19.3 hours per month was found with a time per consultation ranging from 5 minutes to 1.5 hours [81], and in Malawi, CHWs spent between 8 to 28 hours per week on community case management activities [82]. Another study in 6 African countries, mentioned that CHWs spent between 1 to 9 hours a week on integrated community case management (iCCM) and that a 30\% increase in their utilization would increase their time by 1 to 2 hours per week [83]. The results of these studies are consistent with our findings that CHWs activities could be combined with regular income-earning activities.

By using the minimum monthly salary for each country, we estimated the value of the yearly time spent by CHWs on healthcare activities to be USD \$52 in Burkina Faso, USD \$295 in Nigeria and USD \$141 in Uganda (USD \$4.33-24.58 per month) (chapter 6). Two studies showed higher results than ours, with a monthly time valued between USD \$21.10 and USD \$94.95 in Ghana [80], and from USD \$40 in Ethiopia and Mozambique to USD \$110 in Malawi [83]. In addition, three studies provided the value of the opportunity cost of time of CHWs in Uganda. The first study showed a median of USD \$4.1 per month [81]. The second study provided a mean opportunity cost of time per child referred ranging from USD \$0.19 to USD $\$ 0.29$ [79], and the last study valued the time spent by CHWs between USD \$244 and USD \$579 per 1,000 children [59].

\subsection{RECOMMENDATIONS FOR FURTHER RESEARCH}

In this section, methodological recommendations and areas for future research resulting from the implementation of diagnosis and treatment in the community are discussed.

\subsubsection{Methodological recommendations}

\subsubsection{Timeline of the intervention study}

In the intervention study (chapter 4), the different phases (i.e. pre-intervention and intervention) did not occur during the same period. Although it would be ideal to implement non-intervention and intervention components simultaneously, this would require randomizing villages into intervention villages and non-intervention villages during the same period - doubling the resources required for the study in 3 countries. Although, there could be changes in the cost of living from one year to the next, which could affect the costs obtained and compared, we judged these changes in costs to be minimal in the remote settings in which the interventions were implemented. 
Our study on the costs of severe illness (chapter 5) showed that many households did not remember the costs spent at providers and the date/time of symptoms and visits to providers. The reason was that parents of children who received RA were interviewed post-intervention while parents of children who did not receive RA were interviewed within the 2 weeks of the illness episode. We recommend having similar recall periods for both groups to reduce recall bias. To achieve this, collaboration with drug shops could be of benefit as they are often the first place where people go for treatment. Drug shop owners could keep a register of parents of children who bought drugs. All parents of sick children who visited a drug shop could then be interviewed 2-3 weeks later, by the time the illness episode is completed, according to certain criteria (i.e. severe symptoms).

\subsubsection{Decreasing response bias and providing more accurate estimates}

In the study on the time allocated by CHWs to child's care (chapter 6), different methods were used between the two phases which may have caused a response bias. To decrease response bias, we recommend using the same method for data collection throughout an intervention. The same method - direct observation or CHWs filling in the forms themselves - might be utilised in both phases. Unlike our study, we suggest to collect data both at night and during the day so that time allocations reflect any time-use for healthcare during the night, making the estimates more accurate.

\subsubsection{Economic costs of illness}

As previously mentioned, only financial costs of an episode of illness were calculated in this thesis (chapters 2, 4 and 5). The full economic cost of an episode of illness was not calculated. However, understanding the different economic costs (e.g. opportunity cost of time of parents of sick children, cost of production loss) is important because it gives full information on the total economic loss caused by the illness to the household. Future research could estimate the economic costs of uncomplicated and severe illness which is a gap in the research conducted for this thesis.

\subsubsection{Areas for future research - Subsidising diagnosis and treatment}

The intervention research set out to determine how and whether improved access through an intervention package increased access and reduced private costs. The package demonstrated better access to care, reduced clinical duration of illness and decreased household costs. The broader purpose of the research was to demonstrate feasibility of implementing community-based care. However, the 
costs of the intervention package were not borne by Ministries of Health (MOH) and if in the future, MOHs intend to implement the package in rural areas as recommended by WHO, they would need either to fund it themselves or to seek funding via the Global Fund to Fight AIDS, Tuberculosis and Malaria (GFATM), the main funding organization for malaria treatment and prevention. Alternatively, (as occurred in Burkina Faso) MOHs could examine the extent to which there is community support to contribute to the package, thus involving the communities and reducing the costs for the $\mathrm{MOH}$ and/or the GFATM. If MOHs were to share the costs with communities, they would reduce their own costs but need to allow more community control and rights. In the latter case, the objective would be to make the package sustainable over time by encouraging community investment.

A strength of the Burkina Faso intervention (mentioned earlier) was community contribution to the costs of CHW time through partial payment of ACTs. Community contributions to remuneration of drugs and CHW time were considered important and likely to contribute to sustainability by the $\mathrm{MOH}$ who wished to expand access to healthcare but did not wish to encourage the concept of "gratuité" or a "free" service. The approach of a partial subsidy or sharing the costs with communities is a key concept that might be tested more widely in other countries. Sharing the costs with the communities might repeat or modify the approach used in Burkina Faso or might seek household contributions in an alternative form - for example, via a community health insurance fund. Parents could pay a fee for their child - a premium - and in exchange they might have unlimited access to one component of the package or access the full package without the need to find money for treatment in an emergency.

However, one of many difficulties in rural areas is that most households are agriculturally based (i.e. they have limited cash) and in any future test of community contributions, it might be important to facilitate mechanisms that are fair and feasible for household contributions in an agricultural economy. Lack of cash at specific times of the year to pay is often a barrier [84, 85]. Therefore, different types of non-cash mechanisms for contributions to such a health insurance scheme could be explored for fairness, feasibility, acceptability and affordability. Community schemes enabling payment in-kind (e.g. in food crops) to finance diagnosis and treatment have been tested in Asia [86] but not in Africa and future research might evaluate methods to enable household contribution to costs without sacrificing household participation. Elements that should be considered to make enrolment in the community contribution schemes successful are the 
percentage of the population covered, the quality of care offered, the timing of premium payments and the attractiveness of the benefit package [87]. CHWs or village representatives might contribute to defining thresholds for household premium contributions.

\subsection{IMPLICATIONS AND RECOMMENDATIONS FOR POLICY AND PRACTICE}

\subsubsection{Improving the quality of life of disabled children and their household} Our study on disability (chapter 3 ) showed that both physical and mental disability affects the life of the whole household by placing physical, emotional and financial burden on family members. None of the parents received any external help with caring and educating their child and most parents did not see any progress in the condition of their child. There is a clear need to improve the quality of life of both disabled children and their families.

To improve the quality of life of both children and households, we recommend community support strategies - such as training CHWs or parents in basic rehabilitation therapy and simple techniques (e.g. play therapy (i.e. pushing a pushchair, balancing on or playing with a ball) for children with motor problems; memory games, painting, dancing/movement therapy for children with cognitive disability), and collaboration between parents caring for disabled children. The latter strategy might involve less finance but would involve social networking facilitate sharing of experiences and provision of mutual support - or workshops where "Appropriate Paper Technology Chairs" could be constructed for physically disabled children (a cost-effective way to produce and provide furniture with recycled materials) [88].

\subsubsection{Financing the "package" of improving access to diagnosis and treatment in the community}

Our intervention to improve access to rapid diagnosis and treatment (chapters 4-6) was feasible, had positive effects on health, and reduced out-of-pocket costs for the families. The project, carried out in several districts, can be implemented on a substantially larger scale by MOHs. To achieve this, countries can apply for funding to finance such large-scale implementation, which is strongly encouraged by the GFATM and WHO. Funding applications require the applicant to detail the different implementation steps and costs. The intervention carried out in this 
thesis and published elsewhere offers information on how to implement such an intervention and involve local communities in the development of the programme.

Key to the success of the intervention is the link between the community and health facility staff who require training to supervise and support CHWs and to manage the commodity supply chain. The frequency and cost of meetings between CHWs and supervisors, remuneration of CHW time, allocation of responsibilities for monitoring and supplying commodities/materials (e.g. patients' registers, drug accountability, etc.) requires detailed costing and planning. The GFATM requires active involvement of non-governmental organizations in applications as well as independent monitoring and evaluation of process and outcomes. The GFATM also requires collaboration and involvement of organisations that have experience in supporting the development of key components, particularly with community education, support for drug supply chain management and documentation, monitoring and evaluation of scale-up so that components can be improved as scale-up occurs. The main challenges countries may encounter are the need to increase population awareness, ensure a continual supply of commodities, and develop, strengthen, remunerate and supervise community human resources to deliver the package, to increase uptake and access.

\subsubsection{Community sensitization and education}

The intervention study showed that CHWs could be trained and could be effective (chapters 4-6). CHWs, who are usually the first point of care in the community, can offer one solution to the shortage of health workers in hard to reach villages and in communities where there is no immediate access to a healthcare facility. In our intervention study, the main reasons for not going to a $\mathrm{CHW}$ were that parents were not aware of the presence of a CHW in their community, or thought that CHWs could not treat well or did not perceive the symptoms to be severe enough to warrant $\mathrm{CHW}$ intervention. Therefore, to make CHWs programmes a success, we recommend community sensitization and education programmes (e.g. explanation of symptoms and actions that need to be taken - where to go first; diagnosis before treatment, and referral where necessary) as well as CHW training programmes, and promotion of the importance of the CHW role in communities.

\subsection{CONCLUSION}

The first part of this thesis (chapters 2 and 3) provided information on the economic and financial factors that influence access to healthcare facilities in rural 
Africa and on the consequences of delayed access to diagnosis and treatment of malaria. In the second part (chapters 4-6), RDTs and antimalarial treatment (ACT and RA) were introduced through CHWs in the community to improve healthcare access and reduce treatment delays. The intervention showed that the use of CHWs increased and illness duration, out-of-pocket costs and the time to reach treatment decreased. Providing and strengthening immediate and rapid access to diagnosis and treatment in the community is thus a first step to reduce the burden of malaria, make access to healthcare fairer and more equitable, and support universal health coverage. 


\section{REFERENCES}

1. Hoogeveen JG. Measuring welfare for small but vulnerable groups: Poverty and disability in Uganda. J Afr Econ. 2005;14:603-31.

2. Mitra S. The recent decline in the employment of persons with disabilities in South Africa, 1998-2006. S Afr J Econ. 2008;76:480-92.

3. Mitra S, Sambamoorthi U. Disability and the rural labor market in India: Evidence for males in Tamil Nadu. World Dev. 2008;36:934-52.

4. O'Keefe P. People with disabilities in India: from commitments to outcomes. Washington, DC: World Bank, Human Development Unit - South Asia Region; 2009.

5. Trani J-F, Loeb M. Poverty and disability: A vicious circle? Evidence from Afghanistan and Zambia. J Int Dev. 2012;24 Suppl 1:S19-52.

6. Filmer D. Disability, poverty, and schooling in developing countries: results from 14 household surveys. World Bank Econ Rev. 2008;22:141-63.

7. Yeo R, Moore K. Including disabled people in poverty reduction work: "Nothing about us, without us". World Dev. 2003;31:571-90.

8. Ajayi IO, Nsungwa-Sabiiti J, Siribié M, Falade CO, Sermé L, Balyeku A, et al. Feasibility of malaria diagnosis and management in Burkina Faso, Nigeria, and Uganda: a community-based observational study. Clin Infect Dis. 2016;63 Suppl 5:S245-55.

9. Hennessee I, Chinkhumba J, Briggs-Hagen M, Bauleni A, Shah MP, Chalira A, et al. Household costs among patients hospitalized with malaria: evidence from a national survey in Malawi, 2012. Malar J. 2017;16:395.

10. Onwujekwe O, Uguru N, Etiaba E, Chikezie I, Uzochukwu B, Adjagba A. The economic burden of malaria on households and the health system in Enugu State southeast Nigeria. PLoS One. 2013;8:e78362.

11. Menon MP, Njau JD, McFarland DA, Uganda Malaria Indicator Survey Technical Working Group. Cost and predictors of care-seeking behaviors among caregivers of febrile children-Uganda, 2009. Am J Trop Med Hyg. 2016;94:932-7.

12. Akazili J, Aikins M, Binka FN. Malaria treatment in Northern Ghana: what is the treatment cost per case to households? Afr J Health Sci. 2007;14:70-9.

13. Onwujekwe O, Hanson K, Uzochukwu B, Ichoku H, Ike E, Onwughalu B. Are malaria treatment expenditures catastrophic to different socio-economic and geographic groups and how do they cope with payment? A study in southeast Nigeria. Trop Med Int Health. 2010;15:18-25.

14. Mota RE, Lara AM, Kunkwenzu ED, Lalloo DG. Health seeking behavior after fever onset in a malaria-endemic area of Malawi. Am J Trop Med Hyg. 2009;81:935-43.

15. Ewing VL, Lalloo DG, Phiri KS, Roca-Feltrer A, Mangham LJ, SanJoaquin MA. Seasonal and geographic differences in treatment-seeking and household cost of febrile illness among children in Malawi. Malar J. 2011;10:32.

16. Brehaut JC, Kohen DE, Garner RE, Miller AR, Lach LM, Klassen AF, et al. Health among caregivers of children with health problems: findings from a Canadian populationbased study. Am J Public Health. 2009;99:1254-62.

17. Brehaut JC, Kohen DE, Raina P, Walter SD, Russell DJ, Swinton M, et al. The health of primary caregivers of children with cerebral palsy: how does it compare with that of other Canadian caregivers? Pediatrics. 2004;114:e182-91. 
18. Cheshire A, Barlow JH, Powell LA. The psychosocial well-being of parents of children with cerebral palsy: a comparison study. Disabil Rehabil. 2010;32:1673-7.

19. Dambi JM, Jelsma J, Mlambo T. Caring for a child with Cerebral Palsy: The experience of Zimbabwean mothers. Afr J Disabil. 2015;4:168.

20. Davis E, Shelly A, Waters E, Boyd R, Cook K, Davern M, et al. The impact of caring for a child with cerebral palsy: quality of life for mothers and fathers. Child Care Health Dev. 2010;36:63-73.

21. Navaie-Waliser M, Feldman PH, Gould DA, Levine C, Kuerbis AN, Donelan K. When the caregiver needs care: the plight of vulnerable caregivers. Am J Public Health. 2002;92:409-13.

22. Sawyer MG, Bittman M, La Greca AM, Crettenden AD, Borojevic N, Raghavendra $P$, et al. Time demands of caring for children with cerebral palsy: what are the implications for maternal mental health? Dev Med Child Neurol. 2011;53:338-43.

23. Hartley S, Ojwang P, Baguwemu A, Ddamulira M, Chavuta A. How do carers of disabled children cope? The Ugandan perspective. Child Care Health Dev. 2005;31:167-80.

24. Gona JK, Mung'ala-Odera V, Newton CR, Hartley S. Caring for children with disabilities in Kilifi, Kenya: what is the carer's experience? Child Care Health Dev. 2011;37:175-83.

25. McNally A, Mannan H. Perceptions of caring for children with disabilities: Experiences from Moshi, Tanzania. Afr J Disabil. 2013;2:21.

26. The African Child Policy Forum (ACPF). Access denied: Voices of persons with disabilities from Africa. Addis Ababa: ACPF; 2014.

27. Awor P, Wamani H, Tylleskar T, Jagoe G, Peterson S. Increased access to care and appropriateness of treatment at private sector drug shops with integrated management of malaria, pneumonia and diarrhoea: a quasi-experimental study in Uganda. PLoS One. 2014;9:e115440.

28. Ndiaye Y, Ndiaye JL, Cisse B, Blanas D, Bassene J, Manga IA, et al. Community case management in malaria: review and perspectives after four years of operational experience in Saraya district, south-east Senegal. Malar J. 2013;12:240.

29. Mekonnen Z, Ali S, Belay G, Suleman S, Chatterjee S. Evaluation of the performance of CareStart Malaria Pf/Pv Combo rapid diagnostic test for the diagnosis of malaria in Jimma, southwestern Ethiopia. Acta Trop. 2010;113:285-8.

30. Moges B, Amare B, Belyhun Y, Tekeste Z, Gizachew M, Workineh M, et al. Comparison of CareStart ${ }^{\mathrm{TM}} \mathrm{HRP} 2 / \mathrm{pLDH}$ COMBO rapid malaria test with light microscopy in north-west Ethiopia. Malar J. 2012;11:234.

31. Sharew B, Legesse M, Animut A, Jima D, Medhin G, Erko B. Evaluation of the performance of CareStart Malaria Pf/Pv Combo and Paracheck Pf tests for the diagnosis of malaria in Wondo Genet, southern Ethiopia. Acta Trop. 2009;111:321-4.

32. Hamer DH, Brooks ET, Semrau K, Pilingana P, MacLeod WB, Siazeele K, et al. Quality and safety of integrated community case management of malaria using rapid diagnostic tests and pneumonia by community health workers. Pathog Glob Health. 2012;106:32-9.

33. Ruizendaal E, Dierickx S, Peeters Grietens K, Schallig HD, Pagnoni F, Mens PF. Success or failure of critical steps in community case management of malaria with rapid diagnostic tests: a systematic review. Malar J. 2014;13:229. 
34. Visser T, Bruxvoort K, Maloney K, Leslie T, Barat LM, Allan R, et al. Introducing malaria rapid diagnostic tests in private medicine retail outlets: A systematic literature review. PLoS One. 2017;12:e0173093.

35. Mukanga D, Tibenderana JK, Kiguli J, Pariyo GW, Waiswa P, Bajunirwe F, et al. Community acceptability of use of rapid diagnostic tests for malaria by community health workers in Uganda. Malar J. 2010;9:203.

36. Seidenberg PD, Hamer DH, Iyer H, Pilingana P, Siazeele K, Hamainza B, et al. Impact of integrated community case management on health-seeking behavior in rural Zambia. Am J Trop Med Hyg. 2012;87(5 Suppl):105-10.

37. Lemma H, Byass P, Desta A, Bosman A, Costanzo G, Toma L, et al. Deploying artemether-lumefantrine with rapid testing in Ethiopian communities: impact on malaria morbidity, mortality and healthcare resources. Trop Med Int Health. 2010;15:241-50.

38. Phiri TB, Kaunda-Khangamwa BN, Bauleni A, Chimuna T, Melody D, Kalengamaliro $\mathrm{H}$, et al. Feasibility, acceptability and impact of integrating malaria rapid diagnostic tests and pre-referral rectal artesunate into the integrated community case management programme. A pilot study in Mchinji district, Malawi. Malar J. 2016;15:177.

39. Blanas DA, Ndiaye Y, Nichols K, Jensen A, Siddiqui A, Hennig N. Barriers to community case management of malaria in Saraya, Senegal: training, and supply-chains. Malar J. 2013;12:95.

40. Chinbuah AM, Gyapong JO, Pagnoni F, Wellington EK, Gyapong M. Feasibility and acceptability of the use of artemether-lumefantrine in the home management of uncomplicated malaria in children 6-59 months old in Ghana. Trop Med Int Health. 2006;11:1003-16.

41. Onyango EO, Ayodo G, Watsierah CA, Were T, Okumu W, Anyona SB, et al. Factors associated with non-adherence to Artemisinin-based combination therapy (ACT) to malaria in a rural population from holoendemic region of western Kenya. BMC Infect Dis. 2012;12:143.

42. Kamat VR, Nyato DJ. Community response to artemisinin-based combination therapy for childhood malaria: a case study from Dar es Salaam, Tanzania. Malar J. 2010;9:61.

43. Ajayi IO, Falade CO, Olley BO, Yusuf B, Gbotosho S, Iyiola T, et al. A qualitative study of the feasibility and community perception on the effectiveness of artemetherlumefantrine use in the context of home management of malaria in south-west Nigeria. BMC Health Serv Res. 2008;8:119.

44. Asante KP, Abokyi L, Zandoh C, Owusu R, Awini E, Sulemana A, et al. Community perceptions of malaria and malaria treatment behaviour in a rural district of Ghana: implications for artemisinin combination therapy. BMC Public Health. 2010;10:409.

45. Ajayi IO, Browne EN, Garshong B, Bateganya F, Yusuf B, Agyei-Baffour P, et al. Feasibility and acceptability of artemisinin-based combination therapy for the home management of malaria in four African sites. Malar J. 2008;7:6.

46. Ajayi IO, Browne EN, Bateganya F, Yar D, Happi C, Falade CO, et al. Effectiveness of artemisinin-based combination therapy used in the context of home management of malaria: a report from three study sites in sub-Saharan Africa. Malar J. 2008;7:190. 
47. Banek K, Lalani M, Staedke SG, Chandramohan D. Adherence to artemisinin-based combination therapy for the treatment of malaria: a systematic review of the evidence. Malar J. 2014;13:7.

48. Lawford H, Zurovac D, O'Reilly L, Hoibak S, Cowley A, Munga S, et al. Adherence to prescribed artemisinin-based combination therapy in Garissa and Bunyala districts, Kenya. Malar J. 2011;10:281.

49. Yakasai AM, Hamza M, Dalhat MM, Bello M, Gadanya MA, Yaqub ZM, et al. Adherence to artemisinin-based combination therapy for the treatment of uncomplicated malaria: a systematic review and meta-analysis. J Trop Med. 2015;2015:189232.

50. Bhattarai A, Ali AS, Kachur SP, Mårtensson A, Abbas AK, Khatib R, et al. Impact of artemisinin-based combination therapy and insecticide-treated nets on malaria burden in Zanzibar. PLoS Med. 2007;4:e309.

51. Chanda P, Masiye F, Chitah BM, Sipilanyambe N, Hawela M, Banda P, et al. A costeffectiveness analysis of artemether lumefantrine for treatment of uncomplicated malaria in Zambia. Malar J. 2007;6:21.

52. Morel CM, Lauer JA, Evans DB. Cost effectiveness analysis of strategies to combat malaria in developing countries. BMJ. 2005;331:1299.

53. Muheki C, McIntyre D, Barnes KI. Artemisinin-based combination therapy reduces expenditure on malaria treatment in KwaZulu Natal, South Africa. Trop Med Int Health. 2004;9:959-66.

54. Simba DO, Warsame M, Kakoko D, Mrango Z, Tomson G, Premji Z, et al. Who gets prompt access to artemisinin-based combination therapy? A prospective community-based study in children from rural Kilosa, Tanzania. PLoS One. 2010;5:e12104.

55. Whitty CJ, Chandler C, Ansah E, Leslie T, Staedke SG. Deployment of ACT antimalarials for treatment of malaria: challenges and opportunities. Malar J. 2008;7 Suppl 1:S7.

56. Wiseman V, Kim M, Mutabingwa TK, Whitty CJ. Cost-effectiveness study of three antimalarial drug combinations in Tanzania. PLoS Med. 2006;3:e373.

57. Gomes M, Ribeiro I, Warsame M, Karunajeewa H, Petzold M. Rectal artemisinins for malaria: a review of efficacy and safety from individual patient data in clinical studies. BMC Infect Dis. 2008;8:39.

58. Gomes MF, Faiz MA, Gyapong JO, Warsame M, Agbenyega T, Babiker A, et al. Prereferral rectal artesunate to prevent death and disability in severe malaria: a placebo-controlled trial. Lancet. 2009;373:557-66.

59. Hansen KS, Ndyomugyenyi R, Magnussen P, Lal S, Clarke SE. Cost-effectiveness analysis of malaria rapid diagnostic tests for appropriate treatment of malaria at the community level in Uganda. Health Policy Plan. 2017;32:676-89.

60. Sam-Wobo SO, Agbeyangi OA, Ekpo UF, Akinloye OA, Mafiana CF, Adeleke MA. Rectal artesunates, their utilization, and parental perception in the management of malaria in children from Abeokuta, southwestern Nigeria. Vector Borne Zoonotic Dis. 2012;12:151-5.

61. Simba DO, Kakoko DC, Warsame M, Premji Z, Gomes MF, Tomson G, et al. Understanding caretakers' dilemma in deciding whether or not to adhere with referral advice after pre-referral treatment with rectal artesunate. Malar J. 2010;9:123. 
62. Tozan Y, Klein EY, Darley S, Panicker R, Laxminarayan R, Breman JG. Prereferral rectal artesunate for treatment of severe childhood malaria: a cost-effectiveness analysis. Lancet. 2010;376:1910-5.

63. Buchner DL, Brenner JL, Kabakyenga J, Teddy K, Maling S, Barigye C, et al. Stakeholders' perceptions of integrated community case management by community health workers: a post-intervention qualitative study. PLoS One. 2014;9:e98610.

64. Matovu F, Nanyiti A, Rutebemberwa E. Household health care-seeking costs: experiences from a randomized, controlled trial of community-based malaria and pneumonia treatment among under-fives in eastern Uganda. Malar J. 2014;13:222.

65. Soremekun S, Kasteng F, Lingam R, Vassall A, Kertho E, Settumba S, et al. Variation in the quality and out-of-pocket cost of treatment for childhood malaria, diarrhoea, and pneumonia: Community and facility based care in rural Uganda. PLoS One. 2018;13:e0200543.

66. Msellem MI, Martensson A, Rotllant G, Bhattarai A, Strömberg J, Kahigwa E, et al. Influence of rapid malaria diagnostic tests on treatment and health outcome in fever patients, Zanzibar: a crossover validation study. PLoS Med. 2009;6:e1000070.

67. Ansah EK, Epokor M, Whitty CJM, Yeung S, Hansen KS. Cost-effectiveness analysis of introducing RDTs for malaria diagnosis as compared to microscopy and presumptive diagnosis in central and peripheral public health facilities in Ghana. Am J Trop Med Hyg. 2013;89:724-36.

68. Batwala V, Magnussen P, Hansen KS, Nuwaha F. Cost-effectiveness of malaria microscopy and rapid diagnostic tests versus presumptive diagnosis: implications for malaria control in Uganda. Malar J. 2011;10:372.

69. Chanda P, Castillo-Riquelme M, Masiye F. Cost-effectiveness analysis of the available strategies for diagnosing malaria in outpatient clinics in Zambia. Cost Eff Resour Alloc. 2009;7:5.

70. Chanda P, Hamainza B, Moonga HB, Chalwe V, Banda P, Pagnoni F. Relative costs and effectiveness of treating uncomplicated malaria in two rural districts in Zambia: implications for nationwide scale-up of home-based management. Malar J. 2011;10:159.

71. Lubell Y, Reyburn H, Mbakilwa H, Mwangi R, Chonya K, Whitty CJ, et al. The costeffectiveness of parasitologic diagnosis for malaria-suspected patients in an era of combination therapy. Am J Trop Med Hyg. 2007;77(6 Suppl):128-32.

72. Rolland E, Checchi F, Pinoges L, Balkan S, Guthmann JP, Guerin PJ. Operational response to malaria epidemics: are rapid diagnostic tests cost-effective? Trop Med Int Health. 2006;11:398-408.

73. Shillcutt S, Morel C, Goodman C, Coleman P, Bell D, Whitty CJ, et al. Cost-effectiveness of malaria diagnostic methods in sub-Saharan Africa in an era of combination therapy. Bull World Health Organ. 2008;86:101-10.

74. Uzochukwu BS, Obikeze EN, Onwujekwe OE, Onoka CA, Griffiths UK. Costeffectiveness analysis of rapid diagnostic test, microscopy and syndromic approach in the diagnosis of malaria in Nigeria: implications for scaling-up deployment of ACT. Malar J. 2009;8:265.

75. Yukich J, D’Acremont V, Kahama J, Swai N, Lengeler C. Cost savings with rapid diagnostic tests for malaria in low-transmission areas: evidence from Dar es Salaam, Tanzania. Am J Trop Med Hyg. 2010;83:61-8. 
76. White MT, Conteh L, Cibulskis R, Ghani AC. Costs and cost-effectiveness of malaria control interventions--a systematic review. Malar J. 2011;10:337.

77. Mosha JF, Conteh L, Tediosi F, Gesase S, Bruce J, Chandramohan D, et al. Cost implications of improving malaria diagnosis: findings from north-eastern Tanzania. PLoS One. 2010;5:e8707.

78. Kindermans J-M, Pécoul B, Perez-Casas C, Den Boer M, Berman D, Cox I. Changing national malaria treatment protocols in Africa: what is the cost and who will pay? - Case studies: Burundi, Kenya, Rwanda, Tanzania and Uganda. Geneva: Médecins sans frontières; 2002.

79. Nanyonjo A, Bagorogoza B, Kasteng F, Ayebale G, Makumbi F, Tomson G, et al. Estimating the cost of referral and willingness to pay for referral to higherlevel health facilities: a case series study from an integrated community case management programme in Uganda. BMC Health Serv Res. 2015;15:347.

80. Agyei-Baffour P, Hansen KS, Browne EN, Magnussen P. The amount and value of work time of community medicine distributors in community case management of malaria among children under five years in the Ejisu-Juaben District of Ghana. Malar J. 2012;11:277.

81. Kasteng F, Settumba S, Källander K, Vassall A, inSCALE Study Group. Valuing the work of unpaid community health workers and exploring the incentives to volunteering in rural Africa. Health Policy Plan. 2016;31:205-16.

82. Jarrah Z, Lee A, Wright A, Schulkers K, Collins D. Costing of integrated community case management in Malawi. Medford, MA: Management Sciences for Health; 2013.

83. Daviaud E, Besada D, Leon N, Rohde S, Sanders D, Oliphant N, et al. Costs of implementing integrated community case management (iCCM) in six African countries: implications for sustainability. J Glob Health. 2017;7:010403.

84. Basaza R, Criel B, Van der Stuyft P. Community health insurance in Uganda: why does enrolment remain low? A view from beneath. Health Policy. 2008;87:172-84.

85. De Allegri M, Sanon M, Bridges J, Sauerborn R. Understanding consumers' preferences and decision to enrol in community-based health insurance in rural West Africa. Health Policy. 2006;76:58-71.

86. Dave P. Commuinity and self-financing in voluntary health programmes in India. Health Policy Plan. 1991;6:20-31.

87. Carrin G, Waelkens MP, Criel B. Community-based health insurance in developing countries: a study of its contribution to the performance of health financing systems. Trop Med Int Health. 2005;10:799-811.

88. Cerebral Palsy Africa. Appropriate Paper-Based Technology (APT) [Internet]. [cited 2019 Apr 29]. Available from: http://www.cerebralpalsyafrica.org/equipment/ index.html 


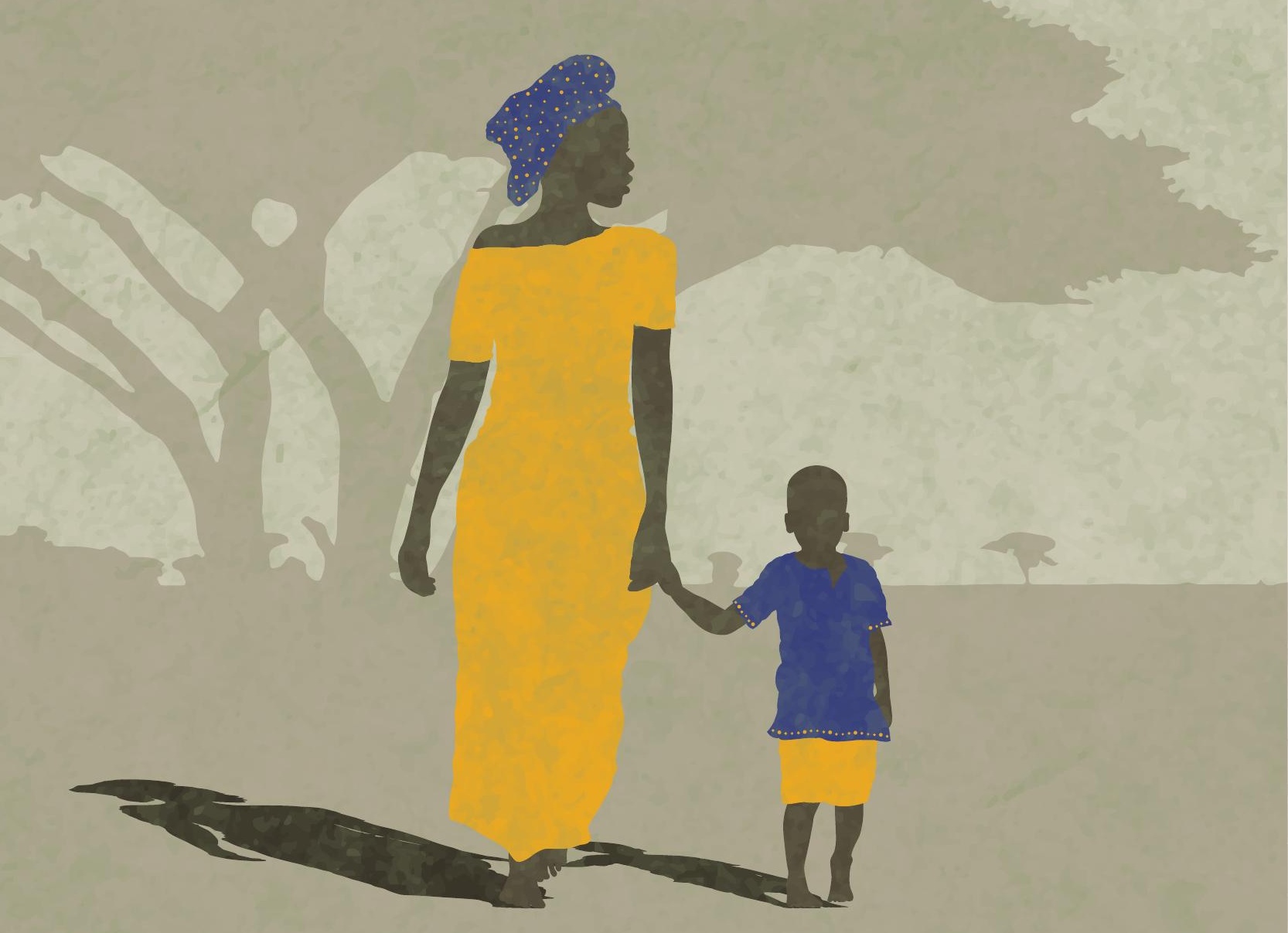




\section{SUMMARY}


This thesis describes the economic and financial factors that influence access to healthcare of children in rural Africa, discusses the consequences of delayed access to diagnosis and treatment of malaria, and tests and evaluates a strategy for reducing delays by bringing access closer to sick children in their communities.

When a child has uncomplicated malaria, immediate treatment and management is essential to prevent the disease from evolving to severe or cerebral malaria, disability or death. If the child is not treated rapidly, parasites continue to multiply, invade and destroy red blood cells. Consequently, the disease progresses unimpeded to severe malaria and is potentially fatal. Surviving children could be left with (severe) physical and/or mental disabilities which cause an emotional, physical, financial and economic burden for the family.

Although rapid access to healthcare is crucial, and facility management is essential in severe or cerebral malaria, it is often difficult for poor families to reach treatment or care because of the long distance, the lack of transport and the associated costs, although many countries have a policy of free care for children under five years old. To reduce barriers and make access to healthcare easier and more equitable, the World Health Organization recommends the use of rapid diagnosis and treatment in the community. This thesis details some of the impediments and solutions to improving access to care for childhood malaria.

In chapter 1, general information is provided on malaria, and an overview of the adverse short and long-term consequences of the disease and a discussion on malaria control and treatment interventions are outlined. The chapter ends with the research objectives and an overview of the thesis.

In chapter 2, research was undertaken to understand why some parents delay access to a healthcare facility for severe malaria and evaluate the role of the private costs of illness in preventing or delaying access to a facility. In a case-control study in Tanzania we compared the out-of-pocket costs of an episode of febrile illness for children treated at a public healthcare facility, at a private healthcare facility, and managed in the community. Parents of children were interviewed in the community. Cases were represented by children who went to a healthcare facility and controls by children who did not. A multivariable regression analysis was performed to understand the factors that influenced access to healthcare facilities. To complement the data on costs, a separate study was conducted at hospitals with parents of children who were admitted. The results showed that 
the total out-of-pocket costs for children who went to a healthcare facility were 6 times higher than the costs for children who were not taken to a facility. The hospital study revealed that children admitted at a private hospital had 3 times higher private costs than those admitted at a public hospital. In addition, there was a positive relationship between the severity of the illness and the attendance of a healthcare facility: the more severe the symptoms, the higher the chance of attending a facility. Severity of the illness rather than household wealth influenced hospital attendance. The study suggested that without community-based malaria control strategies, households tended to use a "wait-and-see" approach and go to a healthcare facility; once the child had severe symptoms (which increases the child's risk for death and disability), the access to care was immediate.

In a qualitative study, chapter 3 explores the daily life and challenges of parents of six children, each with one or more severe physical and/or mental disabilities resulting from a cerebral infection, mainly malaria. The results show that severely disabled children need constant care and supervision and this increases physical and financial burden, leaving families exhausted, sad and worried about the future. None of the disabled children were in school; parents and other family members had to stop working or reduce their working time in order to take care of the disabled child. Disability disadvantaged not only the child but also the household. Because of a decrease in occupational earnings, households had reduced financial resources and ran into difficulties in providing food and/or basic necessities, and appeared to be poorer than they would otherwise have been. With lower education than non-disabled counterparts, children may have fewer future employment prospects and consequently lower future income. The family gradually accumulated debts. Removing themselves from this poverty trap had become difficult.

Together, chapters 2 and 3 show that the out-of-pocket costs prevent access to healthcare facilities and that delays in reaching immediate treatment may allow the illness to progress into more severe stages thus increasing the risks of disability and death. In chapters 4 to $\mathbf{6}$, a community-based intervention to improve childhood access to malaria diagnosis and treatment was implemented in rural areas of Burkina Faso, Nigeria and Uganda. During the intervention, community health workers (CHWs) were trained following the integrated community case management (iCCM) recommendations and received rapid diagnostic tests (RDTs) and antimalarial treatment (artemisinin-based combination therapy (ACT) and rectal artesunate (RA)) so that sick children $(>15,000)$ could be rapidly diagnosed 
and treated close to their home. The logic is that the availability of RDTs and treatment within the community enables children with malaria to be treated rapidly so that the evolution of uncomplicated malaria cases to severe/cerebral cases is avoided and the potential risks and burden for death and disability are reduced. A shorter duration of the illness might occur.

In chapter 4, we assessed the impact of the intervention on household costs of illness, extrapolating costs to the district level for each participating country if the intervention was scaled up. The intervention showed that the total out-of-pocket costs per episode of illness were between two to three times lower because of the intervention, with a potential total mean household saving per year for a whole district ranging from USD 29,965 in Burkina Faso to USD 303,467 in Uganda. The study revealed that improving access to malaria diagnostics and treatment in malaria-endemic areas would enable households to save money for each episode of illness, although the intervention would increase the public costs of providing healthcare.

Chapter 5 evaluates the private costs of care and time taken to reach care for severely ill children treated with RA in the community by a CHW versus children who were not treated. We tried to understand why some parents, despite immediate access to CHWs and RA for severe disease, did not go to CHWs for treatment, and whether the expectation of high costs influenced their behaviour and whether the costs for those who sought RA were different from those who did not access RA. The study showed that access to RA was faster in severe malaria for those who had CNS symptoms (i.e. repeated convulsions, altered consciousness or coma) as well as those who did not. Children with CNS symptoms treated with RA had similar costs to children who were not treated with RA. For children who did not have CNS symptoms, expenditures for RA-treated children were higher, primarily because of the costs of transportation of the child to the hospital. For children with the most severe symptoms, RA has been shown to offer faster treatment without increasing the out-of-pocket costs. In addition, all parents of children who received RA went to a healthcare facility, following the CHW's referral advice.

Chapter 6 evaluated the change in time spent by CHWs in providing voluntary healthcare in communities because of an intervention that depended upon them being the first point of contact for a sick child. The study also calculated the public health costs of remunerating CHWs for part-time care of sick children. The intervention increased access to diagnosis and treatment without substantially 
increasing the time allocated to healthcare by CHWs: CHWs spent between 66 and 90 minutes per day (average 80 minutes) on child healthcare provision during the high malaria season, compared with 19-53 minutes (average of 30 minutes) before the intervention. Part-time remuneration was calculated at USD 52 in Burkina Faso, USD 295 in Nigeria and USD 141 in Uganda per CHW for one year. In addition, this research suggested that the use of CHWs can improve access to care in the community; they can be trained to recognize severe symptoms, diagnose, treat and refer children correctly. It also suggests that introducing RDTs and treatment into communities via CHWs would not require full-time $\mathrm{CHW}$ work, not even during the high malaria season. CHWs can thus provide healthcare and continue to allocate the majority of their time to their main income-earning occupations.

The last chapter of this thesis, chapter 7, summarizes the main findings and discusses some general strengths, limitations and results of this thesis as well as the implications for research, policy and practice. The intervention was feasible. It increased access to diagnosis and treatment, decreased the risk for severe/cerebral malaria and reduced private costs. To implement the package, Ministries of Health might fund it themselves or fund it through the Global Fund to Fight AIDS, Tuberculosis and Malaria, or share the costs with the community via payments in-kind. The feasibility, affordability and acceptability of the latter option could be explored through future research. This final chapter ends with the implications and recommendations for policy and practice. Community strategies to support households with a disabled child, funding applications for large-scale implementation of the intervention package, CHW training programmes, and community sensitization and education are suggested. 


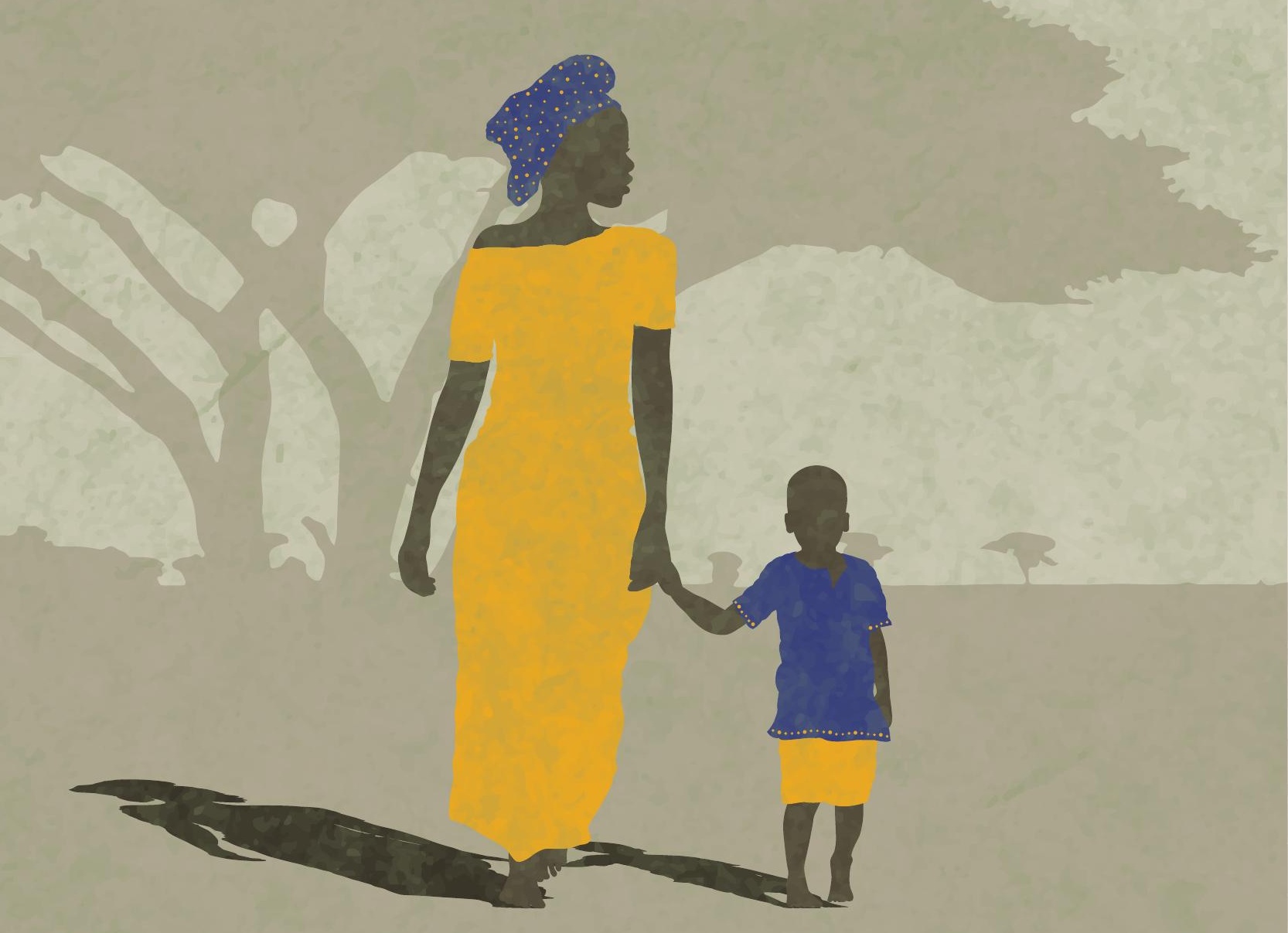


VALORISATION 
This valorisation chapter discusses the value of the results in a broader context. More specifically, it translates the results to both the scientific and non-scientific communities who play a role in improving access to healthcare in rural areas of developing countries. It first presents the innovation of the separate studies and then provides the relevance of the results for the different target groups (i.e. households and communities, community health workers, researchers, policymakers and Ministries of Health). Activities that could be implemented for each target group are also described to show the possible value of the results in the future.

\section{INNOVATION OF THE DIFFERENT STUDIES}

This section discusses the innovation and value of the results of the separate studies. The causes and consequences of delayed access to diagnosis and treatment were first explored $[1,2]$. The role of out-of-pocket costs in reducing access to healthcare facilities [1], and causing delays in reaching diagnosis and treatment allowing the illness to progress from uncomplicated to severe/cerebral malaria and disability was documented [2]. To improve access to care, rapid diagnosis tests (RDTs) and treatment (artemisinin-based combination therapies for uncomplicated and rectal artesunate for severe malaria) were introduced via community health workers (CHWs) in rural communities of Burkina Faso, Nigeria and Uganda [3-5]. The main results showed that the use of CHWs increased, and illness duration, private costs and the time to reach treatment decreased $[3,4]$.

\section{Digital stories and a qualitative approach to raise the voice of parents of severely disabled children}

Parents of 6 children who had a cerebral infection that caused permanent disability were interviewed about their daily life and challenges [2]. They were worried, stressed, exhausted and depressed, and had to reduce their working time or leave their jobs to take care of their disabled children. As a consequence, households were pushed further into poverty. By using digital stories and a qualitative approach with only a few participants, we were able to probe deeply and enable parents to make their voices heard by sharing their narratives.

\section{Changing the way of using healthcare}

Healthcare facilities where prompt diagnosis and treatment are available are usually located far away and reaching a facility could take up to a few hours and be expensive. As a consequence, parents of sick children anticipated high costs of healthcare [1]. They used a wait-and-see approach and often reached a facility 
when the child was very sick [1]. As healthcare facilities are usually difficult and expensive to reach, the strategy to introduce RDTs and treatment in the community tried to change the perception of seeking care by bringing access to healthcare directly to parents of sick children [3-5]. This strategy was shown to improve access to care so that sick children can receive immediate treatment closer to their home.

\section{Training voluntary community members to provide healthcare}

To successfully bring RDTs and treatment in the community, CHWs play a central role. CHWs are community members who volunteer to provide healthcare in their community. The intervention showed that CHWs could be easily trained to differentiate symptoms, take a RDT, analyse the results of the RDT, treat according to the symptoms and the results of the test, and refer sick children with severe symptoms to the closest healthcare facility for further management. By using voluntary members of the community to provide healthcare, one solution to the shortage of health workers has been offered in hard to reach villages and in communities where there is no immediate access to a healthcare facility.

\section{RELEVANCE AND ACTIVITIES}

\section{Households and communities}

The intervention showed several benefits for the households. Illness duration, out-of-pocket costs and the time to reach treatment decreased $[3,4]$. Therefore, it is important to let populations know about these advantages of using the intervention, especially when not all parents of sick children regularly go to a CHW. In this context, meetings and workshops with the community as well as sensitization and education programmes could be organized. A description of such activities is given under the sub-section "Policymakers and Ministries of health" as it is also relevant for this target group.

\section{Community health workers}

The intervention showed that CHWs could be trained and could be effective. CHWs are usually the first point of care in the community, thus offering immediate treatment to sick children. However, CHWs are volunteers who may need to decrease their time allocated to income-generating work in order to serve the population [5]. As long as they remain volunteers, their effectiveness will strongly depend on their motivation to continue despite potentially reduced occupational income. One study showed that status and recognition in the community and commitment to the well-being of children play an important role on CHW's 
motivation [6]. Therefore, to keep CHWs motivated and increase their self-esteem and personal satisfaction, it may be important for them to know how important they are within the community and the health system, and to acknowledge them frequently for the benefits they bring to the households and the community. To achieve this, meetings with CHWs, supervisors and policymakers/Ministries of Health could be organized where CHWs appreciation and importance could be explained. In addition, CHWs could also receive a certificate or extra training. An identification badge, a t-shirt, and a bicycle have also been mentioned to increase their sense of pride and self-worth [6]. Finally, a financial compensation for their work, time and efforts such as the model implemented in Burkina Faso, or a mixed-model of financial and in-kind compensations could be another solution to encourage motivation and avoid decreases in their income.

\section{Researchers}

It is important that the results of the intervention are made available to the research community so that researchers can build on and further develop this agenda. We published several articles in peer-reviewed open access journals so that our results can be easily accessible, especially for developing countries.

As explained, only the financial costs of an episode of illness were calculated in the different studies of this thesis. This leaves room for further research on the broader economic costs of uncomplicated and severe malaria so that a more complete picture of the households and CHWs costs is available. In addition, as suggested, future research could evaluate methods to encourage community investment in the costs of delivering RDTs and treatment.

\section{Policymakers and Ministries of health}

The findings of the intervention should be of great interest for policymakers and Ministries of Health (MOHs) of malaria-endemic countries. To disseminate our results, as previously mentioned, we published several articles in peer-reviewed open access journals. In addition, the $\mathrm{MOH}$ was directly involved and responsible for the implementation of the intervention in Uganda, and in Nigeria, the Federal $\mathrm{MOH}$ supported the study by providing RDT kits in addition to those procured by the World Health Organization [7].

Our results improve the understanding of the importance of reducing uncomplicated malaria to reduce prevalence of severe malaria and emphasised the need for avoiding cerebral malaria and consequent disability. Children with severe 
physical and mental disability due to a cerebral infection were often deprived of schooling and parents had to stop working or reduce their working time in order to take care of their child [2]. As a consequence, household occupational earnings decreased, and financial resources were reduced. With lower education than non-disabled counterparts, disabled children may have fewer future employment opportunities and consequently lower future income. It is thus of interest to malaria-endemic countries to diagnose malaria and provide treatment at an early and uncomplicated stage of the disease to avoid evolution of uncomplicated to severe/cerebral malaria, disability and death. This keeps the children and their families "healthy", "productive" and "wealthier" for the future. Our intervention of RDTs and treatment in the community delivered via CHWs demonstrated how this might be implemented [3-5]. The results show that the intervention was feasible, had positive effects on health and reduced out-of-pocket costs for families. The project was carried out in several districts in each country but can be implemented on a much larger scale by MOHs when they apply for funding to the Global Fund to Fight AIDS, Tuberculosis and Malaria. By investing now in diagnosis and treatment in the community, countries can thus prevent and avoid the negative consequences of (severe) malaria in the future.

Our findings could also be helpful to increase the use of CHWs. Although the intervention had several benefits for the population, not all parents of sick children routinely go to a CHW. The main reasons given were that they were not aware of the presence of a CHW in their community, or they believed that CHWs could not treat well or they did not perceive the symptoms were severe enough to warrant CHW intervention. Therefore, our results showed the importance of raising awareness of the population on the benefits of the intervention and on the presence and role of the CHWs in the community. In this context, should the intervention be scaledup, governments would need to focus on community sensitization and education programmes. They could organize workshops where symptoms, especially those that prevent oral medication (i.e. repeated vomiting, lethargy, convulsion, altered consciousness or coma) could be explained to people, and outline actions that need to be taken when these symptoms occur by showing images/drawings. Simulations and role-plays between participants could also be used. In addition, community sensitization should also concentrate on the role of the CHW. The CHW could be introduced in a community meeting, emphasising the benefits of going to a CHW and explaining the tasks (s)he performs, and facilitate questions by members of the community. Finally, some incentives or promotions (e.g. free drugs at CHWs 
during a certain period of time) could also be introduced to encourage parents of sick children to go to a CHW.

Finally, our results could support the development of health system reforms if governments decide to scale-up the intervention. For instance, CHWs might be remunerated (for specific tasks) and/or obtain a more official status within the formal healthcare system. They could also receive extra training, and a career path linking them with facilities might be outlined. In addition, to increase CHW use and decrease the time to reach treatment in communities where distances to healthcare facilities are great, healthcare reforms could introduce incentives to visit CHWs for febrile children as early as possible. 


\section{REFERENCES}

1. Castellani J, Mihaylova B, Evers SMAA, Paulus ATG, Mrango ZE, Kimbute O, et al. Out-of-pocket costs and other determinants of access to healthcare for children with febrile illnesses: a case-control study in rural Tanzania. PLoS One. 2015;10:e0122386.

2. Castellani J, Kimbute O, Makasi C, Mrango ZE, Paulus ATG, Evers SMAA, et al. Long-term consequences of cerebral infection: daily life and challenges faced by households with permanent childhood disability in rural Tanzania - a qualitative study. Submitted.

3. Castellani J, Nsungwa-Sabiiti J, Mihaylova B, Ajayi IO, Siribié M, Afonne C, et al. Impact of improving community-based access to malaria diagnosis and treatment on household costs. Clin Infect Dis. 2016;63 Suppl 5:S256-63.

4. Castellani J, Mihaylova B, Siribié M, Gansane Z, Ouedraogo AZ, Fouque F, et al. Household costs and time to treatment for children with severe febrile illness in rural Burkina Faso: the role of rectal artesunate. Malar J. 2018;17:380.

5. Castellani J, Mihaylova B, Ajayi IO, Siribié M, Nsungwa-Sabiiti J, Afonne C, et al. Quantifying and valuing community health worker time in improving access to malaria diagnosis and treatment. Clin Infect Dis. 2016;63 Suppl 5:S298-S305.

6. Sanou AK, Jegede AS, Nsungwa-Sabiiti J, Siribié M, Ajayi IO, Turinde A, et al. Motivation of community health workers in diagnosing, treating, and referring sick young children in a multicountry study. Clin Infect Dis. 2016;63 Suppl 5:S27075.

7. Ajayi IO, Nsungwa-Sabiiti J, Siribié M, Falade CO, Sermé L, Balyeku A, et al. Feasibility of malaria diagnosis and management in Burkina Faso, Nigeria, and Uganda: a community-based observational study. Clin Infect Dis. 2016;63 Suppl 5:S245-55. 


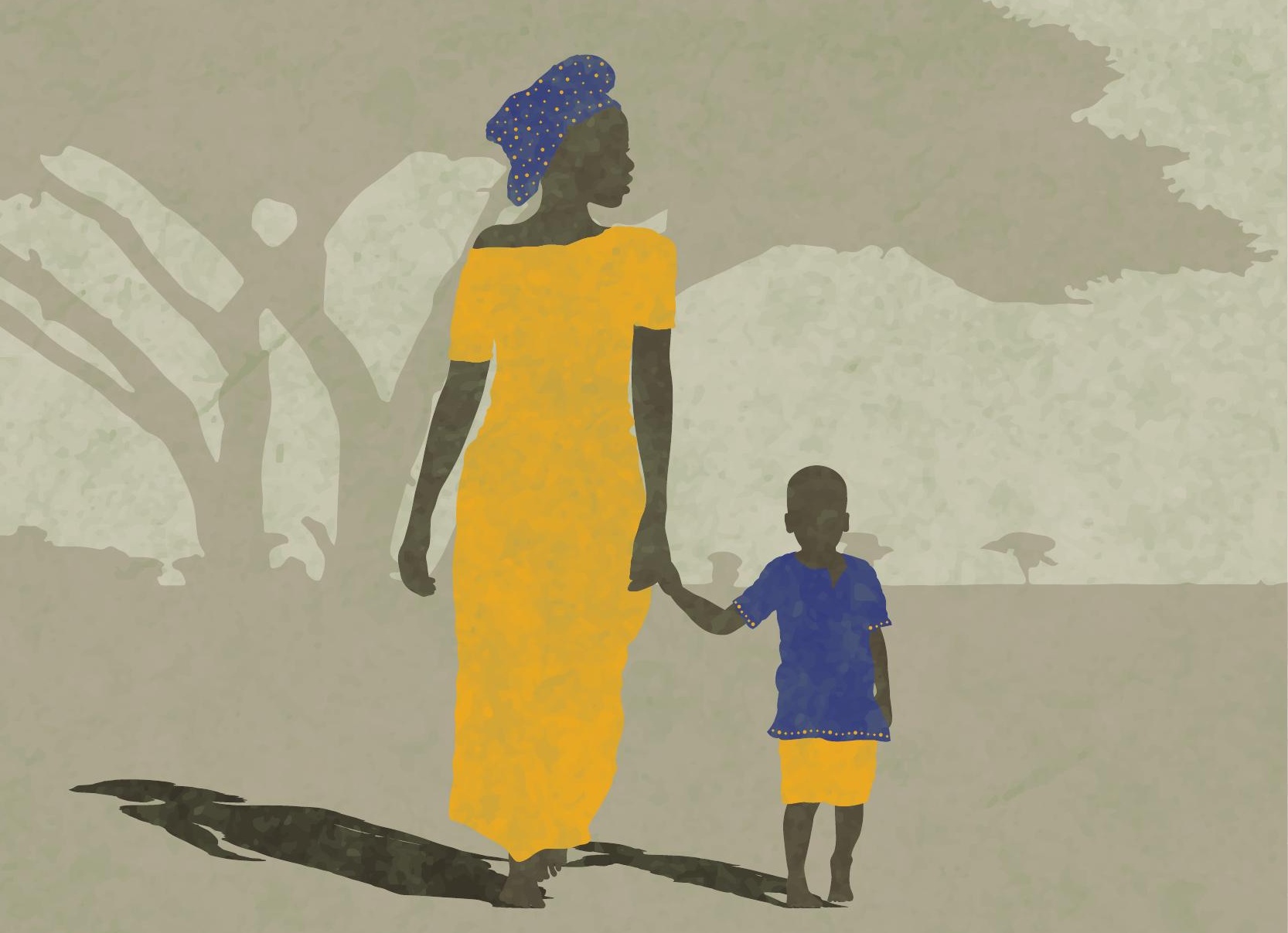


ACKMOWLEDGMENTS 
All good things must come to an end! After many years of working on my thesis, it is time to turn over a new page... This thesis has been a great learning experience for me and I would like to thank everyone who either directly or indirectly contributed to it.

First and foremost, I am extremely grateful to my team of supervisors, Prof. dr. mr. Silvia Evers, Prof. dr. Aggie Paulus, Prof. dr. Borislava Mihaylova and Dr. Melba Gomes. Thank you so much for your continuous patience, support, encouragement, availability, understanding, and time invested to make this thesis possible.

To Silvia and Aggie: Both of you were already my supervisors for my Master thesis and I would like to express my gratitude to you for motivating me to undertake a PhD and for having agreed to supervise my thesis. Thank you very much for your continuous guidance, flexibility, suggestions on the papers, support and encouraging words. I feel fortunate to have been your student.

To Borislava: I am so grateful for your guidance, advice, critical thinking and motivation. You were always there when I needed support and I appreciate your valuable feedback and the time you took to comment on different papers. Thank you very much! After so many years of exchanging emails and talking on Skype, it was a pleasure to finally meet you personally in Oxford.

To Melba: Thank you very much for believing in me, trusting me, offering me research and travel opportunities, and motivating me to undertake and write this $\mathrm{PhD}$ thesis. You introduced me to the world of malaria research in Africa, data and statistics, encouraged me in my most difficult times, and guided me through this long journey. Without you, I would have probably taken another career path. I will therefore always be grateful to you for having changed the course of my life for the best.

To Jan Singlovic, my former co-worker and family friend: Many thanks for your travel advice, as well as your time and patience to train me on Epidata and Stata. I had no knowledge of these software when I started my research, but I have learned so much from you in the process. Thanks to you, I was able to successfully develop databases and conduct data cleaning and analysis. I really enjoyed working with you and I hope there will be further opportunities to work together again. 
I also would like to thank all the co-authors of the articles that were part of this dissertation. I am grateful I could participate in these different projects, and without you, this thesis would not have been possible. A special thanks to Prof. dr. Max Petzold of the University of Gothenburg, Sweden, for his statistical advice and support for several papers that are part of this thesis, and to Prof. dr. Mohammad Abul Faiz of the Mahidol Oxford Tropical Medicine Research Unit, Thailand, for welcoming me in the Saving Brains/disability project and for his advice and support.

I also take the opportunity to thank the Assessment Committee, Prof. dr. Krumeich, Prof. dr. Hoebe, Dr. Lubell, Dr. van der Putten, and Prof. dr. Wiseman, for showing interest in my work and taking the time to review my dissertation.

A special thank to Dr. Florence Fouque, Unit Leader of the Vectors, Environment and Society Department at the UNICEF/UNDP/World Bank/WHO Special Programme for Research \& Training in Tropical Diseases (TDR), for her trust and support, and the opportunity to conduct a research in Burkina Faso on the household costs and time to treatment for children with severe febrile illness which was part of this thesis.

This thesis would not have been possible without the support and contribution of many people in Tanzania, Uganda, Burkina Faso and Nigeria. I would like to particularly thank Dr. Zakayo Mrango, Dr. Charles Makasi, Dr. Omari Kimbute, Dr. Kitego, Sister Aline, Avit, Dennis, Emanuel, Francis, Fred, Irene, Joseph, Juliana, Motta and Patience for welcoming me in Tanzania. It was my first time in Africa and I have so many good memories. "Asante sana" to all of you for the great times in Tanzania, for taking care of me and making sure that I was always feeling safe there. I appreciated our cultural discussions which allowed me to acquire a better understanding of life and become more open-minded. I believe that travelling and living in rural areas for several months is one of the most beautiful trips one can take and it was definitely one of the best experiences in my life. Aside from being a valuable professional experience, it was also a memorable life-changing and personal growth experience. It taught me the real value and meaning of life. Through this experience, I realized how the small things in life and the present moment are precious gifts. My time in Tanzania definitely changed my way of thinking and I am more than grateful to all the wonderful people I have met there. Dr. Zakayo and Dr. Omari, I very much appreciate your trust, support, availability, help, advice and collaboration as well as the logistical arrangements you made for 
my very first research project. Dr. Charles, thank you very much for your support in the Saving Brains/disability project. I appreciated your availability and you were always there to help and advise me when I needed. Juliana, a special thanks to you for your generosity, for welcoming me in your house every weekend, for accompanying me to the market, and teaching me how to cook "Pilau" and "Ugali". Your "Pilau" was the best I ever had and I really enjoyed spending time with you, your family and your friends.

To Pierre, Pip and Tony: I am grateful that you were part of my Tanzanian trips. It was good to have you around and I really enjoyed sharing our respective experiences and opinions through interesting discussions! Pierre, I still can remember our time spent at the Internet café in Kilosa and at the Babylon guesthouse eating "kuku" with a "bia baridi"! Pip and Tony, it was so nice to meet you and I appreciated the opportunity to work with you and to get to know more about the digital stories you were producing.

To Dr. Jesca Nsungwa-Sabiiti, Andrew Balyeku, Lilian Ojanduru and Josephine Kyaligonza: Many thanks for the warm welcome in Uganda. I am grateful I had the opportunity to work with you in Uganda for a few weeks and also to meet the rest of the team involved in the HMM+ project. Dr. Jesca, a special thanks to you for showing me a part of your country at the Murchison Falls National Park. It was just so beautiful and I had a wonderful trip. Thanks to you! I hope one day I can discover more of your country.

To Christine, Hilary, Jyne Judith, Martin, Maureen, Rita, Roger and Vanessa: Thanks to all of you for your great work and efforts on the data entry and cleaning. You were always so enthusiastic each time I told you that I was coming to Uganda and it was always a pleasure to see you. I enjoyed the time I spent with you, our discussions over lunch, our photo sessions and the nightlife in Kampala.

To Dr. Siribié, Dr. Gansane, Armande Sanou, Benjamin Sombié, Luc Sermé, Dr. Ouedraogo and Dr. Sirima: Thank you very much for your hospitality. I appreciated the opportunity to work with you and I was fortunate to have been to travel to Burkina Faso a couple of times. I very much enjoyed my visit to Sidéradougou's health centre which was quite informative. I will also always remember our road trip going there during which a beautiful elephant family suddenly came out of the bush and decided to cross the road in front of our car... It was quite amazing! 
To Dr. Ike Ajayi and Chinenye Afonne: It was such a pleasure to collaborate with you on the HMM+ project. Thank you very much! I really appreciated your availability. You were always there to advise me when I had questions. I exchanged so many emails with both of you, and it was great to finally meet you in person at the workshop in Uganda.

I also would like to thank Brigitte Caenen and Janet Verheijen for their time to organize the calls with my supervisors and discuss administrative issues, Lara Leijtens for her patience, availability and professional layout of this thesis, and Rachel van Esschoten to help me with my last-minute request for this unique and amazing cover.

To my friends (and also former co-workers, in some cases) who have been present for me these past years - I am only listing a few: Alvin, Anna, Aude, Catalina, Chaïpan, Christel, Djomaa, Edson, Eileen, Fanny, Gabriela, Giulia, Heidi, Jérôme, Lana, Lara, Lisa, Lucia, Marianna, Mau, Muriel, Nathalie, Nicole, Nora, Samantha, Samar, Sonia, Suyeon and Yuki. Thank you for your friendship, support, discussions and all the great moments spent together. You might not have realized it, but you brought me all the joy, the fun moments, the laughs, the coffees and the smiles I needed during these past years while I was working on my thesis! Some of you are in Switzerland, others (very) far away; some I know for a long time, others more recently; but I hope we will always keep in touch as we have till now!

To my long-time friends Lynn and Rachna: LYNN!!! Muchas gracias for your support, positive thinking, sense of wonder and encouragement over the years from Groningen to Barcelona! You were always there to remind me how interesting my work and research were, and that one should never forget his/her true identity. Thank you for always encouraging me to persevere, listening to me and always being so enthusiastic about my new projects. We managed to keep in touch all those years and I hope there will be many more. - RACHNA, thanks a lot for always being there through all these years, for your enthusiasm, generosity, support and advice, for all the very long discussions we had together to set the world to rights, and for reading and commenting part of this thesis. I am really lucky to have an amazing friend like you! Although you are so far away in South Africa, your friendship is very precious!

A special thanks to my relatives in the Netherlands and Germany: John, Jenny, Meike, Richard, Marvin, Dennis, Villy and Hans. I was really looking forward 
to celebrating this special day with you in Maastricht and Amsterdam but unfortunately the Covid-19 has decided differently... Hopefully it will only be a matter of time!

Last, but not least, many thanks to my dear parents, my dear sister Géraldine and Travis. Thank you for your love and prayers, for all the delicious food and restaurant outings, for the long discussions over dinner, for your continuous support, trust and encouragement over the years, and for always being here and taking care of me with so much love and affection. You made me what I am today. You always taught me that we should follow our dreams and this $\mathrm{PhD}$ thesis could not have been completed without your support and understanding. A heartfelt thanks to you, always. 


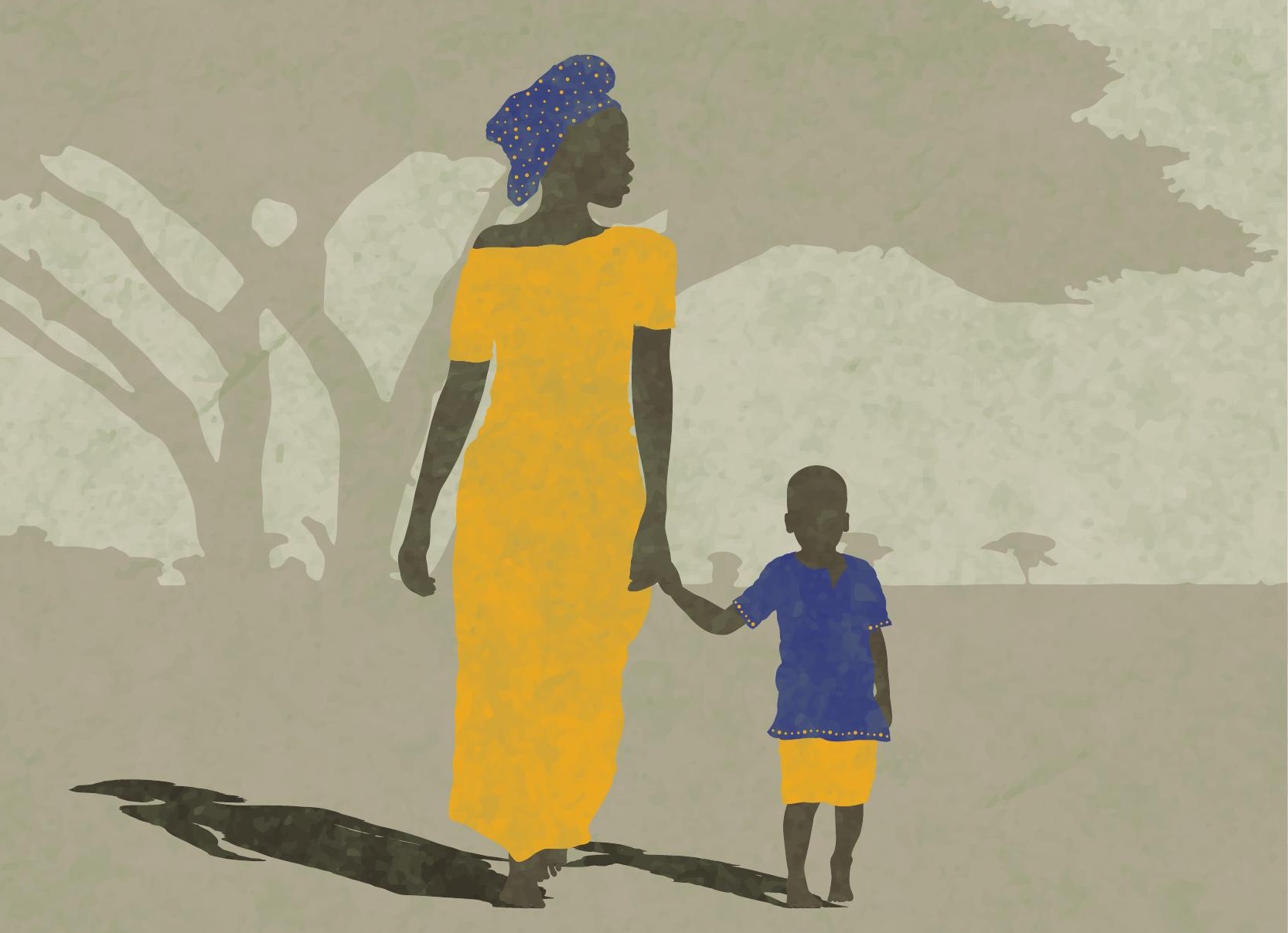


ABOUT THE AUTHOR 
Joëlle Castellani was born in Geneva (Switzerland). After completing her secondary school in Geneva, she studied International Economics and Business at the University of Groningen (the Netherlands), where she obtained her Bachelor's degree in 2009. During her Bachelor programme, Joëlle did an internship at Sanofi Aventis in Gouda (the Netherlands), which gave her an interest in health issues. As a consequence, she decided to pursue her studies with a Master degree in Health Policy, Economics and Management at Maastricht University (the Netherlands), and graduated in 2011. During her Master Programme, she spent 6 months in Tanzania where she conducted fieldwork to investigate access to healthcare facilities in rural settings for children with a severe febrile illness.

In 2012, Joëlle became an external PhD candidate on a part-time basis at CAPHRI Care and Public Health Research Institute, Department of Health Services Research (HSR) of Maastricht University. During her PhD studies, she worked as a consultant for the UNICEF/UNDP/World Bank/WHO Special Programme for Research \& Training in Tropical Diseases (TDR) for which she provided technical assistance in health economics for an extensive community-based intervention study to improve childhood access to malaria diagnosis and treatment for children in Africa. Alongside this project, Joëlle also worked as a consultant for the Mahidol Oxford Tropical Medicine Research Unit where she focused on the consequences of disability resulting from a cerebral infection in early childhood.

Since September 2020, Joëlle has been working as a researcher in epidemiology and clinical research at the UMR 1058 - Pathogenesis \& Control of Chronic Infections, a mixed Unit of the University of Montpellier (France), the "Institut National de la Santé et de la Recherche Médicale" (INSERM - the French National Institute of Health and Medical Research) and the "Etablissement Français du Sang" (EFS - the French National Blood Service) where she focuses on the transmission and control of HIV, tuberculosis and hepatitis for vulnerable populations in Africa and Asia. 


\section{LIST OF PUBLICATIONS}

- Castellani J, Mihaylova B, Siribié M, Gansane Z, Ouedraogo AZ, Fouque F, Sirima SB, Evers SMAA, Paulus ATG, Gomes M. Household costs and time to treatment for children with severe febrile illness in rural Burkina Faso: the role of rectal artesunate. Malar J. 2018;17:380.

- $\quad$ Ajayi IO, Nsungwa-Sabiiti J, Siribié M, Falade CO, Sermé L, Balyeku A, Afonne C, Sanou AK, Kabarungi V, Oshiname FO, Gansane Z, Kyaligonza J, Jegede AS, Tiono AB, Sirima SB, Diarra A, Yusuf OB, Fouque F, Castellani J, Petzold M, Singlovic J, Gomes M. Feasibility of malaria diagnosis and management in Burkina Faso, Nigeria, and Uganda: a community-based observational study. Clin Infect Dis. 2016;63 Suppl 5:S245-55.

- Castellani J, Nsungwa-Sabiiti J, Mihaylova B, Ajayi IO, Siribié M, Afonne C, Balyeku A, Sermé L, Sanou AK, Sombié BS, Tiono AB, Sirima SB, Kabarungi V, Falade CO, Kyaligonza J, Evers SMAA, Paulus ATG, Petzold M, Singlovic J, Gomes M. Impact of improving community-based access to malaria diagnosis and treatment on household costs. Clin Infect Dis. 2016;63 Suppl 5:S256-63.

- $\quad$ Siribié M, Ajayi IO, Nsungwa-Sabiiti J, Afonne C, Balyeku A, Falade CO, Gansane Z, Jegede AS, Ojanduru L, Oshiname FO, Kabarungi V, Kyaligonza J, Sanou AK, Sermé L, Castellani J, Singlovic J, Gomes M. Training community health workers to manage uncomplicated and severe malaria: experience from 3 rural malaria-endemic areas in Sub-Saharan Africa. Clin Infect Dis. 2016;63 Suppl 5:S264-69.

- Sanou AK, Jegede AS, Nsungwa-Sabiiti J, Siribié M, Ajayi IO, Turinde A, Oshiname FO, Sermé L, Kabarungi V, Falade CO, Kyaligonza J, Afonne C, Balyeku A, Castellani J, Gomes M. Motivation of community health workers in diagnosing, treating, and referring sick young children in a multicountry study. Clin Infect Dis. 2016;63 Suppl 5:S270-75.

- $\quad$ Singlovic J, Ajayi IO, Nsungwa-Sabiiti J, Siribié M, Sanou AK, Jegede AS, Falade CO, Sermé L, Gansane Z, Afonne C, Kabarungi V, Kyaligonza J, Castellani J, Petzold M, Gomes M. Compliance with malaria rapid diagnostic testing by community health workers in 3 malaria-endemic countries of Sub-Saharan Africa: an observational study. Clin Infect Dis. 2016;63 Suppl 5:S276-82.

- Castellani J, Mihaylova B, Ajayi IO, Siribié M, Nsungwa-Sabiiti J, Afonne C, Sermé L, Balyeku A, Kabarungi V, Kyaligonza J, Evers SMAA, Paulus ATG, Petzold M, Singlovic J, Gomes M. Quantifying and valuing community health worker time in improving access to malaria diagnosis and treatment. Clin Infect Dis. 2016;63 Suppl 5:S298-305. 
- Castellani J, Mihaylova B, Evers SMAA, Paulus ATG, Mrango ZE, Kimbute O, Shishira JP, Mulokozi F, Petzold M, Singlovic J, Gomes M. Out-of-pocket costs and other determinants of access to healthcare for children with febrile illnesses: a case-control study in rural Tanzania. PLoS One. 2015;10:e0122386.

\section{Submitted article}

- $\quad$ Castellani J, Kimbute O, Makasi C, Mrango ZE, Paulus ATG, Evers SMAA, Hardy P, Sumner T, Keiya A, Mihaylova B, Faiz MA, Gomes M. Long-term consequences of cerebral infection: daily life and challenges faced by households with permanent childhood disability in rural Tanzania - a qualitative study. (Under review). 